\title{
Scenario-based estimation model for methane emissions in the heavy-duty transportation sector
}

\author{
Ronald Andrew Mongold
}

Follow this and additional works at: https://researchrepository.wvu.edu/etd

\section{Recommended Citation}

Mongold, Ronald Andrew, "Scenario-based estimation model for methane emissions in the heavy-duty transportation sector" (2015). Graduate Theses, Dissertations, and Problem Reports. 6249.

https://researchrepository.wvu.edu/etd/6249

This Thesis is protected by copyright and/or related rights. It has been brought to you by the The Research Repository @ WVU with permission from the rights-holder(s). You are free to use this Thesis in any way that is permitted by the copyright and related rights legislation that applies to your use. For other uses you must obtain permission from the rights-holder(s) directly, unless additional rights are indicated by a Creative Commons license in the record and/ or on the work itself. This Thesis has been accepted for inclusion in WVU Graduate Theses, Dissertations, and Problem Reports collection by an authorized administrator of The Research Repository @ WVU. For more information, please contact researchrepository@mail.wvu.edu. 


\title{
SCENARIO-BASED ESTIMATION MODEL FOR METHANE EMISSIONS IN THE HEAVY-DUTY TRANSPORTATION SECTOR
}

\author{
Ronald Andrew Mongold
}

Thesis submitted

to the College of Engineering and Mineral Resources

at West Virginia University

in partial fulfillment of the requirements for the degree of

Master of Science in

Mechanical Engineering

Hailin Li, Ph.D., Chair

Nigel Clark, Ph.D.

Scott Wayne, Ph.D.

David L. McKain Jr.

Department of Mechanical and Aerospace Engineering

Morgantown, West Virginia

2015

Keywords: Natural Gas, Heavy-duty Vehicle, Methane Emissions, Scenario Based Estimation Model

Copyright 2015 Ronald Mongold 


\section{Abstract \\ Scenario-Based Estimation Model for Natural Gas Emissions in the Heavy-duty Transportation Sector}

by Ronald Mongold

Natural gas (NG) is a promising alternative fuel to reduce exhaust emissions of greenhouse gases (GHG), particulate matter (PM) and nitrogen oxides $\left(\mathrm{NO}_{\mathrm{x}}\right)$ from heavy-duty (HD) vehicles. Past HD NG vehicle research has focused on the fuel consumption and exhaust emission of PM and NOx. Recent global warming concerns have raised interest in methane emissions from NG vehicles. However, there is currently no model available to estimate the methane emissions from HD NG vehicles. There is also a need to project the methane emissions of HD NG vehicles in 2035.

This research developed a scenario based estimation model for methane emissions of the heavyduty transportation sector. The methane emissions sources considered include: tailpipe; crankcase; dynamic ventilation; fueling tank; and fueling stations. The main work conducted includes (1) processing experimental data and developing model input data; (2) estimating the population scenarios of the HD transportation sector in 2035, including HD NG vehicles and NG fuel stations; (3) developing operation characteristics for each type of vehicle; (4) developing a 2035 methane emissions and fuel consumption scenario; (5) developing, coding, and demonstrating the methane emissions estimation model; (6) estimating the methane emissions of the HD transportation sector in 2035. In this research, the methane emissions and fuel consumptions measured were statistically analyzed and characterized to fuel specific methane emissions (FSME) and distance specific fuel consumption for idle activity and three driving activities noted as city, arterial, and highway operation activities. The idle activity had methane emissions and fuel consumption characterized to FSME and time specific fuel consumption. With an input of the vehicle population and operation characteristics, the model was able to estimate the total fuel consumed and total methane emissions associated with tailpipes, crankcases, dynamic ventilation, on-board fuel storage tanks, and refueling stations. The total methane emissions and fuel consumption were further processed to calculate the FSME.

The estimation model was validated using the stasis scenario developed in this research. The model was validated by comparing the estimated FSME output with the input and verifying calculations. The contribution of tailpipes, crankcases, and fuel stations to the methane emissions of HD spark ignition (SI) CNG vehicles were 33.2\%, 59.4\%, and 7.4\%, respectively, for the stasis scenario, representing current vehicle technology. The validated model was applied to estimate the methane emissions in the HD transportation sector with the high, medium and low methane emissions and fuel consumption scenarios. It was concluded that the total methane emissions estimated using the high, medium, and low scenarios were $46.8 \%, 20.5 \%$, and $6.9 \%$, respectively, of the stasis scenario. The reduced methane emissions were the comprehensive impact of the expected reduction in fuel consumption and FSME. The contribution of each source to the total methane emissions will be presented and discussed. Such a model can also be used to estimate the emissions of other pollutants with the input of fuel specific emissions data, vehicle operation characteristics, and emissions. 


\section{Dedication}

This thesis is dedicated to my loving family. My father, Ronald Mongold, who has always encouraged me to perform to the best of my abilities, regardless of difficulty. I try to mirror my work ethic after you, and try to show the perfectionist qualities you have instilled unto me. My mother, Brenda Mongold, who always encouraged me to pursue and achieve any level of education I desired. My siblings, Derek Mongold M.D., Jessica Sowers, and Roshawna Iman, who served as role models throughout my life and always raised the bar for achievement. 


\section{Acknowledgements}

I would like to express my special appreciation and thanks to my advisor Dr. Hailin Li, you have been a tremendous mentor for me. I would like to thank you for encouraging my research and for allowing me to grow as a research engineer. Your advice on research as well as on my career has been priceless. I would also like to thank Dr. Nigel Clark, Mr. Dave McKain, and Dr. Scott Wayne for serving as my committee members. I also want to thank you for letting my defense be an enjoyable moment, and for your brilliant comments and suggestions, thanks to you. I would especially like to thank my fellow graduate students, technicians, and everyone involved in the project at West Virginia University. All of you have been there to support me when I processed data and developed the estimation model for my master's thesis.

Decisions for the estimation model were guided by project team advisors and a steering committee comprised of representatives from industry partners and regulatory bodies. Many decisions for structure and input were decided by these groups. This thesis employed emissions estimates for future scenarios that were determined by a research team in the program. In some cases the research team considered specific likely or emerging technology changes that would reduce emissions and in other cases estimated reductions based on historical, related reductions, input from technical experts, or assumptions about the elimination or change of certain practices.

A special thanks to Clay Bell for your help with the vehicle emissions data processing program, Dr. Nigel Clark for your work on the emissions and fuel consumption scenarios, April Covington for the acquisition and preprocessing of the station data, John Hailer and Cesar Sandoval for your work on the LNG vehicle and station tank modeling, Dr. Derek Johnson for your work on the fuel tank experimental data, Dr. Hailin Li for your work on the population scenarios, Dave McKain for preprocessing the raw data into a more convenient format, your work developing the crankcase estimation model, and processing the dynamic ventilation data, and Arvind Thiruvengadam and Marc Bresch for your work on raw data collection. The contribution of the technical staff of CAFEE in conducting the chassis dynamometer and on-road testing of the tailpipe and crankcase emissions, and fuel consumptions are also appreciated.

I also want to thank my family. Words cannot express how grateful I am to my mother, father, and siblings for all of the sacrifices that you've made on my behalf. Your prayer for me was what sustained me thus far. I would also like to thank all of my friends who supported me in writing and incented me to strive towards my goal. Finally I would like to thank God for all of the gifts He has bestowed upon me throughout my life.

I would like to acknowledge the financial support provided by the Environmental Defense Fund, Cummins, Cummins-Westport, Royal Dutch Shell, the American Gas Association, Chart Industries, Clean Energy, the International Council on Clean Transportation, PepsiCo, Volvo Group, Waste Management, and Westport Innovations. Funding for EDF's methane research series, including the West Virginia University study, is provided for by Fiona and Stan Druckenmiller, Heising-Simons Foundation, Bill and Susan Oberndorf, Betsy and Sam Reeves, Robertson Foundation, Alfred P. Sloan Foundation, TomKat Charitable Trust, and the Walton Family Foundation. 


\section{Table of Contents}

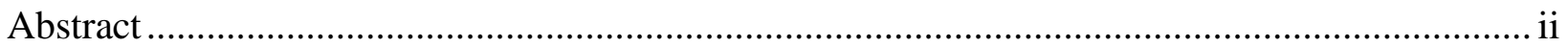

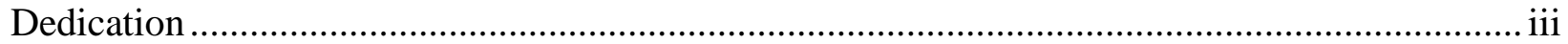

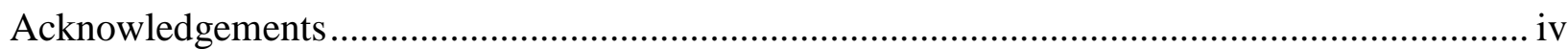

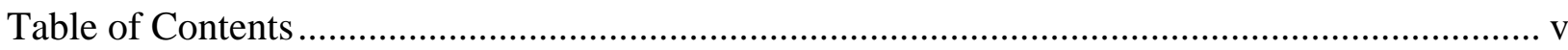

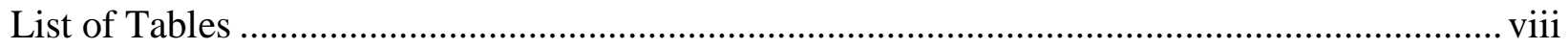

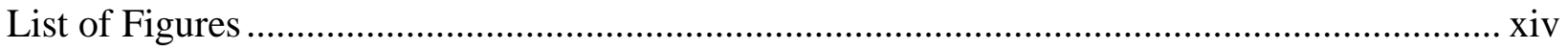

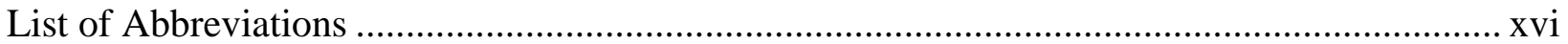

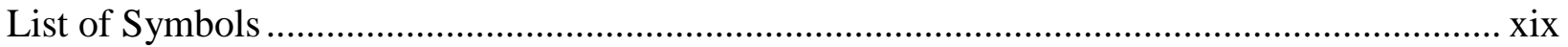

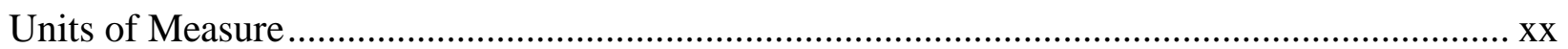

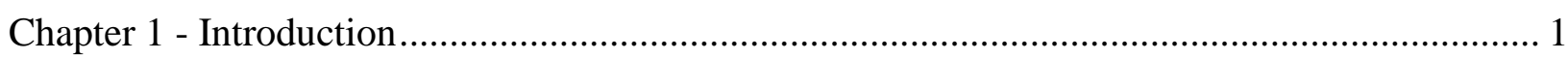

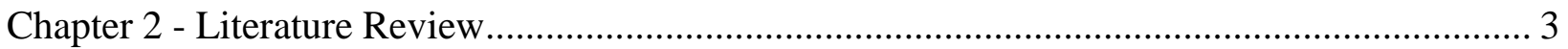

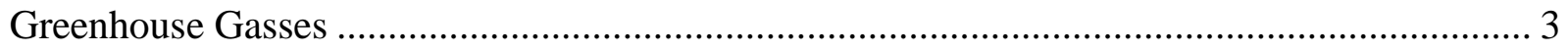

Types of Greenhouse Gasses ………………………………………………………….... 4

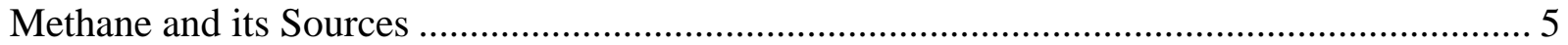

Methane Emission Sources from the Heavy-duty Transportation Sector.................................. 9

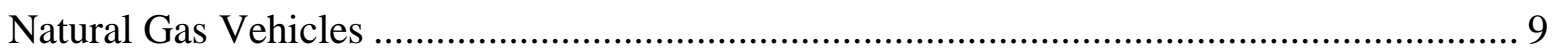

Tailpipe Emissions ................................................................................................. 12

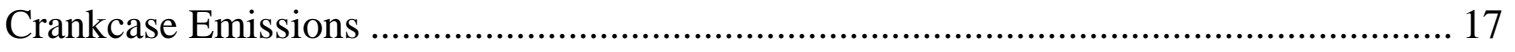

Dynamic Ventilation Emissions ............................................................................... 17

Fuel Tank Boil-off Emissions .................................................................................... 17

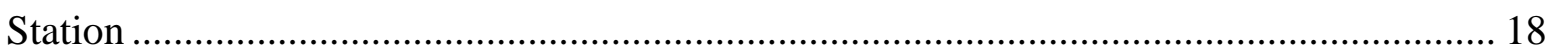

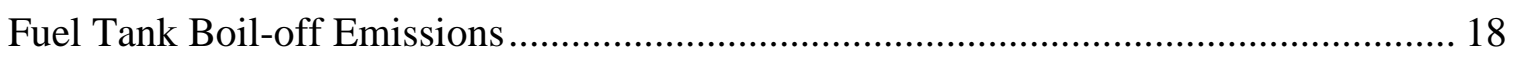

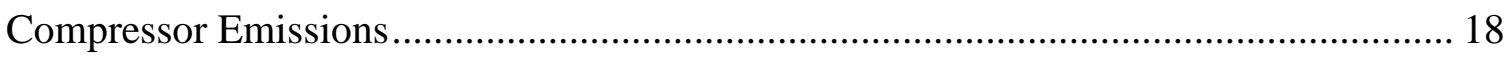

Continuous Emissions......................................................................................... 19

Existing Emissions Estimation Models ......................................................................... 19

Chapter 3 - Experimental Data Measurement and Process......................................................... 22

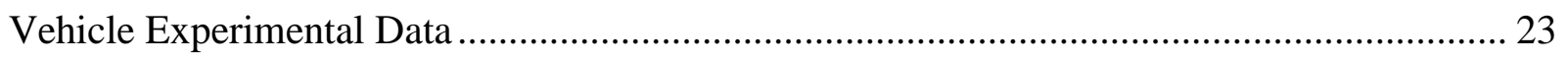

Experimental Data Derived from Driving Schedules ......................................................... 23

Statistics of Microtrips of Tested Driving Schedules ………………............................... 26

Summary of Vehicle Experimental Data ............................................................................ 29

Methane Emissions from the Onboard Fuel System........................................................... 31 


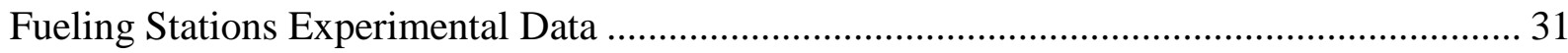

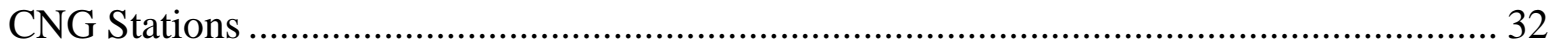

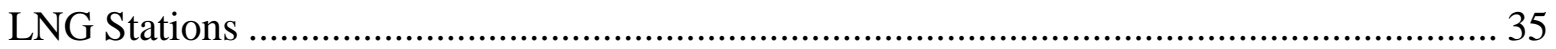

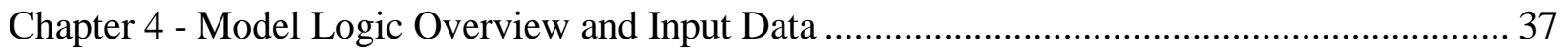

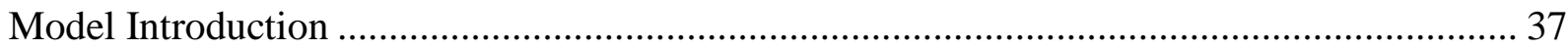

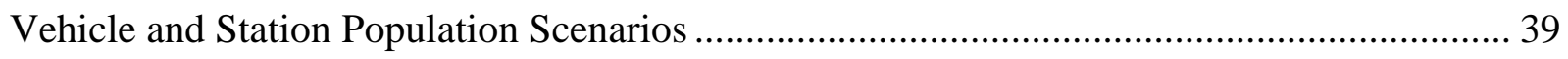

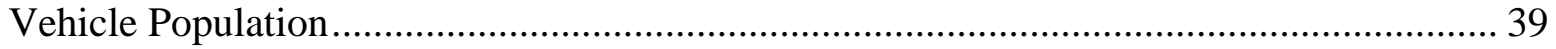

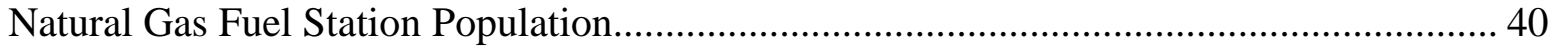

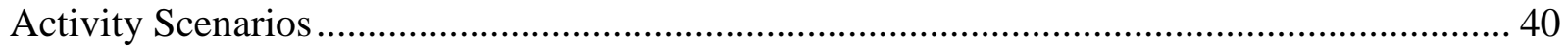

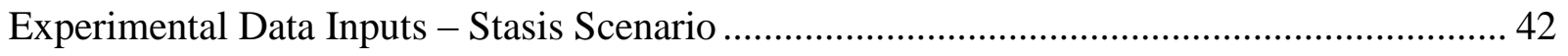

Vehicle Experimental Data Input....................................................................... 42

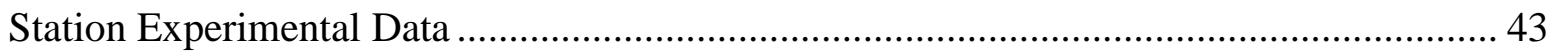

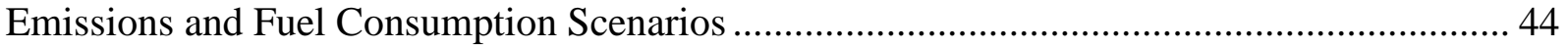

Vehicle Emissions and Fuel Consumption Scenarios..................................................... 44

Station Emissions and Fuel Consumption scenarios ................................................... 45

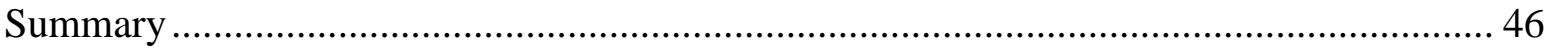

Chapter 5 - Demonstration of Methane Emissions Estimation Model with Stasis Emissions and

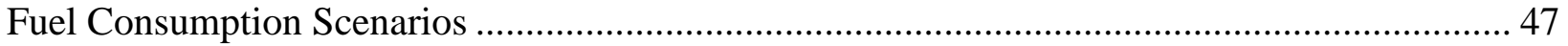

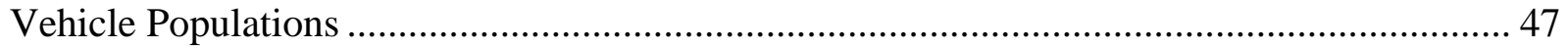

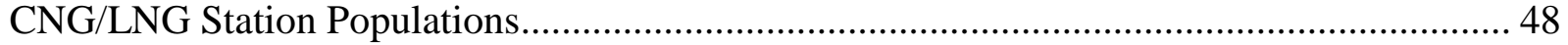

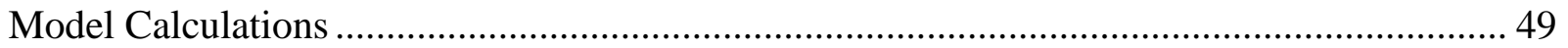

Error Check of the Estimation Model Calculations - 9 Liter OTR Tractor ......................... 62

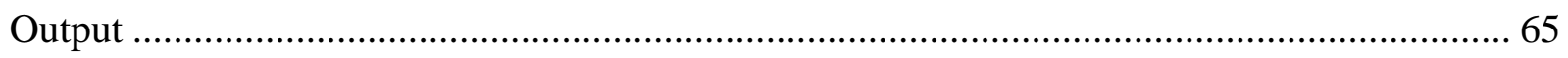

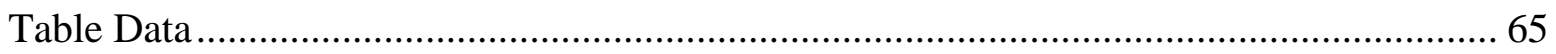

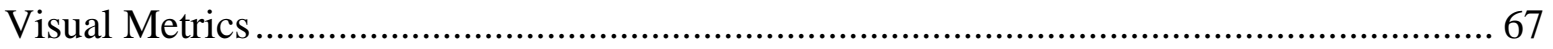

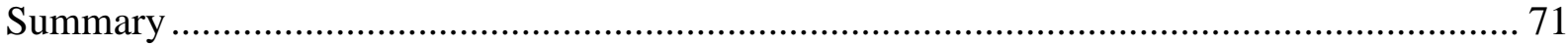

Chapter 6 - 2035 Heavy-Duty Natural Gas Sector Methane Emissions Estimated by the Model 72 Methane Emissions Estimated by the Control Scenario ................................................... 72

Table Data Output Results for the Control Scenario ................................................. 72

Visual Metrics Output Results for the Control Scenario .............................................. 73

Impact of Emissions and Fuel Consumption Scenarios on Estimated Methane Emissions ..... 77

Impact of Population Scenarios on Estimated Methane Emissions .................................... 81

Impact of HPDI Penetration Scenarios on Estimated Methane Emissions............................ 84 
Case Study: Effect of Dynamic Ventilation and Manual Ventilation on HPDI Engine OTR

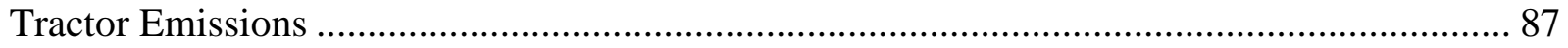

Case Study: Effect of CNG Station Utilization on Methane Emissions ............................... 87

Case Study: Effect of Emissions and/or Fuel Consumption Scenario on Overall Emissions .. 92

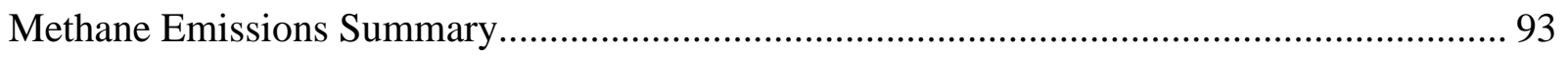

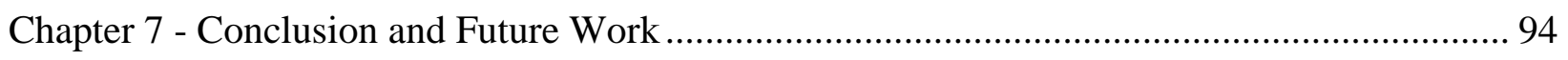

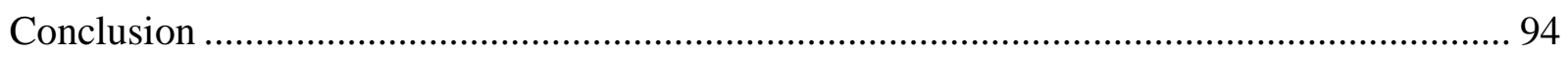

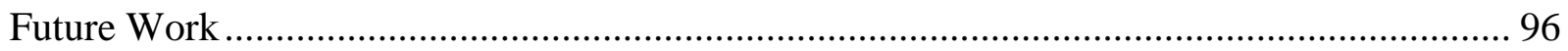

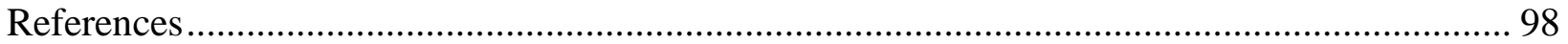




\section{List of Tables}

Table 1: Definitions of Carbon Footprint [Wiedmann and Minx, 2008] .................................... 3

Table 2: Activities Caused by Anthropogenic Methane Emissions by Sector [Karakurt et al.,

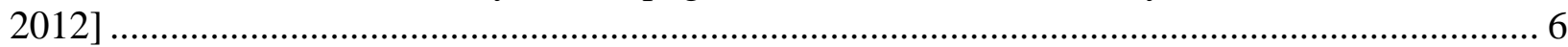

Table 3: Vehicle Classes by GVWR and EPA Group .......................................................... 10

Table 4: Mean Carbon Dioxide Tailpipe Emissions from Heavy-Duty, CNG-, LNG-, and DieselFueled Vehicles, and Corresponding Methane Emission Rates from Same Vehicle Samples [Davies et al., 2005]. 15

Table 5: Comparison of Reported Tailpipe Emission Rates for Methane from Heavy-Duty, CNG, LNG-, and Diesel-Fueled Vehicles, and Corresponding Carbon Dioxide Emission Rates from

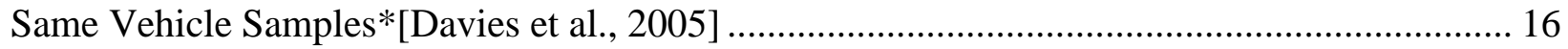

Table 6: Compressors Measured in Compressor Emissions Study [Harrison et al., 2011] .......... 18

Table 7: Sampling Results for Centrifugal Compressor Vents [Harrison et al., 2011] ............... 19

Table 8: Fugitive Emissions from Valves and Flanges using Hi-Flow Sampler Compared to Previous Results [Harrison et al., 2011] .................................................................................. 19

Table 9: Vehicles Used in this Research with Processed Data ............................................... 22

Table 10: Stations Used in this Research with Processed Data .............................................. 22

Table 11: Vehicles Tested on Chassis Dynamometer Driving Schedules ................................. 23

Table 12: Methane Emissions from 9L SI NG Vehicles with Crankcase Methane Emissions

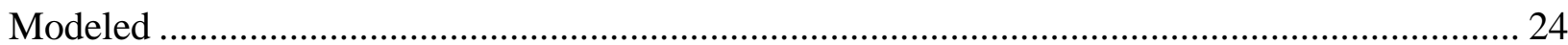

Table 13: Methane Emissions from 9L SI NG Vehicles with Tailpipe and Crankcase Methane

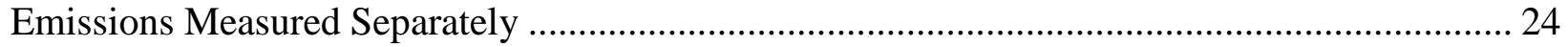

Table 14: Methane Emissions from 9L SI NG Vehicles with Tailpipe and Crankcase Methane

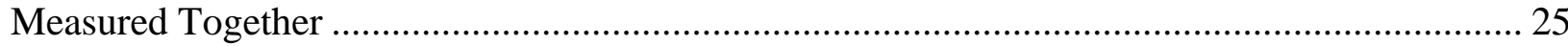

Table 15: Methane Emissions from 15L HPDI Vehicles with Tailpipe and Fueling System Vent

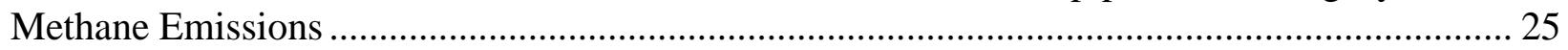

Table 16: Methane Emissions from 12L SI NG Vehicles with Crankcase Methane Emissions

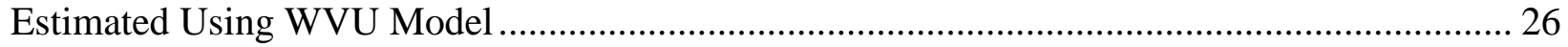

Table 17: Methane Emissions from 12L SI NG Vehicles with Tailpipe and Crankcase Methane

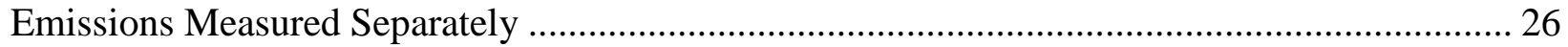

Table 18: Methane Emissions from 12 Liter SI NG Vehicle with Tailpipe and Crankcase

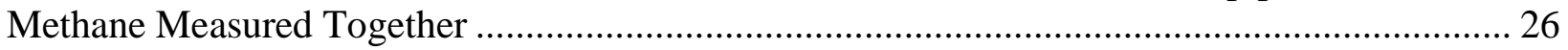

Table 19: Bins of Average Speed for Each Activity .......................................................... 27

Table 20: Driving Schedules for a 9 Liter OTR Tractor (V3) ................................................. 27

Table 21: Microtrip Separation of UDDS Driving Schedule for a 9 Liter OTR Tractor (V3) ..... 28 
Table 22: Statistics of Activities for the UDDS Driving Schedule of a 9 Liter OTR Tractor (V3) 28

Table 23: Statistics of Activities for All Driving Schedules of a 9 Liter OTR Tractor (V3) ....... 29 Table 24: Tailpipe and Crankcase Emissions and DSEC for Three 9L Stoichiometric OTR

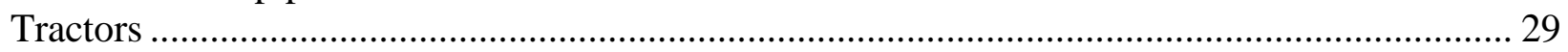

Table 25: Average Distance Specific Fuel Energy for Each Activity for Each Vehicle Type ..... 30

Table 26: Average Tailpipe FSME for Each Activity for Each Vehicle Type (g/kg fuel) .......... 30

Table 27: Average Crankcase FSME for Each Activity for Each SI Vehicle Type (g/kg fuel) ... 30

Table 28: Average Dynamic Ventilation FSME for Each Activity for HPDI Vehicles .............. 31

Table 29: Methane Emissions from Dispensing Nozzles Measured (Nozzle Dead Space and

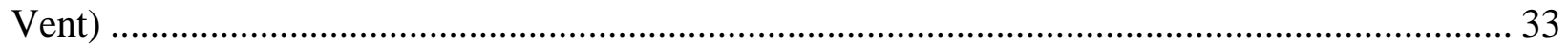

Table 30: Actuator Emissions Associated with Vehicle Refueling Events .............................. 32

Table 31: Fuel Consumption and Compressor on/off Time (Station ID \#4) .............................. 33

Table 32: Methane Emissions from Compressors (Station ID \#4) ........................................ 34

Table 33: Methane Emissions from Continuous Emissions Sources (Station ID\#4) .................. 34

Table 34: Summary of Methane Emissions from CNG Stations (ID\#4) .................................. 34

Table 35: Average Methane Emissions from CNG Stations ................................................. 35

Table 36: Average Methane Emissions from LNG Stations ................................................... 36

Table 37: Projected Heavy-duty Natural Gas Vehicle Population in 2035 .............................. 39

Table 38: The Scenarios for USA Heavy-Duty OTR Tractors in 2035 (Medium HPDI

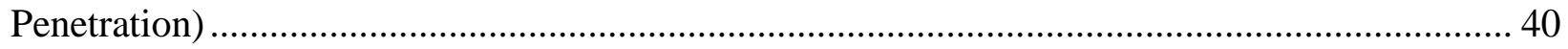

Table 39: The Scenarios for USA Heavy-Duty Long Haul OTR Tractors in 2035 with Different

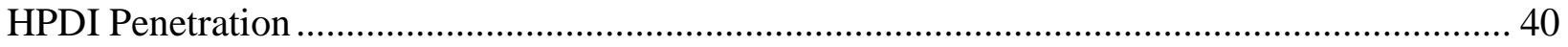

Table 40: Projected Population of Natural Gas Fuel Stations for Heavy-Duty Natural Gas

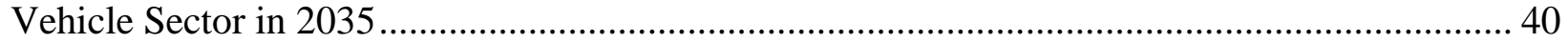

Table 41: Percent of Estimated Miles and Time for Each Type of Vehicle ............................. 41

Table 42: AVMT and Idle Time for Each Type of Vehicle .................................................. 41

Table 43: Number of Operational Days per Year for Each Vehicle Type................................ 41

Table 44: Average Distance Specific Fuel Energy for Each Activity for Each Vehicle Type ..... 42

Table 45: Average Tailpipe FSME for Each Activity for Each Vehicle Type .......................... 42

Table 46: Average Crankcase FSME for Each Activity for Each SI Vehicle Type ................... 43

Table 47: Average Dynamic Ventilation FSME for Each Activity for HPDI Vehicles .............. 43

Table 48: Average Methane Emissions from CNG Stations ................................................... 43

Table 49: Average Methane Emissions from LNG Stations ................................................. 44 
Table 50: Stasis, High, Medium, and Low Scenarios of Methane Emissions and Fuel Consumption for Vehicles 45

Table 51: Stasis, High, Medium, and Low Scenarios of Emissions for CNG Station Methane Emissions 45

Table 52: Stasis, High, Medium, and Low Scenarios of Emissions for LNG Stations ............... 46

Table 53: Selectable Options Example from Estimation Model ............................................. 47

Table 54: Selection Dependency Example from Estimation Model......................................... 48

Table 55: User Input of Vehicle Population for Transit Buses ............................................... 48

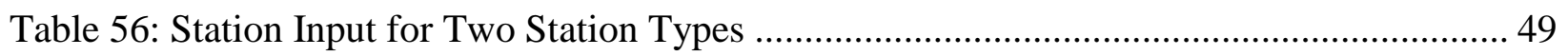

Table 57: TVMT of Transit Buses in Each Activity.............................................................. 50

Table 58: Tailpipe DSME from Transit Buses in Each Activity in Stasis............................... 51

Table 59: Annual Methane Emissions from Tailpipe of Transit Buses for Stasis Scenario......... 51

Table 60: DSME from Crankcase of Transit Buses for Stasis Scenario................................... 52

Table 61: Annual Methane Emissions from Crankcase of Transit Buses for Stasis Scenario ..... 53

Table 62: DSME from Dynamic Ventilation of HPDI OTR Tractors for Stasis Scenario........... 53

Table 63: Annual Methane Emissions from Dynamic Ventilation of HPDI OTR Tractors for

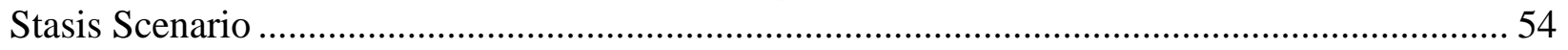

Table 64: FSME from Vehicle Tank BOG of HPDI OTR Tractors for Stasis Scenario .............. 55

Table 65: Annual Methane Emissions from Vehicle Tank BOG of HPDI OTR Tractors for Stasis

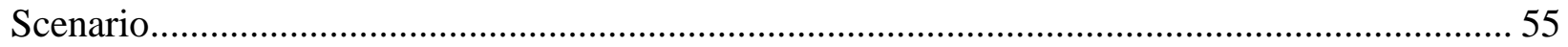

Table 66: Annual Methane Emissions from Compressor of Transit Buses for Stasis Scenario ... 56

Table 67: FSME from Station Tank BOG of HPDI OTR Tractors for Stasis Scenario .............. 57

Table 68: Annual Methane Emissions from Station Tank BOG of HPDI OTR Tractors for Stasis

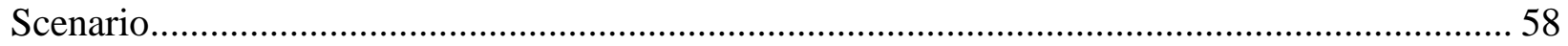

Table 69: FSME from Station Tank Bulk Fuel Delivery of HPDI OTR Tractors for Stasis

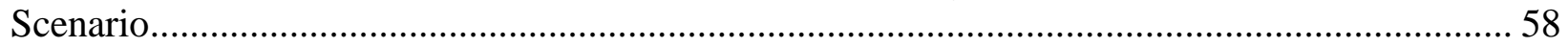

Table 70: Annual Methane Emissions from Station Tank Bulk Fuel Delivery of HPDI OTR

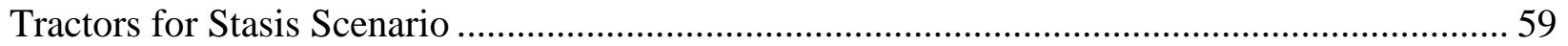

Table 71: FSME from Vehicle Manual Ventilation of HPDI OTR Tractors for Stasis Scenario 59 Table 72: Annual Methane Emissions from Vehicle Manual Ventilation HPDI OTR Tractors for Stasis Scenario . 60

Table 73: Annual Methane Emissions from LNG Stations of All LNG Vehicle Types for Stasis Scenario.

Table 74: Annual Methane Emissions from CNG Stations of All CNG Vehicle Types for Stasis Scenario. 61 
Table 75: Annual Methane Emissions from LNG SI Vehicles of All LNG SI Vehicle Types for Stasis Scenario . 61

Table 76: Annual Methane Emissions from CNG Vehicles of All CNG Vehicle Types for Stasis Scenario. 62

Table 77: Annual Methane Emissions from All Vehicles of All Vehicle Types for Stasis Scenario 62

Table 78: Vehicle FSME Input for CNG and LNG 9 Liter OTR Tractors by Source and Activity 63

Table 79: Annual Methane Emissions from each Source For CNG and LNG 9L OTR Tractors 63 Table 80: Annual Methane Vehicle Emissions Output for CNG and LNG 9 Liter OTR Tractors by Source and Activity. 64

Table 81: Annual Fuel Consumption Output for CNG and LNG 9 Liter OTR Tractors by Source and Activity...... 64

Table 82: Vehicle FSME Output for CNG and LNG 9 Liter OTR Tractors by Source and Activity 65

Table 83: Vehicle FSME Input and Output for CNG and LNG 9 Liter OTR Tractors by Source and Activity. 65

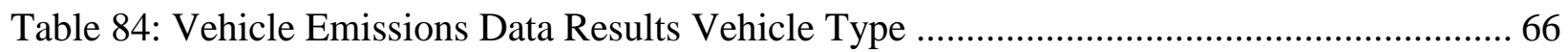

Table 85: Vehicle Emissions Data Results Activity Type ................................................... 66

Table 86: Station Emissions Data Results by Station and Activity Type .................................. 67

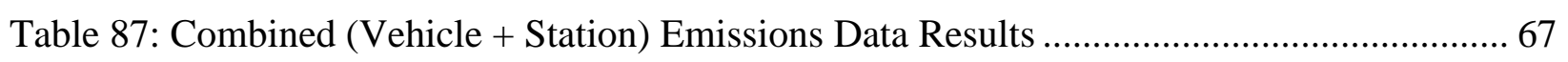

Table 88: Combined (Vehicle + Station) Emissions by Vehicle Type .................................... 67

Table 89: Methane Emissions from Each Source and Their Contributions (Control Scenarios) 72 Table 90: Total Fuel Consumption and Vehicle Only Methane Emissions for each Vehicle Type

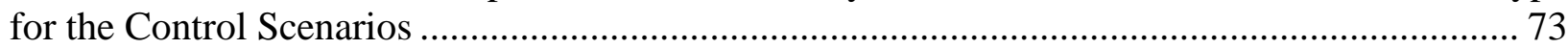

Table 91: Total Fuel Consumption and Station Only Methane Emissions for each Station Type

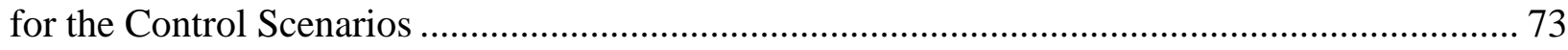

Table 92: Total Fuel Consumption and Methane Emissions for each Station Type for the Control

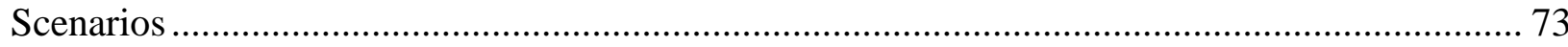

Table 93: Stasis, High, Medium, and Low Scenarios of Methane Emissions and Fuel

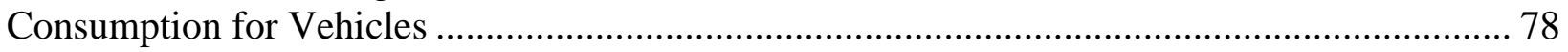

Table 94: Stasis, High, Medium, and Low Scenarios of Methane Emissions and Fuel

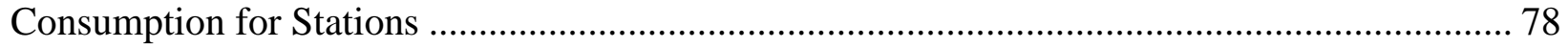

Table 95: Effect of Variable Emissions and Fuel Consumption Scenarios on Combined Methane

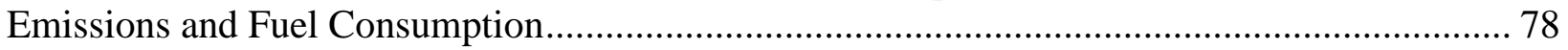

Table 96: Percent of Combined Methane Emissions, Fuel Consumption, and FSME Relative to Stasis Emissions and Fuel Consumption Scenarios................................................................. 79 
Table 97: Effect of Variable Emissions and Fuel Consumption Scenarios on Vehicle FSME .... 79

Table 98: Ratio of Vehicle FSME Relative to Stasis FSME and Fuel Consumption Scenario.... 79

Table 99: Effect of Emissions and Fuel Consumption Scenarios on Total Annual Vehicle

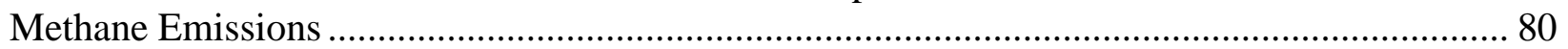

Table 100: Population Scenarios for Heavy-duty NG Vehicle Sector in 2035 ........................ 81

Table 101: Effect of Population Scenarios on Combined Methane Emissions and Fuel ............ 82

Table 102: Percent of the Combined Methane Emissions, Fuel Consumption, and FSME Relative

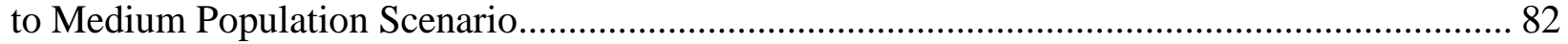

Table 103: Effect of Population Scenarios on Total Vehicle FSME ........................................ 82

Table 104: Ratio of FS Total Vehicle Methane Emissions Relative to Medium Population

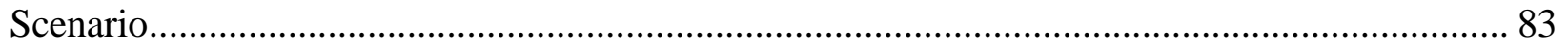

Table 105: Effect of Population Scenarios on Total Annual Vehicle Methane Emissions .......... 84

Table 106: HPDI Penetration Scenarios for Long Haul OTR Tractors ....................................... 84

Table 107: Effect of HPDI Penetration Scenarios on Combined Methane Emissions and Fuel .. 85 Table 108: Percent of the Combined Methane Emissions, Fuel Consumption, and FSME Relative to High HPDI Penetration Scenario ................................................................................. 85

Table 109: Effect of HPDI Penetration Scenarios on Total Vehicle FSME (g/kg fuel) ............. 85

Table 110: Ratio of FS Total Vehicle Methane Emissions Relative to High HPDI Penetration

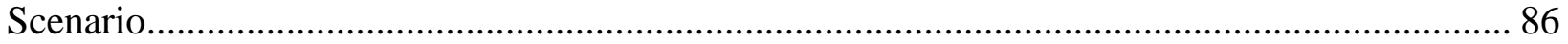

Table 111: Effect of HPDI Penetration Scenarios on Total Annual Vehicle Methane Emissions

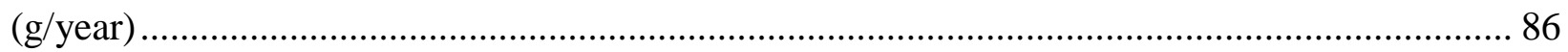

Table 112: Effect of Eliminating Dynamic Ventilation and Manual Ventilation on 15L OTR

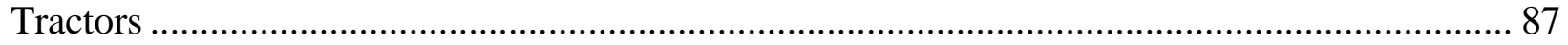

Table 113: Effect of CNG Station Utilization on Methane Emissions and Fuel Consumption ... 88 Table 114: Percent of the Combined Methane Emissions, Fuel Consumption, and FSME Relative

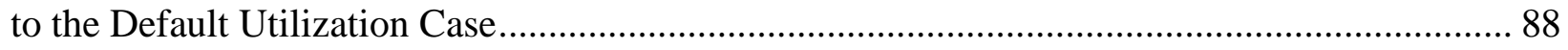

Table 115: Effect of Station Utilization on CNG Station Methane Emissions and Fuel

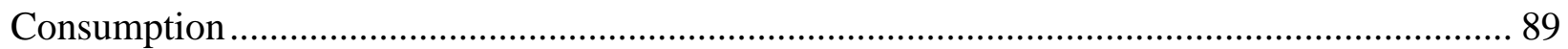

Table 116: Percent of the CNG Station Methane Emissions, Fuel Consumption, and FSME

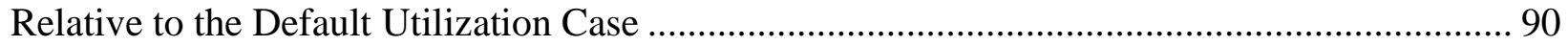

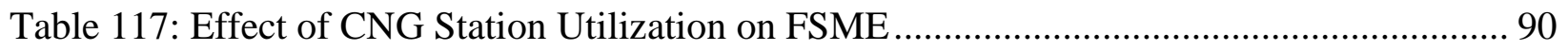

Table 118: Ratio of FSME Relative Default CNG Station Utilization..................................... 90

Table 119: Effect of CNG Station Utilization on Combined Annual Methane Emissions .......... 91

Table 120: Effect of Emissions and/or Fuel Consumption Scenarios on Overall Annual Methane

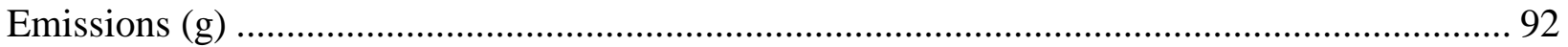


Table 121: Effect of Emissions and/or Fuel Consumption Scenarios on Overall Fuel

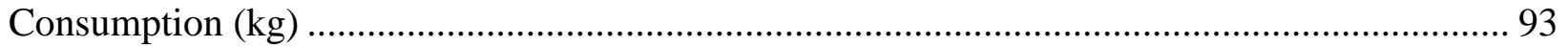

Table 122: Effect of Emissions and/or Fuel Consumption Scenarios on Overall FSME (g/kg fuel)

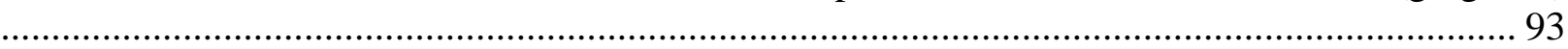




\section{List of Figures}

Figure 1: Estimated Remaining Emissions in Year 3000 [Solomon et al., 2009] ........................ 5

Figure 2: Methane Sources and Sinks [Milich, 1999] ........................................................ 6

Figure 3: Trends in Methane Emissions by Anthropogenic Sectors from 1990 to 2010 [Karakurt et al., 2012]

Figure 4: Contribution of Sectors to Anthropogenic Methane Emissions in 2010 [Karakurt et al.,

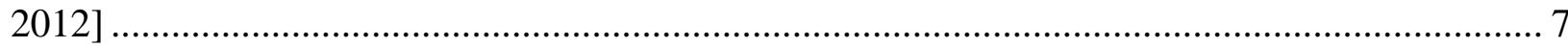

Figure 5: Anthropogenic Methane Emissions by Source in 2010 [Yusuf et al. 2012] ................. 8

Figure 6: Total U.S. Methane Emissions by Source in 2011 [EPA, 2013 a] ............................. 8

Figure 7: U.S. Methane Emissions From 1990 to 2011 [EPA, 2013 a].................................... 9

Figure 8: Average THC Emissions from Transit Buses with Different Technologies [Cooper et al. 2012]

Figure 9: Average NOx Emissions from Transit Buses with Different Technologies [Cooper et al. 2012] 11

Figure 10: Tailpipe Methane Emissions from CNG Transit Buses Operating on WMATA Driving Schedule [Melendez et al., 2005]

Figure 11: Tailpipe NOx Emissions from Two CNG and Two Diesel Fuel Transit Buses Operating on WMATA Driving Schedule [Melendez et al., 2005] ...................................... 13

Figure 12: Tailpipe NMHC (CNG) and THC (Diesel) Emissions from Two CNG and Two Diesel Fuel Transit Buses Operating on WMATA Driving Schedule [Melendez et al., 2005].............. 14

Figure 13: Tailpipe Carbon Dioxide Emissions from Two CNG and Two Diesel Fuel Transit Buses Operating on WMATA Driving Schedule [Melendez et al., 2005] ................................ 14

Figure 14: On-road Test Routes Used in Transit Bus Emissions Study [Li et al., 2014] ............ 16

Figure 15: MOBILE5a, MOBILE6, VT-MICRO, and CMEM Estimation Models Comparison with EPA Measured Data [Rakha et al., 2003] ........................................................................... 20

Figure 16: Model Logic Overview Flowchart .................................................................... 38

Figure 17: Annual Methane Emissions of Heavy-Duty Natural Gas Vehicles by Source ........... 68

Figure 18: FSME of Heavy-Duty Natural Gas Vehicles by Source ........................................ 68

Figure 19: Methane Emissions Sources of Heavy-Duty Natural Gas Vehicles* (FSME = 13.21

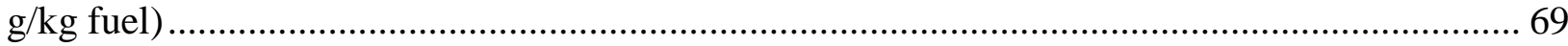

Figure 20: Methane Emissions Sources from (a) All CNG Vehicles; (b) All LNG Vehicles* ... 70 Figure 21: LNG OTR Tractor Methane Emissions Sources from (a) All LNG SI Vehicles; (b) All

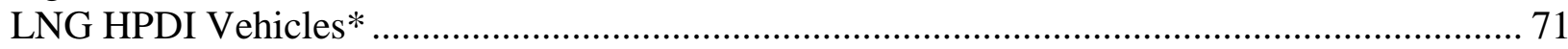

Figure 22: Methane Emissions Sources (Control Scenarios) Grouped by: (a) All Sources and (b) Top Four Emission Sources ..... 74 
Figure 23: Annual Methane Emissions of Heavy-Duty Natural Gas Vehicles Estimated from the Control Scenarios 75

Figure 24: FSME of Heavy-Duty Natural Gas Vehicles Estimated from the Control Scenarios. 75 Figure 25: Methane Emissions Sources (Control Scenarios) from (a) all CNG Vehicles; (b) all LNG Vehicles 76

Figure 26: LNG OTR Tractor Methane Emissions Sources (Control Scenarios) from (a) all LNG SI vehicles; (b) all LNG HPDI vehicles 77

Figure 27: Effect of Emissions and Fuel Consumption Scenarios on Vehicle FSME................. 80

Figure 28: Effect of Emissions and Fuel Consumption Scenarios on Total Annual Vehicle

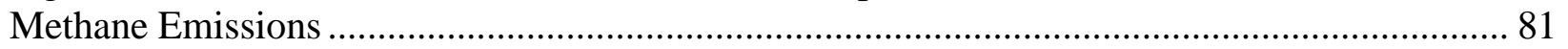

Figure 29: Effect of Population Scenarios on Vehicle FSME .............................................. 83

Figure 30: Effect of Population Scenarios on Total Annual Vehicle Methane Emissions ........... 84

Figure 31: Effect of HPDI Penetration Scenarios on Vehicle FSME ...................................... 86

Figure 32: Effect of HPDI Penetration Scenarios on Total Annual Vehicle Methane Emissions 87

Figure 33: CNG Station FSME with Respect to Utilization Factor........................................ 89

Figure 34: Effect of CNG Station Utilization on FSME....................................................... 91

Figure 35: Effect of CNG Station Utilization on Combined Annual Methane Emissions .......... 92 


\section{List of Abbreviations}

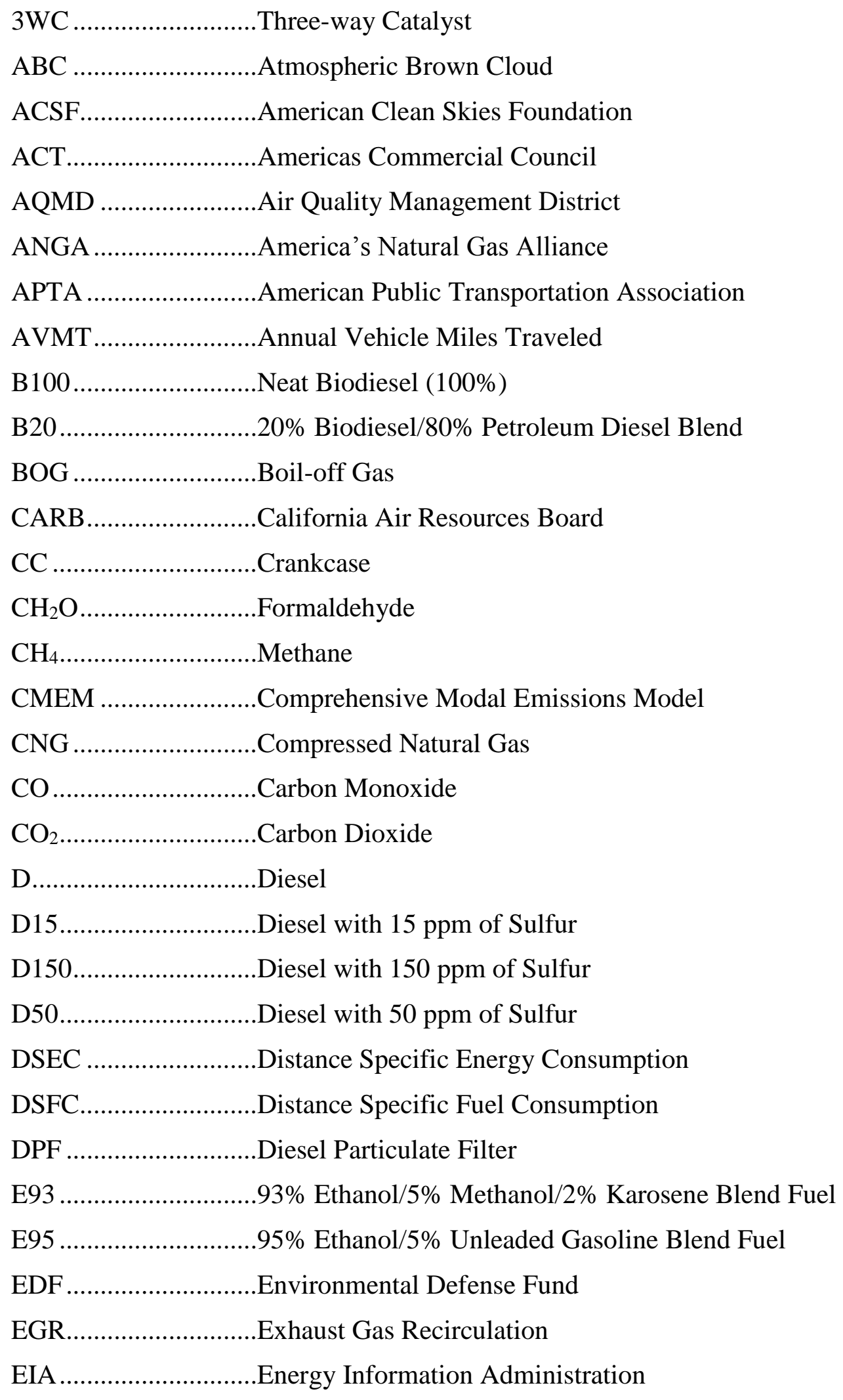


EMFAC ARB Emission Factors Modeling Software

EPA. Environmental Protection Agency

FSME ..Fuel Specific Methane Emissions

GHG .Greenhouse Gas

GRI Global Reporting Initiative

GVWR Gross Vehicle Weight Rating

GWP Global Warming Potential

$\mathrm{HC}$ Hydrocarbons

HFC. ..Hydrofluorocarbons

HHDDT ..Heavy Heavy-Duty Diesel Truck

IMechE Institution of Mechanical Engineers

IVE International Vehicle Emissions Model

KAT Knoxville Area Transit

LHDDE Light Heavy-Duty Engine

LNG ..Liquefied Natural Gas

MDPV ..Medium-Duty Passenger Vehicles

MHDDE ..Medium Heavy-Duty Diesel Engine

MMT Million Metric Tons

$\mathrm{NO}_{2}$ ..Nitrogen Dioxide

NPC. .National Petroleum Council

NREL ...National Renewable Energy Laboratory

$\mathrm{O}_{3}$ ..Ozone

OCTA ..Orange County Transportation Authority

$\mathrm{OC}$ Oxidation Catalyst

OD. Number of Operational Days per Year

$\mathrm{OH}$. ..Hydroxyl

ORNL ..Oak Ridge National Laboratory

PAH ..Polycyclic Aromatic Hydrocarbons

PDM .Percent Distribution of Miles

PEMS ..Portable Emissions Measurement System

PFC Perfluorocarbons

ppm ..Parts per Million

RME ..Relative Methane Emissions 


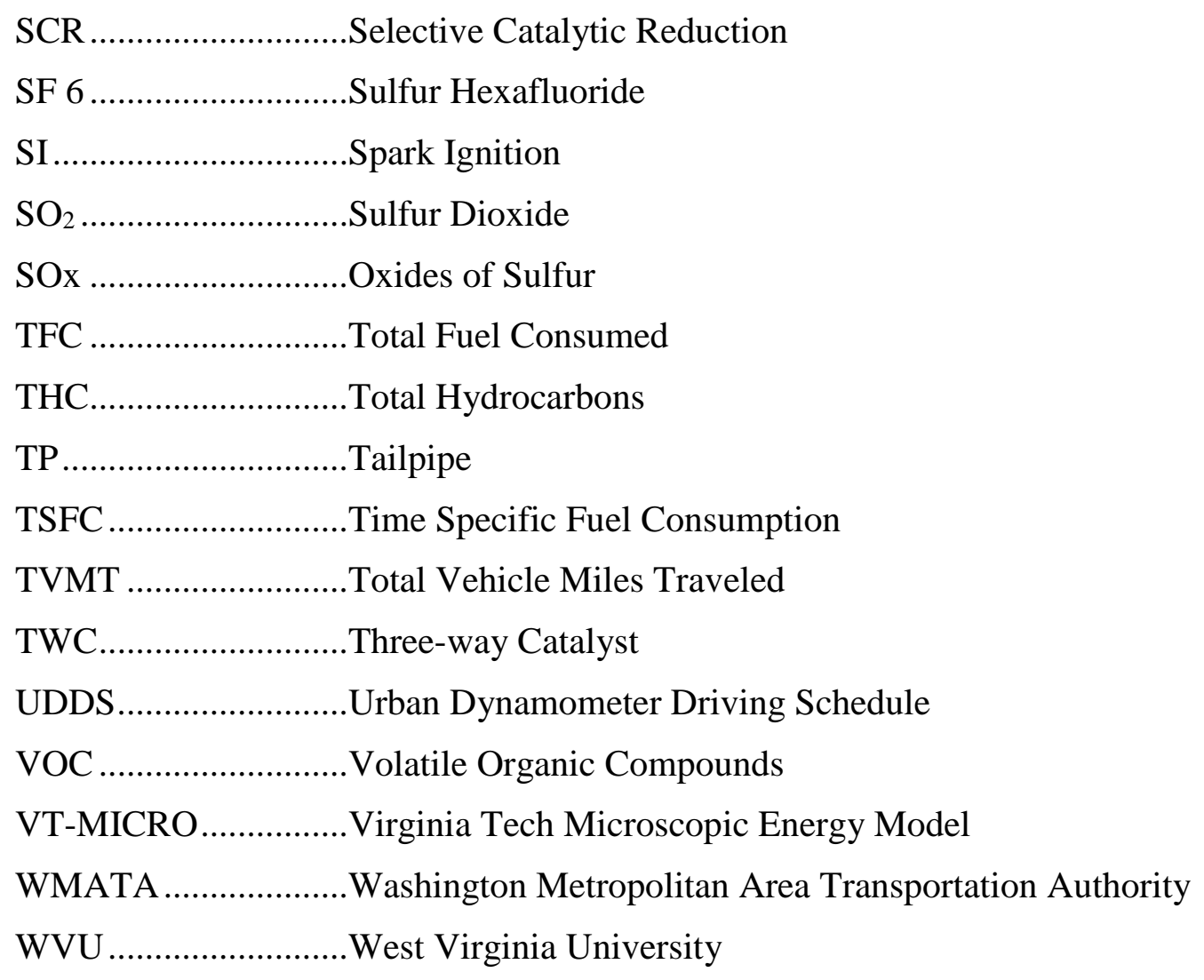




\section{List of Symbols}

Symbol

AVMT

DSFC

FSME

$\mathrm{m}$

$\dot{m}$

MMT

$\mathrm{n}$

OD

PDM

$\mathrm{t}$

TFC

TSFC

TVMT
Meaning

annual vehicle miles traveled

distance specific fuel consumption

fuel specific methane emissions

annual mass emissions

mass flow rate

million metric tons

number of a quantity

number of operational days

percent distribution of miles

time

total fuel consumption

time specific fuel consumption

total vehicle miles traveled
Unit of Measure

$\mathrm{mi} / \mathrm{yr}$

$\mathrm{kg} / \mathrm{mi}$

$\mathrm{g}$ emission $/ \mathrm{kg}$ fuel

$\mathrm{g}$ (per year)

g/day

$10^{6}$ ton

day

$\%$

S

$\mathrm{kg}$ (per year)

$\mathrm{kg} / \mathrm{hr}$

mi (per year) 


\section{Units of Measure}

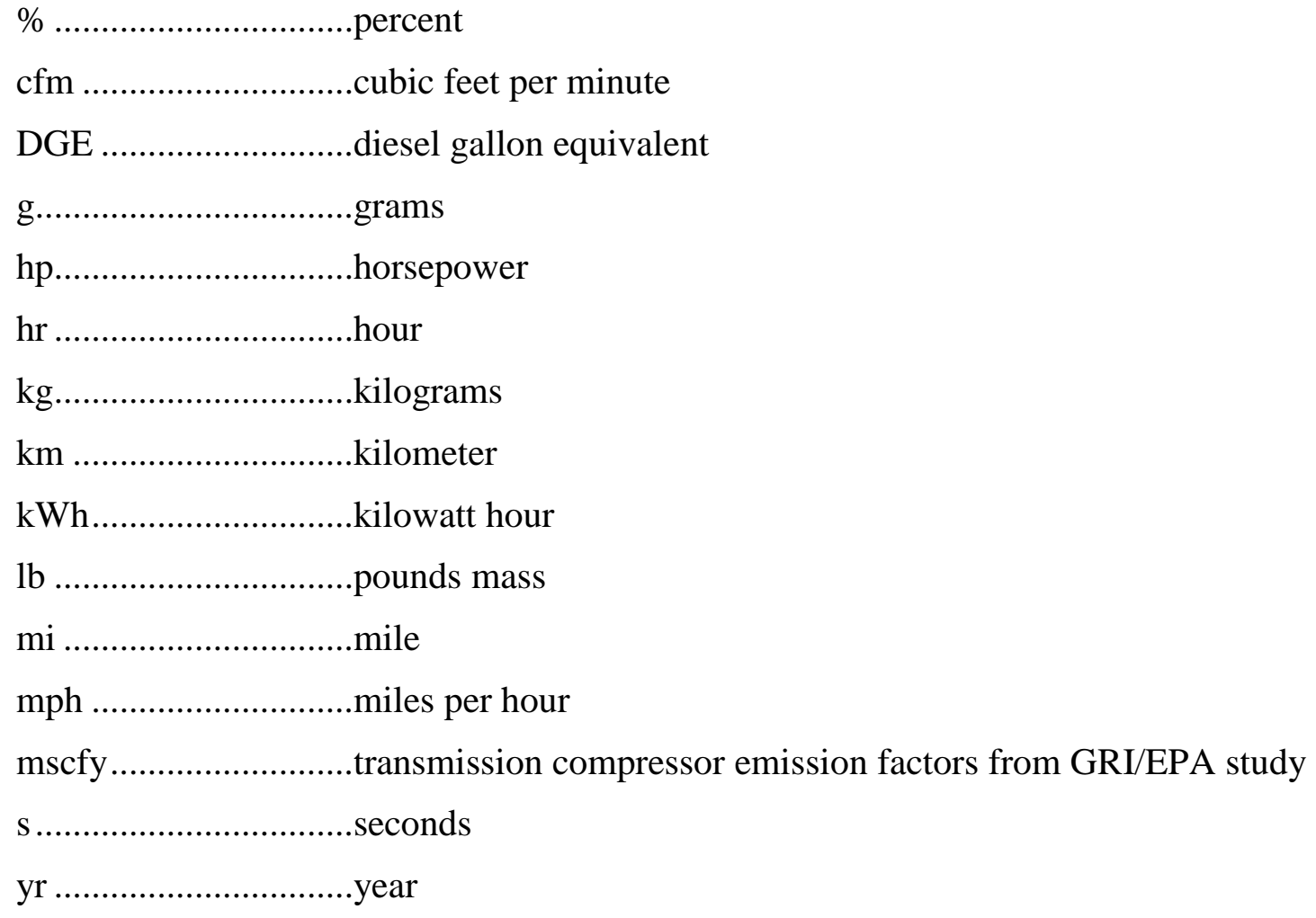




\section{Chapter 1 - Introduction}

Greenhouse gas (GHG) emissions have been a topic of much interest in the past decades. The most discussed greenhouse gas emissions include the following: carbon dioxide $\left(\mathrm{CO}_{2}\right)$; carbon monoxide $(\mathrm{CO})$; oxides of nitrogen $\left(\mathrm{NO}_{\mathrm{x}}\right)$; ozone $\left(\mathrm{O}_{3}\right)$; sulfur dioxide $\left(\mathrm{SO}_{2}\right)$; and methane $\left(\mathrm{CH}_{4}\right)$. There has been recent interest in methane emissions due to a high global warming potential. Although $\mathrm{CO}_{2}$ is the most abundant greenhouse gas, methane is nineteen to twenty five times more effective at trapping heat over a 100-year period (Boucher et al., 2009; EPA, 2013 b; Houghton, 1995). Methane comes from many natural and man-made sources, such as wetlands, wet-paddy rice farming, livestock farming, biomass burning, landfills, coal mining, venting of natural gas or natural-gas pipeline leaks, wetland bogs, wetland swamps, upland soils and riparian area, oceans, estuaries, rivers, permafrost, lakes, gas hydrates, terrestrial and marine geologic sources, wildfires, vegetation, terrestrial arthropods, and wild animals. The natural gas vehicle sector is one of these sources, with the heavy-duty sector consisting of the highest portion of vehicle emissions. The largest quantifiable vehicle emissions consist of the following: tailpipe; crankcase; HPDI dynamic ventilation; and vehicle fuel tank boil off gas (BOG). The largest quantifiable station emissions consist of the following: dispenser nozzle; compressor; station fuel tank BOG; vehicle manual ventilation prior to refueling; emissions associated with delivery; and continuous emissions.

The Environmental Defense Fund (EDF) has been working with scientists, industry companies, and academic experts to quantify and reduce methane emissions (EDF, 2015). There are several modules along the supply chain. One example is measurements of methane emissions at production sites, such as natural gas wells (Allen et al, 2013). The information in this thesis is part of the module attributed directly to natural gas vehicles or stations. The behavior of the vehicle directly affects some of the station sources. Emissions models of the heavy-duty natural gas vehicle sector, especially models with natural gas station emissions as part of the overall emissions, are currently very limited. There is a need for a natural gas emissions model capable of determining the emissions associated with heavy-duty natural gas vehicle fleets. There has been steady growth in natural gas vehicle fuel consumption from 1997 to 2014. One of the biggest drivers of this market is the heavy-duty sector. The fuel consumed by heavy-duty natural gas vehicles is projected to continue to grow (EIA, 2014; Liss, 2012). The emissions from these vehicles and the respective amount from each source needs to be determined to quantify the impact of heavy-duty natural gas vehicle growth on the total methane released to the environment in the future.

Methane emissions from the heavy-duty natural gas vehicle sector include methane emissions from vehicles and refueling stations. Emissions from vehicles include tailpipe, crankcase for spark ignited (SI) engine powered vehicles, dynamic ventilation for high pressure direct injection (HPDI) engine powered vehicles, and vehicle fuel systems such as onboard storage tanks. Emissions from refueling stations include refueling nozzles, compressors for compressed natural 
gas (CNG) stations, storage tank BOG, manual ventilation, and delivery emissions for liquefied natural gas (LNG) stations, and any other part which continuously emits methane.

The main objective of the estimation model is to use fixed inputs from measured data, given in rates of emissions or fuel consumption associated with each source, and modifiable inputs of heavy-duty natural gas vehicle fleet scenarios to determine the overall methane emissions from heavy-duty natural gas stations and vehicles. The following are sub-objectives of the estimation model:

- Establish a database of processed vehicle fuel consumption and vehicle and station emissions derived from measured and modeled experimental data of each vehicle type

- Create a user friendly tool to allow a user input of vehicle fleet population and operational characteristics and station population

- Develop a projection of vehicle and station population, operational characteristics, and future technology improvements for each emission source and fuel economy for 2035 as a default user input

- Output visual metrics for visual comparison in addition to the estimated methane emissions

- Provide insight for individual sources of methane emissions and the magnitude of each to guide future efforts toward reducing future emissions more efficiently 


\section{Chapter 2 - Literature Review}

\section{Greenhouse Gasses}

Scientific evidence suggests that emissions of greenhouse gasses may be the leading cause of an atmospheric condition called global warming. Land use and land use policies are key elements in determining the influence on the greenhouse effect (Adger and Brown, 1994). Immediate and sustained warming leads to possible climate impacts such as Arctic sea ice retreat, heavier rainfall and flooding, melting of permafrost, glaciers, and snowpack, changes in water supply, and hurricane intensity increases. (Solomon et al., 2009).

The development of global warming depends, to a large extent, on the carbon footprint. In the past, there have been numerous approaches used to define a carbon footprint. These range from simple online calculators to input-output-based methods and tools or complex life-cycle analysis. However there were clear discrepancies between public and academic definitions of the term. Definitions of previous literature were tabulated, as shown in Table 1 (Wiedmann and Minx, 2008).

Table 1: Definitions of Carbon Footprint [Wiedmann and Minx, 2008]

\begin{tabular}{|c|c|}
\hline Source & Definition \\
\hline BP (2007) & $\begin{array}{l}\text { "The carbon footprint is the amount of carbon dioxide emitted due to your daily } \\
\text { activities - from washing a load of laundry to driving a carload of kids to school." }\end{array}$ \\
\hline $\begin{array}{l}\text { British Sky } \\
\text { Broadcasting } \\
\text { (Sky) (Patel 2006) }\end{array}$ & $\begin{array}{l}\text { The carbon footprint was calculated by "measuring the } \mathrm{CO}_{2} \text { equivalent emissions from } \\
\text { its premises, company-owned vehicles, business travel and waste to landfill." (Patel } \\
\text { 2006) }\end{array}$ \\
\hline $\begin{array}{l}\text { Carbon Trust } \\
(2007)\end{array}$ & $\begin{array}{l}\text { "... a methodology to estimate the total emission of greenhouse gases (GHG) in carbon } \\
\text { equivalents from a product across its life cycle from the production of raw material } \\
\text { used in its manufacture, to disposal of the finished product (excluding in-use } \\
\text { emissions). } \\
\text { "... a technique for identifying and measuring the individual greenhouse gas emissions } \\
\text { from each activity within a supply chain process step and the framework for } \\
\text { attributing these to each output product (we [The Carbon Trust] will refer to this as the } \\
\text { product's 'carbon footprint')." (CarbonTrust 2007, p.4) }\end{array}$ \\
\hline Energetics (2007) & $\begin{array}{l}\text { "... the full extent of direct and indirect } \mathrm{CO}_{2} \text { emissions caused by your business } \\
\text { activities." }\end{array}$ \\
\hline ETAP (2007) & $\begin{array}{l}\text { "...the 'Carbon Footprint' is a measure of the impact human activities have on the } \\
\text { environment in terms of the amount of greenhouse gases produced, measured in } \\
\text { tonnes of carbon dioxide." }\end{array}$ \\
\hline $\begin{array}{l}\text { Global Footprint } \\
\text { Network (2007) }\end{array}$ & $\begin{array}{l}\text { "The demand on biocapacity required to sequester (through photosynthesis) the } \\
\text { carbon dioxide }\left(\mathrm{CO}_{2}\right) \text { emissions from fossil fuel combustion." (GFN 2007; see also text) }\end{array}$ \\
\hline $\begin{array}{l}\text { Grub \& Ellis } \\
(2007)\end{array}$ & $\begin{array}{l}\text { "A carbon footprint is a measure of the amount of carbon dioxide emitted through the } \\
\text { combustion of fossil fuels. In the case of a business organization, it is the amount of } \\
\mathrm{CO}_{2} \text { emitted either directly or indirectly as a result of its everyday operations. It also } \\
\text { might reflect the fossil energy represented in a product or commodity reaching } \\
\text { market." }\end{array}$ \\
\hline $\begin{array}{l}\text { Paliamentary } \\
\text { Office of Science } \\
\text { and Technology } \\
\text { (POST 2006) }\end{array}$ & $\begin{array}{l}\text { "A 'carbon footprint' is the total amount of } \mathrm{CO}_{2} \text { and other greenhouse gases, emitted } \\
\text { over the full life cycle of a process or product. It is expressed as grams of } \mathrm{CO}_{2} \\
\text { equivalent per kilowatt hour of generation (gCO2eq/kWh), which accounts for the } \\
\text { different global warming effects of other greenhouse gases." }\end{array}$ \\
\hline
\end{tabular}

Wiedmann and Minx [2008] chose the following definition after comparing and contrasting the definitions: "The carbon footprint is a measure of the exclusive total amount of $\mathrm{CO}_{2}$ emissions 
that is directly and indirectly caused by an activity or is accumulated over the life stages of a product." Commonly accepted accounting principles and modeling approaches were used as a basis for the scientific definition. Carbon footprint was measured in units of mass. A life cycle analysis, either a process analysis or an environmental input-output method, was used. "Carbon footprint" was most often used as a synonym for $\mathrm{CO}_{2}$ or greenhouse gases, such as methane, expressed in $\mathrm{CO}_{2}$ equivalents.

\section{Types of Greenhouse Gasses}

Reports in literature state that greenhouse gasses are a major cause of air pollution. Fossil fuel combustion in the power generation and transportation sectors, cooking with solid fuels, and forest and savannah burning are the major sources of this pollution (Ramanathan and Feng, 2009). The main by-product of burning these materials is $\mathrm{CO}_{2}$. There are products of incomplete combustions as well, such as $\mathrm{CO}$ and $\mathrm{NO}_{\mathrm{x}}$, that react with the atmosphere to form ozone, another greenhouse gas. Aerosol precursor gases, such as $\mathrm{SO}_{2}$, are also formed and have negative effects on human health and the ecosystem. Greenhouse gasses absorb and emit long wave radiation (Raval and Ramanathan, 1989). Chlorofluorocarbons (CFCs) that were used as refrigerants and propellants were discovered to have up to ten thousand times the $\mathrm{CO}_{2}$ effect on a per molecule basis (Molina and Rowland, 1974). Human activities have also introduced aerosols, such as soot, nitrogen dioxide $\left(\mathrm{NO}_{2}\right)$, and sulfur dioxide, into the atmosphere. Scientists have speculated that sunlight is being reflected before it reaches the surface because of these aerosols. Aerosols produce atmospheric brown clouds (ABCs) that are brighter and release less precipitation (Ramanathan and Feng, 2009).

One of the earliest works on the greenhouse effect was conducted by Svante Arrhenius, a Swedish chemist. Arrhenius developed a mathematical model which reported that doubling the amount of $\mathrm{CO}_{2}$ would increase the temperature by $5 \mathrm{~K}$ (Arrhenius, 1896). A proper accounting of the energy balance was shown in the work by Manabe and Wetherald (Manabe and Wetherald, 1967). A study by Wang [1976] showed that methane and nitrous oxide were strong greenhouse gasses as well. These gasses alter ozone chemistry and result in lower atmospheric ozone along with increased $\mathrm{CO}$ and $\mathrm{NO}_{\mathrm{x}}$ (Wang et al., 1976). Fishman proposed that $\mathrm{CO}$ and $\mathrm{NO}_{\mathrm{x}}$ are not only an air pollutant but a contributor to global warming (Fishman et al., 1980). A report by the Intergovernmental Panel on Climate Change (IPCC) stated that about half of the total forcing was from $\mathrm{CO}_{2}$ and the rest was due to increased methane, halocarbons, and ozone (Intergovernmental Panel on Climate Change, 2001). Conversely Wiedmann and Minx [2008] suggested that $\mathrm{CO}_{2}$ should be the only greenhouse gas measured even though other greenhouse gases such as methane exist in the Earth's atmosphere.

A study by Solomon [2009] proposed that atmospheric temperature increases due to $\mathrm{CO}_{2}$ emissions would not decrease even if $\mathrm{CO}_{2}$ emissions were to end completely. The effects would not be fully reversed even after a millennium. Solomon used the scope of this time scale to declare the effects "irreversible". Geo-engineering to remove gasses and/or introduce active cooling was neglected in the model used. After one millennium, approximately twenty percent of added $\mathrm{CO}_{2}$ remained in the atmosphere and the remaining eighty percent was mixed into the ocean. A model was made to predict the amount of remaining $\mathrm{CO}_{2}$ if emissions increased at two percent per year until peak concentrations were reached then ceased for the rest of a millennium. The two percent increase reflected the trend observed over the past decade. The results are shown in Figure 1 (Solomon et al., 2009). The emissions all start to converge at the end of the 
millennium. This suggests the prediction of "irreversible" is an accurate statement. Solomon et al. [2009] concluded that most models that predict the effects of reducing or eliminating $\mathrm{CO}_{2}$ emissions were incorrect. $\mathrm{CO}_{2}$ emissions have a long term effect that cannot be neglected because $\mathrm{CO}_{2}$ emissions have ceased. Trace gases, principally methane, NOx, and CFCs, increased the radiative forcing from 1980 to 1990 by 43\% (Lashof and Ahuja, 1990).

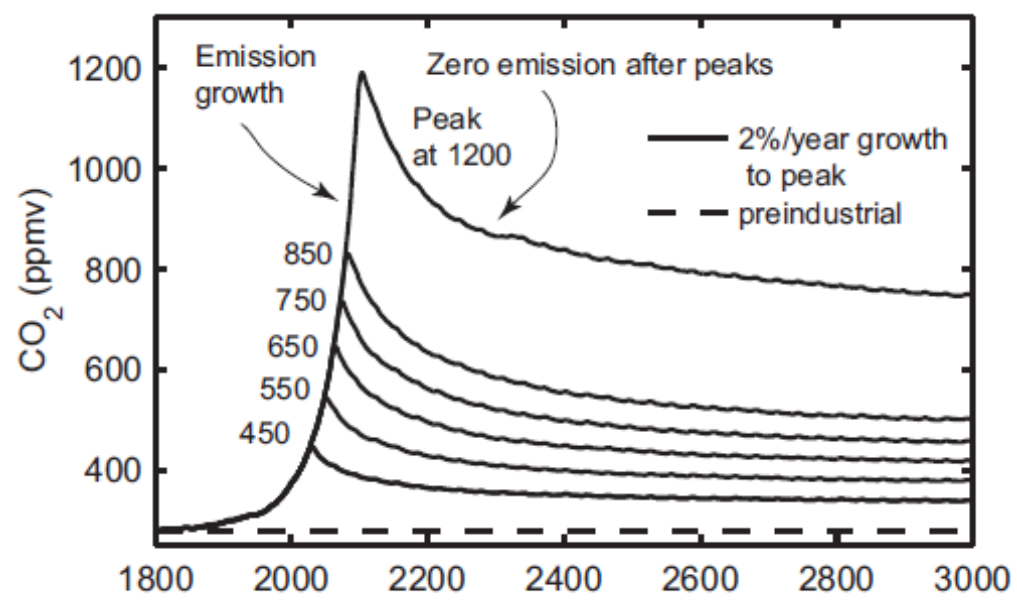

Figure 1: Estimated Remaining Emissions in Year 3000 [Solomon et al., 2009]

\section{Methane and its Sources}

Methane was $19 \pm 12 \%$ to 25 times more effective at trapping heat than $\mathrm{CO}_{2}$, or global warming potential (GWP), over a 100-year period (Boucher et al., 2009; EPA, 2013 b; Houghton, 1995). Alvarez et al. [2012] elaborated on the effect of policy tradeoffs and stressed the importance of technology warming potential (TWP) in addition to GWP. TWP uses the same inputs and radiative forcing equations as GWP. However, GWP only considers radiative forcing of single emission pulses. A pulse TWP is the same as GWP. TWP reveals time-dependent tradeoffs between two alternative technologies. The TWP depends on the time application of the tradeoff, such as a CNG vehicle one day rental, 15-day life cycle, or vehicle fleet conversion.

Methane is oxidized in the troposphere by hydroxyl $(\mathrm{OH})$. This reaction leads to formation of formaldehyde $\left(\mathrm{CH}_{2} \mathrm{O}\right), \mathrm{CO}$, and $\mathrm{O}_{3}$ if there is enough $\mathrm{NOx}$ (Wuebbles et al., 2000). One study estimates that methane yields a contribution to global warming of about $19 \%$, second only to $\mathrm{CO}_{2}$ (about 64\%) (Hayes, 2004). Milich [1999] predicted that there were nearly twice as many anthropogenic sources of methane, such as wetlands, wet-paddy rice farming, livestock farming, biomass burning, landfills, coal mining, and venting of natural gas or natural-gas pipeline leaks. A bar chart with anthropogenic and natural sources and sinks of methane was created, as shown in Figure 2. Another compilation of anthropogenic sources is shown in Table 2. The Environmental Protection Agency (EPA) cites the following natural sources of methane: wetland bogs, wetland swamps, upland soils and riparian area, oceans, estuaries, rivers, permafrost, lakes, gas hydrates, terrestrial and marine geologic sources, wildfires, vegetation, terrestrial arthropods, and wild animals. Temperatures are predicted to be about $60^{\circ} \mathrm{F}$ lower without the natural sources (EPA, 2010). Milich [1999] concluded that methane needed to be analyzed as well as $\mathrm{CO}_{2}$ when taking national greenhouse gas inventories (Milich, 1999). 


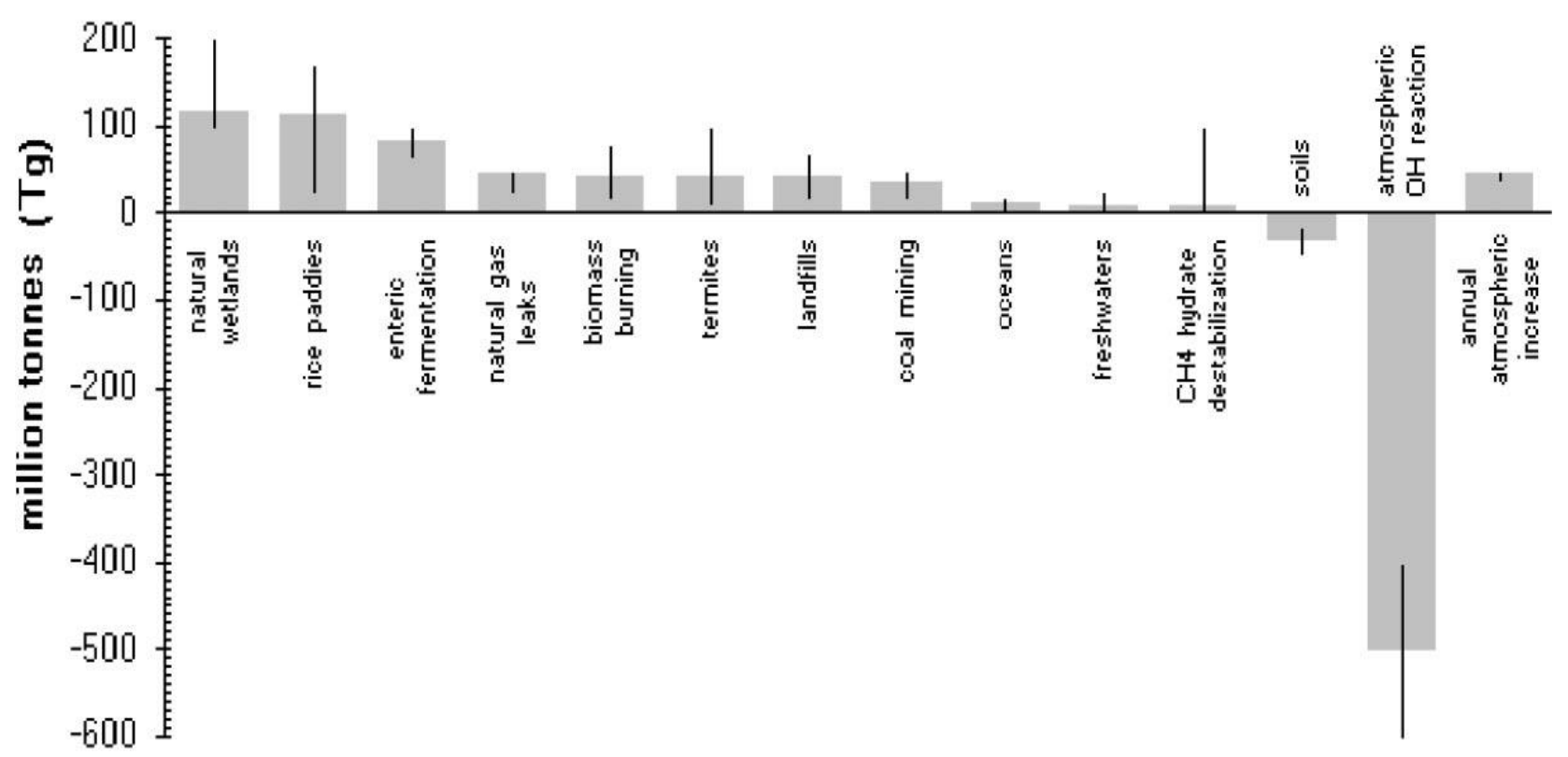

Figure 2: Methane Sources and Sinks [Milich, 1999]

Table 2: Activities Caused by Anthropogenic Methane Emissions by Sector [Karakurt et al., 2012]

\begin{tabular}{|c|c|c|c|}
\hline Energy & Industry & Agriculture & Waste \\
\hline Coal Mining Activities & Chemical Production & Manure Management & Landfilling of Solid Waste \\
\hline Natural Gas and Oil Systems & Iron and Steel Production & Enteric Fermentation & Wastewater \\
\hline Stationary and Mobile Combustion & Metal Production & Rice Cultivation & Waste Combustion \\
\hline Biomass Combustion & Mineral Products & Other & Solvent and Other Product Use \\
\hline \multirow{2}{*}{} & Petrochemical Production & & \\
\cline { 2 - 2 } & Silicon Carbide Production & & \\
\hline
\end{tabular}

A study by Karakurt [2012] predicted that $40 \%$ of global methane emissions come from natural sources. Anthropogenic sources contribute to the remaining 60\%. Figure 3 shows the trends in methane emissions from anthropogenic sources by sector from 1990 to 2010. Figure 4 shows the percentage contribution of each sector in 2010. Agriculture is the largest source (50.63\%) followed by the energy sector (28.65\%). A study by Yusuf et al. [2012] gave similar results: 53\% from the agriculture sector; $28 \%$ from the energy sector; and 19\% from the waste sector. The industry sector was neglected in this study. A more detailed description of the methane sources is shown in Figure 5. 


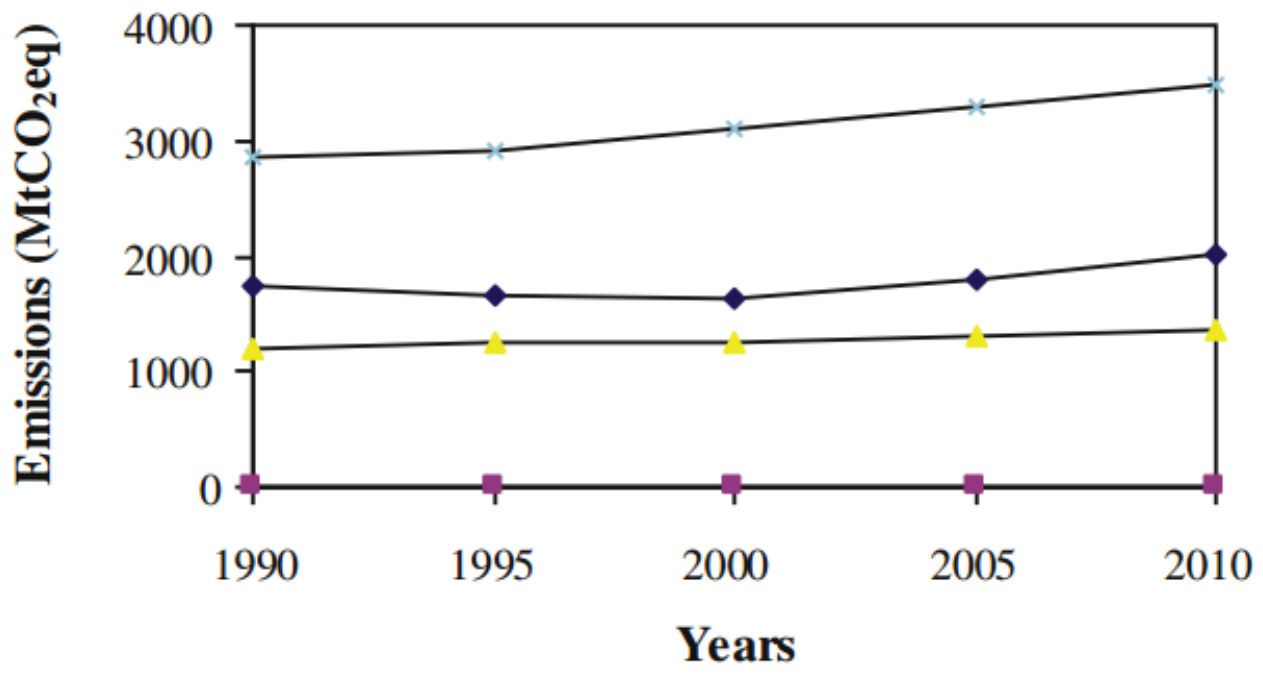

$\longrightarrow$ Energy $\rightarrow$ Industry $\longrightarrow$ Waste $\rightarrow-$ Agriculture

Figure 3: Trends in Methane Emissions by Anthropogenic Sectors from 1990 to 2010 [Karakurt et al., 2012]

Waste

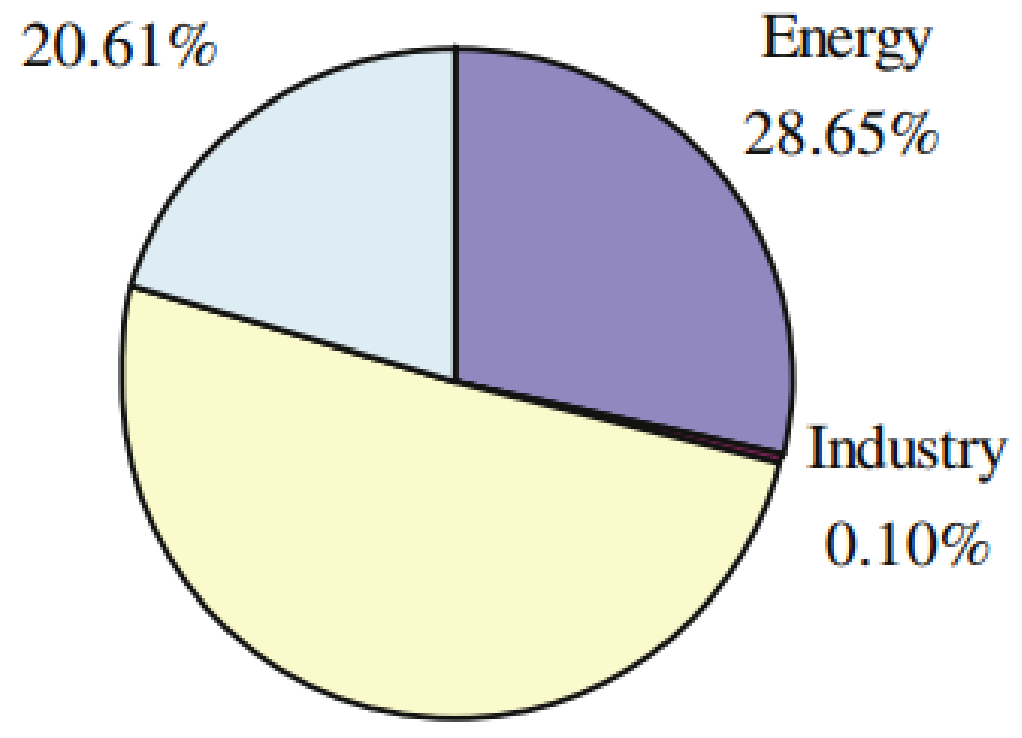

Agriculture

$50.63 \%$

Figure 4: Contribution of Sectors to Anthropogenic Methane Emissions in 2010 [Karakurt et al., 2012] 


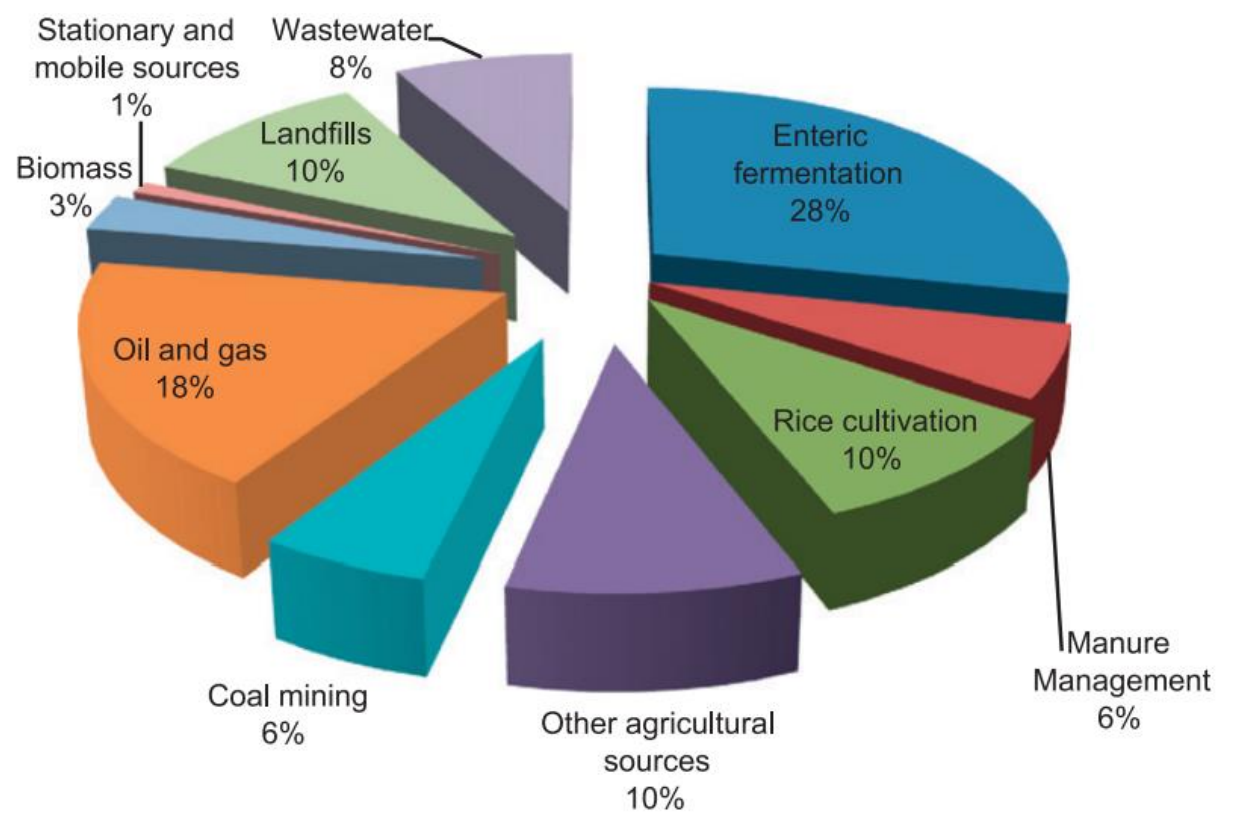

Figure 5: Anthropogenic Methane Emissions by Source in 2010 [Yusuf et al. 2012]

Methane emissions also come from human sources, about $9 \%$ of all U.S. greenhouse emissions in 2011 (EPA, 2013 b). However recent evidence shows that although some historic cumulative EPA estimates have been overestimated for methane emissions, most of the cumulative estimates have been underestimated (Caulton et al., 2014). Some of these sources include: natural gas and petroleum systems in industry, domestic livestock, manure storage, landfills, and vehicles (EPA, 2013 b). Other human sources include coal mining, wastewater treatment, rice cultivation, enteric fermentation, and combustion. The U.S. methane emissions for 2011 are shown in Figure 6. The emissions are sorted by source (EPA, 2013 a).

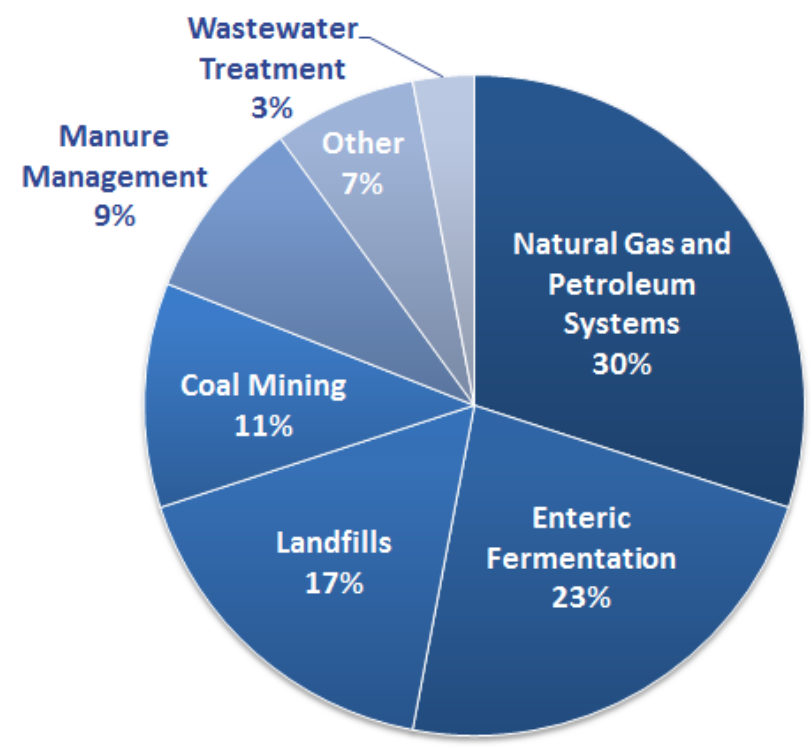

Figure 6: Total U.S. Methane Emissions by Source in 2011 [EPA, 2013 a] 
Methane emissions have decreased since 1990, although the industry has grown larger. The methane emissions from 1990 to 2011 are shown in Figure 7. Methane emissions have decreased by $8 \%$ from 1990 to 2011 . The growth in the methane industry has been offset by technological advances and more strenuous regulations (EPA, 2013 a).

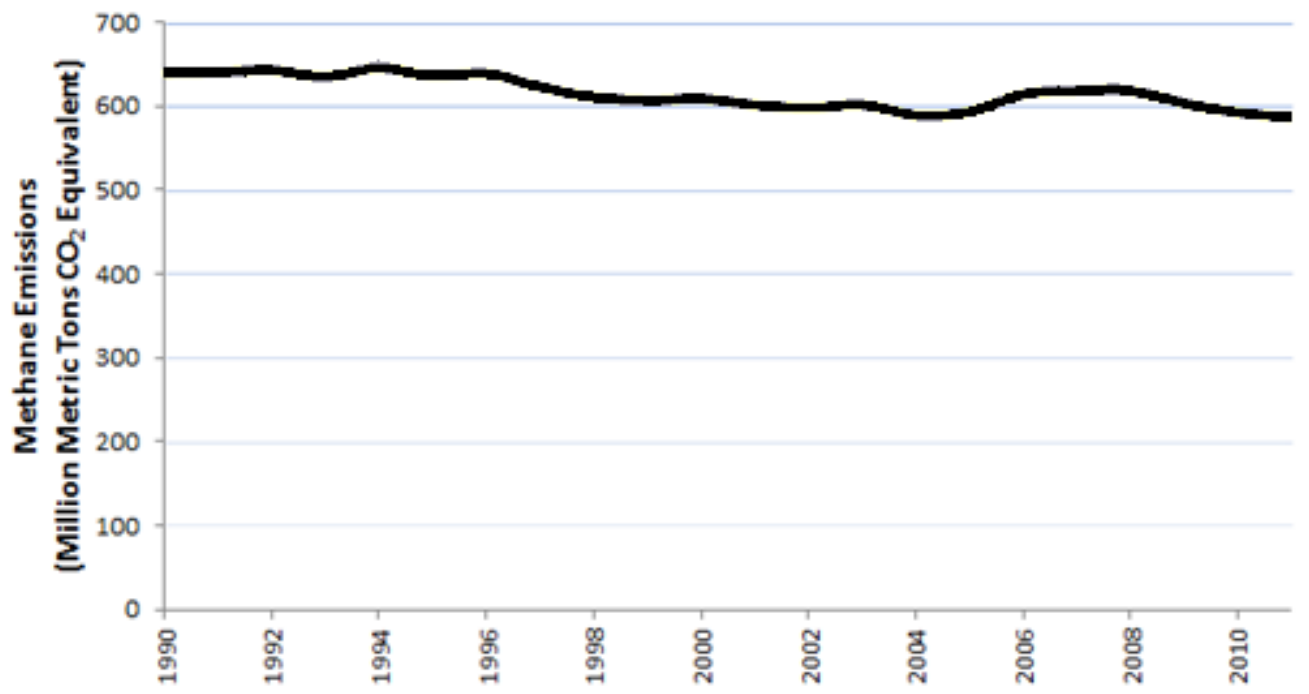

Figure 7: U.S. Methane Emissions From 1990 to 2011 [EPA, 2013 a]

Methane emissions from the transportation sector are small but increasing rapidly and need to be analyzed as the industry grows, especially the application of natural gas as a fuel for heavy-duty vehicles.

\section{Methane Emission Sources from the Heavy-duty Transportation Sector}

Natural gas is one of the alternative fuels used in the heavy-duty vehicle sector. The composition of natural gas used in natural gas vehicles can vary by source, treatment, local conditions, and time. Methane has the highest percent composition in natural gas. Methane emissions can come from various wells-to-wheels sources. EDF has been working with scientists, industry companies, and academic experts to quantify and reduce methane emissions (EDF, 2015). There are several modules along the supply chain. One example is measurements of methane emissions at production sites, such as natural gas wells (Allen et al, 2013). The information in this thesis is part of the module attributed directly to vehicles or stations. The behavior of the vehicle directly affects some of the station sources.

\section{Natural Gas Vehicles}

Vehicles are classified by gross vehicle weight rating (GVWR). Table 3 shows the vehicle classes and EPA groups. All vehicles over 8,500 GVWR, classes $2 \mathrm{C}$ to 8 , are classified as heavyduty. The vehicles in this research effort are all class 7 or class 8 . 
Table 3: Vehicle Classes by GVWR and EPA Group

\begin{tabular}{|c|c|c|c|c|c|c|c|c|c|}
\hline Class & 1 & 2 & $2 \mathrm{C}$ & 3 & 4 & 5 & 6 & 7 & 8 \\
\hline $\begin{array}{c}\text { GVWR } \\
(\mathrm{Ib})\end{array}$ & $<6,000$ & $\begin{array}{c}6,001- \\
10,000\end{array}$ & $\begin{array}{r}8,500- \\
10,000\end{array}$ & $\begin{array}{c}10,001- \\
14,000\end{array}$ & $\begin{array}{c}14,001- \\
16,000\end{array}$ & $\begin{array}{c}16,001- \\
19,500\end{array}$ & $\begin{array}{c}19,501- \\
26,000\end{array}$ & $\begin{array}{c}26,001- \\
33,000\end{array}$ & $>33,000$ \\
\hline $\begin{array}{c}\text { EPA } \\
\text { Group }\end{array}$ & \multicolumn{3}{|c|}{ MDPV LHDDE } & MHDDE & HHDDE \\
\hline
\end{tabular}

Natural gas use in the transportation sector has increased in the last few decades, albeit on a small base. The growth has been driven by lower natural gas prices compared to gasoline and diesel (Liss, 2012). Emissions regulations have become more strenuous over the last decade for all fuel types (CFR 40 Part 86, 1990; CFR 40 Part 1036.108, 2014). This makes natural gas more attractive as particulates from CNG are smaller than diesel engines (Greenwood et al., 1996). There are also various financial incentives for natural gas vehicles (NGV America, 2013 b).

Research for heavy-duty natural gas vehicles has focused on the regulated emissions, such as $\mathrm{CO}_{2}$ (only regulated recently), nitrous oxide, methane, hydrofluorocarbons (HFCs), perfluorocarbons (PFCs), and sulfur hexafluoride (SF 6), and unregulated emissions, such as carbonyl compounds, volatile organic compounds (VOC), and polycyclic aromatic hydrocarbons (PAH). The emissions levels are driven by engine certification. The methane emissions standard is $0.10 \mathrm{~g} / \mathrm{hp}$-hr measured over a transient duty cycle, as specified in 40 CFR part 86 subpart N. The standard was in effect in model year 2014 for compression ignition engines and will be in effect in model year 2016 for SI engines (CFR 40 Part 86, 1990; CFR 40 Part 1036.108, 2014). European regulations are already more strenuous than U.S. regulations. Euro VI standard for methane emissions is $0.16 \mathrm{~g} / \mathrm{kWh}$ (Willner, 2013).

Cooper et al. [2012] explored emissions of different fuel types including: ethanol/gasoline blend (E95); ethanol/methanol/kerosene blend (E93); diesel with 15ppm sulfur (D15); diesel with 50 ppm sulfur (D50); diesel with over $150 \mathrm{ppm}$ sulfur (D > 150); biodiesel (B100); and biodiesel/diesel blend (B20). Some vehicles had exhaust gas recirculation (EGR) or an aftertreatment system including: diesel particulate filter (DPF); selective catalytic reduction (SCR); oxidation catalyst (OC); and three-way catalyst (3WC). Figure 8 and Figure 9 show the mean total hydrocarbons (THC) and NOx, respectively, for different fuel technologies. With a three-way catalyst, THC from CNG is on par with other technologies and NOx is much lower. However by comparison, research for methane emissions is relatively weak. 


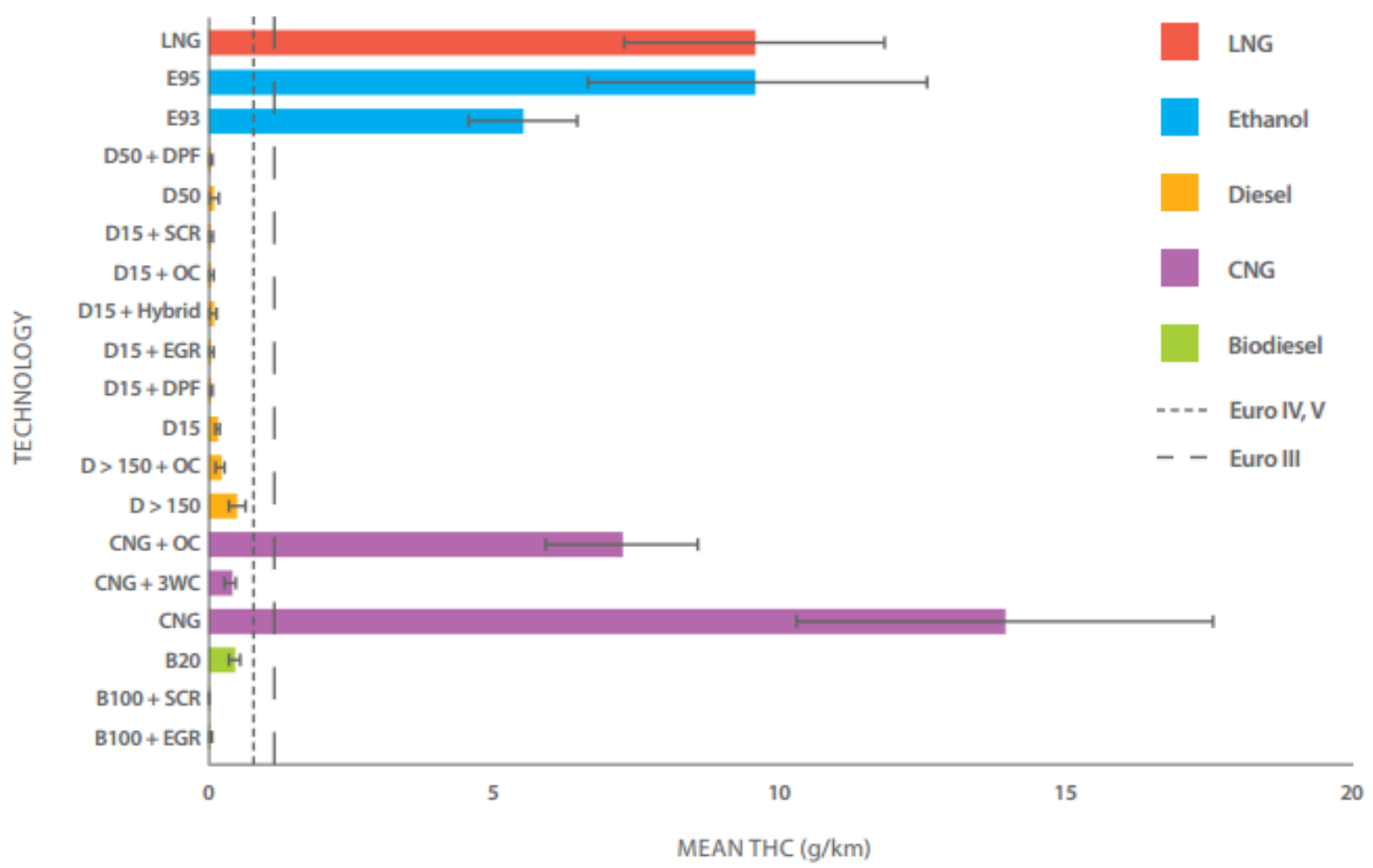

Figure 8: Average THC Emissions from Transit Buses with Different Technologies [Cooper et al. 2012]

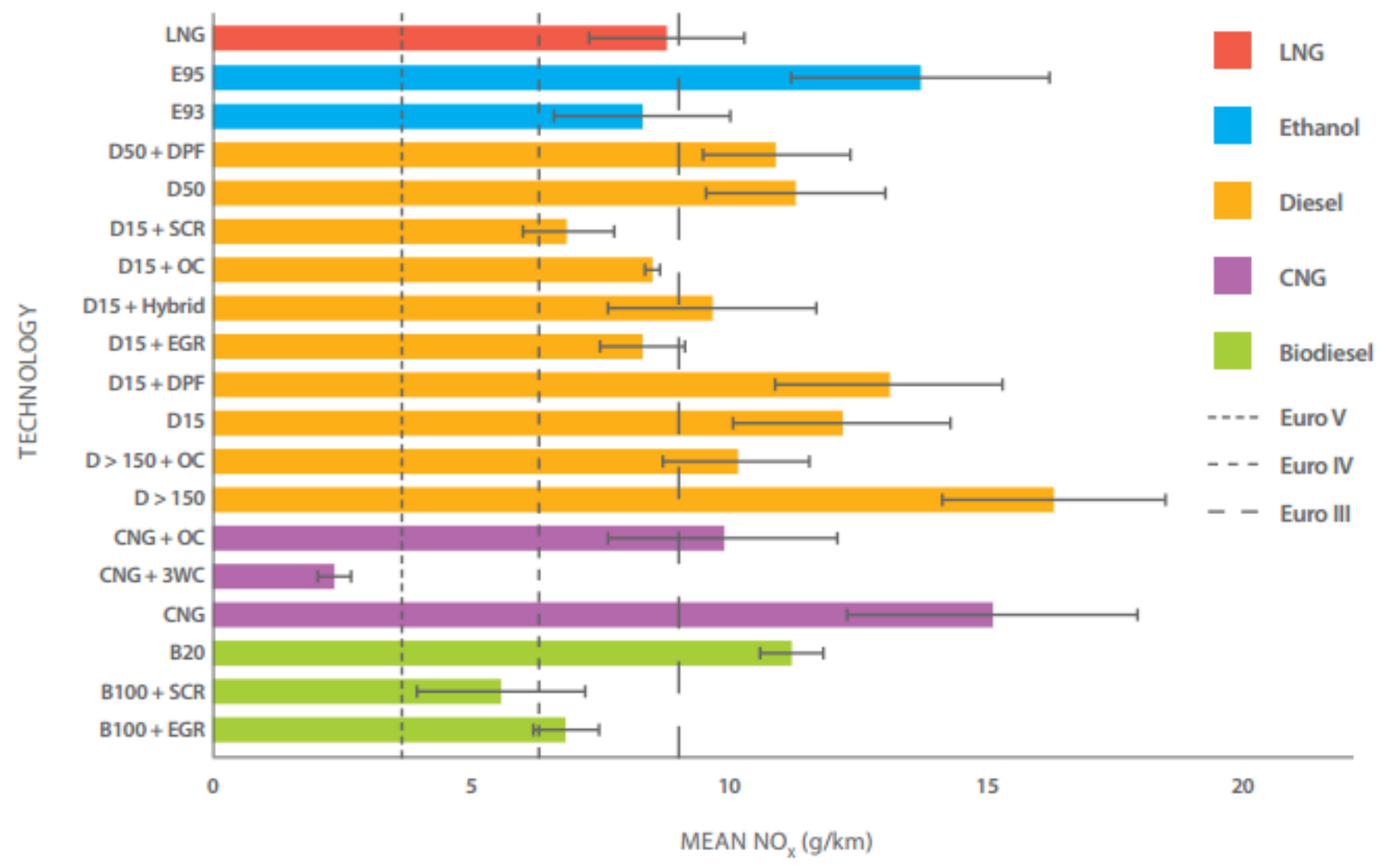

Figure 9: Average NOx Emissions from Transit Buses with Different Technologies [Cooper et al. 2012] 


\section{Tailpipe Emissions}

Earlier natural gas engines were mostly lean burn engines (Heck and Farrauto, 2001). However, industry leaders have suggested that less natural gas engines currently in production are employing lean burn technology. Feist et al. [2010] showed that NOx and THC increased as the methane number decreased and the Wobbe level increased for lean burn heavy-duty on-highway natural gas engines. The stoichiometric engines showed no clear trend. High altitudes were shown to have no effect on particulate matter, NOx, or non-methane hydrocarbons (HC), although CO increased slightly (Graboski et al., 1997). Another study showed that NOx and THC emissions were lower for stoichiometric operation than lean bean operation. This is due to the employment of a three-way catalyst (Einwall et al., 2005).

Natural gas buses that have been retrofitted with economic oxidation formulation oxidation catalysts have reductions in $\mathrm{CO}$, THC, carbonyl compound, VOC, and PAH emissions compared to buses without a catalyst (Thiruvengadam et al., 2011). The drawbacks of stoichiometric operation were higher heat losses, higher pumping work at low to medium loads, higher thermal stress on the engine, higher tendency to knock, lower compression ratio to suppress knock, and lower brake efficiency. The drawbacks can be offset by diluting the stoichiometric mixture with EGR (Einwall et al., 2005).

There has been recent chassis dynamometer testing and research on buses, refuse trucks, and OTR tractors. However, most of the past work does not include crankcase emissions. Therefore the total vehicle only emissions from most of the past work are not comparable to the emissions in this thesis.

Figure 10 shows tailpipe methane emissions from CNG buses tested by West Virginia University (WVU) and the National Renewable Energy Laboratory (NREL). The buses tested by WVU were consistent with the tests by NREL on the same buses. Using the WVU method, the bus with the Cummins Westport (CWI) engine averaged $17.3 \mathrm{~g} / \mathrm{mi}$ and the bus with the John Deere engine averaged $10.6 \mathrm{~g} / \mathrm{mi}$ of methane. Figure 11, Figure 12, and Figure 13 show NOx, hydrocarbon, and $\mathrm{CO}_{2}$ emissions, respectively, from the same CNG buses tested by WVU and NREL as well as two diesel buses. The CNG buses had similar NOx, higher hydrocarbon, and lower $\mathrm{CO}_{2}$ emissions on average. Non-methane hydrocarbon (NMHC) was measured CNG buses instead of THC. It should be noted that the CNG buses had no aftertreatment system. The buses were tested on the Washington Metropolitan Area Transit Authority (WMATA) driving schedule (Melendez et al., 2005). The WMATA driving schedule was also used in this thesis. 


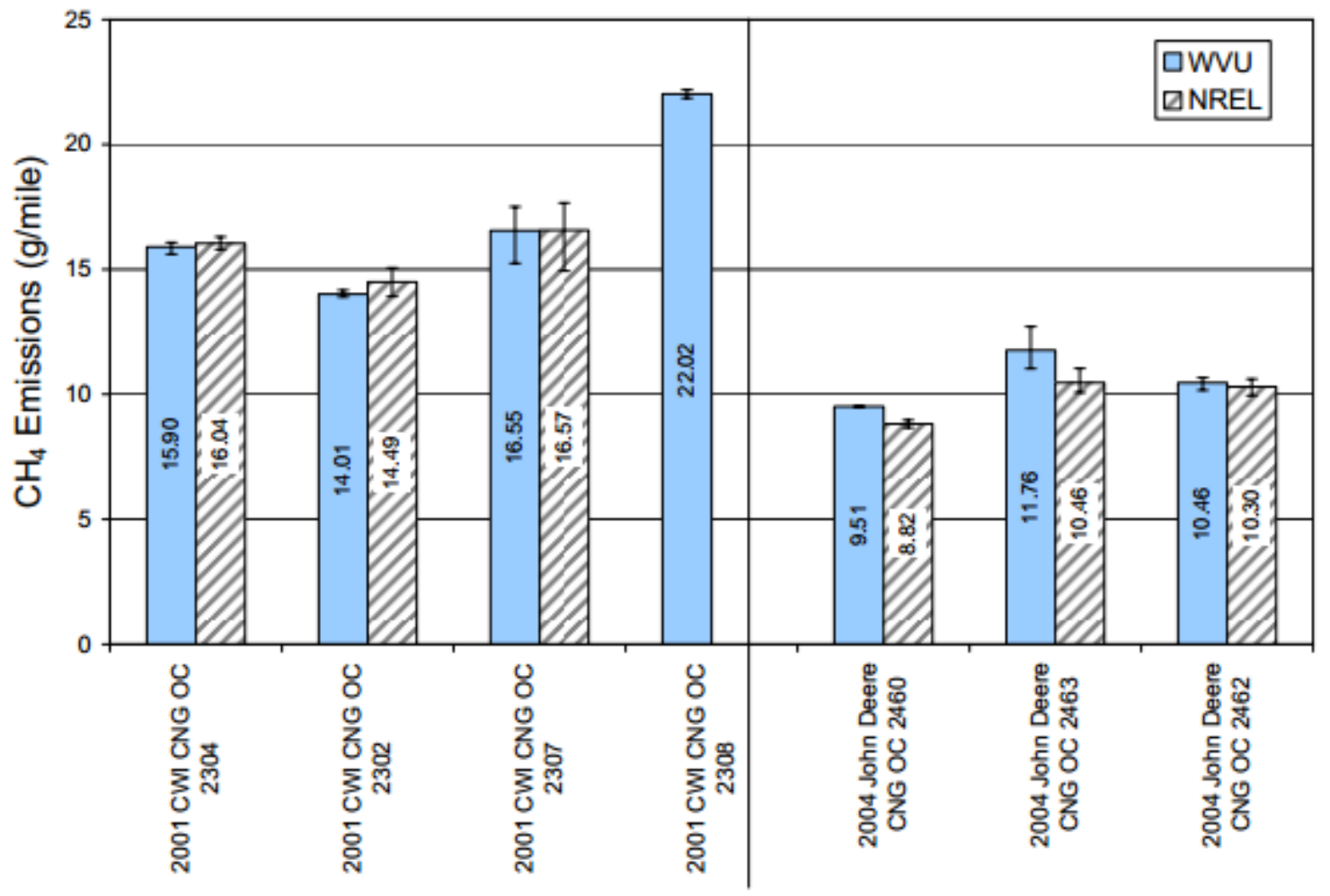

Figure 10: Tailpipe Methane Emissions from CNG Transit Buses Operating on WMATA Driving Schedule [Melendez et al., 2005]

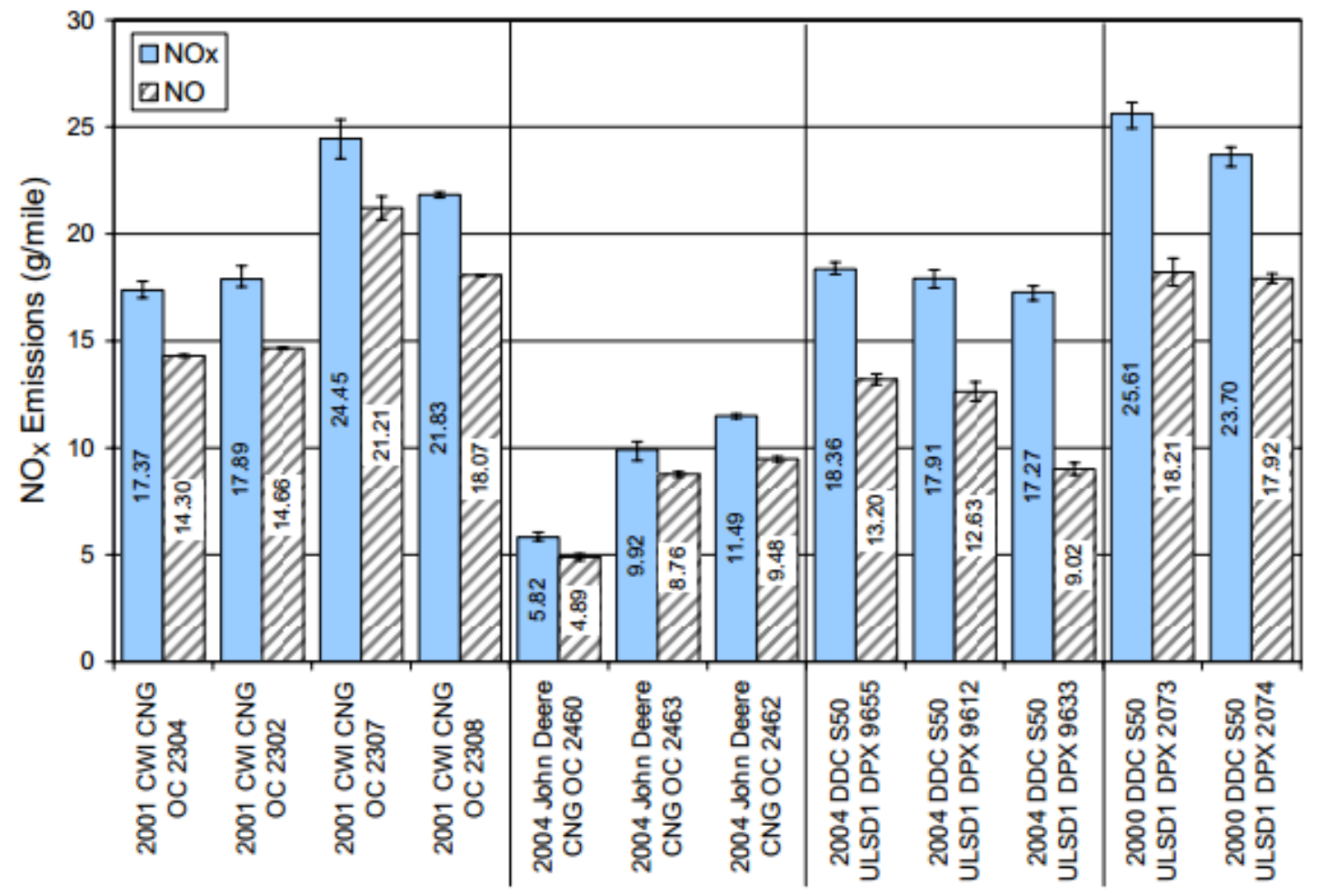

Figure 11: Tailpipe NOx Emissions from Two CNG and Two Diesel Fuel Transit Buses Operating on WMATA Driving Schedule [Melendez et al., 2005] 


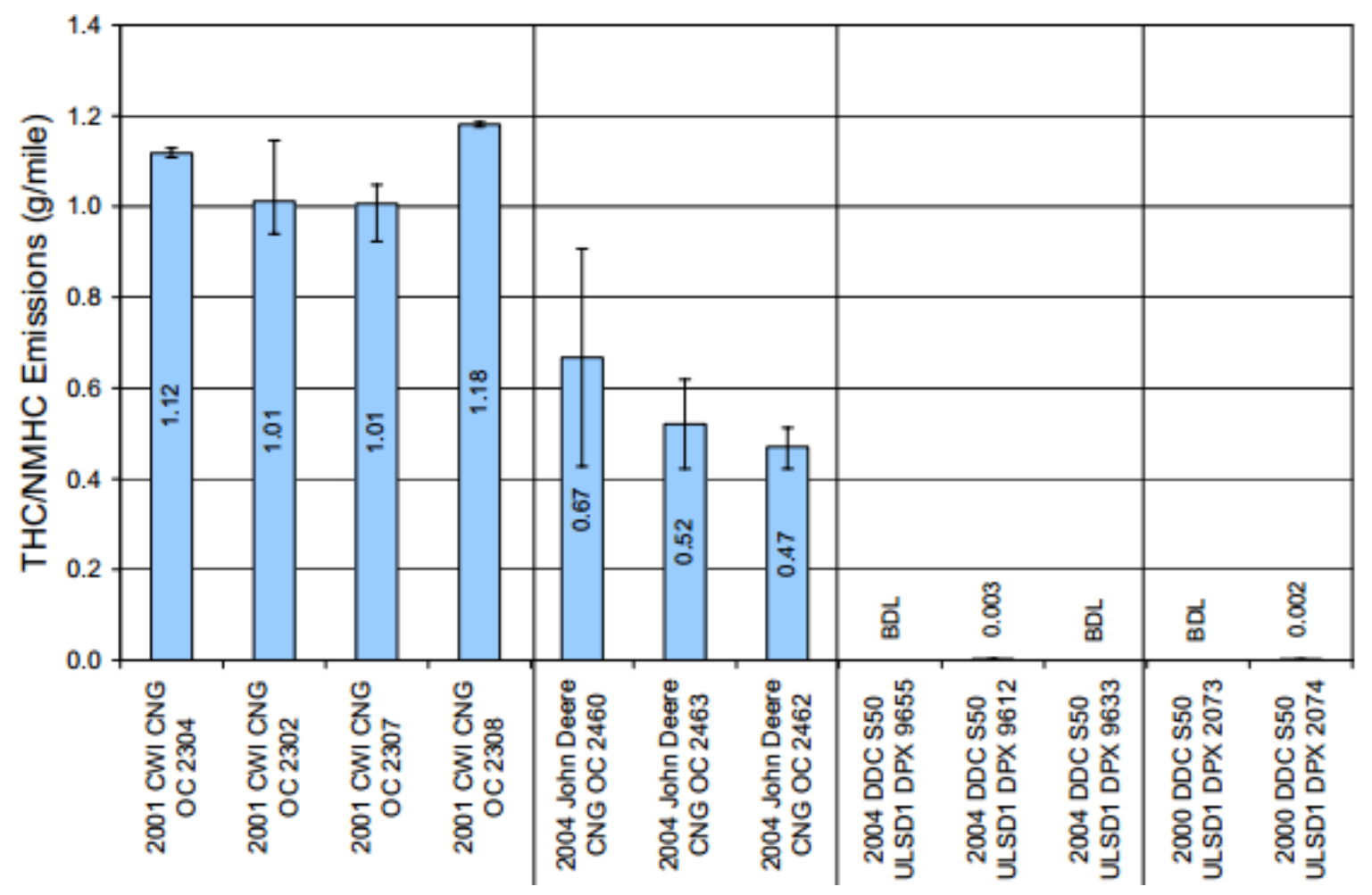

Figure 12: Tailpipe NMHC (CNG) and THC (Diesel) Emissions from Two CNG and Two Diesel Fuel Transit Buses Operating on WMATA Driving Schedule [Melendez et al., 2005]

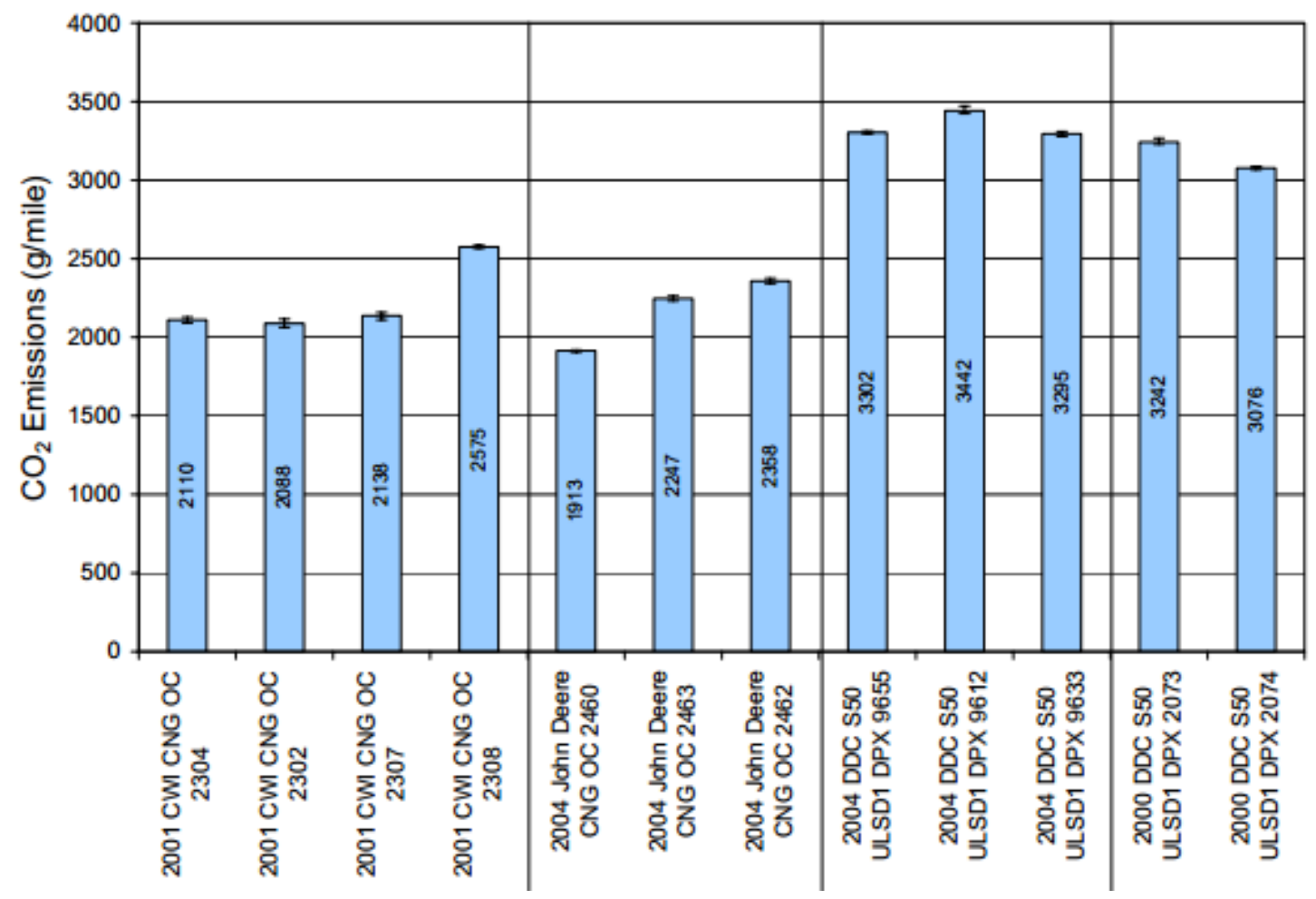

Figure 13: Tailpipe Carbon Dioxide Emissions from Two CNG and Two Diesel Fuel Transit Buses Operating on WMATA Driving Schedule [Melendez et al., 2005] 
A study by Karavalakis et al. [2013] showed that higher hydrocarbons had higher fuel economy, $\mathrm{CO}_{2}$, and NOx emissions and lower THC, methane, $\mathrm{CO}$, particulate matter, and particle number emissions when varying the fuel composition. The refuse trucks were tested on the William $\mathrm{H}$. Martin cycle, based on Waste Management sanitation vehicles data in Washington, Pennsylvania, developed by WVU. The William H. Martin cycle was modified to determine the emissions contributions of transport, curbside pickup, and compaction operation, or the Air Quality Management District (AQMD) cycles used in this study (Walkowicz et al., 2003).

Davis et al. [2005] compared results from available $\mathrm{CO}_{2}$ and methane GHG emissions data. Table 4 shows $\mathrm{CO}_{2}$, methane, and GWP CO 2 equivalent tailpipe emissions from existing WVU mobile chassis dynamometer experimental data. Table 5 shows $\mathrm{CO}_{2}$, methane, and $\mathrm{GWP}^{\mathrm{CO}} 2$ equivalent tailpipe emissions from multiple sources. The results of the study concluded that not enough data were obtained to compare the natural gas emissions to the diesel emissions. However a conclusion was made that the driving schedule (drive cycle) tested makes a significant difference in tailpipe emissions.

Table 4: Mean Carbon Dioxide Tailpipe Emissions from Heavy-Duty, CNG-, LNG-, and Diesel-Fueled Vehicles, and Corresponding Methane Emission Rates from Same Vehicle Samples [Davies et al., 2005]

\begin{tabular}{|c|c|c|c|c|c|}
\hline $\begin{array}{l}\text { Fuel } \\
\text { Type }\end{array}$ & $\begin{array}{c}\text { Vehicle } \\
\text { Type/Control } \\
\text { Technology }\end{array}$ & Drive Cycle & $\begin{array}{c}\text { Mean } \mathrm{CO}_{2} \\
\text { Emissions } \\
(\mathrm{g} / \mathrm{mi})\end{array}$ & $\begin{array}{c}\text { Mean } \mathrm{CH}_{4} \text { Emissions } \\
\text { from Same Sample } \\
(\mathrm{g} / \mathrm{mi})\end{array}$ & $\begin{array}{l}\text { GWP -Weighted } \\
\text { Emissions } \mathrm{CO}_{2} \mathrm{E} \\
\text { (g/mi) }\end{array}$ \\
\hline LNG & Transit Bus & CBD Cycle & 2,374 & 11.3 & 2,634 \\
\hline \multirow{7}{*}{ CNG } & Chassis Bus & Arterial Cycle & 1,937 & 10.4 & 2,177 \\
\hline & Refuse Truck & CBD Cycle & 2,844 & 14.6 & 3,179 \\
\hline & Refuse Truck & $\begin{array}{l}\text { New York } \\
\text { Garbage } \\
\text { Truck Cycle }\end{array}$ & 6,810 & 48.3 & 7,922 \\
\hline & School Bus & CBD Cycle & 2,008 & 18.5 & 2,434 \\
\hline & $\begin{array}{l}\text { Street } \\
\text { Sweeper }\end{array}$ & $\begin{array}{l}\text { NYC Street } \\
\text { Sweeper } \\
\text { Cycle }\end{array}$ & 4,079 & 26.2 & 4,681 \\
\hline & Tractor Truck & $\begin{array}{l}\text { City } \\
\text { Suburban } \\
\text { Route }\end{array}$ & 2,018 & 41.7 & 2,977 \\
\hline & Transit Bus & $\begin{array}{l}\text { Triple Length } \\
\text { CBD }\end{array}$ & 2,495 & 9.5 & 2,713 \\
\hline Diesel & Refuse Truck & WHM Cycle & 3,314 & Not tested & 3,314 \\
\hline
\end{tabular}


Table 5: Comparison of Reported Tailpipe Emission Rates for Methane from Heavy-Duty, CNG-, LNG-, and Diesel-Fueled Vehicles, and Corresponding Carbon Dioxide Emission Rates from Same Vehicle Samples*[Davies et al., 2005]

\begin{tabular}{|c|c|c|c|c|c|c|}
\hline $\begin{array}{l}\text { Fuel } \\
\text { Type }\end{array}$ & $\begin{array}{c}\text { Vehicle } \\
\text { Type/Control } \\
\text { Technology }\end{array}$ & Drive Cycle & Source & $\begin{array}{c}\text { Mean } \mathrm{CH}_{4} \\
\text { Emissions } \\
\text { (g/mi) }\end{array}$ & $\begin{array}{c}\text { Mean } \mathrm{CO}_{2} \\
\text { Emissions } \\
\text { from Same } \\
\text { Sample (g/mi) }\end{array}$ & $\begin{array}{c}\text { GWP- } \\
\text { Weighted } \\
\text { Emissions } \\
\mathrm{CO}_{2} \mathrm{E}(\mathrm{g} / \mathrm{mi})\end{array}$ \\
\hline \multirow[b]{2}{*}{ LNG } & $\begin{array}{l}\text { Heavy-duty (HD) } \\
\text { vehicles }\end{array}$ & Not specified & EPA (2004) & 6.9 & Not reported & Not available \\
\hline & Transit Bus & Arterial cycle & This study & 11.8 & 1,717 & 1,988 \\
\hline \multirow{6}{*}{ CNG } & Garbage Truck & $\begin{array}{l}\text { AQMD } \\
\text { Compactor } \\
\text { cycle }\end{array}$ & This study & 9.9 & 1,689 & 1,917 \\
\hline & Transit Bus & $\begin{array}{l}\text { Triple Length } \\
\text { CBD }\end{array}$ & This study & 9.5 & 2,495 & 2,714 \\
\hline & $\begin{array}{l}\text { Buses (1999 } \\
\text { DDC Series 50G) }\end{array}$ & CBD cycle & ERMD (2001) & 16.4 & 2,287 & 2,664 \\
\hline & $\begin{array}{l}\text { Buses (1999 } \\
\text { DDC Series 50G) }\end{array}$ & NY BUS cycle & ERMD (2001) & 54.5 & 5,609 & 6,863 \\
\hline & Buses & Not specified & EPA (2004) & 12.4 & Not reported & $\begin{array}{c}\text { Not } \\
\text { available }\end{array}$ \\
\hline & HD vehicles & Not specified & EPA (2004) & 9.6 & Not reported & $\begin{array}{c}\text { Not } \\
\text { available }\end{array}$ \\
\hline \multirow{3}{*}{ Diesel } & $\begin{array}{l}\text { Advanced HD } \\
\text { vehicles }\end{array}$ & FTP cycle & $\begin{array}{l}\text { Browning } \\
(2004)\end{array}$ & 0.004 & 1,588 & 1,588 \\
\hline & $\begin{array}{l}\text { Moderate HD } \\
\text { vehicles }\end{array}$ & FTP cycle & $\begin{array}{l}\text { Browning } \\
(2004)\end{array}$ & 0.004 & 1,627 & 1,627 \\
\hline & $\begin{array}{l}\text { Uncontrolled HD } \\
\text { vehicles }\end{array}$ & FTP cycle & $\begin{array}{l}\text { Browning } \\
\text { (2004) }\end{array}$ & 0.004 & 1,765 & 1,765 \\
\hline
\end{tabular}

*Note: "This study" refers to the study by Davies et al. [2005]

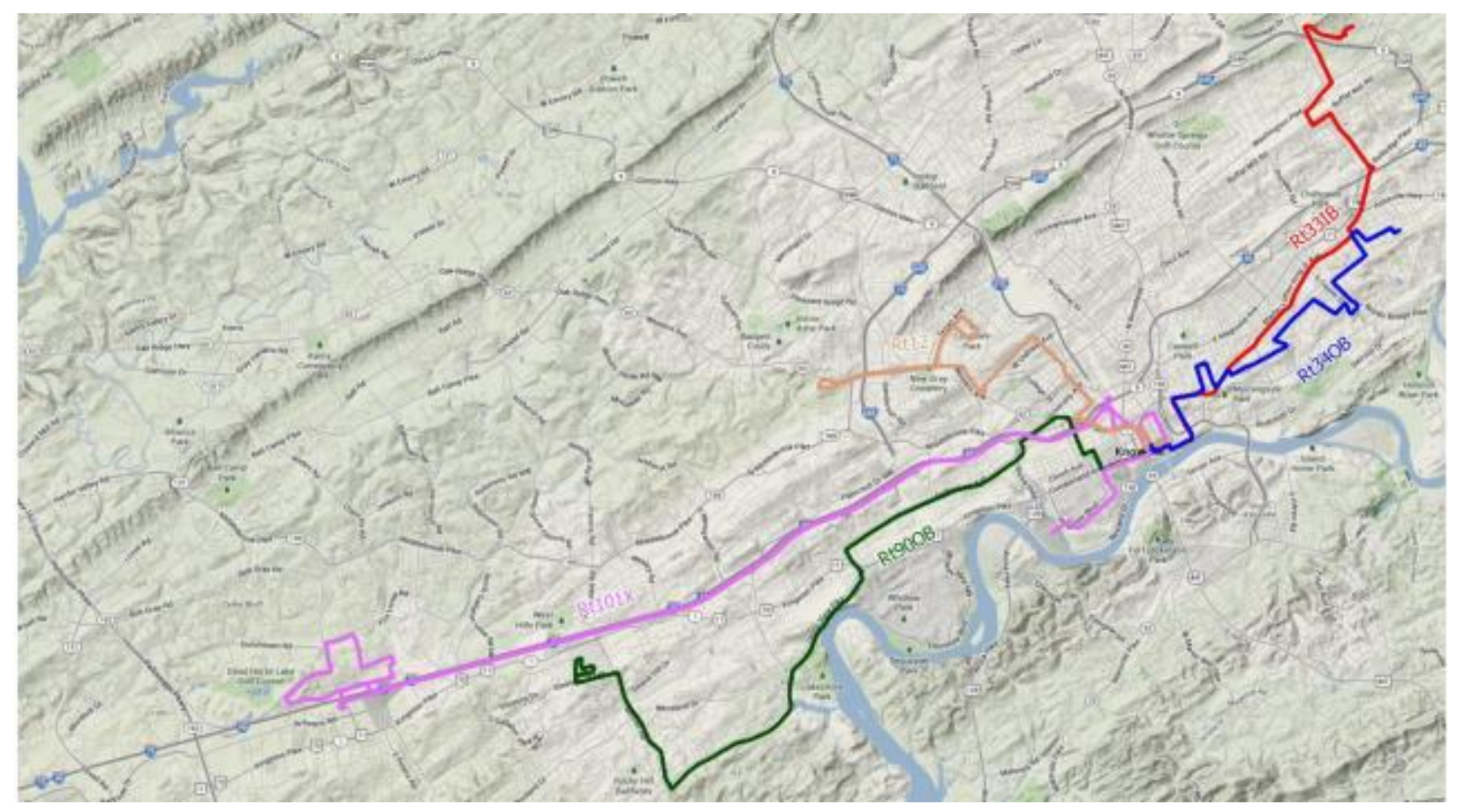

Figure 14: On-road Test Routes Used in Transit Bus Emissions Study [Li et al., 2014] 
Some of the first on-road emissions testing were performed by WVU (Bata et al., 1991; Clark et al., 1995; Wang et al., 1997). On-road tested has also been performed in Milan comparing natural gas refuse trucks with those consuming diesel (Pastorello et al., 2011; Fontaras et al., 2012). Figure 14 shows an example of on-road emissions testing routes for transit buses operated by the Knoxville Area Transit (KAT). Burnette [2014] emphasized the importance of separating emissions test data into modes, or speed bins. The modes consisted of idle (with creep), start/stop (sustained speed $<25 \mathrm{mph}$ ), urban, and highway (sustained speed $>40 \mathrm{mph}$ ).

\section{Crankcase Emissions}

Crankcase emissions have been measured for vehicles powered by diesel engines, but there has been little research on crankcase emissions for natural gas engines (Zielinska et al., 2008; Clark et al., 2006; Calcagno, 2005; Cadle, 2007). Expected regulations should place importance on measurements of this source. Methane is emitted from the crankcase when there is blow-by in the piston-cylinder crevice. Blow-by occurs when gas in the cylinder escapes between the piston, piston rings, and the cylinder. Each part has measurement tolerances. There has to be enough of a gap for the piston to move freely along the cylinder. The construction of the device determines how much blow-by will occur. The manner in which the engine is operated also affects the blowby. Blow-by occurs most often during the compression stroke when there are high pressures in the piston-cylinder device. There are no blow-by methane emissions during the compression stroke of a HPDI engine since the methane is directly injected into the cylinder at the end of the compression stroke (Abramek, 2007).

\section{Dynamic Ventilation Emissions}

During highly transient vehicle operation, a small amount of excess fuel is built up in the fuel common rail. Since there is little way of mitigating heat transfer between the fuel rail and the hot combustion chamber, the LNG expands due to temperature increase. When the LNG is heated, the pressure of the LNG increases much more rapidly (and to higher pressures) than the diesel fuel. The diesel pressure has to be higher than the LNG for the HPDI engine to function properly. The fuel rail control system occasionally vents the LNG, now a gas, to reduce the LNG fuel pressure. This is termed "dynamic ventilation" (IMechE, 2013). There has been little data published about dynamic ventilation. The research team at WVU has identified that dynamic ventilation is an important source of methane emissions from natural gas vehicles powered by HPDI engines.

\section{Fuel Tank Boill-off Emissions}

Chen et al. performed research on vehicle tank venting due to boil-off (Chen et al., 2004). Natural gas in vehicles is stored at high pressures in a CNG tank or as a cryogenic liquid in a LNG tank (Li and Karim, 2005 a). The CNG tanks are usually filled with CNG at 4,000 psi and maintained around 3,600 psi (Wang and Huang, 2000). Methane liquefies around $-161^{\circ} \mathrm{C}$, with variations due to altitude. $\mathrm{LNG}$ is typically stored around $-180^{\circ} \mathrm{C}$ in a vacuum insulated cryogenic tank (Beer et al., 2002). CNG at atmospheric temperature and pressure occupies 600 times as much volume as LNG. However LNG is prone to venting due to boil-off (Chen et al., 2004). 


\section{Station}

Methane emissions can also come from refueling stations. A study by Alvarez et al. [2012] outlines the need for technology improvement in the natural gas infrastructure and reductions in leakages. However, station emissions are much lower than vehicle emissions by comparison.

\section{Fuel Tank Boill-off Emissions}

LNG station tank BOG is similar to vehicle tank BOG. LNG station tank BOG occurs due to heat transfer through the tank shell during storage and through hoses and dispensers during refueling. This causes fluctuations in fuel flow and changes in fuel composition. The number of vehicles refueled per day affects the amount of BOG. One approach to mitigating station BOG is to use an electric generator to consume the BOG (Chen et al., 2004; Querol et al., 2010). Catalytic combustion is an option for fugitive methane mitigation (Hayes, 2004). Reliquifaction is another method to mitigate BOG (Shin and Lee, 2009). However details of reliquefaction aren't discussed in detail for this study.

\section{Compressor Emissions}

Harrison et al. [2011] collected data from compressors at gathering/boosting facilities, gas processing plants, and transmission compressor stations. A description of compressors measured is shown in Table 6. The largest emissions were associated with the following sources: centrifugal compressor seal oil gas; reciprocating compressor piston rod packing systems; and compressor blowdown line open-ended lines. Results for transmission compression, gathering/boosting, and gas processing plant measurements from compressors are shown in Table 7. Stations may employ a vapor recovery unit to recover flash losses, working losses, and standing losses or replace old parts with newer, more efficient ones. A newly installed packing may leak 60 cubic feet per hour compared to a worn packing that has been reported to leak up to 900 cubic feet per hour. Centrifugal compressor wet seals may vent 40 to 200 cubic feet per minute (cfm), whereas dry seals typically leak 0.5 to $3 \mathrm{cfm}$ (Targa Resources and the Gas Processors Association, 2006). It should be noted that results from this thesis show that newer compressors do not have blowdown emissions and were excluded in this study.

Table 6: Compressors Measured in Compressor Emissions Study [Harrison et al., 2011]

\begin{tabular}{||c|c|c|c|c||}
\hline Site & Survey Date & Description & Measured Equipment & Year Built \\
\hline Site 1 & $11 / 2009,5 / 2011$ & Transmission Compressor Station & 6 Reciprocating Compressors & 1965 \\
\hline Site 2 & $11 / 2009,5 / 2011$ & Transmission Compressor Station & 3 Centrifugal Compressors & 1982 \\
\hline Site 3 & $11 / 2009,5 / 2011$ & Transmission Compressor Station & 5 Reciprocating Compressors & $1992-2009$ \\
\hline Site 4 & $2 / 2010$ & Transmission Compressor Station & 15 Reciprocating Compressors & 1948 \\
\hline Site 5 & $2 / 2010$ & Transmission Compressor Station & 5 Reciprocating Compressors & 1948 \\
\hline Site 6 & $5 / 2011$ & Gathering/Boosting compressors & 13 Reciprocating Compressors & 1992 \\
\hline Site 7 & $5 / 2011$ & Gathering/Boosting compressors & 6 Reciprocating Compressors & 1993 \\
\hline Site 8 & $5 / 2011$ & Gathering/Boosting compressors & 6 Reciprocating Compressors & 1992 \\
\hline Site 9 & $5 / 2011$ & Gas Processing Plant & 2 Centrifugal Compressors & 1993 \\
\hline Site 10 & $5 / 2011$ & Gathering/Boosting compressors & 4 Centrifugal Compressors & 1971 \\
\hline Site 11 & $5 / 2011$ & Gas Processing Plant & 6 Centrifugal Compressors & 1950 \\
\hline \hline
\end{tabular}


Table 7: Sampling Results for Centrifugal Compressor Vents [Harrison et al., 2011]

\begin{tabular}{||l|c|c|c||}
\hline Scenario & Sample Size & $\begin{array}{c}\text { Average CH } \\
\text { Emission Factor } \\
\text { (Mscfy) }\end{array}$ & $\begin{array}{c}\text { 1996 GRI/EPA } \\
\text { Emission Factor } \\
\text { (Mscfy) }\end{array}$ \\
\hline Average BD vent for Run & 3 & 83 & \multirow{2}{*}{9,352} \\
\hline Average BD vent for Idle + Run* & 11 & 1,584 & 165 \\
\hline Wet Seal (Run) & 9 & 8,137 & 165 \\
\hline
\end{tabular}

*For some sites, the running and idle compressors were routed to vent with blowdown lines and PRVs, therefore individual compressor operating mode emission factors could not be calculated.

${ }^{1}$ Hummel, K.E., Campbell, L.M., and M.R. Harrison 'Vol. 8), Table 4-15, 1996 GRI/EPA CH4 study, adjusted for 24.2\% time the compressor is pressurized.

\section{Continuous Emissions}

Research has also been conducted acknowledging leaks due to weathering, metering, and fueling connectors, but there is little research about quantification (Wegrzyn and Gurevich, 2000).

Harrison et al. [2011] also collected data from fugitive sources such as valves, flanges, and other components in a few locations. The results of the fugitive data are shown in Table 8 . These leaks were classified as continuous emissions in this thesis.

Table 8: Fugitive Emissions from Valves and Flanges using Hi-Flow Sampler Compared to Previous Results [Harrison et al., 2011]

\begin{tabular}{||c|c|c|c|}
\hline $\begin{array}{c}\text { Facility } \\
\text { Component }\end{array}$ & $\begin{array}{c}\text { Total Number of } \\
\text { Components } \\
\text { Screened }\end{array}$ & $\begin{array}{c}\text { Component Emission } \\
\text { Factor } \\
\text { (Mscfy) }\end{array}$ & $\begin{array}{c}\text { 1996 GRI/EPA } \\
\text { Emission Factor } \\
\text { (Mscfy) }\end{array}$ \\
\hline Valves & 1,634 & 0.093 & \multirow{2}{*}{0.184} \\
\hline Flanges & 1,244 & 0.051 & \\
\hline
\end{tabular}

\section{Existing Emissions Estimation Models}

Wang co-authored several papers outlining the GREET model throughout its introduction and various updates during its evolution. The model analyzes the fuel cycle, which includes the following output: energy feedstock production, feedstock transportation, and storage; fuel production; fuel transportation, storage, and distribution; and fuel combustion for each transportation fuel. CNG is one of the fuel types analyzed. The GREET models are more focused on the energy associated with production than the specific vehicle and station emissions. Some vehicle emissions come from other models such as the MOBILE5a (Wang, 1996; Wang, 1999; Wang, 2001). The most current GREET model to date is the GREET 2013 for fuel-cycle analysis and GREET 2.7 version for vehicle-cycle analysis. The report about GREET 2.7 has data based on a mid-sized passenger car platform, although preliminary work has been performed on heavyduty vehicles. Six vehicles types were analyzed in the literature using the GREET 2.7 model. The total energy use, fossil and petroleum energy use, and greenhouse gas and air pollutants such as methane, $\mathrm{NOx}, \mathrm{CO}_{2}$, particulate matter, oxides of sulfur ( $\mathrm{SOx}$ ), VOC, and $\mathrm{CO}$ can be found with GREET 2.7 (Burnham, et al. 2006).

Rakha et al. [2003] compared several tailpipe emissions models for light-duty gasoline vehicles. The models include MOBILE5a, MOBILE6, Virginia Tech Microscopic Energy Model (VTMICRO), and Comprehensive Modal Emissions Model (CMEM). MOBILE5 was used by the 
EPA and estimated HC, CO, and NOx. Another model, the ARB emission factors modeling software (EMFAC), was used by the California Air Resources Board (CARB) and estimated HC, $\mathrm{CO}$, and NOx. Average speed trips from driving cycles were analyzed by both models to determine the emissions factors. MOBILE6 estimates emissions factors based on different roadway types and has results that are closer to the EPA measured field data than the MOBILE5a and EMFAC models. The CMEM model is a power-demand based emission model developed at University of California, Riverside. The VT-MICRO is a microscopic energy and emission model developed at Virginia Tech with chassis dynamometer data collected at Oak Ridge National Laboratory (ORNL). Figure 15 shows the MOBILE5a, MOBILE6, VT-MICRO, and CMEM Estimation Models data when compared to the EPA measured data. The VT-MICRO estimation model showed the best correlation with the EPA measured data (Rakha et al., 2003). These light-duty gasoline emissions models serve as a good platform for creating the tailpipe emissions portion of the heavy-duty natural gas vehicle model.

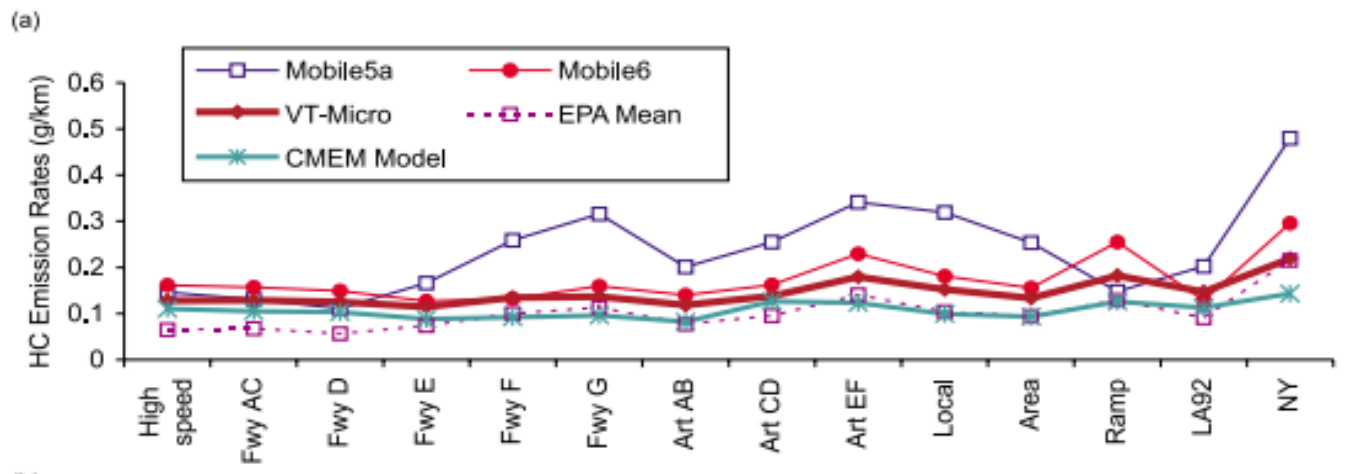

(b)

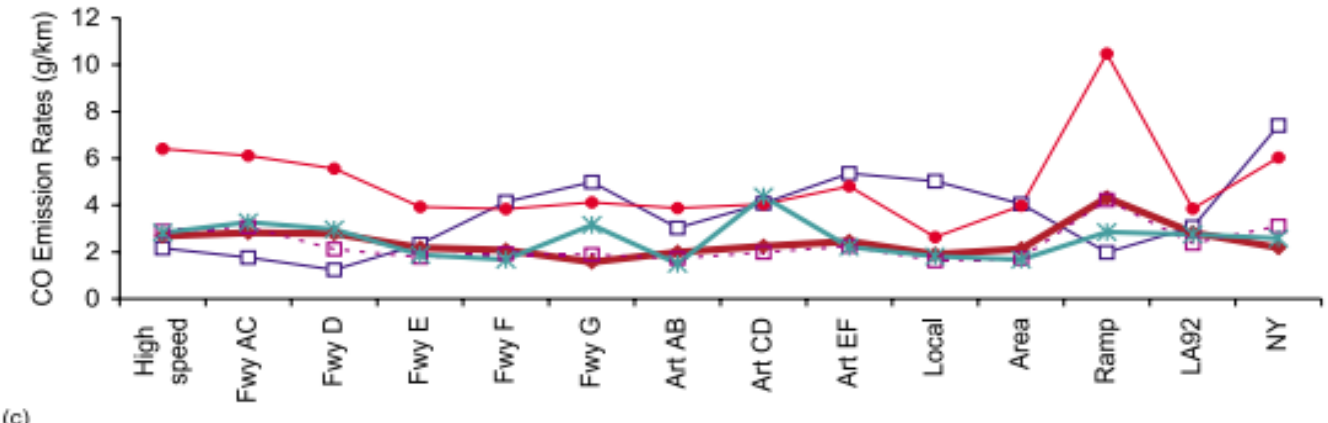

(c)

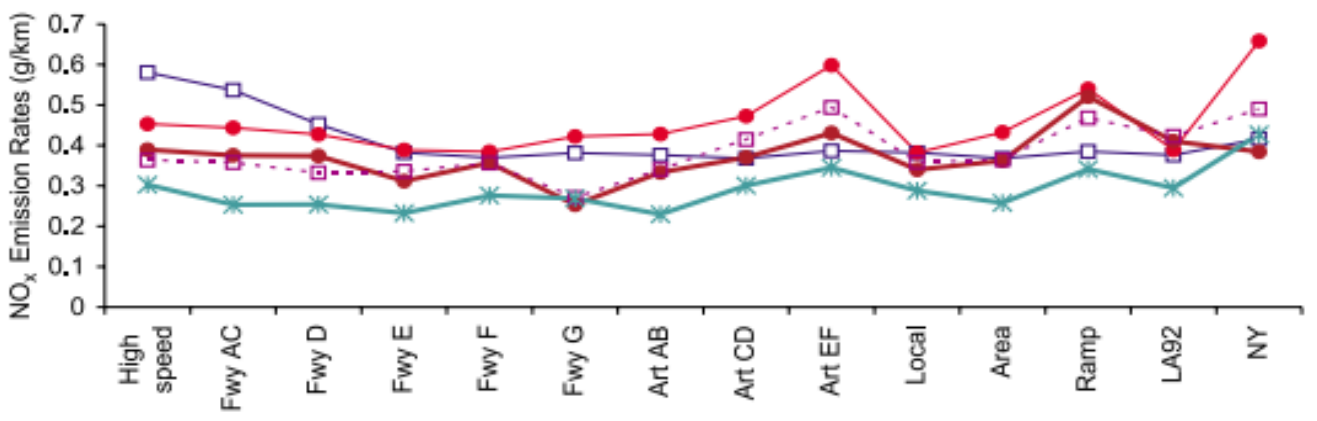

Figure 15: MOBILE5a, MOBILE6, VT-MICRO, and CMEM Estimation Models Comparison with EPA Measured Data [Rakha et al., 2003] 
Davis et al. [2005] modified the EPA MOBILE model and California EMFAC model to develop the International Vehicle Emissions (IVE) model. The model uses vehicle engine technology, vehicle driving behaviors, and local vehicle emissions factors. It can be used to predict future emissions with a given fleet, fuel, and vehicles flows and congestion.

The estimation model in this thesis uses similar methodologies to the models discussed in this literature review to estimate the methane emissions from heavy-duty natural gas vehicles. The models, such as MOBILE5a, MOBILE6, VT-MICRO, CMEM, and EMFAC, used experimental data from vehicles tested on specific driving schedules to estimate tailpipe emissions and/or fuel consumption rates. However these models were not developed for heavy-duty natural gas vehicles, do not account for crankcase, dynamic ventilation, or station emissions, and do not break the driving schedules into microtrips for more accurate weighting of operational activity. The experimental data from previous tailpipe emissions models were used to predict the future methane emissions for the IVE model. However the IVE model does not include crankcase, dynamic ventilation, or station emissions. The vehicle information is not comprehensive and needs to be expanded upon as well. Overall these models provide experimental methodology. 


\section{Chapter 3 - Experimental Data Measurement and Process}

The objective of the experimental study was to experimentally measure the methane emissions of heavy-duty natural gas vehicles and fueling stations. The experimental raw data were measured by other WVU research members. The data obtained were processed and used as an input to the model, categorized as the stasis emissions and fuel consumption scenario. The vehicle emissions sources include: tailpipe; crankcase (SI engines only); dynamic ventilation (HPDI engines only); and vehicle fuel tank BOG (LNG only). The station emissions sources include: nozzle emissions; compressor emissions (CNG only); station fuel tank BOG (LNG only); manual ventilation on vehicle tanks prior to refueling (HPDI engines only); bulk fuel delivery (LNG only); and continuous emissions, which include all other emissions not aforementioned.

The methane emissions from the vehicles were categorized into two groups: (1) the methane emissions associated with the actual operation of the vehicle, such as the methane emissions from the tailpipe, crankcase (SI engines), and dynamic ventilation (HPDI engines); (2) the fugitive emissions associated with BOG from the on-board fuel system. The fuel system includes the components from the storage tank which release BOG as a result of LNG tank pressures exceeding maximum design pressures.

Experimental data were processed for fifteen vehicles, (seven types of vehicles). The vehicle types used and the number of each are shown in Table 9. Data were also processed for eight CNG and six LNG fueling stations, shown in Table 10.

Table 9: Vehicles Used in this Research with Processed Data

\begin{tabular}{|c|c|c|c|}
\hline Fuel Type & Vehicle Classification & Engine Displacement (L) & Number of Vehicles \\
\hline \multirow{4}{*}{ CNG } & SI Transit Bus & 9 & 3 \\
\cline { 2 - 4 } & SI Refuse Truck & 9 & 5 \\
\cline { 2 - 4 } & SI Short Haul OTR Tractor & 9 & $3^{\mathrm{A}}$ \\
\cline { 2 - 4 } & SI Long Haul OTR Tractor & 12 & $3^{\mathrm{A}}$ \\
\hline \multirow{3}{*}{ LNG } & SI Short Haul OTR Tractor & 9 & $3^{\mathrm{A}}$ \\
\cline { 2 - 4 } & SI Long Haul OTR Tractor & 12 & $3^{\mathrm{A}}$ \\
\cline { 2 - 4 } & HPDI Long Haul OTR Tractor & 15 & 4 \\
\hline
\end{tabular}

A The same OTR tractor emissions data were used for CNG and LNG for each engine displacement

Table 10: Stations Used in this Research with Processed Data

\begin{tabular}{|c|c|c|}
\hline Fuel Type & Station Classification & Number of Stations \\
\hline \multirow{2}{*}{ CNG } & Time Fill & 1 \\
\cline { 2 - 3 } & Fast Fill & 7 \\
\hline LNG & Fast Fill & 6 \\
\hline
\end{tabular}




\section{Vehicle Experimental Data}

\section{Experimental Data Derived from Driving Schedules}

The WVU research team measured tailpipe, crankcase, and dynamic venting data from vehicles operating on driving schedules specific to each vehicle type. A driving schedule represents the operation schedule of a specific type of vehicle. Each driving schedule was used to simulate operational behavior for the given classification of vehicle. Vehicles were measured on a chassis dynamometer with predetermined driving schedules and experimental data were collected. There were six different predetermined chassis dynamometer driving schedules used in this research. These are shown in Table 11. There were 60 total chassis tests with 375.3 miles and 18.3 hours of data accumulated. Different vehicles were tested with different driving schedules. Table A-1 in Appendix A shows the driving schedule data of the vehicles tested on the chassis dynamometer. Each type of vehicles was tested on specific schedules representing its operating characteristics.

Table 11: Vehicles Tested on Chassis Dynamometer Driving Schedules

\begin{tabular}{|c|c|c|c|c|}
\hline $\begin{array}{c}\text { Chassis Dynamometer } \\
\text { Driving Schedule }\end{array}$ & $\begin{array}{c}\text { Reference for } \\
\text { Driving Schedule }\end{array}$ & $\begin{array}{c}\text { Transit } \\
\text { Bus }\end{array}$ & $\begin{array}{c}\text { Refuse } \\
\text { Truck }\end{array}$ & $\begin{array}{c}\text { OTR } \\
\text { Tractor }\end{array}$ \\
\hline AQMD Refuse Truck & Walkowicz et al., 2003 & & $\mathrm{X}$ & \\
\hline HHDDT Cruise & Shah et al., 2004 & $\mathrm{X}$ & $\mathrm{X}$ & $\mathrm{X}$ \\
\hline HHDDT Transient & Shah et al., 2004 & & & $\mathrm{X}$ \\
\hline Manhattan & McKain et al., 2000 & $\mathrm{X}$ & & \\
\hline OCTA & Wayne et al., 2004 & $\mathrm{X}$ & & \\
\hline UDDS & Kruse and Huls, 1973 & $\mathrm{X}$ & $\mathrm{X}$ & $\mathrm{X}$ \\
\hline
\end{tabular}

The experimental data of each vehicle were also collected with a portable emissions measurement system (PEMS) during on-road operation. The on-road driving schedules were gathered from in-use data. Therefore each on-road test input speed was unique depending on the amount of traffic, driving conditions, and any other cause for speed fluctuation. There were 120 total on-road tests with 2981.5 miles and 99.7 hours accumulated.

Natural gas consists of mostly methane. However some methane was not burned during combustion in the natural gas engine. These unburned methane molecules exit the vehicle through the vehicle exhaust system. The amount of tailpipe emissions depend mostly on the engine used, the aftertreatment system employed, and the driving schedule of the vehicle. The PEMS provides methane, $\mathrm{CO}, \mathrm{CO}_{2}, \mathrm{NOx}$, oxygen, and particulate matter emissions for total mass in $10 \mathrm{~Hz}$ increments. Oxygen and particulate matter emissions data were not collected in this study and only methane emissions data were used in the estimation model. The unit has a GPS system to track location. The vehicle's diagnostic link was used to obtain engine data (Krishnamurthy, 2003).

Crankcase emissions were not measured for the initial five vehicles because they were assumed to be negligible. There are currently no restrictions on crankcase methane emissions. The rest of the vehicles had crankcase emissions either measured with a separate system or had tailpipe and crankcase emissions measured together. The vehicles with crankcase and tailpipe emissions measured together were used as a reference and not used as an input to the estimation model 
since the sources could not be seperated accurately. A model, based on boost pressure, was developed by David McKain to estimate the crankcase emissions for vehicles with tailpipe measurements only. Table 12 shows the driving schedule data for 9 liter SI engine natural gas vehicles with the tailpipe emissions measured and the crankcase emissions estimated by the model developed by WVU faculty. All emissions from each respective vehicle type were of the same order of magnitude. The vehicle number designation, defined as the order of vehicles tested, is given to discern vehicles of the same type. Some vehicles, such as vehicle 9 (V9), were tested for verification purpose and not used in this study.

Table 12: Methane Emissions from 9L SI NG Vehicles with Crankcase Methane Emissions Modeled

\begin{tabular}{|c|c|r|r|r|r|r|r|}
\hline Vehicle & Test Type & $\begin{array}{c}\text { Total } \\
\text { Distance } \\
\text { (miles) }\end{array}$ & $\begin{array}{c}\text { Total } \\
\text { Duration } \\
\text { (hours) }\end{array}$ & $\begin{array}{c}\text { Fuel } \\
\text { Energy } \\
\text { (MJ) }\end{array}$ & $\begin{array}{c}\text { Tailpipe } \\
\text { Methane } \\
\text { (g) }\end{array}$ & $\begin{array}{c}\text { Crankcase } \\
\text { Methane } \\
\text { (g) }\end{array}$ & FSME (g/kg) \\
\hline OTR Tractor (V3) & Chassis & 28.8 & 0.9 & 1006.7 & 128.2 & 96.2 & 10.9 \\
\hline OTR Tractor (V10) & On-Road & 115.0 & 3.4 & 3248.6 & 256.6 & 443.9 & 10.5 \\
\hline OTR Tractor (V11) & On-Road & 155.2 & 5.1 & 4658.9 & 336.1 & 620.7 & 10.0 \\
\hline Refuse Truck (V5) & Chassis & 21.2 & 1.7 & 890.0 & 79.1 & 169.1 & 13.6 \\
\hline Refuse Truck (V6) & Chassis & 28.0 & 2.0 & 1065.0 & 99.1 & 192.3 & 13.3 \\
\hline Refuse Truck (V7) & Chassis & 20.9 & 1.7 & 826.7 & 77.9 & 170.1 & 14.6 \\
\hline Refuse Truck (V7) & On-Road & 135.4 & 5.6 & 3978.1 & 206.2 & 638.1 & 10.3 \\
\hline Refuse Truck (V12) & On-Road & 38.9 & 5.3 & 2840.1 & 100.9 & 502.7 & 10.3 \\
\hline Refuse Truck (V13) & On-Road & 42.4 & 3.7 & 1833.4 & 63.2 & 341.7 & 10.7 \\
\hline Transit Bus (V15) & On-Road & 41.8 & 2.4 & 1293.6 & 199.2 & 233.1 & 16.4 \\
\hline Transit Bus (V16) & On-Road & 42.0 & 2.2 & 1337.4 & 250.4 & 229.5 & \\
\hline
\end{tabular}

Table 13 shows the driving schedule data for 9 liter SI engine natural gas vehicles with the tailpipe and crankcase emissions measured. All driving schedules in this table were measured by a chassis dynamometer. The driving schedule data for the fuel specific methane emissions (FSME) were similar to those shown in Table 12.

Table 13: Methane Emissions from 9L SI NG Vehicles with Tailpipe and Crankcase Methane Emissions Measured Separately

\begin{tabular}{|c|c|r|r|r|r|r|r|}
\hline Vehicle & Test & $\begin{array}{c}\text { Total } \\
\text { Distance } \\
\text { Tyiles) }\end{array}$ & $\begin{array}{c}\text { Total } \\
\text { Duration } \\
\text { (hours) }\end{array}$ & $\begin{array}{c}\text { Fuel } \\
\text { Energy } \\
\text { (MJ) }\end{array}$ & $\begin{array}{c}\text { Tailpipe } \\
\text { Methane } \\
\text { (g) }\end{array}$ & $\begin{array}{c}\text { Crankcase } \\
\text { Methane } \\
(\mathrm{g})\end{array}$ & FSME (g/kg) \\
\hline OTR Tractor (V10) & Chassis & 28.9 & 0.9 & 1045.6 & 101.8 & 120.2 & 10.3 \\
\hline Refuse Truck (V7) & Chassis & 27.8 & 2.0 & 1079.6 & 101.4 & 213.5 & 14.2 \\
\hline Transit Bus (V14) & Chassis & 20.5 & 1.7 & 1026.1 & 163.4 & 182.7 & 16.4 \\
\hline Transit Bus (V15) & Chassis & 20.6 & 1.7 & 899.7 & 175.9 & 150.5 & 17.7 \\
\hline
\end{tabular}

Table 14 shows the driving schedule data for 9 liter SI engine natural gas vehicles with the tailpipe and crankcase emissions measured. All driving schedules for this table were measured on-road. The driving schedule data for the FSME were on the same order of magnitude as those shown in Table 12 and Table 13. Table 15 shows the driving schedule data for 15 liter HPDI engine natural gas OTR tractors with the tailpipe emissions measured. The amount of fuel consumed was natural gas only. The amount of \#2 diesel consumed in HPDI engine vehicles was not included in this table. The FSME include only tailpipe emissions and were not comparable to any of the other vehicles. All emissions from each respective OTR tractor type were of the same order of magnitude. The variability of the 15 liter HPDI engine OTR tractors was between 3.6 
$\mathrm{g} / \mathrm{kg} \mathrm{NG}$ fuel and $5.8 \mathrm{~g} / \mathrm{kg} \mathrm{NG}$ fuel. The lowest value was $62 \%$ of the highest value. The minimum and maximum values were both from chassis dynamometer tests. The HPDI dynamic methane ventilation was calculated by other researchers using other methods. The HPDI emissions data were not as granular as the tailpipe and crankcase emissions. The HPDI dynamic ventilation emissions were also based less on average speed and more on rate of acceleration and deceleration. The emissions data were averaged over speed distributions. The data measured by the WVU project team was compared experimental data from the engine manufacturer. The engine manufacturer worked closely with the WVU project team to determine the appropriate numbers for HPDI dynamic ventilation.

Table 14: Methane Emissions from 9L SI NG Vehicles with Tailpipe and Crankcase Methane Measured Together

\begin{tabular}{|c|c|r|r|r|r|r|}
\hline Vehicle & $\begin{array}{c}\text { Test } \\
\text { Type }\end{array}$ & $\begin{array}{c}\text { Total } \\
\text { Distance } \\
\text { (miles) }\end{array}$ & $\begin{array}{c}\text { Total } \\
\text { Duration } \\
\text { (hours) }\end{array}$ & $\begin{array}{c}\text { Fuel } \\
\text { Energy } \\
\text { (MJ) }\end{array}$ & $\begin{array}{c}\text { Total } \\
\text { Methane } \\
\text { (g) }\end{array}$ & FSME (g/kg) \\
\hline OTR Tractor (V10) & On-Road & 235.2 & 6.4 & 6453.5 & 1186.4 & 8.9 \\
\hline OTR Tractor (V11) & On-Road & 233.3 & 6.8 & 6511.8 & 1328.4 & 9.9 \\
\hline Refuse Truck (V7) & On-Road & 83.9 & 3.2 & 2567.8 & 441.8 & 8.4 \\
\hline Refuse Truck (V12) & On-Road & 142.6 & 8.5 & 5573.2 & 1022.2 & 14.5 \\
\hline Refuse Truck (V13) & On-Road & 64.3 & 3.2 & 2431.6 & 726.5 & 15.8 \\
\hline Transit Bus (V15) & On-Road & 41.6 & 2.3 & 1342.2 & 435.2 & 19.0 \\
\hline Transit Bus (V16) & On-Road & 41.8 & 2.3 & 1366.6 & 534.3 & \\
\hline
\end{tabular}

Table 15: Methane Emissions from 15L HPDI Vehicles with Tailpipe and Fueling System Vent Methane Emissions

\begin{tabular}{|c|c|r|r|r|r|r|r|}
\hline Vehicle & Test Type & $\begin{array}{c}\text { Total } \\
\text { Distance } \\
\text { (miles) }\end{array}$ & $\begin{array}{c}\text { Total } \\
\text { Duration } \\
\text { (hours) }\end{array}$ & $\begin{array}{c}\text { Fuel } \\
\text { Energy } \\
(\text { MJ) }\end{array}$ & $\begin{array}{c}\text { Tailpipe } \\
\text { Methane } \\
(\mathrm{g})\end{array}$ & $\begin{array}{c}\text { Dynamic Vent } \\
\text { Methane }(\mathrm{g})\end{array}$ & FSME $(\mathrm{g} / \mathrm{kg})^{\mathrm{BC}}$ \\
\hline OTR Tractor (V17) & Chassis & 31.7 & 1.0 & 1031.7 & 107.4 & $\mathrm{n} / \mathrm{a}^{\mathrm{D}}$ & 5.8 \\
\hline OTR Tractor (V17) & On-Road & 125.3 & 3.9 & 3011.6 & 311.7 & $\mathrm{n} / \mathrm{a}^{\mathrm{D}}$ & 5.6 \\
\hline OTR Tractor $\left(\mathrm{V} 18^{\mathrm{A}}\right)$ & On-Road & 322.5 & 7.0 & 7212.7 & 625.3 & $\mathrm{n} / \mathrm{a}^{\mathrm{D}}$ & 4.7 \\
\hline OTR Tractor $\left(\mathrm{V} 19^{\mathrm{A}}\right)$ & On-Road & 230.5 & 4.5 & 5894.3 & 589.9 & $\mathrm{n} / \mathrm{a}^{\mathrm{D}}$ & 5.5 \\
\hline OTR Tractor $(\mathrm{V} 20)$ & Chassis & 20.6 & 0.4 & 855.6 & 35.4 & $\mathrm{n} / \mathrm{a}^{\mathrm{D}}$ & 3.6 \\
\hline OTR Tractor $(\mathrm{V} 20)$ & On-Road & 210.8 & 5.3 & 6518.6 & 461.2 & $\mathrm{n} / \mathrm{a}^{\mathrm{D}}$ & 3.8 \\
\hline
\end{tabular}

Note: ${ }^{A}$ The measurements of V18 and V19 include some long idle periods for vehicle weighing and LNG tank analyses.

${ }^{B}$ HPDI FSME was tailpipe only

${ }^{\mathrm{C}}$ HPDI FSME was natural gas fuel only

D The dynamic ventilation was not calculated by the microtrip method

Table 16 shows the data for 12 liter SI engine natural gas OTR tractors with the tailpipe emissions measured and the crankcase emissions estimated by the model developed by WVU researchers. All emissions from each respective vehicle type were of the same order of magnitude. The 12 liter SI engine natural gas vehicles had the most variability of any vehicle, the lowest value was $55 \%$ of the highest value. 
Table 16: Methane Emissions from 12L SI NG Vehicles with Crankcase Methane Emissions Estimated Using WVU Model

\begin{tabular}{|c|c|r|r|r|r|r|r|}
\hline Vehicle & Test Type & $\begin{array}{c}\text { Total } \\
\text { Distance } \\
\text { (miles) }\end{array}$ & $\begin{array}{c}\text { Total } \\
\text { Duration } \\
\text { (hours) }\end{array}$ & $\begin{array}{c}\text { Fuel } \\
\text { Energy } \\
\text { (MJ) }\end{array}$ & $\begin{array}{c}\text { Tailpipe } \\
\text { Methane } \\
\text { (g) }\end{array}$ & $\begin{array}{c}\text { Crankcase } \\
\text { Methane } \\
\text { (g) }\end{array}$ & FSME (g/kg) \\
\hline OTR Tractor (V25) & On-Road & 161.8 & 4.1 & 4851.7 & 302.0 & 556.8 & 8.6 \\
\hline OTR Tractor (V26) & On-Road & 118.3 & 2.8 & 4050.7 & 74.2 & 320.7 & 4.7 \\
\hline
\end{tabular}

Table 17 shows the emissions data for 12 liter SI engine natural gas OTR tractors with the tailpipe and crankcase emissions measured seperately. All emissions from each respective vehicle type were of the same order of magnitude. The variability for the 12L OTR tractors with tailpipe and crankcase emissions measured separately, shown in Table 17, was less than the same vehicle type with the tailpipe measured and crankcase modeled, shown in Table 16.

Table 17: Methane Emissions from 12L SI NG Vehicles with Tailpipe and Crankcase Methane Emissions Measured Separately

\begin{tabular}{|c|c|r|r|r|r|r|r|}
\hline Vehicle & Test Type & $\begin{array}{c}\text { Total } \\
\text { Distance } \\
\text { (miles) }\end{array}$ & $\begin{array}{c}\text { Total } \\
\text { Duration } \\
\text { (hours) }\end{array}$ & $\begin{array}{c}\text { Fuel } \\
\text { Energy } \\
\text { (MJ) }\end{array}$ & $\begin{array}{c}\text { Tailpipe } \\
\text { Methane } \\
\text { (g) }\end{array}$ & $\begin{array}{c}\text { Crankcase } \\
\text { Methane } \\
\text { (g) }\end{array}$ & FSME (g/kg) \\
\hline OTR Tractor (V23) & Chassis & 28.9 & 0.8 & 1007.8 & 67.9 & 135.2 & 9.8 \\
\hline OTR Tractor (V25) & Chassis & 8.2 & 0.4 & 330.9 & 8.3 & 38.2 & 6.8 \\
\hline OTR Tractor (V26) & Chassis & 28.7 & 0.8 & 1101.8 & 62.6 & 122.1 & 8.1 \\
\hline
\end{tabular}

Table 18 shows the driving schedule data for 12 liter SI engine natural gas OTR tractors with the tailpipe and crankcase emissions measured together. All emissions from each respective vehicle type were of the same order of magnitude. The variability for the 12L OTR tractors with tailpipe and crankcase emissions measured together, shown in Table 18, was on the same order of magnitude as the 12L OTR tractors with tailpipe and crankcase emissions measured seperately.

Table 18: Methane Emissions from 12 Liter SI NG Vehicle with Tailpipe and Crankcase Methane Measured Together

\begin{tabular}{|c|c|c|c|c|c|r|}
\hline Vehicle & Test Type & $\begin{array}{c}\text { Total } \\
\text { Distance } \\
\text { (miles) }\end{array}$ & $\begin{array}{c}\text { Total } \\
\text { Duration } \\
\text { (hours) }\end{array}$ & $\begin{array}{c}\text { Fuel } \\
\text { Energy } \\
\text { (MJ) }\end{array}$ & $\begin{array}{c}\text { Total } \\
\text { Methane } \\
\text { (g) }\end{array}$ & FSME (g/kg) \\
\hline OTR Tractor (V25) & On-Road & 98.1 & 2.4 & 2927.6 & 550.9 & 9.2 \\
\hline
\end{tabular}

Statistics of Microtrips of Tested Driving Schedules

The driving schedules for each vehicle were divided into idle and non-idle microtrips. A non-idle microtrip was defined as a portion of a tested cycle where the vehicle speed starts at zero mph, accelerates to a higher speed, travels an indeterminate distance, and decelerates to zero $\mathrm{mph}$. The non-idle microtrip was followed by an idle microtrip. An idle microtrip maintains idle speed until the next non-idle microtrip begins. Idle speed, on an instantaneous basis, is defined as any speed less than $1 \mathrm{mph}$ (this is different than idle classification of entire microtrips discussed later). Due to this definition, some non-idle microtrips have a noticeable percentage of idle. The first microtrip was a non-idle microtrip. 
Sensors inherently had noise and registered small velocity measurements, even when the vehicle was stationary. False microtrips can develop out of this noise. Therefore a filter was applied to eliminate the false microtrips, defined as any microtrip with missing data or irregularities in processed data. If the maximum speed of a microtrip was less than $3.6 \mathrm{mph}$ and the duration of the microtrip was less than 5 seconds, the velocity of the entire microtrip was set to zero. These numbers were chosen to eliminate as many false microtrips without eliminating any correct microtrips. Some false microtrips were not removed by this filter. An average velocity of 0.2 mph was used as an upper bound for the idle activity as a redundant filter for the sensor noise removal (this is different than idle classification of instantaneous data discussed earlier). The non-idle microtrips were sorted to city, arterial, and highway activities by the average velocity, as shown in Table 19.

Table 19: Bins of Average Speed for Each Activity

\begin{tabular}{|c|c|}
\hline Activity & Bin of Average Speed (mph) \\
\hline Idle & {$[0-0.2]$} \\
\hline City & $(0.2-10]$ \\
\hline Arterial & $(10-40]$ \\
\hline Highway & $>40$ \\
\hline
\end{tabular}

Table 20 and Table 21 show an example of the original driving schedules and the separation of microtrips for the UDDS driving schedule, respectively, for a 9 liter OTR tractor (V3). The percent idle comes from the previously defined instantaneous data classification of idle (instantaneous speed less than $1 \mathrm{mph}$ ), not the entire microtrip data classification (entire microtrip speed less than $0.2 \mathrm{mph}$ ). The distance specific energy consumption (DSEC) and FSME for tailpipe (TP) and crankcase (CC) depend on the driving schedule.

Table 20: Driving Schedules for a 9 Liter OTR Tractor (V3)

\begin{tabular}{|c|r|r|r|r|r|r|r|}
\hline $\begin{array}{c}\text { Driving Schedule } \\
\text { Name }\end{array}$ & Duration & Distance & $\begin{array}{c}\text { Mean } \\
\text { Speed }\end{array}$ & $\begin{array}{c}\text { Percent } \\
\text { Idle }\end{array}$ & DSEC & FSME-TP & FSME-CC \\
\cline { 2 - 8 } & \multicolumn{1}{c|}{ sec } & \multicolumn{1}{c|}{ miles } & \multicolumn{1}{c|}{$\mathrm{mph}$} & \multicolumn{1}{c|}{$\%$} & $\mathrm{MJ} / \mathrm{mile}$ & $\mathrm{g} / \mathrm{kg}$ fuel & g/kg fuel \\
\hline HHDDT S_1 & 760.0 & 10.5 & 49.9 & 8.2 & 31.8 & 6.3 & 2.5 \\
\hline HHDDT S_2 & 760.0 & 10.5 & 49.9 & 8.1 & 31.3 & 6.5 & 4.7 \\
\hline HHDDT TRANSIENT & 688.0 & 2.9 & 14.9 & 20.2 & 45.8 & 5.7 & 5.6 \\
\hline UDDS & 1060.0 & 5.5 & 18.8 & 35.5 & 42.2 & 6.0 & 7.2 \\
\hline
\end{tabular}


Table 21: Microtrip Separation of UDDS Driving Schedule for a 9 Liter OTR Tractor (V3)

\begin{tabular}{|c|c|c|c|c|c|c|c|c|}
\hline \multirow{2}{*}{$\begin{array}{c}\text { Microtrip } \\
\text { Name }\end{array}$} & Duration & Distance & $\begin{array}{c}\text { Percent } \\
\text { Idle }\end{array}$ & $\begin{array}{c}\text { Mean } \\
\text { Speed }\end{array}$ & Activity & DSEC & FSME-TP & FSME-CC \\
\cline { 7 - 9 } & $\mathrm{s}$ & miles & $\%$ & $\mathrm{mph}$ & & $\mathrm{MJ} / \mathrm{mile}$ & $\mathrm{g} / \mathrm{kg}$ fuel & $\mathrm{g} / \mathrm{kg}$ fuel \\
\hline UDDS M1 & 108.1 & 0.52 & 1.9 & 17.4 & Arterial & 57.3 & 19.3 & 6.6 \\
\hline UDDS M2 & 40.3 & 0.00 & 100.0 & 0.0 & Idle & N/A & 4.5 & 22.2 \\
\hline UDDS M3 & 7.9 & 0.01 & 10.1 & 4.2 & City & 131.8 & 11.5 & 7.5 \\
\hline UDDS M4 & 20.6 & 0.00 & 100.0 & 0.0 & Idle & N/A & 11.9 & 22.1 \\
\hline UDDS M5 & 9.7 & 0.01 & 25.8 & 2.6 & City & 105.2 & 15.8 & 13.4 \\
\hline UDDS M6 & 7.0 & 0.00 & 100.0 & 0.0 & Idle & N/A & 11.0 & 20.3 \\
\hline UDDS M7 & 191.8 & 1.14 & 1.2 & 21.5 & Arterial & 45.3 & 7.9 & 6.3 \\
\hline UDDS M8 & 32.3 & 0.00 & 100.0 & 0.0 & Idle & N/A & 0.6 & 20.1 \\
\hline UDDS M9 & 261.2 & 3.33 & 0.6 & 45.9 & Highway & 30.2 & 1.7 & 5.3 \\
\hline UDDS M10 & 26.5 & 0.00 & 100.0 & 0.0 & Idle & N/A & 0.0 & 24.5 \\
\hline UDDS M11 & 108.0 & 0.52 & 1.3 & 17.4 & Arterial & 58.3 & 5.3 & 6.8 \\
\hline UDDS M12 & 40.3 & 0.00 & 100.0 & 0.0 & Idle & N/A & 0.2 & 22.5 \\
\hline UDDS M13 & 7.9 & 0.01 & 11.4 & 4.2 & City & 93.1 & 10.6 & 12.3 \\
\hline UDDS M14 & 20.6 & 0.00 & 100.0 & 0.0 & Idle & N/A & 0.9 & 23.2 \\
\hline
\end{tabular}

All of the microtrips in the same bin were added together consecutively to create activities for each vehicle. For example, all microtrips from driving schedules tested for vehicle 3 with an average speed between $0.2 \mathrm{mph}$ and $10 \mathrm{mph}$ were added consecutively to make one set of data with multiple microtrips, or a city activity for vehicle 3 . There were four city microtrips in the UDDS cycle, as shown in the example in Table 21. Table 22 shows the activity data for the UDDS driving schedule for the example 9 liter OTR tractor (V3). It should be noted that percent idle was calculated by computing the percentage of time that the instantaneous measured speed was less than $1 \mathrm{mph}$. This is different than the average speed used to determine the activity. Therefore all activities have a portion of idle time. The instantaneous method was used because average speed can't be used on an instantaneous basis, and the percent idle was calculated with the instantaneous data.

Table 22: Statistics of Activities for the UDDS Driving Schedule of a 9 Liter OTR Tractor (V3)

\begin{tabular}{|c|r|r|r|r|r|r|r|}
\hline \multirow{2}{*}{ Activity } & Duration & Distance & Mean Speed & Percent Idle & DSEC & FSME-TP & FSME-CC \\
\cline { 2 - 8 } & \multicolumn{1}{c|}{$\mathrm{sec}$} & \multicolumn{1}{c|}{ miles } & \multicolumn{1}{c|}{$\mathrm{mph}$} & \multicolumn{1}{c}{$\%$} & MJ/mile & $\mathrm{g} / \mathrm{kg}$ fuel & $\mathrm{g} / \mathrm{kg}$ fuel \\
\hline Idle & 187.6 & 0.00 & 0.0 & $100.0 \%$ & $\mathrm{~N} / \mathrm{A}$ & 3.0 & 22.2 \\
\hline City & 25.5 & 0.03 & 3.6 & $16.5 \%$ & 102.6 & 12.4 & 10.6 \\
\hline Arterial & 407.9 & 2.18 & 19.3 & $1.4 \%$ & 50.3 & 10.2 & 6.5 \\
\hline Highway & 261.2 & 3.33 & 45.9 & $0.6 \%$ & 29.9 & 1.7 & 5.3 \\
\hline
\end{tabular}

Table 23 shows the activity data for all driving schedules of the 9 liter OTR tractor (V3) used as an example. 
Table 23: Statistics of Activities for All Driving Schedules of a 9 Liter OTR Tractor (V3)

\begin{tabular}{|c|r|r|r|r|r|r|r|}
\hline \multirow{2}{*}{ Activity } & Duration & Distance & $\begin{array}{c}\text { Mean } \\
\text { Speed }\end{array}$ & $\begin{array}{c}\text { Percent } \\
\text { Idle }\end{array}$ & DSEC & FSME-TP & FSME-CC \\
\cline { 2 - 8 } & \multicolumn{1}{c|}{ sec } & \multicolumn{1}{c|}{ miles } & \multicolumn{1}{c|}{$\mathrm{mph}$} & \multicolumn{1}{c}{$\%$} & MJ/mile & g/kg fuel & g/kg fuel \\
\hline Idle & 372.0 & 0.0 & 0.0 & $100.0 \%$ & N/A & 3.5 & 22.3 \\
\hline City & 209.0 & 0.4 & 6.5 & $5.6 \%$ & 61.9 & 13.4 & 10.8 \\
\hline Arterial & 839.1 & 4.8 & 20.6 & $1.8 \%$ & 46.0 & 7.6 & 5.3 \\
\hline Highway & 1606.8 & 24.3 & 54.4 & $0.2 \%$ & 30.2 & 5.7 & 3.6 \\
\hline
\end{tabular}

Table 24 shows the tailpipe and crankcase emissions and the distance specific fuel energy (time specific fuel energy for idle activities) for all of the 9 liter OTR tractors. Data from each vehicle were combined to create this dataset. For example, the data from Table 23 were used for OTR Tractor A (V3). Each vehicle was weighted equally for the average.

Table 24: Tailpipe and Crankcase Emissions and DSEC for Three 9L Stoichiometric OTR Tractors

\begin{tabular}{|c|c|r|r|r|r|c|}
\hline & Vehicle & \multicolumn{1}{c|}{ Idle } & \multicolumn{1}{c|}{ City } & \multicolumn{1}{c|}{ Arterial } & Highway & \multicolumn{1}{c|}{ Test Methods } \\
\hline \multirow{4}{*}{$\begin{array}{c}\text { Tailpipe } \\
\text { Methane } \\
\text { (g/kg fuel) }\end{array}$} & OTR Tractor (V3) & 3.49 & 13.35 & 7.61 & 5.66 & Chassis Only \\
\cline { 2 - 7 } & OTR Tractor (V10) & 1.38 & 12.42 & 6.04 & 2.91 & Chassis/On-Road \\
\cline { 2 - 7 } & OTR Tractor (V11) & 2.10 & 4.28 & 3.18 & 4.13 & On-Road Only \\
\cline { 2 - 7 } & Average & $\mathbf{2 . 3 2}$ & $\mathbf{1 0 . 0 2}$ & $\mathbf{5 . 6 1}$ & $\mathbf{4 . 2 3}$ & $\mathbf{N} . A$. \\
\hline \multirow{2}{*}{$\begin{array}{c}\text { Crankcase } \\
\text { Methane } \\
\text { (g/kg fuel) }\end{array}$} & OTR Tractor (V3) & 22.26 & 10.84 & 5.30 & 3.61 & Chassis Only \\
\cline { 2 - 7 } & OTR Tractor (V10) & 16.21 & 7.83 & 7.31 & 5.42 & Chassis/On-Road \\
\cline { 2 - 7 } & OTR Tractor (V11) & 16.90 & 11.24 & 6.14 & 5.70 & On-Road Only \\
\cline { 2 - 7 } & Average & $\mathbf{1 8 . 4 6}$ & $\mathbf{9 . 9 7}$ & $\mathbf{6 . 2 5}$ & $\mathbf{4 . 9 1}$ & N.A. \\
\hline \multirow{3}{*}{$\begin{array}{c}\text { Fuel energy } \\
\text { (MJ/mile) }\end{array}$} & OTR Tractor (V3) & $164.04^{*}$ & 61.86 & 46.00 & 30.15 & Chassis Only \\
\cline { 2 - 7 } Idle (MJ/hr) & OTR Tractor (V10) & $193.26 *$ & 61.22 & 35.02 & 25.20 & Chassis/On-Road \\
\cline { 2 - 7 } & OTR Tractor (V11) & $215.68^{*}$ & 52.21 & 32.16 & 22.91 & On-Road Only \\
\cline { 2 - 7 } & Average & $\mathbf{1 9 0 . 9 9 *}$ & $\mathbf{5 8 . 4 3}$ & $\mathbf{3 7 . 7 3}$ & $\mathbf{2 6 . 0 9}$ & N.A. \\
\hline
\end{tabular}

Appendix B shows details of the measured experimental vehicle emissions data. Data tables for each activity are shown in Table B-9 for 9 liter SI engine buses, Table B-10 for 9 liter SI engine refuse trucks, Table B-11 for 9 liter SI engine OTR tractors, Table B-12 for 12 liter SI engine OTR tractors, and Table B-13 for 15 liter HPDI engine OTR tractors.

\section{Summary of Vehicle Experimental Data}

Table 25 shows the average DSEC for each activity for each vehicle type. The idle activity had energy consumption measured in time specific units since the vehicle theoretically travels no distance during idle. 
Table 25: Average Distance Specific Fuel Energy for Each Activity for Each Vehicle Type

\begin{tabular}{|c|c|r|r|r|}
\hline \multirow{2}{*}{ Vehicle Type } & \multicolumn{1}{|c|}{ Idle } & \multicolumn{1}{c|}{ City } & Arterial & Highway \\
\cline { 2 - 5 } & MJ/hr & \multicolumn{3}{|c|}{ MJ/mile } \\
\hline Refuse Trucks & 235.92 & 112.99 & 34.43 & 24.48 \\
\hline Transit Buses & 278.98 & 56.03 & 35.08 & 22.61 \\
\hline 9L SI OTR Tractor & 190.99 & 58.43 & 37.73 & 26.09 \\
\hline 12L SI OTR Tractor & 200.52 & 67.87 & 42.31 & 29.83 \\
\hline 15L HPDI OTR Tractor & 282.39 & 94.66 & 27.86 & 24.49 \\
\hline
\end{tabular}

Table 26 shows the average tailpipe FSME for each activity for each vehicle type. There was a clear trend in emissions for the non-idle activities. As the average speed increased (lower for city and higher for highway), the emissions decreased. The refuse trucks were outliers and did not follow this trend. The phenomenon can be partially attributed to refuse compaction. Refuse compaction required a greater output from the engine during the city activity. The increased output raised the temperature and caused the aftertreatment system to perform more efficiently than other vehicles during the city activity.

Table 26: Average Tailpipe FSME for Each Activity for Each Vehicle Type (g/kg fuel)

\begin{tabular}{|l|r|r|r|r|}
\hline \multirow{2}{*}{ Vehicle Type } & \multicolumn{1}{|c|}{ Idle } & \multicolumn{1}{l|}{ City } & Arterial & Highway \\
\cline { 2 - 5 } & \multicolumn{5}{|c|}{ g/kg fuel } \\
\hline Refuse Trucks & 0.67 & 2.99 & 5.39 & 2.20 \\
\hline Transit Buses & 3.85 & 10.23 & 9.00 & 8.24 \\
\hline 9L SI OTR Tractor & 2.32 & 10.02 & 5.61 & 4.23 \\
\hline 12L SI OTR Tractor & 0.55 & 3.61 & 3.32 & 2.33 \\
\hline 15L HPDI OTR Tractor & 14.14 & 7.33 & 6.51 & 4.50 \\
\hline
\end{tabular}

Table 27 shows the average crankcase FSME for each activity for each SI engine vehicle type. The same trend can be observed for the non-idle activities as the tailpipe emissions for all vehicles.

Table 27: Average Crankcase FSME for Each Activity for Each SI Vehicle Type (g/kg fuel)

\begin{tabular}{|l|r|r|r|r|}
\hline \multirow{2}{*}{ Vehicle Type } & \multicolumn{1}{|c|}{ Idle } & \multicolumn{1}{c|}{ City } & \multicolumn{1}{c|}{ Arterial } & Highway \\
\cline { 2 - 5 } & \multicolumn{4}{|c|}{ g/kg fuel } \\
\hline Refuse Trucks & 16.62 & 9.06 & 7.39 & 5.56 \\
\hline Transit Buses & 12.81 & 10.38 & 8.00 & 6.63 \\
\hline 9L SI OTR Tractor & 18.46 & 9.97 & 6.25 & 4.91 \\
\hline 12L SI OTR Tractor & 21.52 & 7.77 & 6.47 & 5.01 \\
\hline
\end{tabular}

Table 28 shows the average dynamic ventilation FSME for each activity for HPDI engine vehicles. The same trend can be observed for the non-idle activities as the tailpipe emissions for all vehicles. 
Table 28: Average Dynamic Ventilation FSME for Each Activity for HPDI Vehicles

\begin{tabular}{|c|r|r|r|r|}
\hline \multirow{2}{*}{ Vehicle Type } & \multicolumn{1}{|c|}{ Idle } & \multicolumn{1}{|c|}{ City } & Arterial & Highway \\
\cline { 2 - 5 } & \multicolumn{4}{|c|}{ g/kg NG fuel } \\
\hline 15L HPDI OTR Tractor & 0.00 & 22.10 & 10.15 & 4.81 \\
\hline
\end{tabular}

\section{Methane Emissions from the Onboard Fuel System}

The onboard vehicle fuel system can have fugitive and purposeful emissions. These emissions were associated with fuel being delivered to the engine. Methane can be emitted from valves, fittings, flanges, and other connections that methane passes through on a vehicle. These emissions were found to be negligible for both $\mathrm{LNG}$ and $\mathrm{CNG}$ vehicles. Fuel system emissions were also associated with fuel being stored and vented, even though fuel was not being consumed. For CNG vehicles, all onboard fuel system emissions were negligible.

The major constituent of this type of emission was fuel tank BOG from a LNG vehicle. BOG occurs when LNG vehicles are out of operation for longer than the fuel tank designed five day hold time or sooner based on operating conditions and amount of LNG fuel in the fuel tank. These vehicles may lose a high fraction of fuel. However the statistical data for the vehicle tank BOG were unknown. An assumption of $1 \%$ of vehicles losing $10 \%$ of fuel consumed was made. Therefore the input for the total vehicle tank BOG emissions was $0.1 \%$ of total fuel.

\section{Fueling Stations Experimental Data}

The methane emissions from fueling stations were categorized into the following four groups:

- The fugitive methane emissions from station systems that continuously release methane. This category includes leaks from pipelines, connectors, and meters which are not attributed to vehicle refueling events. The methane emissions of this category were reported as grams of methane emissions per day.

- The emissions associated with the refueling process. The methane emissions from this category were reported as grams of methane emissions per refueling event.

- The methane emissions associated with the actual operation of CNG gas station systems necessary for refueling vehicles. This category included compressors, connectors, and meters that release methane only during actual operation for vehicle refueling. The methane emissions from this category were reported as grams of methane emissions per $\mathrm{kg}$ fuel dispensed to the vehicles.

- The methane emissions associated with the actual operation of LNG gas station systems including: LNG boil off gas (BOG) from LNG station storage tanks, methane emissions associated with bulk delivery of LNG fuel to the station, and manual ventilation of HPDI OTR tractor fuel tanks prior to refueling. The methane emissions from this group were reported as a percentage of fuel dispensed to the vehicles.

It is important to note that the fuel entering the engine was assumed to be the total fuel delivered by the station. The emissions lost from the stations and vehicles were not accounted for in the total fuel delivered to the vehicles. Most emissions inputs were based on the total fuel consumed. If the methane lost, based on total fuel consumed, were added to the total fuel consumed, an iterative process would need to be performed until the total fuel consumption converged. 
However the emissions lost were small compared to the fuel consumed. Therefore the error attributed to this assumption was small.

\section{CNG Stations}

The methane emissions from CNG fueling stations will be categorized into the following three types of emissions:

- Methane emissions associated with each refueling activity, such as the connection and disconnection of the nozzle and natural gas operated actuators used in the refueling process (only one of the eight measured stations had natural gas operated actuators).

- The methane emissions associated with the operation of the compressor.

- The continuous emissions not associated with dispenser nozzles or compressors.

There were eight stations with emissions data. Nozzle emissions for one station, a time fill station, were excluded from the study due to difference in refueling practices. Seven stations were used in the nozzle calculations. All stations were used in the compressor and continuous calculations.

One out of the eight stations had natural gas operated actuator valves, two opening emissions and two closing emissions per refueling event. The rest had air operated valves. Details of the actuators are shown in Table 29.

Table 29: Actuator Emissions Associated with Vehicle Refueling Events

\begin{tabular}{|c|c|}
\hline Event & Emissions (g) \\
\hline Each Open Event & 0.46 \\
\hline Each Close Event & 0.52 \\
\hline Per Refueling Event ${ }^{\mathrm{A}}$ & 1.96 \\
\hline
\end{tabular}

A Only 1 out of 8 stations had natural gas operated actuators. Therefore the average for all stations is $0.25 \mathrm{~g} / \mathrm{event}$

Table 30 shows the methane emissions measured from dispenser nozzles for fast fill CNG stations audited. The nozzle emissions consisted of the fuel released from the physical dead space volume of the nozzle when disconnected (referred to as nozzle dead space emissions), the excess fuel from the fueling hose manually released upon completion of fueling (referred to as vent emissions), and natural gas operated actuator valves associated with direct fluid flow control operation (referred to as actuator emissions). The nozzle dead space and vent emissions from all stations were averaged separately. Some stations did not have nozzle emissions measured. Therefore each station was not weighted equally like other emissions sources. All nozzle emissions were averaged. The average of the nozzle dead space emissions ( $0.46 \mathrm{~g} / \mathrm{event})$, the average of the vent emissions (2.97 g/event), and the actuator emissions ( $0.25 \mathrm{~g} / \mathrm{event})$ were added together to get the CNG Vehicle Refueling emissions (3.61 g/event). 
Table 30: Methane Emissions from Dispensing Nozzles Measured (Nozzle Dead Space and Vent)

\begin{tabular}{|c|c|c|c|}
\hline \multicolumn{2}{|c|}{ Nozzle Dead Space Emissions } & \multicolumn{2}{|c|}{ Vent Emissions } \\
\hline \multirow{2}{*}{ Station ID } & Emissions & \multirow{2}{*}{ Station ID } & Emissions \\
\hline & g/event & & g/event \\
\hline \#4 & 0.28 & $\# 2$ & 3.8 \\
\hline$\# 4$ & 0.43 & $\# 2$ & 4.1 \\
\hline$\# 4$ & 0.34 & $\# 2$ & 3.9 \\
\hline$\# 4$ & 0.41 & $\# 6$ & 2.02 \\
\hline$\# 5$ & 0.92 & $\# 6$ & 0.51 \\
\hline \#5 & 0.06 & $\# 6$ & 2.50 \\
\hline$\# 5$ & 0.02 & $\# 6$ & 2.48 \\
\hline$\# 6$ & 0.56 & $\# 6$ & 2.55 \\
\hline$\# 6$ & 0.73 & $\# 6$ & 2.79 \\
\hline$\# 6$ & 0.73 & $\# 6$ & 2.35 \\
\hline$\# 6$ & 0.89 & $\# 6$ & 2.53 \\
\hline$\# 6$ & 1.15 & $\# 8$ & 6.54 \\
\hline$\# 7$ & 0.11 & $\# 8$ & 2.41 \\
\hline$\# 7$ & 0.19 & $\# 8$ & 3.11 \\
\hline$\# 7$ & 0.07 & & \\
\hline$\# 7$ & 0.18 & & \\
\hline$\# 7$ & 0.09 & & \\
\hline$\# 8$ & 0.11 & & \\
\hline$\# 8$ & 0.39 & & \\
\hline$\# 8$ & 0.22 & & \\
\hline Average & 0.39 & Average & 2.97 \\
\hline
\end{tabular}

In this document, Station ID\#4 was assumed to refuel 80 transit buses. This station was used as an example to demonstrate the procedure for calculating the FSME from compressors (on/off) and continuous leaking sources.

The methane emissions from compressors were estimated with an assumption that each station had two working compressors and one dryer. The number of hours the compressor was in use (on) was calculated by dividing the total annual fuel dispensed (calculated by the vehicle experimental data and the estimation model) by the total capacity of compressors. The rest of the hours in the day were considered the number of hours the compressor was off.

Table 31 shows the fuel delivery estimated by the vehicle scenario model and the on/off time of compressors of one CNG station (station ID \#4) with the assumption of refueling 80 transit buses each day. The fuel delivery was derived from the vehicle experimental data and the estimation model for the fuel consumption (described in the following chapter). Each station was assumed to have two active compressors and one redundant compressor. The dryer and actuator emissions were added to the compressor emissions since all three were primarily fuel-use dependent.

Table 31: Fuel Consumption and Compressor on/off Time (Station ID \#4)

\begin{tabular}{|r|c|r|r|r|r|r|}
\hline \multirow{2}{*}{$\begin{array}{c}\text { Number of } \\
\text { Vehicles }\end{array}$} & \multicolumn{2}{|c|}{ Fuel Consumed } & \multicolumn{2}{c|}{$\begin{array}{c}\text { Compressor } \\
\text { Capacity }\end{array}$} & $\begin{array}{c}\text { Hours On } \\
\text { (Each Compressor) }\end{array}$ & $\begin{array}{c}\text { Hours Off } \\
\text { (Each Compressor) }\end{array}$ \\
\cline { 2 - 7 } & $\mathrm{kg} / \mathrm{year}$ & $\mathrm{kg} / \mathrm{day}$ & CFM & $\mathrm{kg} / \mathrm{hour}$ & $\mathrm{hr} /$ day & $\mathrm{hr} /$ day \\
\hline 80 & $2,102,880$ & 6,740 & 800 & 970 & & 3.0 \\
\hline
\end{tabular}


The daily compressor-on emissions were calculated by multiplying the hourly emissions rate by the number of hours the compressor was operating. The dryer emissions were included in compressor-on emissions as the dryer only emitted methane when the compressor was operating. The daily compressor-off emissions were calculated by multiplying the hourly emissions rate by the number of hours the compressor was not operating. The total compressor emissions were calculated by adding the daily emissions from compressor when it was on (including dryer and actuators) and off. Table 32 shows the estimated methane emissions from the compressors. The FSME from the compressor (including on/off) calculated with the annual fuel delivery estimated from vehicle scenarios and the assumed 80 refueling events each day were $0.50 \mathrm{~g} / \mathrm{kg}$ fuel.

Table 32: Methane Emissions from Compressors (Station ID \#4)

\begin{tabular}{|c|r|r|r|}
\hline & Compressor-On & Compressor-Off & \multicolumn{1}{c|}{ Total } \\
\hline Hours On (hr/day) & 3.0 & 21.0 & 24.0 \\
\hline Emissions (g/hr) & 74.7 & 13.4 & N/A \\
\hline Emissions (g/day) & 221.6 & 281.8 & 503.5 \\
\hline Fuel Delivery Estimated from Scenario Model (kg/day) & 5757.4 \\
\hline \multicolumn{2}{|c|}{ Compressor FSME (g/kg fuel) } & 0.5 \\
\hline
\end{tabular}

Table 33 shows the continuous methane emissions from CNG stations (station ID \#4). Numerous emissions locations were quantified with the minimum, maximum, and average methane emissions rates of $0.8,13.5$, and $5.9 \mathrm{~g} / \mathrm{hr}$, respectively. The total continuous methane emissions from this station were $27.2 \mathrm{~g} /$ hour.

Table 33: Methane Emissions from Continuous Emissions Sources (Station ID\#4)

\begin{tabular}{|c|r|}
\hline \multicolumn{2}{|c|}{ Continuous Emissions } \\
\hline $\mathrm{g} / \mathrm{hr}$ & $\mathrm{kg} / \mathrm{day}$ \\
\hline 27.2 & 0.65 \\
\hline
\end{tabular}

Table 34 shows a summary of the methane emissions from fuel dispenser nozzles, compressors, and continuous sources (station ID \#4) with the assumed 80 refueling events of transit buses.

Table 34: Summary of Methane Emissions from CNG Stations (ID\#4)

\begin{tabular}{|r|c|c|c|}
\hline $\begin{array}{c}\text { Compressor-On/Dryer } \\
\text { Emissions }\end{array}$ & $\begin{array}{c}\text { Compressor-Off } \\
\text { Emissions }\end{array}$ & $\begin{array}{c}\text { Continuous } \\
\text { Emissions }\end{array}$ & $\begin{array}{c}\text { Nozzle } \\
\text { Emissions }\end{array}$ \\
\hline $\mathrm{g} / \mathrm{kg}$ fuel & $\mathrm{g} / \mathrm{kg}$ fuel & $\mathrm{g} /$ day & $\mathrm{g} / \mathrm{event}$ \\
\hline 0.22 & 0.28 & 652.8 & 3.61 \\
\hline
\end{tabular}

The continuous emissions and compressor emissions rates were measured at every station. The amount of fuel used and the number of refueling events were taken from the estimation model with the present day input scenario and assumptions. Since every station had representative data, each station was weighted equally by vehicle type. Table 35 shows the compressor emissions, continuous emissions, and nozzle emissions from CNG stations for each CNG vehicle type. The average emissions of each vehicle were used as the input to the estimation model. The continuous and nozzle emissions were independent of the fuel use. The compressor emissions were inversely proportional to the fuel use. The refuse trucks had the highest emissions due to 
consuming the least fuel, as a function of number of vehicles, fuel economy, and operational characteristics.

Table 35: Average Methane Emissions from CNG Stations

\begin{tabular}{|c|r|r|r|}
\hline \multirow{2}{*}{ Vehicle Type } & Compressor & Continuous & Nozzle Emissions \\
\cline { 2 - 4 } & g/kg fuel & g/day & \multicolumn{1}{|c|}{ g/event } \\
\hline Transit Bus & 0.70 & 816 & 3.61 \\
\hline Refuse Truck* & 1.12 & 816 & 3.61 \\
\hline 9L OTR Tractor & 0.68 & 816 & 3.61 \\
\hline 12L OTR Tractor & 0.49 & 816 & 3.61 \\
\hline Average & $\mathbf{0 . 7 5}$ & $\mathbf{8 1 6}$ & $\mathbf{3 . 6 1}$ \\
\hline
\end{tabular}

*Only 50 vehicles refueled (compared to 80 for all other vehicle types)

Appendix $\mathrm{C}$ shows details of the $\mathrm{CNG}$ station data processing. The effects of $\mathrm{CNG}$ station utilization were analyzed, but not explored in detail in this thesis. Details of the CNG station utilization is shown in Appendix D for varying vehicle population and vehicle types. Appendix E shows a case study for implementing a standard station with standard emissions factors to yield the same results as all stations averaged together.

\section{LNG Stations}

The methane emissions from LNG fuel stations will be categorized into five types of emissions: (1) methane emissions associated with each refueling activity, such as the connection and disconnection of the dispenser nozzle; (2) methane emissions associated with the ventilation of the station LNG storage tank; (3) methane emissions associated with LNG vehicle on-board storage $\operatorname{tank}(\mathrm{s})$ manually ventilated for pressure management prior to refueling the vehicle. These emissions may occur at a station or prior to the vehicle entering the station property; (4) methane emissions associated with bulk fuel delivery to the station fuel storage tank; and (5) methane emissions associated with the continuous emissions of the LNG station system (not including aforementioned emissions);

The nozzle emissions were the fuel released from the physical dead space volume of the nozzle when disconnected, referred to as nozzle dead space emissions, and the excess fuel from the fueling hose manually released upon completion of fueling, referred to as vent emissions. The nozzle dead space and vent emissions from all stations were averaged separately. The averages of the measurements were not weighted because some stations did not have nozzle emissions measured and measurements were taken at two additional locations where only nozzle emissions were recorded. The average of the nozzle dead space and vent emissions were added together to obtain the total nozzle emissions.

The continuous emissions rates were measured at every station. The continuous emissions were calculated for each LNG station. The amount of fuel used and number of refueling events was taken from the estimation model with the stasis fuel input scenario. Since every station had representative data, each station was weighted equally for each vehicle type. 
Station tank BOG gas emissions rates are not known nationally. Observations and a model created by WVU researchers provide some insight into station BOG emissions. For a fully utilized station, no BOG will occur. For example, one of the audited stations dispensed 3,000 gallons per day, which was enough LNG delivery to the station fuel storage tank to keep pressures lower than the safety pressure. This station served fewer than 80 vehicles, the value used as an assumption for a fully utilized station in this research. However if a station were severely underutilized, distributing about 1,500 gallons per day, about 5\% of the total fuel would be vented to the atmosphere. Few of these types of stations are anticipated to exist in year 2035. An assumption of one in fifty stations was made. Therefore the input value to the estimation model was $0.1 \%$ of total fuel consumed for station BOG.

Observations from the long term station audits showed that LNG vehicle fuel tank manual venting released nearly $5 \%$ of the methane used. This practice should be avoided. However the fraction of tanks that were manually vented was not known precisely. An assumption of one in twenty HPDI engine OTR tractors venting was made for the stasis scenario. Therefore $0.25 \%$ of fuel or $2.5 \mathrm{~g} / \mathrm{kg}$ fuel was used as the input to the estimation model for the stasis scenario. There was no observed manual ventilation for LNG SI engine OTR tractors.

Observations, albeit from a small sample size, from the long term station audits showed that methane emissions from bulk fuel delivery ranged from $0.08 \%$ to $0.128 \%$, with one high emissions event neglected. A conservative estimate of $0.128 \%$ was used as an input to the estimation model for the stasis scenario.

Table 36 shows the nozzle emissions, continuous emissions, manual vehicle tank venting, station fuel tank BOG, and delivery emissions for LNG stations for each LNG vehicle type. The average of the vehicles was used as the input to the estimation model. Nozzle emissions and continuous emissions had different units than the other emissions sources because they were not directly fuel dependent. Nozzle emissions can be considered indirectly fuel dependent, but the model assumes one refueling event per day for simplification.

Table 36: Average Methane Emissions from LNG Stations

\begin{tabular}{|c|r|r|r|r|r|}
\hline $\begin{array}{c}\text { Vehicle Type } \\
\begin{array}{c}\text { Refueled at } \\
\text { LNG Station }\end{array}\end{array}$ & $\begin{array}{c}\text { Nozzle } \\
\text { Emissions }\end{array}$ & Continuous & $\begin{array}{c}\text { Manual Vehicle } \\
\text { Tank Venting }\end{array}$ & $\begin{array}{c}\text { Station Fuel } \\
\text { Tank BOG }\end{array}$ & Delivery \\
\cline { 2 - 6 } & g/event & \multicolumn{1}{c|}{ g/day } & Total Fuel & \% Total Fuel & \% Total Fuel \\
\hline 9L SI OTR Tractor & 17.7 & 12.8 & 0.250 & 0.100 & 0.128 \\
\hline 12L SI OTR Tractor & 17.7 & 12.8 & 0.250 & 0.100 & 0.128 \\
\hline 15L HPDI OTR Tractor & 17.7 & 12.8 & 0.250 & 0.100 & 0.128 \\
\hline Average & $\mathbf{1 7 . 7}$ & $\mathbf{1 2 . 8}$ & $\mathbf{0 . 2 5 0}$ & $\mathbf{0 . 1 0 0}$ & $\mathbf{0 . 1 2 8}$ \\
\hline
\end{tabular}

Appendix F shows details of the LNG station data processing. The effects of LNG station utilization were analyzed, but not included in this thesis. Appendix G shows details of the LNG station utilization. 


\section{Chapter 4 - Model Logic Overview and Input Data}

\section{Model Introduction}

The objective of this model is to estimate methane emissions from the heavy-duty transportation sector using fuel-based calculations with the following inputs or scenarios for each type of vehicle:

- Vehicle and station population scenarios

- Activity scenarios

- Experimental data input

- Emissions and fuel consumption scenarios

The flowchart of the model is shown in Figure 16. The model had two input sources. The first input was from the model user. In this research, the user input was from estimated scenarios used to predict the natural gas emissions for the United States in 2035. A medium population, medium HPDI penetration, medium emissions and fuel consumption scenario was used as the control case in this thesis. The user input included the following: vehicle fleet (fuel type, type of vehicle, engine type, and aftertreatment used); operation behavior (activities); vehicle population; and the amount of miles traveled for each activity.

The second input was a non-editable database included in the model as an input from WVU. This input included experimental data collected from vehicles and stations tested by WVU. The data included the following: tailpipe emissions; crankcase emissions (SI engine vehicles only); dynamic ventilation (HPDI engines only); mile specific fuel consumption (MSFC); vehicle fuel tank BOG emissions; average number of refueling events per day; number of operational days; hours of idle per day; number of vehicles served per station; refueling nozzle emissions; compressor emissions (CNG stations only); station tank BOG emissions (LNG stations only); vehicle manual ventilation prior to refueling (HPDI engines only); delivery emissions (LNG stations only); continuous station emissions from all remaining station components.

The estimation model calculates the total emissions for the entire fleet and stations used, based on the inputs. The model converts the data to methane emissions per time, methane emissions per distance, and methane emissions per $\mathrm{kg}$ fuel consumed. The data were outputted as methane emissions per $\mathrm{kg}$ fuel consumed. Comparative visual metrics were created for the amount of emissions from each source. These visual metrics show the percentage of total methane from each source.

Decisions for the estimation model were guided by project team advisors and a steering committee comprised of representatives from industry partners and regulatory bodies. Many decisions for structure and input were decided by these groups. This thesis employed emissions estimates for future scenarios that were determined by a research team in the program. In some cases the research team considered specific likely or emerging technology changes that would reduce emissions and in other cases estimated reductions based on historical, related reductions, input from technical experts, or assumptions about the elimination or change of certain practices. 


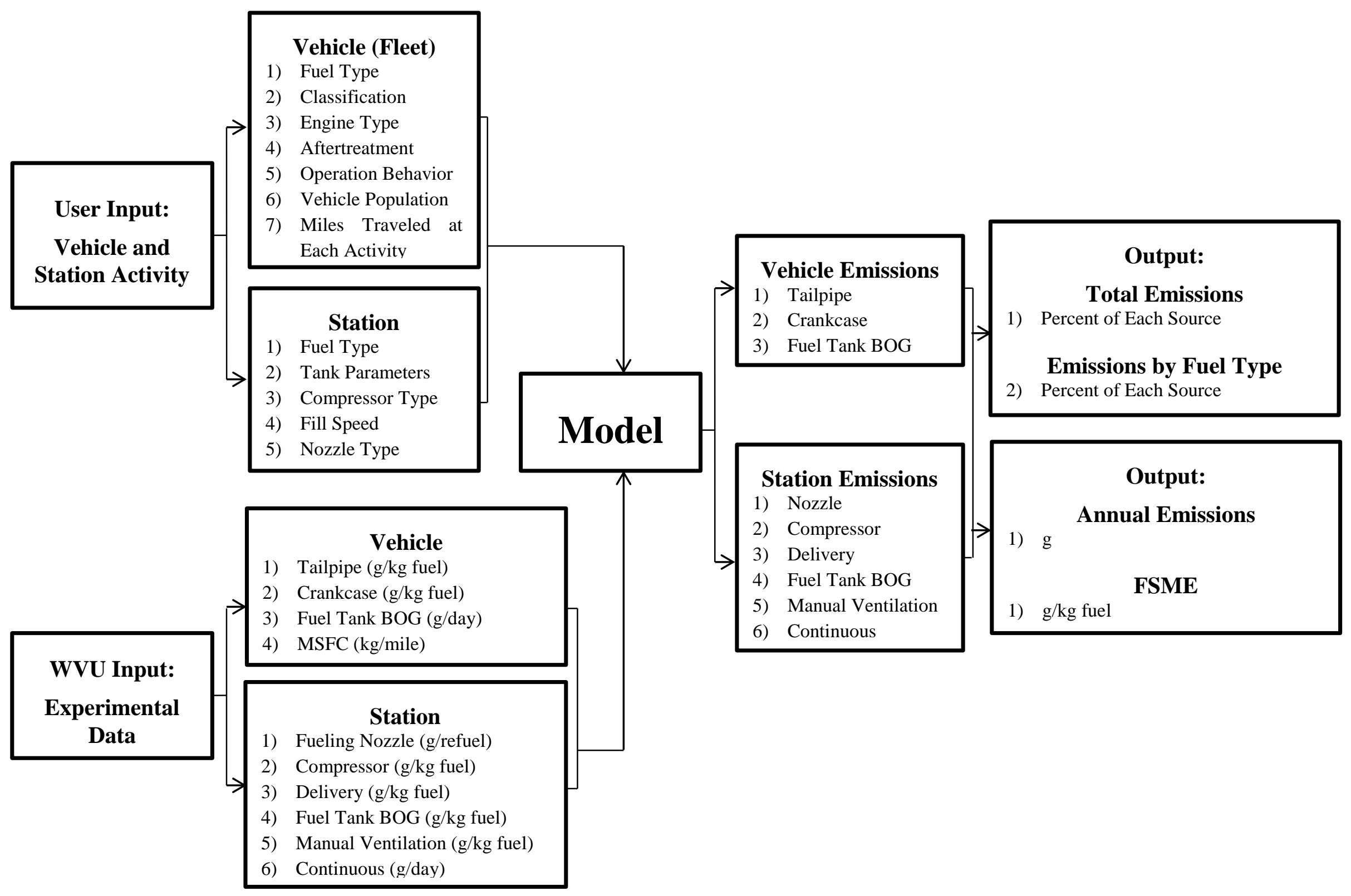

Figure 16: Model Logic Overview Flowchart 


\section{Vehicle and Station Population Scenarios}

\section{Vehicle Population}

The possible scenarios were a combination of high, medium, and low estimates for vehicle populations. The following sources of the data were used for the heavy-duty natural gas vehicle scenario:

- U.S. Energy Information Administration (EIA).

- National Petroleum Council (NPC)

- Americas Commercial Transportation (ACT) Research Co.

- American Clean Skies Foundation (ACSF)

The heavy-duty natural gas vehicle population data were further processed to develop a low, medium, and high penetration scenario. The low penetration scenario was developed by averaging the data reported by EIA and NPC (most conservative two estimates). The medium penetration scenario was developed by averaging the data reported by all four sources. The high penetration scenario was developed by averaging the data reported by ACT and ACFS (most optimistic two estimates).

The projected low, medium, and high population scenarios of the heavy-duty natural gas vehicle sector in 2035 are shown in Table 37.

Table 37: Projected Heavy-duty Natural Gas Vehicle Population in 2035

\begin{tabular}{|c|l|l|l|l|l|}
\hline \multicolumn{2}{|c|}{ Vehicle Type } & $\begin{array}{l}\text { Refuse Truck } \\
\text { (CNG only) }\end{array}$ & $\begin{array}{l}\text { Transit Bus } \\
\text { (CNG only) }\end{array}$ & $\begin{array}{l}\text { OTR Tractor* } \\
\text { (CNG/LNG) }\end{array}$ & Total* \\
\hline Low & $\begin{array}{l}\text { Projected population of } \\
\text { each type of NG vehicle }\end{array}$ & 80,000 & 21,000 & 441,200 & 542,200 \\
\hline Medium & $\begin{array}{l}\text { Projected population of } \\
\text { each type NG vehicle }\end{array}$ & 104,000 & 31,500 & 773,200 & 908,700 \\
\hline High & $\begin{array}{l}\text { Projected population of } \\
\text { each type NG vehicle }\end{array}$ & 128,000 & 42,000 & $1,105,300$ & $1,275,300$ \\
\hline
\end{tabular}

* The percentage of natural gas vehicles was calculated with the assumed heavy-duty vehicle population of 2,500,000 excluding school buses $(500,000)$

Table 38 shows the projected low, medium, and high scenarios of OTR tractors in 2035 with an assumed medium (50\%) market penetration of HPDI engine long haul OTR tractors. Retrofit OTR tractors were also tested in this study, but emissions levels were not reflective of predicted values in 2035 and were therefore excluded from this thesis. 
Table 38: The Scenarios for USA Heavy-Duty OTR Tractors in 2035 (Medium HPDI Penetration)

\begin{tabular}{|c|c|c|c|c|c|c|}
\hline Vehicle Category & \multicolumn{2}{|c|}{ Short Haul ( $\leq \mathbf{3 2 0}$ hp) } & \multicolumn{3}{|c|}{ Long Haul (>320 hp) } & Total \\
\hline $\begin{array}{c}\text { Population Fraction of Heavy-duty } \\
\text { Natural Gas OTR Tractor Market }\end{array}$ & \multicolumn{2}{|c|}{$50.0 \%$} & \multicolumn{3}{|c|}{$50.0 \%$} & $100.0 \%$ \\
\hline Engine Technology & SI & SI & SI & HPDI & SI & \\
\hline Fuel Type & CNG & LNG & CNG & LNG & LNG & \\
\hline $\begin{array}{c}\text { Population Fraction of } \\
\text { Vehicle Category }\end{array}$ & $60.0 \%$ & $40.0 \%$ & $25.0 \%$ & $50.0 \%$ & $25.0 \%$ & \\
\hline $\begin{array}{c}\text { Population Fraction of } \\
\text { Total OTR Tractors }\end{array}$ & $30.0 \%$ & $20.0 \%$ & $12.5 \%$ & $25.0 \%$ & $12.5 \%$ & $100.0 \%$ \\
\hline Low & 132,360 & 88,240 & 55,150 & 110,300 & 55,150 & 441,200 \\
\hline Medium & 231,960 & 154,640 & 96,650 & 193,300 & 96,650 & 773,200 \\
\hline High & 331,590 & 221,060 & 138,162 & 276,325 & 138,163 & $1,105,300$ \\
\hline
\end{tabular}

Table 39 shows the market penetration scenario of long haul OTR tractors with low, medium, and high HPDI penetrations.

Table 39: The Scenarios for USA Heavy-Duty Long Haul OTR Tractors in 2035 with Different HPDI Penetration

\begin{tabular}{|c|c|c|c|}
\hline \multirow{2}{*}{} & CNG & \multicolumn{2}{|c|}{ LNG } \\
\cline { 2 - 4 } & SI CNG & LNG HPDI & SI LNG \\
\hline Low & $40 \%$ & $20 \%$ & $40 \%$ \\
\hline Medium & $25 \%$ & $50 \%$ & $25 \%$ \\
\hline High & $10 \%$ & $80 \%$ & $10 \%$ \\
\hline
\end{tabular}

\section{Natural Gas Fuel Station Population}

The number of stations was based on the assumption that natural gas stations would refuel 50 refuse trucks, 80 transit buses, or 80 OTR tractors per station. Table 40 shows the projected number of stations correlated to the number of predicted vehicles.

Table 40: Projected Population of Natural Gas Fuel Stations for Heavy-Duty Natural Gas Vehicle Sector in 2035

\begin{tabular}{|c|c|c|c|c|}
\hline \multicolumn{2}{|r|}{ NG Fuel Station Type } & CNG & LNG & Total \\
\hline Low & Projected population of natural gas stations & 3945 & 3172 & 7117 \\
\hline Medium & Projected population of natural gas stations & 6189 & 5559 & 11748 \\
\hline High & Projected population of natural gas stations & 9341 & 9168 & 18509 \\
\hline
\end{tabular}

\section{Activity Scenarios}

Literature data, referenced in Appendices A, B and C, were used to provide estimates for the annual vehicle miles traveled (AVMT) of all vehicles and the percentage of idle time of the OTR tractors. Driving schedules from chassis dynamometer and in-use data, representative of daily use, were processed by the same methods used in the vehicle emissions and fuel energy portion of this study to find the percentage of idle time for the transit buses and refuse trucks. Table 41 shows the percent of estimated miles and time for each activity of each vehicle type. The percentage of miles, along with the AVMT for each vehicle type, was used to determine how 
many miles in each activity each vehicle type traveled per year. The percentage of idle time was used to determine the hours of idle per day.

Table 41: Percent of Estimated Miles and Time for Each Type of Vehicle

\begin{tabular}{|c|c|r|r|r|r|c|}
\hline & Vehicle Type & \multicolumn{1}{|c|}{ Idle } & City & Arterial & Highway & Total \\
\hline \multirow{4}{*}{$\%$ miles operation } & Refuse Truck & $0.00 \%$ & $15.10 \%$ & $48.60 \%$ & $36.40 \%$ & $100.00 \%$ \\
\cline { 2 - 7 } & Transit Bus & $0.00 \%$ & $5.60 \%$ & $88.30 \%$ & $6.10 \%$ & $100.00 \%$ \\
\cline { 2 - 7 } & Long Haul OTR Tractor & $0.00 \%$ & $0.35 \%$ & $6.28 \%$ & $93.37 \%$ & $100.00 \%$ \\
\cline { 2 - 7 } & Short Haul OTR Tractor & $0.00 \%$ & $1.45 \%$ & $37.89 \%$ & $60.66 \%$ & $100.00 \%$ \\
\hline \multirow{4}{*}{$\%$ time operation } & Refuse Truck & $45.80 \%$ & $23.60 \%$ & $22.50 \%$ & $8.10 \%$ & $100.00 \%$ \\
\cline { 2 - 7 } & Transit Bus & $28.60 \%$ & $10.50 \%$ & $59.40 \%$ & $1.50 \%$ & $100.00 \%$ \\
\cline { 2 - 6 } & Long Haul OTR Tractor & $23.30 \%$ & N.D. $^{\mathrm{A}}$ & N.D. $^{\mathrm{A}}$ & N.D. $^{\mathrm{A}}$ & N.D. $^{\mathrm{A}}$ \\
\cline { 2 - 6 } & Short Haul OTR Tractor & $36.00 \%$ & N.D. $^{\mathrm{A}}$ & N.D. $^{\mathrm{A}}$ & N.D. $^{\mathrm{A}}$ & N.D. $^{\mathrm{A}}$ \\
\hline
\end{tabular}

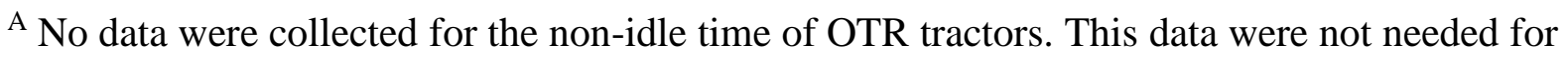
the activity scenario

Table 42 shows the AVMT and idle time for each of the vehicle types. An eight hour working day was assumed for each vehicle type to determine the average idle time per day. Details of the driving schedules used for the refuse truck, transit bus, and OTR tractors are shown in Appendix $\mathrm{H}$ and Appendix I and Appendix $\mathrm{J}$ respectively.

Table 42: AVMT and Idle Time for Each Type of Vehicle

\begin{tabular}{|c|r|r|r|r|r|}
\hline & \multicolumn{4}{|c|}{ AVMT (mi) } & \multirow{2}{*}{ Idle Time (hr) } \\
\cline { 2 - 5 } & \multicolumn{1}{|c|}{ City } & Arterial & Highway & Total & \\
\hline Refuse truck & 3,775 & 12,150 & 9,100 & 25,000 & 3.66 \\
\hline Transit bus & 2,240 & 35,320 & 2,440 & 40,000 & 2.29 \\
\hline Short haul OTR tractor & 725 & 18,945 & 30,330 & 50,000 & 2.88 \\
\hline Long haul OTR tractor & 350 & 6,280 & 93,370 & 100,000 & 1.86 \\
\hline
\end{tabular}

An assumption for number of operation days was made to calculate the idle emissions. Table 43 shows the assumed number of operational days per year for each vehicle type. The refuse truck is assumed to work five days per week and all other vehicle types are assumed to work six days per week.

Table 43: Number of Operational Days per Year for Each Vehicle Type

\begin{tabular}{|c|r|}
\hline Vehicle Type & $\begin{array}{c}\text { Annual Days of Operation } \\
\text { (day/year) }\end{array}$ \\
\hline Refuse truck & 260 \\
\hline Transit bus & 312 \\
\hline Short haul OTR tractor & 312 \\
\hline Long haul OTR tractor & 312 \\
\hline
\end{tabular}


Each vehicle was assumed to refuel once per day, regardless of fuel use. None of the daily fuel uses exceeded maximum fuel tank capacity. This assumption was made to simplify the fueling nozzle calculations.

\section{Experimental Data Inputs - Stasis Scenario}

Experimental data were derived for vehicles and stations, as shown in the previous chapter. This section highlights the inputs used in the estimation model. It should be noted that the fuel consumed and the FSME are natural gas only, unless otherwise stated.

\section{Vehicle Experimental Data Input}

Table 44 shows the average DSEC for each activity for each vehicle type. The idle activity had energy consumption measured in time specific units since the vehicle travels no distance during idle.

Table 44: Average Distance Specific Fuel Energy for Each Activity for Each Vehicle Type

\begin{tabular}{|c|c|r|r|r|}
\hline \multirow{2}{*}{ Vehicle Type } & \multicolumn{1}{|c|}{ Idle } & \multicolumn{1}{|c|}{ City } & Arterial & Highway \\
\cline { 2 - 5 } & MJ/hr & \multicolumn{3}{|c|}{ MJ/mile } \\
\hline Refuse Trucks & 235.92 & 112.99 & 34.43 & 24.48 \\
\hline Transit Buses & 278.98 & 56.03 & 35.08 & 22.61 \\
\hline 9L SI OTR Tractor & 190.99 & 58.43 & 37.73 & 26.09 \\
\hline 12L SI OTR Tractor & 200.52 & 67.87 & 42.31 & 29.83 \\
\hline 15L HPDI OTR Tractor ${ }^{A}$ & 282.39 & 94.66 & 27.86 & 24.49 \\
\hline
\end{tabular}

${ }^{A}$ Includes diesel and natural gas fuel energy

Table 45 shows the average tailpipe FSME for each activity for each vehicle type. The values from each vehicle type were averaged and each vehicle was weighted equally.

Table 45: Average Tailpipe FSME for Each Activity for Each Vehicle Type

\begin{tabular}{|l|r|r|r|r|}
\hline \multirow{2}{*}{\multicolumn{1}{|c|}{ Vehicle Type }} & \multicolumn{1}{|c|}{ Idle } & \multicolumn{1}{l|}{ City } & \multicolumn{1}{c|}{ Arterial } & Highway \\
\cline { 2 - 5 } & \multicolumn{4}{|c|}{ g/kg fuel } \\
\hline Refuse Trucks & 0.67 & 2.99 & 5.39 & 2.20 \\
\hline Transit Buses & 3.85 & 10.23 & 9.00 & 8.24 \\
\hline 9L SI OTR Tractor & 2.32 & 10.02 & 5.61 & 4.23 \\
\hline 12L SI OTR Tractor & 0.55 & 3.61 & 3.32 & 2.33 \\
\hline 15L HPDI OTR Tractor & 14.14 & 7.33 & 6.51 & 4.50 \\
\hline
\end{tabular}

Table 46 shows the average crankcase FSME for each activity for each SI engine vehicle type. The values from each vehicle type were averaged and each vehicle was weighted equally. 
Table 46: Average Crankcase FSME for Each Activity for Each SI Vehicle Type

\begin{tabular}{|l|r|r|r|r|}
\hline \multirow{2}{*}{ Vehicle Type } & \multicolumn{1}{|c|}{ Idle } & \multicolumn{1}{c|}{ City } & \multicolumn{1}{c|}{ Arterial } & Highway \\
\cline { 2 - 5 } & \multicolumn{4}{|c|}{ g/kg fuel } \\
\hline Refuse Trucks & 16.62 & 9.06 & 7.39 & 5.56 \\
\hline Transit Buses & 12.81 & 10.38 & 8.00 & 6.63 \\
\hline 9L SI OTR Tractor & 18.46 & 9.97 & 6.25 & 4.91 \\
\hline 12L SI OTR Tractor & 21.52 & 7.77 & 6.47 & 5.01 \\
\hline
\end{tabular}

Table 47 shows the average dynamic ventilation FSME for each activity for HPDI engine vehicles.

Table 47: Average Dynamic Ventilation FSME for Each Activity for HPDI Vehicles

\begin{tabular}{|c|r|r|r|r|}
\hline \multirow{2}{*}{ Vehicle Type } & \multicolumn{1}{|c|}{ Idle } & City & Arterial & Highway \\
\cline { 2 - 5 } & \multicolumn{4}{|c|}{$\mathrm{g} / \mathrm{kg}$ fuel } \\
\hline 15L HPDI OTR Tractor $^{\mathrm{A}}$ & 0.00 & 22.10 & 10.15 & 4.81 \\
\hline
\end{tabular}

A The fuel consumed is natural gas only

\section{Station Experimental Data}

Table 48 shows the compressor, continuous, and nozzle emissions from CNG stations for each CNG vehicle type. The average emissions of each vehicle were used as the input to the estimation model. Each vehicle was weighted equally.

Table 48: Average Methane Emissions from CNG Stations

\begin{tabular}{|c|r|r|r|}
\hline \multirow{2}{*}{ Vehicle Type } & \multicolumn{1}{|c|}{ Compressor } & Continuous & Nozzle Emissions \\
\cline { 2 - 4 } & g/kg fuel & g/day & \multicolumn{2}{|c|}{ g/event } \\
\hline Transit Bus & 0.70 & 816 & 3.61 \\
\hline Refuse Truck* & 1.12 & 816 & 3.61 \\
\hline 9L OTR Tractor & 0.68 & 816 & 3.61 \\
\hline 12L OTR Tractor & 0.49 & 816 & 3.61 \\
\hline Average & $\mathbf{0 . 7 5}$ & $\mathbf{8 1 6}$ & $\mathbf{3 . 6 1}$ \\
\hline
\end{tabular}

*Only 50 vehicles refueled (compared to 80 for all other vehicle types)

Table 49 shows the nozzle emissions, continuous emissions, manual vehicle tank venting, station fuel tank BOG, and delivery emissions for LNG stations for each LNG vehicle type. An average of the vehicle emissions was used as the input to the estimation model. 
Table 49: Average Methane Emissions from LNG Stations

\begin{tabular}{|c|c|c|r|r|r|}
\hline $\begin{array}{c}\text { Vehicle Type } \\
\text { Refueled at } \\
\text { LNG Station }\end{array}$ & $\begin{array}{c}\text { Nozzle } \\
\text { Emissions }\end{array}$ & Continuous & $\begin{array}{c}\text { Manual Vehicle } \\
\text { Tank Venting }\end{array}$ & $\begin{array}{c}\text { Station Fuel } \\
\text { Tank BOG }\end{array}$ & Delivery \\
\cline { 2 - 6 } & g/event & g/day & \% Total Fuel & \% Total Fuel & \% Total Fuel \\
\hline 9L SI OTR Tractor & 17.7 & 12.8 & 0.250 & 0.100 & 0.128 \\
\hline 12L SI OTR Tractor & 17.7 & 12.8 & 0.250 & 0.100 & 0.128 \\
\hline 15L HPDI OTR Tractor & 17.7 & 12.8 & 0.250 & 0.100 & 0.128 \\
\hline Average & $\mathbf{1 7 . 7}$ & $\mathbf{1 2 . 8}$ & $\mathbf{0 . 2 5 0}$ & $\mathbf{0 . 1 0 0}$ & $\mathbf{0 . 1 2 8}$ \\
\hline
\end{tabular}

\section{Emissions and Fuel Consumption Scenarios}

All available measurements and data from WVU were used as an input for the estimation model as a table database reference. The reductions were for vehicles and fueling stations. The stasis case scenario represented the average of the current measurements for each respective vehicle and engine type. This case represented no improvement in current technologies, which is not feasible in year 2035 due to upcoming regulations and current regulations outside of the U.S. The methane emissions standard is $0.10 \mathrm{~g} / \mathrm{hp}$ - $\mathrm{hr}$ measured over a transient duty cycle, as specified in 40 CFR part 86 subpart N. The standard was in effect in model year 2014 for compression ignition engines and will be in effect in model year 2016 for SI engines (CFR 40 Part 86, 1990; CFR 40 Part 1036.108, 2014). The Euro VI standards for methane emissions are $0.16 \mathrm{~g} / \mathrm{kWh}$ (Willner, 2013). The high, medium, and low case scenarios were a percent reduction in the stasis scenario case, with low being the most optimistic reductions. It should be noted that the stasis scenario reflects the current technology measurements, but this scenario is not reflective of current emissions. Older technology, such as outdated existing infrastructure and vehicles that may be currently used, were not included when applicable in the stasis measurements. Therefore any conclusion of current methane emissions cannot be determined by this study.

\section{Vehicle Emissions and Fuel Consumption Scenarios}

Vehicle reductions include normalized rates for emissions and fuel consumption for each vehicle type. The estimation model has a modifiable input of high, medium, and low scenarios for emission and fuel consumption. Table 50 shows the high, medium, and low scenarios for tailpipe, crankcase, and HPDI dynamic venting emissions and fuel consumption for vehicles. Tailpipe emissions reduction estimates were based on historical trends from other fuel type emissions reductions as well are predicted improvements in catalyst systems. Crankcase emissions reductions were based on current capabilities of closing crankcases and the ease of reducing engine emission certification levels by doing so. The HPDI venting emissions reduction was based on the value of capturing and reusing the vented natural gas. The vehicle fuel tank BOG was based on estimated technology improvements to increase hold time, such as more insulation and reduction in heat transfer. Fuel consumption was calculated by the vehicle experimental data and the estimation model. 
Table 50: Stasis, High, Medium, and Low Scenarios of Methane Emissions and Fuel Consumption for Vehicles

\begin{tabular}{|c|c|c|c|c|c|c|}
\hline & $\begin{array}{c}\text { Tailpipe } \\
\text { Methane }\end{array}$ & $\begin{array}{c}\text { Crankcase } \\
\text { Methane }\end{array}$ & $\begin{array}{c}\text { HPDI } \\
\text { Dynamic } \\
\text { Ventilation }\end{array}$ & $\begin{array}{c}\text { Vehicle } \\
\text { On-board } \\
\text { Tank BOG }\end{array}$ & $\begin{array}{c}\text { Fuel } \\
\text { Consumption } \\
\text { Non-idle } \\
\text { Operation }\end{array}$ & $\begin{array}{c}\text { Fuel } \\
\text { Consumption } \\
\text { During Idle } \\
\text { Operation }\end{array}$ \\
\hline Stasis & \multicolumn{7}{|c|}{$100 \%$ Average of current measurement } \\
\hline High & $75 \%$ & $25 \%$ & $50 \%$ & $75 \%$ & $90 \%$ & $100 \%$ \\
\hline Medium & $35 \%$ & $10 \%$ & $20 \%$ & $50 \%$ & $75 \%$ & $90 \%$ \\
\hline Low & $15 \%$ & $2 \%$ & $10 \%$ & $25 \%$ & $50 \%$ & $60 \%$ \\
\hline
\end{tabular}

Station Emissions and Fuel Consumption scenarios

CNG station reductions include normalized rates for emissions from CNG station components. Table 51 shows the high, medium, and low scenarios for nozzle, compressor, and continuous emissions from CNG stations. CNG nozzle emissions reductions were based on the ease of rerouting the highest portion of methane vented back to the station. Actuator emissions can be eliminated by using pneumatic air controlled actuators, which were already used at seven of the eight audited stations. The measured CNG compressor emissions represented two decades of technologies. The CNG compressor reductions were based on the trend in technology improvements. The CNG continuous emissions reductions were based on estimated improvements in station standard operation practice and regulations to enforce these improved practices

Table 51: Stasis, High, Medium, and Low Scenarios of Emissions for CNG Station Methane Emissions

\begin{tabular}{|c|c|c|c|}
\hline Scenario & $\begin{array}{c}\text { Emissions from } \\
\text { Dispenser Nozzle }\end{array}$ & $\begin{array}{c}\text { Emissions from } \\
\text { Compressor }\end{array}$ & $\begin{array}{c}\text { Continuous Station } \\
\text { Emissions }\end{array}$ \\
\hline Stasis & \multicolumn{2}{|c|}{ Average of the current survey data } \\
\hline High & $50 \%$ & $50 \%$ & $80 \%$ \\
\hline Medium & $20 \%$ & $20 \%$ & $50 \%$ \\
\hline Low & $10 \%$ & $5 \%$ & $20 \%$ \\
\hline
\end{tabular}

LNG station reductions include normalized rates for emissions from LNG station components. Table 52 shows the high, medium, and low scenarios for nozzle, station tank, continuous, and manual venting emissions from LNG stations. LNG nozzle emissions reductions were based on expected reduction in refueling event emissions variability. The station fuel tank BOG reductions were based on a WVU station fuel tank BOG model developed by other research members. The model showed that station fuel tank BOG was based largely on utilization. In addition, existing technology such as generators, oxidation, reliquefaction, or simply rerouting the emissions back to the supply line should further decrease the emissions. Reductions in vehicle manual ventilation prior to refueling were based on the ability of LNG stations to accept return vapor or warm LNG, colder stations due to higher utilization, and an adoption of better refueling practices for vehicle operators. Delivery emissions reductions were based on more consistent delivery practices and the capture of connector volume emissions. 
Table 52: Stasis, High, Medium, and Low Scenarios of Emissions for LNG Stations

\begin{tabular}{|c|c|c|c|c|c|}
\hline & Dispenser Nozzle & $\begin{array}{c}\text { Continuous Station } \\
\text { Emissions }\end{array}$ & $\begin{array}{c}\text { Station } \\
\text { Storage } \\
\text { Tank BOG }\end{array}$ & $\begin{array}{c}\text { Vehicle } \\
\text { Manual } \\
\text { Ventilation }\end{array}$ & Delivery \\
\hline Stasis & \multicolumn{2}{|c|}{$100 \%$ of average of current data measured } \\
\hline High & $50 \%$ & $80 \%$ & $20 \%$ & $50 \%$ & $60 \%$ \\
\hline Medium & $20 \%$ & $50 \%$ & $10 \%$ & $25 \%$ & $40 \%$ \\
\hline Low & $10 \%$ & $20 \%$ & $2 \%$ & $3 \%$ & $20 \%$ \\
\hline
\end{tabular}

\section{Summary}

The estimation model follows a calculation process to provide methane emissions estimates as an output. The following is the order of steps taken by the estimation model to provide the output information:

1. Vehicle fleet information input into the model:
a. Vehicle type
b. Population
c. Activity behavior

2. Experimental data for each vehicle type is extracted from the model database.

3. An output for each source is calculated based on vehicle fleet and experimental data inputs:
a. Tailpipe
b. Crankcase
c. Dynamic ventilation
d. Vehicle tank BOG
e. Refueling nozzles
f. Continuous emissions
g. Compressor
h. Manual ventilation
i. Delivery
j. Station tank BOG

4. Tables and visual metrics are created based on output data

Details of the calculations can be found in Chapter 5. 


\section{Chapter 5 - Demonstration of Methane Emissions Estimation Model with Stasis Emissions and Fuel Consumption Scenarios}

Decisions for the estimation model were guided by project team advisors and a steering committee comprised of representatives from industry partners and regulatory bodies. Many decisions for structure and input were decided by these groups. This chapter demonstrates the detailed calculation of the estimation model. The medium population, medium HPDI penetration, and stasis emissions and fuel consumption scenarios were used in the examples for this chapter.

\section{Vehicle Populations}

The estimation of methane emissions requires the input of the following information:

- Vehicle population data. This includes the model year, number of vehicles in each category, vehicle application or service performed, mileage accumulated per year on average for the vehicle type, fueling system and engine technology, aftertreatment system, maintenance practice, and fuel station used for the class. The model year, aftertreatment, and maintenance practice options were placeholders for future work because they were not considered in this thesis due to limited number of vehicles and resources.

- Gas station information. This includes fuel technology (CNG or LNG), tank parameters (LNG only), compressor type (CNG only), nozzle type, and fill speed (CNG only). Only fuel type was explored in this thesis due to a limited number of observations and resources.

The choices will be limited to a selectable list of options. For example, only CNG and LNG can be selected as options for the fuel type. Table 53 shows an example of the selectable options. Some of the data for the selectable options are redundant, such as the model year, or only have one option, such as aftertreatment. These were left in the model for future research and improvements.

Table 53: Selectable Options Example from Estimation Model

\begin{tabular}{|c|c|c|c|c|}
\hline Model Year & Fuel Type & Vehicle Classification & Engine Type & After Trea \\
\hline $\begin{array}{l}\text { Select Model Year } \\
\text { Select Model Year } \\
\text { Retrofit }\end{array}$ & lect Model Year First & Select Model Year First & Select Model Year First & Select Model \\
\hline $\begin{array}{l}\text { Model Year } 2008 \\
\text { Model Year } 2011 \\
\text { Model Year } 2012 \\
\text { Model Year } 2013 \\
\end{array}$ & lect Model Year First & Select Model Year First & Select Model Year First & Select Model \\
\hline Select Model Year & Select Model Year First & Select Model Year First & Select Model Year First & Select Model \\
\hline
\end{tabular}

Some lists will be dependent on the previously selected list. For example, the engine type cannot be selected until the fuel type, model year, and vehicle classification has already been selected. Also a three-way catalyst aftertreatment cannot be selected for an HPDI engine and SCR and 
DPH aftertreatment cannot be selected for a SI engine. An example of the latter dependency is shown in Table 54.

Table 54: Selection Dependency Example from Estimation Model

\begin{tabular}{|c|c|c|c|c|c|}
\hline Classification & Engine Type & After Treatment & $\begin{array}{c}\text { Maintenance } \\
\text { Practice }\end{array}$ & Activity & $\begin{array}{l}\text { Avera } \\
\text { Trave }\end{array}$ \\
\hline \multirow{4}{*}{ ansit Bus } & \multirow[b]{3}{*}{ SI Stoichio 9L } & & \multirow{4}{*}{7} & Idle Activity & \\
\hline & & & & City Activity & \\
\hline & & TWC & & Arterial Activity & \\
\hline & \multicolumn{2}{|c|}{ TWC } & & Highway Activity & \\
\hline \multirow{4}{*}{ use Truck } & \multirow{4}{*}{ SI Stoichio 9L } & \multirow{4}{*}{ TWC } & \multirow{4}{*}{ Medium Maintenance } & Idle Activity & \\
\hline & & & & City Activity & \\
\hline & & & & Arterial Activity & \\
\hline & & & & Wirkbeave Activit & \\
\hline
\end{tabular}

Table 55 shows an example of input data of a modeled fleet with all of the data selected. One of the possible vehicle types, transit bus, was selected in this example.

Table 55: User Input of Vehicle Population for Transit Buses

\begin{tabular}{|c|c|c|c|c|}
\hline Model Year & Fuel Type & Vehicle Classification & Engine Type & Aftertreatment \\
\hline Model Year 2008 & CNG Fuel & Transit Bus & SI Stoichio 9L & TWC \\
\hline $\begin{array}{l}\text { Maintenance } \\
\text { Practice }\end{array}$ & Activity & $\begin{array}{l}\text { Average Annual Miles } \\
\text { Traveled (miles/year) }\end{array}$ & $\begin{array}{l}\text { Number of } \\
\text { Vehicles }\end{array}$ & Fueling Station Used \\
\hline \multirow{4}{*}{ Medium Maintenance } & Idle Activity & 0 & \multirow{4}{*}{31,500} & \multirow{4}{*}{$\begin{array}{l}\text { CNG Vented Crank Case Compressor } \\
\text { Fast Fill Station Type A Nozzle }\end{array}$} \\
\hline & City Activity & 2,240 & & \\
\hline & Arterial Activity & 35,320 & & \\
\hline & Highway Activity & 2,440 & & \\
\hline
\end{tabular}

\section{CNG/LNG Station Populations}

The estimation of methane emissions requires the input of the following information: (1) station fuel technology (CNG or LNG); (2) whether the station keeps a cold and saturated tank or just a saturated tank if it is a LNG station. Due to the limited number of stations observed, there was no distinction between these two categories. However there is a placeholder for future data acquisition; (3) type of compressor used and fill speed if the fueling station is a CNG station. Due to the limited number of stations observed, there was also no distinction between these two categories. However there is a placeholder for future data acquisition. Table 56 shows an example of input data for a CNG fast fill station with all of the data selected. Only the stations selected as an input, from Table 56 in this example, can be used as an option in Table 55. 
Table 56: Station Input for Two Station Types

\begin{tabular}{|c|c|c|c|c|}
\hline \multicolumn{5}{|c|}{ Station Population } \\
\hline Fuel Type & $\begin{array}{c}\text { Tank Specifications } \\
\text { (For LNG Only) }\end{array}$ & $\begin{array}{c}\text { Compressor Type } \\
\text { (for CNG Only) }\end{array}$ & $\begin{array}{c}\text { Fill Type } \\
\text { (for CNG Only) }\end{array}$ & Nozzle Type \\
\hline CNG & & Vented Crank Case Compressor & Fast Fill & Type A Nozzle \\
\hline LNG & One Temperature & & & Type A Nozzle \\
\hline
\end{tabular}

\section{Model Calculations}

The medium population, medium HPDI penetration, and stasis emissions and fuel consumption scenarios were used for the example calculations. This section outlines the equations used in the estimation model and provides example calculations for each one. Each equation was calculated for each vehicle type. Results from each equation (each vehicle) were summed together to get final overall numbers. Transit buses are used in the examples for CNG vehicles and stations and HPDI engine OTR tractors are used in the examples for LNG vehicles and stations. The city activities are used in the examples for non-idle activity calculations for both vehicle types.

The total annual methane emissions (m) were comprised of the annual methane emissions from vehicles and stations for each vehicle type. Results from each vehicle were summed together to get final overall methane emissions. The example calculations are provided after the inputs are calculated, later in this section. The following equation was used to calculate the total emissions:

$$
m_{\text {total }}=m_{\text {vehicle }}+m_{\text {station }}
$$

The annual methane emissions from the vehicles were comprised of methane emissions from the vehicle tailpipe, crankcase (SI engine only), vehicle fuel tank BOG (LNG only), and dynamic ventilation (LNG HPDI engine only). The example calculations are provided after the inputs are calculated later in this section. The following equations were used to calculate the annual methane emissions from CNG, stoichiometric LNG, and HPDI engine LNG vehicles, respectively:

$$
\begin{aligned}
& m_{\text {CNGvehicle }}=m_{\text {tailpipe }}+m_{\text {crankcase }} \\
& m_{\text {LNGSIvehicle }}=m_{\text {tailpipe }}+m_{\text {crankcase }}+m_{\text {vehicle }}^{\text {tankBOG }} \\
& m_{\text {LNGHPDIvehicle }}=m_{\text {tailpipe }}+m_{\text {dynamic vent }}+m_{\text {vehicle }} \\
& \text { tankBOG }
\end{aligned}
$$

The methane emissions from stations depend on the station type. CNG and LNG stations have different components. The methane emissions from the CNG stations were comprised of fueling nozzle emissions, compressor emissions, and continuous emissions. The methane emissions from the LNG stations were comprised of fueling nozzle emissions, station fuel tank BOG, continuous emissions, tanker bulk delivery, and manual ventilation from HPDI engine OTR tractors prior to refueling. There was no observed manual ventilation for SI engine OTR tractors. The example calculations are provided after the inputs are calculated. The following equations were used to calculate the emissions from CNG and LNG stations, respectively: 


$$
\begin{aligned}
& m_{\text {CNGstation }}=m_{\text {fueling }}+m_{\text {cont. }}+m_{\text {compressor }} \\
& m_{\text {LNGstation }}=m_{\substack{\text { fueling } \\
\text { nozzle }}}+m_{\text {cont. }}+m_{\text {tankBOG }}^{\text {station }}+m_{\text {delivery }}+m_{\substack{\text { vehicle } \\
\text { manual } \\
\text { vent }}}
\end{aligned}
$$

The total vehicle miles traveled (TVMT) for each activity were calculated by the number of vehicles (n), the total AVMT for the vehicle, and the percent distribution of miles (PDM) for that activity. The transit bus city activity was used as an example. The following equation was used to calculate the total vehicle miles traveled:

$$
\begin{aligned}
& T V M T_{\text {activity }}=n_{\text {vehicle }} \times A V M T \times P D M \\
& T V M T_{\text {transitbus,city }}=31,500 \times 40,000 \times 0.056=70,560,000 \mathrm{mi}
\end{aligned}
$$

Table 57 shows the example calculations from Equation 5.7 for each activity from transit buses with the stasis emissions and fuel consumption scenarios.

Table 57: TVMT of Transit Buses in Each Activity

\begin{tabular}{|c|r|}
\hline Activity & \multicolumn{1}{|c|}{ TVMT (miles) } \\
\hline Idle & $70,560,000$ \\
\hline City & $1,112,580,000$ \\
\hline Arterial & $76,860,000$ \\
\hline Highway
\end{tabular}

The total fuel consumed (TFC) for each activity was calculated by the total vehicle miles traveled for the corresponding activity and the distance specific fuel consumption (DSFC). The distance specific fuel consumption was derived in this research from experimental data. The DSFC is for a speed bin and is therefore not reflective of a vehicles overall fuel economy. Calculations and experimental DSFC data were withheld due to sponsor request. Results from each activity were summed to get the total fuel consumption. The following equation was used to calculate the total fuel consumption:

$$
T F C_{\text {activity }}=T V M T_{\text {activity }} \times D S F C_{\text {activity }}
$$

The non-idle distance specific methane emissions (dsme) from the tailpipe were calculated from the FSME and the distance specific fuel consumption, which were both inputs to the estimation model. The transit bus city activity was used as an example. The tailpipe distance specific methane emissions for the non-idle activities were calculated with the following equation:

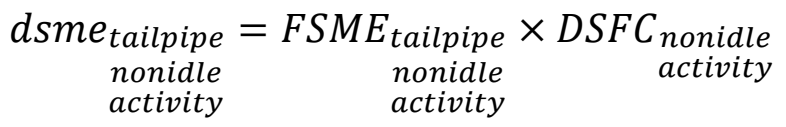

$$
\begin{aligned}
& d \text { sme } \underset{\text { transitbus,city }}{\text { tailpipe }}=10.23 \times 1.19=12.17 \mathrm{~g} / \mathrm{mi}
\end{aligned}
$$

Table 58 shows the example calculations from Equation 5.9 for each activity from transit buses with the stasis emissions and fuel consumption scenarios. 
Table 58: Tailpipe DSME from Transit Buses in Each Activity in Stasis

\begin{tabular}{|c|r|}
\hline Activity & Tailpipe DSME (g/mi) \\
\hline Idle & $\mathrm{N} / \mathrm{A}$ \\
\hline City & 12.2 \\
\hline Arterial & 6.7 \\
\hline Highway & 4.0 \\
\hline
\end{tabular}

The annual non-idle tailpipe methane emissions for the non-idle activities were calculated from the distance specific tailpipe emissions and the total vehicle miles traveled. The transit bus city activity was used as an example. The following equation was used to calculate the annual nonidle tailpipe methane emissions:

$$
\begin{aligned}
& m_{\text {tailpipe }}=D S M E_{\text {tailpipe }} \times T V M T_{\text {nonidle }} \\
& \begin{array}{lll}
\text { nonidle } & \text { nonidle } & \text { activity } \\
\text { activity } & \text { activity } &
\end{array} \\
& m \underset{\text { transitbus,city }}{\text { tailpipe }}=12.17 \times 70,560,000=858,976,272 \mathrm{~g}
\end{aligned}
$$

The annual tailpipe methane emissions for the idle activity were calculated from the fuel specific tailpipe methane emissions, vehicle population, time specific fuel consumption (TSFC), number of operational days (OD), and the total hours of idle per day (t). Results from each non-idle and idle activity were summed to get the total tailpipe emissions for each vehicle type. The transit bus idle activity was used as an example. The following equation was used to calculate the annual tailpipe methane emissions:

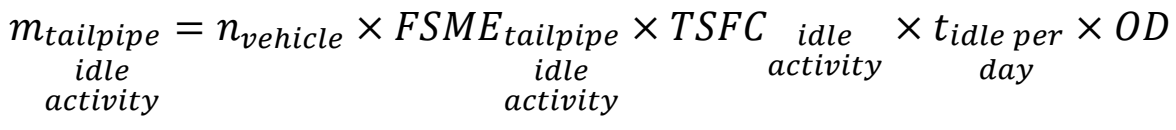

$$
\begin{aligned}
& m \underset{\text { transitbus,idle }}{\text { tailpipe }}=31,500 \times 3.85 \times 5.92 \times 2.29 \times 312 \\
& =512,959,487 \mathrm{~g}
\end{aligned}
$$

Table 59 shows the example calculations from Equation 5.10 and Equation 5.11 for each activity from transit buses with the medium population, medium HPDI penetration, stasis emissions and fuel consumption scenarios.

Table 59: Annual Methane Emissions from Tailpipe of Transit Buses for Stasis Scenario

\begin{tabular}{|c|r|}
\hline Activity & Tailpipe Annual Methane Emissions (g) \\
\hline Idle & $512,959,487$ \\
\hline City & $858,976,272$ \\
\hline Arterial & $7,409,782,800$ \\
\hline Highway & $303,996,672$ \\
\hline $\begin{array}{c}\text { Total Transit Bus } \\
\text { Tailpipe Emissions }\end{array}$ & $9,085,715,231$ \\
\hline
\end{tabular}


The non-idle methane emissions from crankcases in distance specific units were calculated from the crankcase methane emissions in fuel specific units and the distance specific fuel consumption, which were both inputs to the estimation model. The transit bus city activity was used as an example. The crankcase distance specific methane emissions for the non-idle activities were calculated with the following equation:

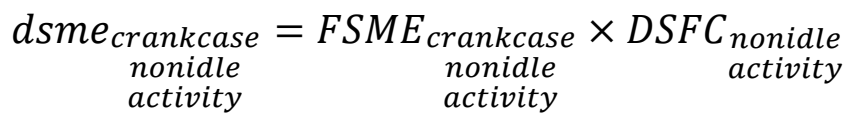

$$
\begin{aligned}
& d s m e \underset{\text { transitbus,city }}{\text { crankcase }}=10.38 \times 1.19=12.35 \mathrm{~g} / \mathrm{mi}
\end{aligned}
$$

Table 60 shows the example calculations from Equation 5.12 for each activity from transit buses with the stasis emissions and fuel consumption scenarios.

Table 60: DSME from Crankcase of Transit Buses for Stasis Scenario

\begin{tabular}{|c|r|}
\hline Activity & Crankcase DSME (g/mi) \\
\hline Idle & $\mathrm{N} / \mathrm{A}$ \\
\hline City & 12.4 \\
\hline Arterial & 5.9 \\
\hline Highway & 3.2 \\
\hline
\end{tabular}

The annual non-idle crankcase methane emissions were calculated from the distance specific crankcase emissions for the non-idle activities and the total vehicle miles traveled. The transit bus city activity was used as an example. The following equation was used to calculate the annual non-idle crankcase methane emissions:

$$
\begin{aligned}
& \begin{array}{c}
m_{\text {crankcase }}^{\text {nonidle }} \\
\text { activty }
\end{array}=D S M E_{\text {crankcase }}^{\text {nonidle }} \begin{array}{r}
\text { activty } \\
\text { activty }
\end{array} \\
& m \underset{\text { transitbus,city }}{\text { crankcase }}=12.35 \times 70,560,000=871,571,232 g
\end{aligned}
$$

The annual crankcase methane emissions for the idle activity were calculated from the fuel specific crankcase methane emissions, vehicle population, time specific fuel consumption, number of operational days, and the total hours of idle per day. Results from each non-idle and idle activity were summed to get the total crankcase emissions for each vehicle type. The transit bus idle activity was used as an example. The annual crankcase methane emissions were calculated with the following equation:

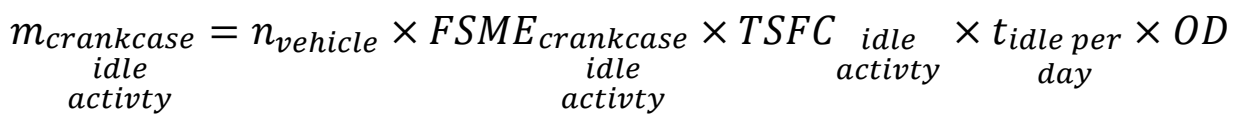

$$
\begin{aligned}
& m_{\text {transitbus,idle }}^{\text {crankcase }}=31,500 \times 12.81 \times 5.92 \times 2.29 \times 312 \\
& =1,706,756,111 \mathrm{~g}
\end{aligned}
$$


Table 61 shows the example calculations from Equation 5.13 and Equation 5.14 for each activity from transit buses with the medium population, medium HPDI penetration, stasis emissions and fuel consumption scenarios.

Table 61: Annual Methane Emissions from Crankcase of Transit Buses for Stasis Scenario

\begin{tabular}{|c|r|}
\hline Activity & Crankcase Annual Methane Emissions (g) \\
\hline Idle & $1,706,756,111$ \\
\hline City & $871,571,232$ \\
\hline Arterial & $6,586,473,600$ \\
\hline Highway & $244,599,264$ \\
\hline $\begin{array}{c}\text { Total Transit Bus } \\
\text { Crankcase Emissions }\end{array}$ & $9,409,400,207$ \\
\hline
\end{tabular}

The non-idle methane emissions from dynamic ventilation in distance specific units were calculated from the dynamic ventilation methane emissions in fuel specific units and the distance specific fuel consumption, which were both inputs to the estimation model. The HPDI engine OTR tractor city activity was used as an example. The dynamic ventilation distance specific methane emissions for the non-idle activities were calculated with the following equation:

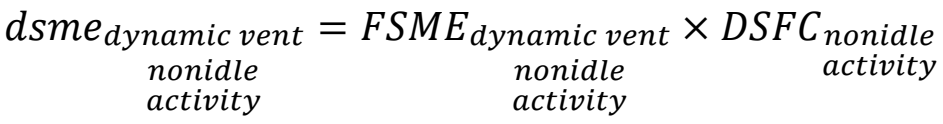

$$
\begin{aligned}
& \text { dsme }_{\text {dynamic vent }}=22.10 \times 1.76=38.93 \mathrm{~g} / \mathrm{mi} \\
& \text { HPDIOTR, city }
\end{aligned}
$$

Table 62 shows the example calculations from Equation 5.15 for each activity from HPDI engine OTR tractors with the stasis emissions and fuel consumption scenarios.

Table 62: DSME from Dynamic Ventilation of HPDI OTR Tractors for Stasis Scenario

\begin{tabular}{|c|r|}
\hline Activity & Dynamic Ventilation DSME (g/mi) \\
\hline Idle & $\mathrm{N} / \mathrm{A}$ \\
\hline City & 38.9 \\
\hline Arterial & 5.3 \\
\hline Highway & 2.2 \\
\hline
\end{tabular}

The annual non-idle dynamic ventilation methane emissions were calculated from the distance specific dynamic ventilation emissions for the non-idle activities and the total vehicle miles traveled. The HPDI engine OTR tractors city activity was used as an example. The following equation was used to calculate the annual non-idle dynamic ventilation methane emissions:

$$
\begin{aligned}
& m_{\text {dynamic vent }}=D S M E_{\text {dynamic vent }} \times T V M T_{\text {nonidle }} \\
& \text { nonidle nonidle activty } \\
& \text { activty activty } \\
& m_{\text {dynamic vent }}=38.93 \times 67,655,000=2,633,999,931 \mathrm{~g}
\end{aligned}
$$


The annual dynamic ventilation methane emissions for the idle activity were calculated from the fuel specific dynamic ventilation methane emissions, vehicle population, time specific fuel consumption, number of operational days, and the total hours of idle per day. Results from each non-idle and idle activity were summed to get the total dynamic ventilation emissions for each vehicle type. The HPDI engine OTR tractor idle activity was used as an example. The annual dynamic ventilation methane emissions were calculated with the following equation:

$$
\begin{aligned}
& m_{\begin{array}{c}
\text { dynamic vent } \\
\text { idle } \\
\text { activty }
\end{array}}=n_{\text {vehicle }} \times F S M E_{\text {dynamic vent }} \times T S F C_{\text {idle }}^{\text {idle }} \begin{array}{c}
\text { activty } \\
\text { activty }
\end{array} \\
& m_{\text {dynamic vent }}=193,300 \times 0 \times 3.51 \times 1.86 \times 312=0 \mathrm{~g}
\end{aligned}
$$

Table 63 shows the example calculations from Equation 5.16 and Equation 5.17 for each activity from HPDI engine OTR tractors with the medium population, medium HPDI penetration, stasis emissions and fuel consumption scenarios.

Table 63: Annual Methane Emissions from Dynamic Ventilation of HPDI OTR Tractors for Stasis Scenario

\begin{tabular}{|c|r|}
\hline Activity & Dynamic Ventilation Annual Methane Emissions (g) \\
\hline Idle & 0 \\
\hline City & $2,633,999,931$ \\
\hline Arterial & $6,373,924,046$ \\
\hline Highway & $39,432,040,261$ \\
\hline $\begin{array}{c}\text { Total HPDI OTR Tractors } \\
\text { Dynamic Ventilation }\end{array}$ & $48,439,964,237$ \\
\hline
\end{tabular}

The fuel specific vehicle tank BOG emissions for all activities were determined from a percent of fuel converted to a FSME (factor of 1000 converting percent of fuel or $\mathrm{kg}$ emissions $/ \mathrm{kg}$ fuel consumed to $\mathrm{g}$ emissions/kg fuel consumed), indirectly based on the amount of fuel consumed per year. The HPDI engine OTR tractor city activity was used as an example. The following equation was used to calculate the fuel specific vehicle tank BOG emissions:

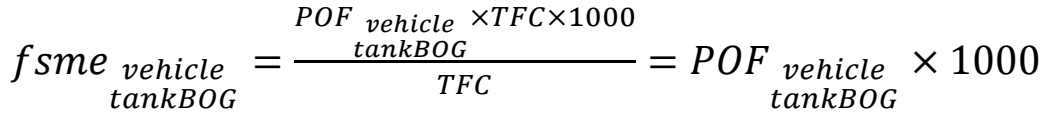

$$
\begin{aligned}
& f \text { sme } \underset{\substack{\text { vehicle } \\
\text { tankBOG } \\
\text { HPIOTR,city }}}{\text { vition }}
\end{aligned}
$$

Table 66 shows the example calculations from Equation 5.18 for each activity from HPDI engine OTR tractors with the stasis emissions and fuel consumption scenarios. 
Table 64: FSME from Vehicle Tank BOG of HPDI OTR Tractors for Stasis Scenario

\begin{tabular}{|c|r|}
\hline Activity & Vehicle Tank BOG FSME (g/kg fuel) \\
\hline Idle & 1.0 \\
\hline City & 1.0 \\
\hline Arterial & 1.0 \\
\hline Highway & 1.0 \\
\hline
\end{tabular}

The annual methane emissions from the vehicle tank BOG were calculated by the vehicle tank BOG methane emissions in fuel specific units and the total fuel consumption for each activity. Results from each activity were summed to get the total vehicle tank BOG emissions for each vehicle type. The HPDI engine OTR tractor city activity was used as an example. The following equation was used to calculate the annual methane emissions from the vehicle tank BOG:

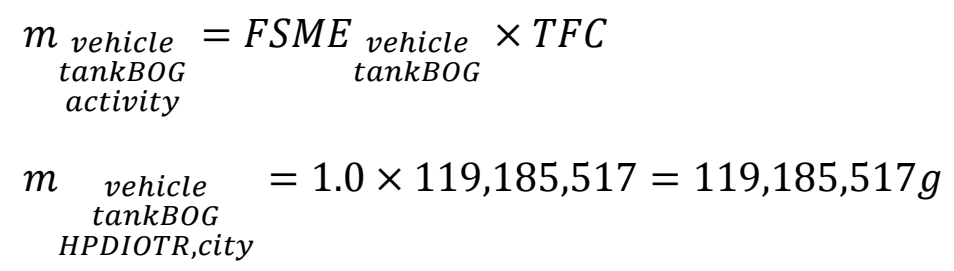

Table 65 shows the example calculations from Equation 5.19 for each activity from HPDI engine OTR tractors with the medium population, medium HPDI penetration, stasis emissions and fuel consumption scenarios.

Table 65: Annual Methane Emissions from Vehicle Tank BOG of HPDI OTR Tractors for Stasis Scenario

\begin{tabular}{|c|r|}
\hline Activity & Vehicle Tank BOG Annual Methane Emissions (g) \\
\hline Idle & $394,007,896$ \\
\hline City & $119,185,517$ \\
\hline Arterial & $627,972,812$ \\
\hline Highway & $8,197,929,368$ \\
\hline $\begin{array}{c}\text { Total HPDI OTR Tractor } \\
\text { Vehicle Tank BOG }\end{array}$ & $9,339,095,594$ \\
\hline
\end{tabular}

The annual methane emissions from the fueling nozzle were calculated by the vehicle population, the number of refueling events per day, the number of days operated per year, and the methane emissions per refueling event. The value for the methane emissions per refueling event was an input to the estimation model. The transit bus was used as an example. The following equation was used to calculate the annual methane emissions from the fueling nozzle:

$$
\begin{aligned}
& \underset{\text { nozzle }}{m_{\text {fueling }}}=n_{\text {vehicle }} \times \underset{\text { per day }}{n_{\text {refueling events }}} \times \underset{\text { per year }}{n_{\text {days operated }}} \times \underset{\text { fueling nozzle }}{\text { perent }} \\
& m_{\substack{\text { fueling } \\
\text { nozzle } \\
\text { transitbus }}}=31,500 \times 1 \times 312 \times 3.61=35,479,080 \mathrm{~g}
\end{aligned}
$$

The number of stations was calculated by the number of vehicles and the number of vehicles that each station will service, on average. The value for the number of vehicles and the number of 
vehicles that each station will service on average was an input to the estimation model. The population of transit buses from the medium population scenario was used as an example. The following equation was used to calculate the number of stations:

$$
\begin{aligned}
& n_{\text {stations }}=\frac{n_{\text {vehicle }}}{\begin{array}{c}
n_{\text {vehicles per }} \\
\text { station }
\end{array}} \\
& n_{\text {stations }}^{\text {transitbus }}=\frac{31,500}{80}=393.75 \text { stations }
\end{aligned}
$$

The continuous annual methane emissions from all station components, excluding the compressor (CNG only), fueling nozzle, fuel tank BOG (LNG only), and delivery (LNG only), were calculated by the number of stations, the continuous methane emissions per day $(\dot{\mathrm{m}})$, and a conversion from days to years. The value for the continuous methane emissions per day was an input to the estimation model. Transit buses were used as an example. The following equation was used to calculate the continuous annual methane emissions:

$$
\begin{aligned}
& m_{\text {cont. }}=n_{\text {station }} \times \dot{m}_{\text {continuous }} \times n \underset{\text { days }}{\text { per year }} \\
& m_{\text {transitbus }}^{\text {cont. }}=393.75 \times 816 \times 365.25=117,354,825 \mathrm{~g}
\end{aligned}
$$

The annual methane emissions from the compressors were calculated by the compressor methane emissions in fuel specific units and the total fuel consumption for each activity. The value for the fuel specific compressor methane emissions was an input to the estimation model. Results from each activity were summed to get the total compressor emissions for each vehicle type. The transit bus city activity was used as an example. The following equation was used to calculate the annual methane emissions from the compressor:

$$
\begin{aligned}
& m \text { compressor }=F S M E_{\text {compressor }} \times T F C \\
& \begin{array}{l}
\text { activity } \\
\text { compressor }
\end{array}=0.75 \times 83,966,400=62,974,800 \mathrm{~g}
\end{aligned}
$$

Table 66 shows the example calculations from Equation 5.23 for each activity from transit buses with the medium population, medium HPDI penetration, stasis emissions and fuel consumption scenarios.

Table 66: Annual Methane Emissions from Compressor of Transit Buses for Stasis Scenario

\begin{tabular}{|c|r|}
\hline Activity & Compressor Annual Methane Emissions (g) \\
\hline Idle & $99,927,173$ \\
\hline City & $62,974,800$ \\
\hline Arterial & $617,481,900$ \\
\hline Highway & $27,669,600$ \\
\hline $\begin{array}{c}\text { Total Transit Bus } \\
\text { Compressor Emissions }\end{array}$ & $808,053,473$ \\
\hline
\end{tabular}


The fuel specific station tank BOG emissions for all activities were determined from a percent of fuel converted to a FSME (factor of 1000 converting percent of fuel or $\mathrm{kg}$ emissions $/ \mathrm{kg}$ fuel consumed to $\mathrm{g}$ emissions/kg fuel consumed), indirectly based on the amount of fuel consumed per year. The HPDI engine OTR tractor city activity was used as an example. The following equation was used to calculate the fuel specific station tank BOG emissions:

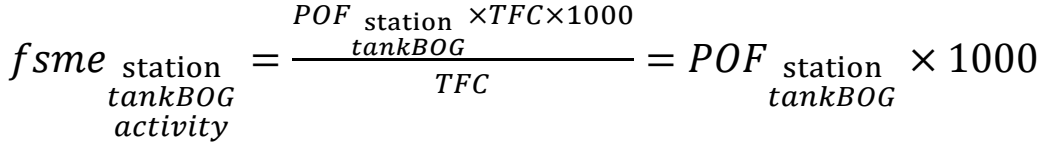

$$
\begin{aligned}
& \text { fsme } \underset{\substack{\text { station } \\
\text { tanBOG } \\
\text { HPIOTR,city }}}{\text { s.t. }}
\end{aligned}
$$

Table 67 shows the example calculations from Equation 5.24 for each activity from HPDI engine OTR tractors with the stasis emissions and fuel consumption scenarios.

Table 67: FSME from Station Tank BOG of HPDI OTR Tractors for Stasis Scenario

\begin{tabular}{|c|r|}
\hline Activity & Station Tank BOG FSME (g/kg fuel) \\
\hline Idle & 1.0 \\
\hline City & 1.0 \\
\hline Arterial & 1.0 \\
\hline Highway & 1.0 \\
\hline
\end{tabular}

The annual methane emissions from the station tank BOG were calculated by the station tank BOG methane emissions in fuel specific units and the total fuel consumption for each activity. Results from each activity were summed to get the total station tank BOG emissions for each vehicle type. The HPDI engine OTR tractor city activity was used as an example. The following equation was used to calculate the annual methane emissions from the station tank BOG:

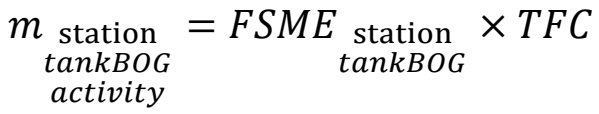

$$
\begin{aligned}
& m \underset{\substack{\text { tankBOG } \\
\text { HPDIOTR,city }}}{\text { station }}=1.0 \times 119,185,517=119,185,517 \mathrm{~g}
\end{aligned}
$$

Table 68 shows the example calculations from Equation 5.25 for each activity from HPDI engine OTR tractors with the medium population, medium HPDI penetration, stasis emissions and fuel consumption scenarios. 
Table 68: Annual Methane Emissions from Station Tank BOG of HPDI OTR Tractors for Stasis Scenario

\begin{tabular}{|c|r|}
\hline Activity & Station Tank BOG Annual Methane Emissions (g) \\
\hline Idle & $394,007,896$ \\
\hline City & $119,185,517$ \\
\hline Arterial & $627,972,812$ \\
\hline Highway & $8,197,929,368$ \\
\hline $\begin{array}{c}\text { Total HPDI OTR Tractor } \\
\text { Station Tank BOG }\end{array}$ & $9,339,095,594$ \\
\hline
\end{tabular}

The fuel specific bulk fuel delivery methane emissions for all activities were determined from a percent of fuel converted to a FSME (factor of 1000 converting percent of fuel or $\mathrm{kg}$ emissions $/ \mathrm{kg}$ fuel consumed to $\mathrm{g}$ emissions $/ \mathrm{kg}$ fuel consumed), indirectly based on the amount of fuel consumed per year. The HPDI engine OTR tractor city activity was used as an example. The following equation was used to calculate the FSME from bulk fuel delivery:

$$
\begin{aligned}
& f \text { sme }_{\text {delivery }}=\frac{P O F_{\text {delivery }} \times T F C \times 1000}{T F C}=P O F_{\text {delivery }} \times 1000 \\
& f \text { Stivity } \\
& \begin{array}{c}
\text { delivery } \\
\text { HPDIOTR,city }
\end{array}
\end{aligned}
$$

Table 69 shows the example calculations from Equation 5.26 for each activity from HPDI engine OTR tractors with the stasis emissions and fuel consumption scenarios.

Table 69: FSME from Station Tank Bulk Fuel Delivery of HPDI OTR Tractors for Stasis Scenario

\begin{tabular}{|c|r|}
\hline Activity & Delivery FSME (g/kg fuel) \\
\hline Idle & 1.28 \\
\hline City & 1.28 \\
\hline Arterial & 1.28 \\
\hline Highway & 1.28 \\
\hline
\end{tabular}

The annual methane emissions from the station tank bulk fuel delivery were calculated by the station tank bulk fuel delivery methane emissions in fuel specific units and the total fuel consumption for each activity. Results from each activity were summed to get the total station tank bulk fuel delivery emissions for each vehicle type. The HPDI engine OTR tractor city activity was used as an example. The following equation was used to calculate the annual methane emissions from the station tank bulk fuel delivery:

$$
\begin{aligned}
& \begin{array}{c}
m_{\text {delivery }} \\
\text { activity }
\end{array}=F S M E_{\text {delivery }}^{\text {activity }} \times T F C \\
& m \underset{\text { HPDIOTR,city }}{\text { delivery }}=1.28 \times 119,185,517=152,557,462 \mathrm{~g}
\end{aligned}
$$

Table 70 shows the example calculations from Equation 5.27 for each activity from HPDI engine OTR tractors with the medium population, medium HPDI penetration, stasis emissions and fuel consumption scenarios. 
Table 70: Annual Methane Emissions from Station Tank Bulk Fuel Delivery of HPDI OTR Tractors for Stasis Scenario

\begin{tabular}{|c|r|}
\hline Activity & Delivery Annual Methane Emissions (g) \\
\hline Idle & $504,330,107$ \\
\hline City & $152,557,462$ \\
\hline Arterial & $803,805,200$ \\
\hline Highway & $10,493,349,591$ \\
\hline $\begin{array}{c}\text { Total HPDI OTR Tractor } \\
\text { Delivery Emissions }\end{array}$ & $11,954,042,361$ \\
\hline
\end{tabular}

The fuel specific vehicle manual ventilation prior to refueling methane emissions for all activities were determined from a percent of fuel converted to a FSME (factor of 1000 converting percent of fuel or $\mathrm{kg}$ emissions $/ \mathrm{kg}$ fuel consumed to $\mathrm{g}$ emissions $/ \mathrm{kg}$ fuel consumed), indirectly based on the amount of fuel consumed per year. The HPDI engine OTR tractor was used as an example. The following equation was used to calculate the FSME from manual ventilation prior to refueling:

$$
\begin{aligned}
& f \text { sme } e_{\substack{\text { vehicle } \\
\text { manual } \\
\text { vent }}}=\frac{\begin{array}{c}
P O F_{\text {vehicle }} \times T F C \times 1000 \\
\text { manual } \\
\text { vent }
\end{array}}{T F C}=P O F_{\begin{array}{c}
\text { vehicle } \\
\text { manual } \\
\text { vent }
\end{array}} \times 1000 \\
& \mathrm{fsme}_{\substack{\text { vehicle } \\
\text { vanual } \\
\text { vent } \\
\text { HPDIOTR }}}=0.0025 * 1000=2.5 \mathrm{~g} / \mathrm{kg} \text { fuel }
\end{aligned}
$$

Table 71 shows the example calculations from Equation 5.28 for each activity from HPDI engine OTR tractors with the stasis emissions and fuel consumption scenarios.

Table 71: FSME from Vehicle Manual Ventilation of HPDI OTR Tractors for Stasis Scenario

\begin{tabular}{|c|r|}
\hline Activity & Manual Vent FSME (g/kg fuel) \\
\hline Idle & 2.5 \\
\hline City & 2.5 \\
\hline Arterial & 2.5 \\
\hline Highway & 2.5 \\
\hline
\end{tabular}

The annual methane emissions from manual ventilation prior to refueling were calculated by the manual ventilation prior to refueling methane emissions in fuel specific units and the total fuel consumption for each activity. Results from each activity were summed to get the total manual ventilation prior to refueling emissions for each vehicle type. The HPDI engine OTR tractor city activity was used as an example. The following equation was used to calculate the annual methane emissions from manual ventilation prior to refueling: 


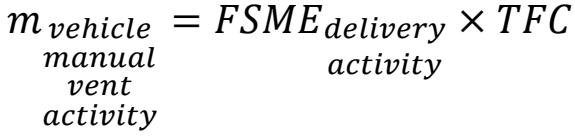

$$
\begin{aligned}
& m \underset{\begin{array}{c}
\text { vehicle } \\
\text { venual } \\
\text { vent } \\
\text { HPDIOTR,city }
\end{array}}{\text {. }}=2.5 \times 119,185,517=297,963,793 \mathrm{~g}
\end{aligned}
$$

Table 72 shows the example calculations from Equation 5.29 for each activity from HPDI engine OTR tractors with the medium population, medium HPDI penetration, stasis emissions and fuel consumption scenarios.

Table 72: Annual Methane Emissions from Vehicle Manual Ventilation HPDI OTR Tractors for Stasis Scenario

\begin{tabular}{|c|r|}
\hline Activity & Manual Vent Annual Methane Emissions (g) \\
\hline Idle & $985,019,741$ \\
\hline City & $297,963,793$ \\
\hline Arterial & $1,569,932,031$ \\
\hline Highway & $20,494,823,420$ \\
\hline $\begin{array}{c}\text { Total HPDI OTR Tractor } \\
\text { Station Tank BOG }\end{array}$ & $23,347,738,985$ \\
\hline
\end{tabular}

Inserting the HPDI engine OTR tractor results from Equation 5.20, Equation 5.22, Equation 5.25, Equation 5.27, and Equation 5.29 into Equation 5.6 yields the following example calculation for HPDI engine OTR tractor LNG station emissions:

$$
\begin{aligned}
\underset{\text { HPDIOTR }}{m_{\text {LNGstation }}} & =1,067,479,920+11,296,452+9,339,095,594 \\
& +11,954,042,361+23,347,738,985 \\
& =45,719,653,312 g
\end{aligned}
$$

Table 73 shows the example calculations from Equation 5.6 for each LNG vehicle type with the medium population, medium HPDI penetration, stasis emissions and fuel consumption scenarios.

Table 73: Annual Methane Emissions from LNG Stations of All LNG Vehicle Types for Stasis Scenario

\begin{tabular}{|c|r|}
\hline Vehicle & LNG Station Annual Methane Emissions (g) \\
\hline 9L SI OTR Tractor & $13,618,972,692$ \\
\hline 12L SI OTR Tractor & $15,401,804,643$ \\
\hline 15L HPDI OTR Tractor & $45,719,653,312$ \\
\hline
\end{tabular}

Inserting the transit bus results from Equation 5.20, Equation 5.22, and Equation 5.23 into Equation 5.5 yields the following example calculation for transit bus CNG station emissions:

$$
\underset{\text { transitbus }}{m_{\text {CNGstion }}}=35,479,080+117,354,825+808,053,473=960,887,378 g
$$


Table 74 shows the example calculations from Equation 5.5 for each CNG vehicle type with the medium population, medium HPDI penetration, stasis emissions and fuel consumption scenarios.

Table 74: Annual Methane Emissions from CNG Stations of All CNG Vehicle Types for Stasis Scenario

\begin{tabular}{|c|r|}
\hline Vehicle & CNG Station Annual Methane Emissions (g) \\
\hline Transit Bus & $960,887,378$ \\
\hline Refuse Truck & $2,856,266,920$ \\
\hline 9L SI OTR Tractor & $7,419,494,828$ \\
\hline 12L SI OTR Tractor & $5,357,886,017$ \\
\hline
\end{tabular}

Inserting the HPDI engine OTR tractor results from Equation 5.10 (non-idle), Equation 5.11 (idle), Equation 5.16 (non-idle), Equation 5.17 (idle), and Equation 5.19 into Equation 5.4 yields the following example calculation for LNG HPDI engine OTR tractor vehicle emissions:

$$
\begin{aligned}
m_{\text {LNGHPDIvehicle }} & =47,423,686,662+48,439,964,237 \\
& +9,339,095,594=105,202,746,494 \mathrm{~g}
\end{aligned}
$$

Inserting the 12L SI OTR tractor results from Equation 5.10 (non-idle), Equation 5.11 (idle), Equation 5.13 (non-idle), Equation 5.14 (idle), and Equation 5.19 into Equation 5.3 yields the following example calculation for LNG SI OTR tractor vehicle emissions:

$$
\begin{aligned}
m_{\text {LNGSIvehicle }}^{m_{\text {12LIOTR }}} & =15,367,195,457+37,525,746,354 \\
& +6,518,603,709=59,411,545,520 \mathrm{~g}
\end{aligned}
$$

Table 75 shows the example calculations from Equation 5.3 for each LNG SI engine vehicle type with the medium population, medium HPDI penetration, stasis emissions and fuel consumption scenarios.

Table 75: Annual Methane Emissions from LNG SI Vehicles of All LNG SI Vehicle Types for Stasis Scenario

\begin{tabular}{|c|r|}
\hline Vehicle & LNG SI Vehicle Annual Methane Emissions (g) \\
\hline 9L SI OTR Tractor & $71,072,413,258$ \\
\hline 12L SI OTR Tractor & $59,411,545,520$ \\
\hline
\end{tabular}

Inserting the transit bus results from Equation 5.10 (non-idle), Equation 5.11 (idle), Equation 5.13 (non-idle), and Equation 5.14 (idle) into Equation 5.2 yields the following example calculation for transit bus vehicle emissions:

$$
\begin{aligned}
m_{\text {CNGvehicle }}^{m_{\text {transitbus }}} & =9,085,715,231+9,409,400,207 \\
& =18,495,115,438 \mathrm{~g}
\end{aligned}
$$

Table 76 shows the example calculations from Equation 5.2 for each CNG vehicle type with the medium population, medium HPDI penetration, stasis emissions and fuel consumption scenarios. 
Table 76: Annual Methane Emissions from CNG Vehicles of All CNG Vehicle Types for Stasis Scenario

\begin{tabular}{|c|r|}
\hline Vehicle & CNG Vehicle Annual Methane Emissions (g) \\
\hline Transit Bus & $18,495,115,438$ \\
\hline Refuse Truck & $35,517,180,400$ \\
\hline 9L SI OTR Tractor & $98,216,546,470$ \\
\hline 12L SI OTR Tractor & $52,892,941,811$ \\
\hline
\end{tabular}

Inserting the results from all vehicles in Equation 5.2 (CNG vehicle), Equation 5.3 (LNG SI engine vehicle), Equation 5.4 (LNG HPDI engine vehicle), Equation 5.5 (CNG station), and Equation 5.6 (LNG station) into Equation 5.1 yields the following example calculation for overall transit bus methane emissions:

$$
m_{\text {total }}=18,495,115,438+960,887,378=19,456,002,816 g
$$

Table 77 shows the example calculations from Equation 5.1 for each vehicle type with the medium population, medium HPDI penetration, stasis emissions and fuel consumption scenarios.

Table 77: Annual Methane Emissions from All Vehicles of All Vehicle Types for Stasis Scenario

\begin{tabular}{|c|c|r|}
\hline Fuel Type & Vehicle Type & $\begin{array}{c}\text { Vehicle Annual } \\
\text { Methane Emissions (g) }\end{array}$ \\
\hline \multirow{4}{*}{ CNG } & Transit Bus & $19,456,002,816$ \\
\cline { 2 - 3 } & Refuse Truck & $38,373,447,320$ \\
\cline { 2 - 3 } & 9L SI OTR Tractor & $105,636,041,298$ \\
\cline { 2 - 3 } & 12L SI OTR Tractor & $58,250,827,828$ \\
\hline \multirow{3}{*}{ LNG } & 9L SI OTR Tractor & $84,691,385,950$ \\
\cline { 2 - 3 } & 12L SI OTR Tractor & $74,813,350,162$ \\
\cline { 2 - 3 } & 15L HPDI OTR Tractor & $150,922,399,806$ \\
\hline Total & N/A & $532,143,455,180$ \\
\hline
\end{tabular}

Error Check of the Estimation Model Calculations - 9 Liter OTR Tractor

The 9 liter OTR tractor was used as an example to check the calculations of the estimation model. This vehicle was chosen because both fuel types were used for this type of vehicle. The tailpipe emissions, crankcase emissions, and fuel consumption were the same for both fuel types. However the CNG and LNG 9 liter OTR tractors had differences between the population, station emissions due to the difference in fuel type, and the presence of vehicle tank BOG for the LNG vehicle. The model needed to reflect these differences as well as have the same input and output for FSME.

Table 78 shows the tailpipe and crankcase emissions input to the model. These were calculated for each vehicle type by averaging the experimental data of each measured vehicle, weighted equally. The CNG and LNG 9L OTR tractors had the same FSME for each respective activity. 
Table 78: Vehicle FSME Input for CNG and LNG 9 Liter OTR Tractors by Source and Activity

\begin{tabular}{|c|r|r|}
\hline \multicolumn{3}{|c|}{ FSME (g/kg fuel) Input } \\
\hline & $\begin{array}{c}\text { Tailpipe } \\
\text { Emissions }\end{array}$ & $\begin{array}{c}\text { Crankcase } \\
\text { Emissions }\end{array}$ \\
\hline CNG Short Haul OTR Tractor SI 9L Idle Activity & 2.32 & 18.46 \\
\hline CNG Short Haul OTR Tractor SI 9L City Activity & 10.02 & 9.97 \\
\hline CNG Short Haul OTR Tractor SI 9L Arterial Activity & 5.61 & 6.25 \\
\hline CNG Short Haul OTR Tractor SI 9L Highway Activity & 4.23 & 4.91 \\
\hline CNG Short Haul OTR Tractor SI 9L Total & N.A. & N.A. \\
\hline LNG Short Haul OTR Tractor SI 9L Idle Activity & 2.32 & 18.46 \\
\hline LNG Short Haul OTR Tractor SI 9L City Activity & 10.02 & 9.97 \\
\hline LNG Short Haul OTR Tractor SI 9L Arterial Activity & 5.61 & 6.25 \\
\hline LNG Short Haul OTR Tractor SI 9L Highway Activity & 4.23 & 4.91 \\
\hline LNG Short Haul OTR Tractor SI 9L Total & N.A. & N.A. \\
\hline
\end{tabular}

The annual methane emissions were calculated by the estimation model with control scenarios (medium population, medium emissions and fuel consumption, and medium HPDI penetration). Table 79 shows the annual emissions from each source for the 9L CNG and LNG OTR tractors. The CNG tractors had higher vehicle emissions due to a higher population. The LNG tractors had higher station emissions, but not high enough to compensate for a lower population of vehicles.

Table 79: Annual Methane Emissions from each Source For CNG and LNG 9L OTR Tractors

\begin{tabular}{|c|r|r|}
\hline \multicolumn{3}{|c|}{ Annual Methane (g/year) } \\
\hline Source & 9L CNG OTR Tractor & 9L LNG OTR Tractor \\
\hline Tail-Pipe & $39,874,688,369$ & $\mathbf{2 6 , 5 8 3 , 1 2 5 , 5 7 9}$ \\
\hline Crankcase & $58,341,858,101$ & $38,894,572,068$ \\
\hline Vehicle Tank BOG & 0 & $5,594,715,612$ \\
\hline Station Continuous & $\mathbf{8 6 4 , 1 7 8 , 5 7 8}$ & $9,037,162$ \\
\hline Fueling Nozzle & $\mathbf{2 6 1 , 2 6 1 , 1 8 7}$ & $\mathbf{8 5 3 , 9 8 3 , 9 3 6}$ \\
\hline Compressor & $6,294,055,063$ & 0 \\
\hline Station Tank BOG & 0 & $5,594,715,612$ \\
\hline Delivery & 0 & $\mathbf{7 , 1 6 1 , 2 3 5 , 9 8 3}$ \\
\hline Vehicle Manual Venting & 0 & $\mathbf{1 3 , 9 8 6 , 7 8 9 , 0 2 9}$ \\
\hline Vehicle & $\mathbf{9 8 , 2 1 6 , 5 4 6 , 4 7 0}$ & $\mathbf{7 1 , 0 7 2 , 4 1 3 , 2 5 8}$ \\
\hline Station & $\mathbf{7 , 4 1 9 , 4 9 4 , 8 2 8}$ & $\mathbf{2 7 , 6 0 5 , 7 6 1 , 7 2 1}$ \\
\hline Total & $\mathbf{1 0 5 , 6 3 6 , 0 4 1 , 2 9 8}$ & $\mathbf{9 8 , 6 7 8 , 1 7 4 , 9 7 9}$ \\
\hline
\end{tabular}

To show details of the calculations, vehicle emissions were analyzed by source. Table 80 shows the annual methane emissions output for CNG and LNG 9 liter OTR tractors. CNG 9 liter OTR tractors had higher emissions due to a higher population $(60 \%$ of the total short haul NG OTR tractors were CNG and $40 \%$ of the total short haul NG OTR tractors were LNG). The tailpipe and crankcase emissions were proportional to the population for each respective activity (CNG 
emissions are $60 \%$ of the total emissions for each activity). The LNG 9L OTR tractor also had vehicle fuel tank BOG. The total emissions for each source were the same as Table 79.

Table 80: Annual Methane Vehicle Emissions Output for CNG and LNG 9 Liter OTR Tractors by Source and Activity

\begin{tabular}{|c|r|r|r|r|}
\hline \multicolumn{7}{|c|}{ Annual Methane Emissions (g/year) } \\
\hline & Tailpipe Emissions & Crankcase Emissions & Vehicle Tank BOG & \multicolumn{1}{|c|}{ Total } \\
\hline CNG Short Haul OTR Tractor SI 9L Idle Activity & $1,958,408,070$ & $15,582,850,415$ & 0 & $17,541,258,485$ \\
\hline CNG Short Haul OTR Tractor SI 9L City Activity & $2,072,640,307$ & $2,062,297,790$ & 0 & $4,134,938,097$ \\
\hline CNG Short Haul OTR Tractor SI 9L Arterial Activity & $19,475,905,662$ & $21,697,755,863$ & 0 & $41,173,661,525$ \\
\hline CNG Short Haul OTR Tractor SI 9L Highway Activity & $16,367,734,330$ & $18,998,954,033$ & 0 & $35,366,688,364$ \\
\hline CNG Short Haul OTR Tractor SI 9L Total & $\mathbf{3 9 , 8 7 4 , 6 8 8 , 3 6 9}$ & $\mathbf{5 8 , 3 4 1 , 8 5 8 , 1 0 1}$ & $\mathbf{0}$ & $\mathbf{9 8 , 2 1 6 , 5 4 6 , 4 7 0}$ \\
\hline LNG Short Haul OTR Tractor SI 9L Idle Activity & $1,305,605,380$ & $10,388,566,944$ & $562,760,940$ & $12,256,933,263$ \\
\hline LNG Short Haul OTR Tractor SI 9L City Activity & $1,381,760,204$ & $\mathbf{1 , 3 7 4 , 8 6 5 , 1 9 3}$ & $137,900,220$ & $2,894,525,618$ \\
\hline LNG Short Haul OTR Tractor SI 9L Arterial Activity & $12,983,937,108$ & $14,465,170,575$ & $2,314,427,292$ & $\mathbf{2 9 , 7 6 3 , 5 3 4 , 9 7 5}$ \\
\hline LNG Short Haul OTR Tractor SI 9L Highway Activity & $10,911,822,887$ & $12,665,969,356$ & $2,579,627,160$ & $26,157,419,402$ \\
\hline LNG Short Haul OTR Tractor SI 9L Total & $\mathbf{2 6 , 5 8 3 , 1 2 5 , 5 7 9}$ & $\mathbf{3 8 , 8 9 4 , 5 7 2 , 0 6 8}$ & $\mathbf{5 , 5 9 4 , 7 1 5 , 6 1 2}$ & $\mathbf{7 1 , 0 7 2 , 4 1 3 , 2 5 8}$ \\
\hline
\end{tabular}

Table 81 shows the annual fuel consumption for CNG and LNG 9 liter OTR tractors. The fuel consumption was also proportional to the vehicle population ( $60 \%$ of the fuel was consumed by the CNG 9L OTR tractors for each respective activity).

Table 81: Annual Fuel Consumption Output for CNG and LNG 9 Liter OTR Tractors by Source and Activity

\begin{tabular}{|c|r|}
\hline \multicolumn{2}{|c|}{ Annual Fuel Consumption (kg/year) } \\
\hline CNG Short Haul OTR Tractor SI 9L Idle Activity & $\mathbf{8 4 4 , 1 4 1 , 4 0 9}$ \\
\hline CNG Short Haul OTR Tractor SI 9L City Activity & $\mathbf{2 0 6 , 8 5 0 , 3 3 0}$ \\
\hline CNG Short Haul OTR Tractor SI 9L Arterial Activity & $3,471,640,938$ \\
\hline CNG Short Haul OTR Tractor SI 9L Highway Activity & $3,869,440,740$ \\
\hline CNG Short Haul OTR Tractor SI 9L Total & $\mathbf{8 , 3 9 2 , 0 7 3 , 4 1 7}$ \\
\hline LNG Short Haul OTR Tractor SI 9L Idle Activity & $562,760,940$ \\
\hline LNG Short Haul OTR Tractor SI 9L City Activity & $137,900,220$ \\
\hline LNG Short Haul OTR Tractor SI 9L Arterial Activity & $\mathbf{2 , 3 1 4 , 4 2 7 , 2 9 2}$ \\
\hline LNG Short Haul OTR Tractor SI 9L Highway Activity & $\mathbf{2 , 5 7 9 , 6 2 7 , 1 6 0}$ \\
\hline LNG Short Haul OTR Tractor SI 9L Total & $\mathbf{5 , 5 9 4 , 7 1 5 , 6 1 2}$ \\
\hline
\end{tabular}

Table 82 shows the FSME for CNG and LNG 9L OTR tractors. The FSME were determined by dividing the annual methane emissions by the annual fuel consumption, for each respective activity. On a FSME basis, the tailpipe and crankcase emissions were the same for LNG and CNG 9L OTR tractors, for each respective activity. The crankcase and tailpipe output emissions were the same as the input emissions, shown in Table 78. 
Table 82: Vehicle FSME Output for CNG and LNG 9 Liter OTR Tractors by Source and Activity

\begin{tabular}{|c|c|c|c|c|}
\hline \multicolumn{5}{|c|}{ FSME Output } \\
\hline & Tailpipe Emissions & Crankcase Emissions & Vehicle Tank BOG & Total \\
\hline & \multicolumn{4}{|c|}{$\mathrm{g} / \mathrm{kg}$ fuel } \\
\hline CNG Short Haul OTR Tractor SI 9L Idle Activity & 2.32 & 18.46 & 0.00 & 20.78 \\
\hline CNG Short Haul OTR Tractor SI 9L City Activity & 10.02 & 9.97 & 0.00 & 19.99 \\
\hline CNG Short Haul OTR Tractor SI 9L Arterial Activity & 5.61 & 6.25 & 0.00 & 11.86 \\
\hline CNG Short Haul OTR Tractor SI 9L Highway Activity & 4.23 & 4.91 & 0.00 & 9.14 \\
\hline CNG Short Haul OTR Tractor SI 9L Total & 4.75 & 6.95 & 0.00 & 11.70 \\
\hline LNG Short Haul OTR Tractor SI 9L Idle Activity & 2.32 & 18.46 & 1.00 & 21.78 \\
\hline LNG Short Haul OTR Tractor SI 9L City Activity & 10.02 & 9.97 & 1.00 & 20.99 \\
\hline LNG Short Haul OTR Tractor SI 9L Arterial Activity & 5.61 & 6.25 & 1.00 & 12.86 \\
\hline LNG Short Haul OTR Tractor SI 9L Highway Activity & 4.23 & 4.91 & 1.00 & 10.14 \\
\hline LNG Short Haul OTR Tractor SI 9L Total & 4.75 & 6.95 & 1.00 & 12.70 \\
\hline
\end{tabular}

Table 83 shows the tailpipe and crankcase emissions input to the model and output of the model. The inputs and outputs were the same for each respective activity. The same results before and after calculations provides confidence that the model developed was able to correctly calculate the methane emissions from heavy-duty natural gas vehicle fleets with the known population and operation activities noted as scenarios. The FSME were converted to annual methane emissions. The annual emissions and total fuel consumption from each vehicle type were added together. The FSME were calculated from the annual emissions and fuel consumption. The resulting output was the same as the FSME input. Therefore the model performs as expected.

Table 83: Vehicle FSME Input and Output for CNG and LNG 9 Liter OTR Tractors by Source and Activity

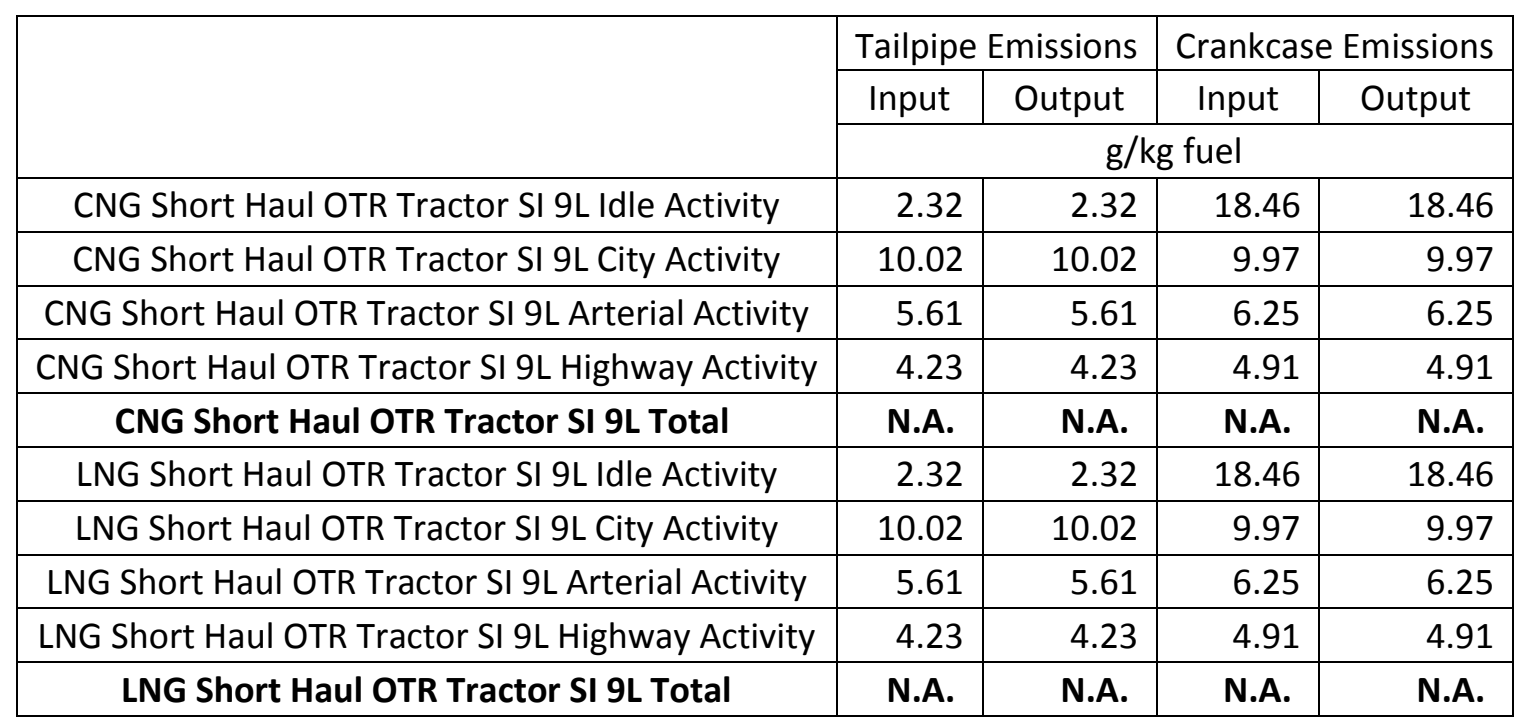

\section{Output}

\section{Table Data}

The emissions distributed by the station will be correlated to the amount of fuel used by the vehicles. For example, the emissions from the refueling nozzle will be correlated to the number of refueling events for each vehicle at the station. The comprehensive methane emissions will be reported in time specific units (grams of methane emissions per year) and fuel specific units (grams of methane emissions per $\mathrm{kg}$ of fuel consumed). The vehicle emissions were also 
reported in distance specific units (grams of methane emissions per mile). For example, the medium population, medium HPDI penetration, and stasis emissions and fuel consumption scenarios are shown in Table 84 and Table 85 for vehicle (by vehicle type and by activity, respectively), Table 86 for station, and Table 87 for overall (vehicle + station) emissions. Combined OTR tractor emissions make up $89.1 \%$ of total annual emissions. The vehicles (0.44MMT) contribute more than the stations (0.09MMT) to the overall emissions $(0.53 \mathrm{MMT})$. The FSME were also higher for the vehicle $(10.94 \mathrm{~g} / \mathrm{kg}$ fuel $)$ than the station $(2.27 \mathrm{~g} / \mathrm{kg}$ fuel $)$. It should be noted that this data is not reflective of current emissions levels.

Table 84: Vehicle Emissions Data Results Vehicle Type

\begin{tabular}{|c|c|c|c|c|}
\hline Vehicle Type & $\begin{array}{c}\text { Annual Methane } \\
\text { Emissions }(\mathrm{g})\end{array}$ & $\begin{array}{c}\text { Total Fuel } \\
\text { Consumed (kg) }\end{array}$ & $\begin{array}{c}\text { FSME } \\
(\mathrm{g} / \mathrm{kg} \text { fuel) }\end{array}$ & RME (\%) \\
\hline Transit Buses & $18,495,115,438$ & $1,077,404,630$ & 17.17 & $1.72 \%$ \\
\hline Refuse Trucks & $35,517,180,400$ & $2,851,628,000$ & 12.46 & $1.25 \%$ \\
\hline 9L OTR Tractors & $169,288,959,728$ & $13,986,789,029$ & 12.10 & $1.21 \%$ \\
\hline 12L OTR Tractors & $112,304,487,330$ & $13,037,207,418$ & 8.61 & $0.86 \%$ \\
\hline 15L HPDI Tractors & $105,202,746,494$ & $9,339,095,594$ & 11.26 & $1.13 \%$ \\
\hline Total & $440,808,489,390$ & $40,292,124,671$ & 10.94 & $1.09 \%$ \\
\hline
\end{tabular}

Table 85: Vehicle Emissions Data Results Activity Type

\begin{tabular}{|c|c|c|c|}
\hline & $\begin{array}{l}\text { Annual Methane } \\
\text { Emissions (g/year) }\end{array}$ & $\begin{array}{l}\text { DSME } \\
\text { (g/mile) }\end{array}$ & $\begin{array}{c}\text { FSME } \\
\left(\mathrm{g} / \mathrm{kg} \mathrm{CH}_{4}\right)\end{array}$ \\
\hline CNG Fuel Bus SI Stoichio 9L TWC Idle Activity & $2,219,715,598$ & - & 16.66 \\
\hline CNG Fuel Bus SI Stoichio 9L TWC City Activity & $1,730,547,504$ & 24.53 & 20.61 \\
\hline CNG Fuel Bus SI Stoichio 9L TWC Arterial Activity & $13,996,256,400$ & 12.58 & 17.00 \\
\hline CNG Fuel Bus SI Stoichio 9L TWC Highway Activity & $548,595,936$ & 7.14 & 14.87 \\
\hline CNG Fuel Refuse Truck SI Stoichio 9L TWC Idle Activity & $8,555,645,280$ & - & 17.29 \\
\hline CNG Fuel Refuse Truck SI Stoichio 9L TWC City Activity & $11,353,992,000$ & 28.92 & 12.05 \\
\hline CNG Fuel Refuse Truck SI Stoichio 9L TWC Arterial Activity & $11,788,629,840$ & 9.33 & 12.78 \\
\hline CNG Fuel Refuse Truck SI Stoichio 9L TWC Highway Activity & $3,818,913,280$ & 4.04 & 7.76 \\
\hline CNG Fuel Short Haul Heavy Duty Truck SI Stoichio 9L TWC Idle Activity & $17,541,258,485$ & - & 20.78 \\
\hline CNG Fuel Short Haul Heavy Duty Truck SI Stoichio 9L TWC City Activity & $4,134,938,097$ & 24.59 & 19.99 \\
\hline CNG Fuel Short Haul Heavy Duty Truck SI Stoichio 9L TWC Arterial Activity & $41,173,661,525$ & 9.37 & 11.86 \\
\hline CNG Fuel Short Haul Heavy Duty Truck SI Stoichio 9L TWC Highway Activity & $35,366,688,364$ & 5.03 & 9.14 \\
\hline LNG Fuel Long Haul Heavy Duty Truck SI Stoichio 12L TWC Idle Activity & $5,499,281,121$ & - & 23.07 \\
\hline LNG Fuel Long Haul Heavy Duty Truck SI Stoichio 12L TWC City Activity & $603,049,608$ & 17.83 & 12.38 \\
\hline LNG Fuel Long Haul Heavy Duty Truck SI Stoichio 12L TWC Arterial Activity & $5,894,207,982$ & 9.71 & 10.79 \\
\hline LNG Fuel Long Haul Heavy Duty Truck SI Stoichio 12L TWC Highway Activity & $47,415,006,809$ & 5.25 & 8.34 \\
\hline LNG Fuel Short Haul Heavy Duty Truck SI Stoichio 9L TWC Idle Activity & $12,256,933,263$ & - & 21.78 \\
\hline LNG Fuel Short Haul Heavy Duty Truck SI Stoichio 9L TWC City Activity & $2,894,525,618$ & 25.82 & 20.99 \\
\hline LNG Fuel Short Haul Heavy Duty Truck SI Stoichio 9L TWC Arterial Activity & $29,763,534,975$ & 10.16 & 12.86 \\
\hline LNG Fuel Short Haul Heavy Duty Truck SI Stoichio 9L TWC Highway Activity & $26,157,419,402$ & 5.58 & 10.14 \\
\hline CNG Fuel Long Haul Heavy Duty Truck SI Stoichio 12L TWC Idle Activity & $5,260,907,427$ & - & 22.07 \\
\hline CNG Fuel Long Haul Heavy Duty Truck SI Stoichio 12L TWC City Activity & $554,338,008$ & 16.39 & 11.38 \\
\hline CNG Fuel Long Haul Heavy Duty Truck SI Stoichio 12L TWC Arterial Activity & $5,347,942,182$ & 8.81 & 9.79 \\
\hline CNG Fuel Long Haul Heavy Duty Truck SI Stoichio 12L TWC Highway Activity & $41,729,754,194$ & 4.62 & 7.34 \\
\hline LNG Fuel Long Haul Heavy Duty Truck HPDI SCR and DPF Idle Activity & $5,965,279,552$ & - & 15.14 \\
\hline LNG Fuel Long Haul Heavy Duty Truck HPDI SCR and DPF City Activity & $3,626,815,289$ & 53.61 & 30.43 \\
\hline LNG Fuel Long Haul Heavy Duty Truck HPDI SCR and DPF Arterial Activity & $11,089,999,867$ & 9.14 & 17.66 \\
\hline LNG Fuel Long Haul Heavy Duty Truck HPDI SCR and DPF Highway Activity & $84,520,651,786$ & 4.68 & 10.31 \\
\hline All Vehicles Total & $440,808,489,390$ & & 10.94 \\
\hline
\end{tabular}


Table 86: Station Emissions Data Results by Station and Activity Type

\begin{tabular}{|l|c|r|}
\hline & $\begin{array}{c}\text { Total Annual Station } \\
\text { Emissions (g/year) }\end{array}$ & $\begin{array}{c}\text { Total Station } \\
\text { FSME }\left(\mathrm{g} / \mathrm{kg} \mathrm{CH}_{4}\right)\end{array}$ \\
\hline CNG Station & $16,594,535,143$ & 0.88 \\
\hline LNG Station & $74,740,430,647$ & 3.48 \\
\hline All Stations Total & $91,334,965,790$ & 2.27 \\
\hline
\end{tabular}

Table 87: Combined (Vehicle + Station) Emissions Data Results

\begin{tabular}{|l|c|c|}
\hline & $\begin{array}{c}\text { Overall Annual Methane } \\
\text { Emissions (g/year) }\end{array}$ & $\begin{array}{c}\text { Overall FSME } \\
\left(\mathrm{g} / \mathrm{kg} \mathrm{CH}_{4}\right)\end{array}$ \\
\hline Total (Vehicle + Station) Emissions & $532,143,455,180$ & 13.21 \\
\hline
\end{tabular}

Table 88 shows the combined emissions by vehicle type. The 15 liter HPDI engine long haul OTR tractor had the highest emissions due to a high vehicle population, dynamic ventilation, and manual ventilation.

Table 88: Combined (Vehicle + Station) Emissions by Vehicle Type

\begin{tabular}{|c|r|r|}
\hline & Annual Emissions (g) & Percent of Emissions (\%) \\
\hline 9L CNG Transit Bus & $19,456,002,816$ & $3.7 \%$ \\
\hline 9L SI CNG Refuse Truck & $38,373,447,320$ & $7.2 \%$ \\
\hline 9L SI CNG Short Haul OTR Tractor & $105,636,041,298$ & $19.9 \%$ \\
\hline 9L SI LNG Short Haul OTR Tractor & $84,691,385,950$ & $15.9 \%$ \\
\hline 12L SI CNG Long Haul OTR Tractor & $58,250,827,828$ & $10.9 \%$ \\
\hline 12L SI LNG Long Haul OTR Tractor & $74,813,350,162$ & $14.1 \%$ \\
\hline 15L HPDI LNG Long Haul OTR Tractor & $150,922,399,806$ & $28.4 \%$ \\
\hline Overall & $532,143,455,180$ & $100.0 \%$ \\
\hline
\end{tabular}

\section{Visual Metrics}

Visual metrics were created to give the user an easier way to compare the sources of emissions. Separate metrics were created for overall emissions and for CNG and LNG fuel to isolate each fuel type. CNG sources do not include delivery emissions, manual tank venting from the stations, or fuel tank BOG from the vehicle or station. LNG sources do not include fugitive compressor emissions. LNG has been split between SI engine and HPDI engine technologies as well. SI engine vehicles have crankcase emissions but no dynamic ventilation or manual ventilation emissions, and HPDI engine vehicles have dynamic ventilation and manual ventilation but no crankcase emissions. The emissions were compared by percentage of each source in pie charts and annual overall emissions and FSME in column charts. For example, Figure 17 and Figure 18 show the annual methane emissions and FSME, respectively, for the medium population, medium HPDI penetration, and stasis emissions and fuel consumption scenarios. The percentage of methane emissions from each source, for the same scenarios, is shown in Figure 19. 


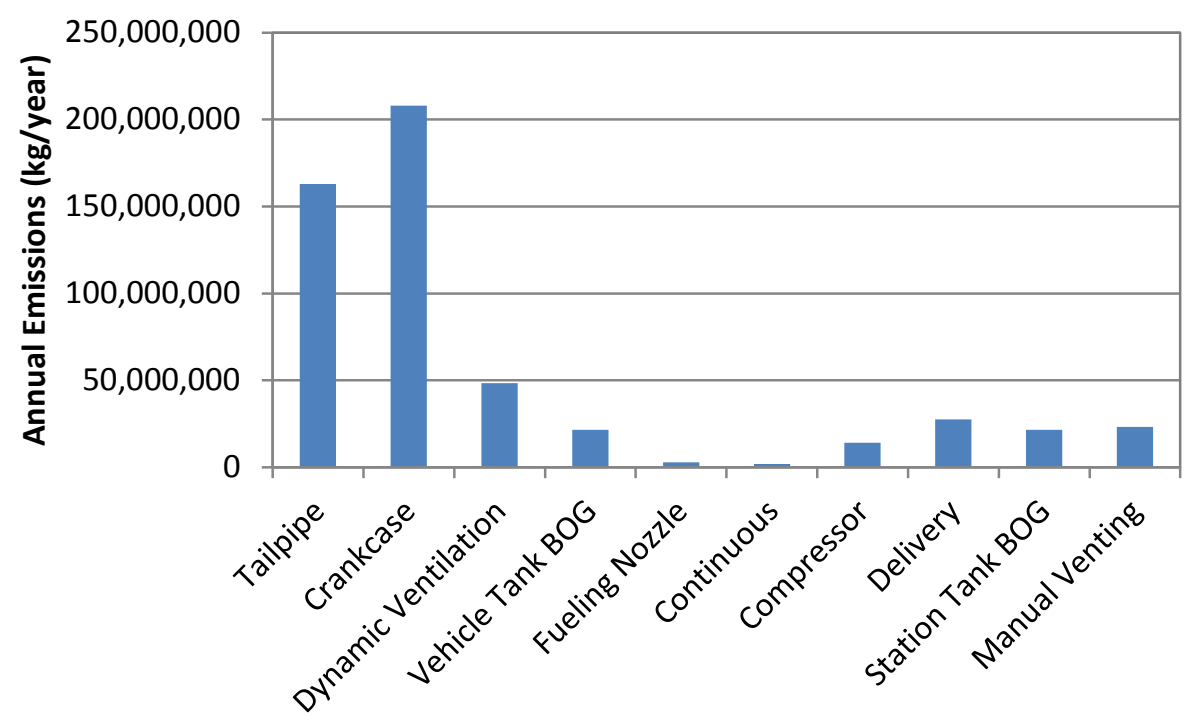

Figure 17: Annual Methane Emissions of Heavy-Duty Natural Gas Vehicles by Source

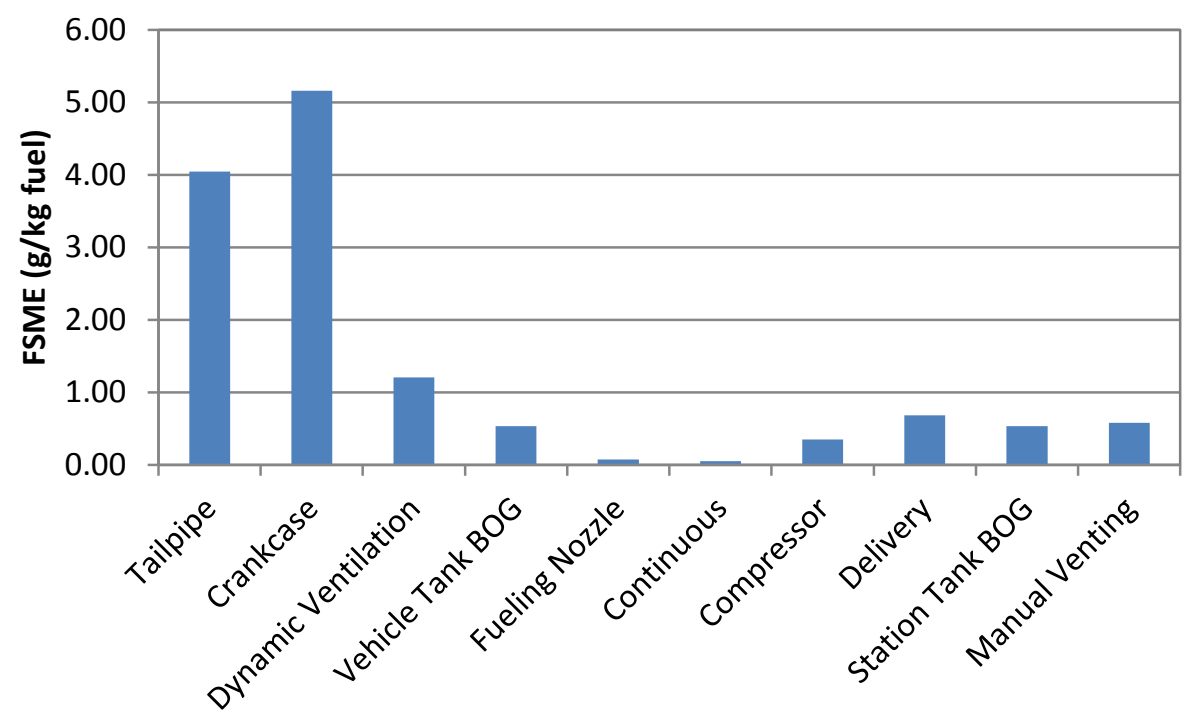

Figure 18: FSME of Heavy-Duty Natural Gas Vehicles by Source 


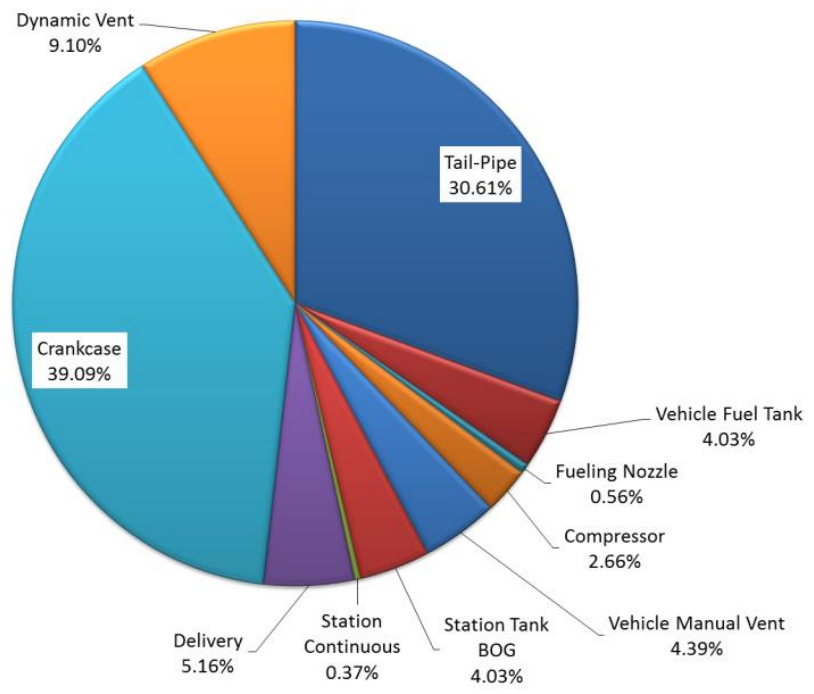

Figure 19: Methane Emissions Sources of Heavy-Duty Natural Gas Vehicles* $($ FSME $=13.21 \mathrm{~g} / \mathrm{kg}$ fuel)

*Note: dynamic vent is due to HPDI engine pressure control and vehicle manual vent is due to operators manually purging pressure in storage tanks for faster refueling at stations

Figure 20 shows the percentage of methane emissions from each type of vehicle for the medium population, medium HPDI penetration, stasis emissions and fuel consumption scenarios for (a) CNG vehicles, including 9 liter SI engine transit buses, 9 liter SI engine refuse trucks, 9 liter SI engine OTR tractors, and 12 liter SI engine OTR tractors; (b) LNG vehicles, including 9 liter SI engine OTR tractors, 12 liter SI engine OTR tractors, and 15 liter HPDI engine OTR tractors. Crankcase emissions were the highest emission sources for each respective fuel type.

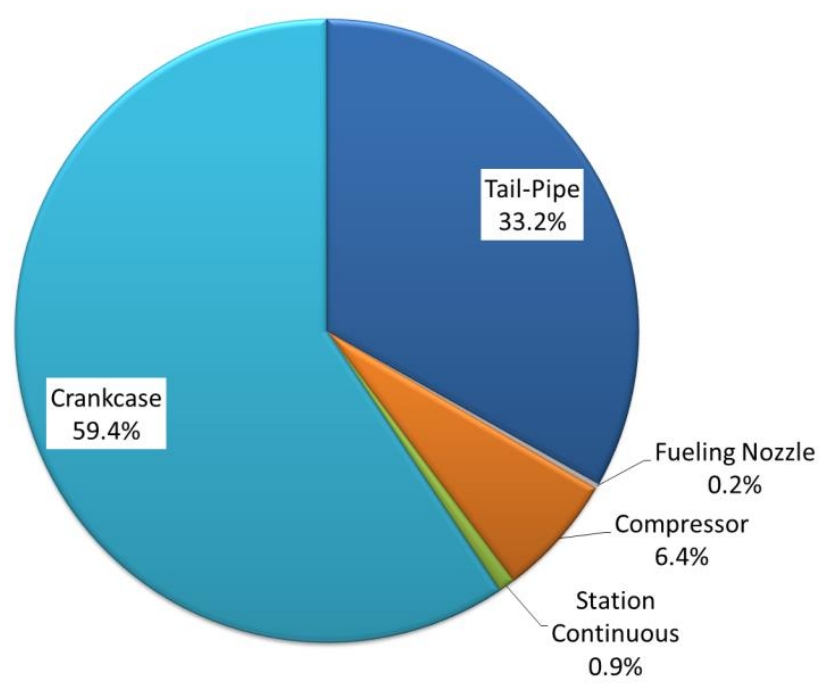

(a) All CNG Vehicles (FSME $=11.77 \mathrm{~g} / \mathrm{kg}$ fuel) 


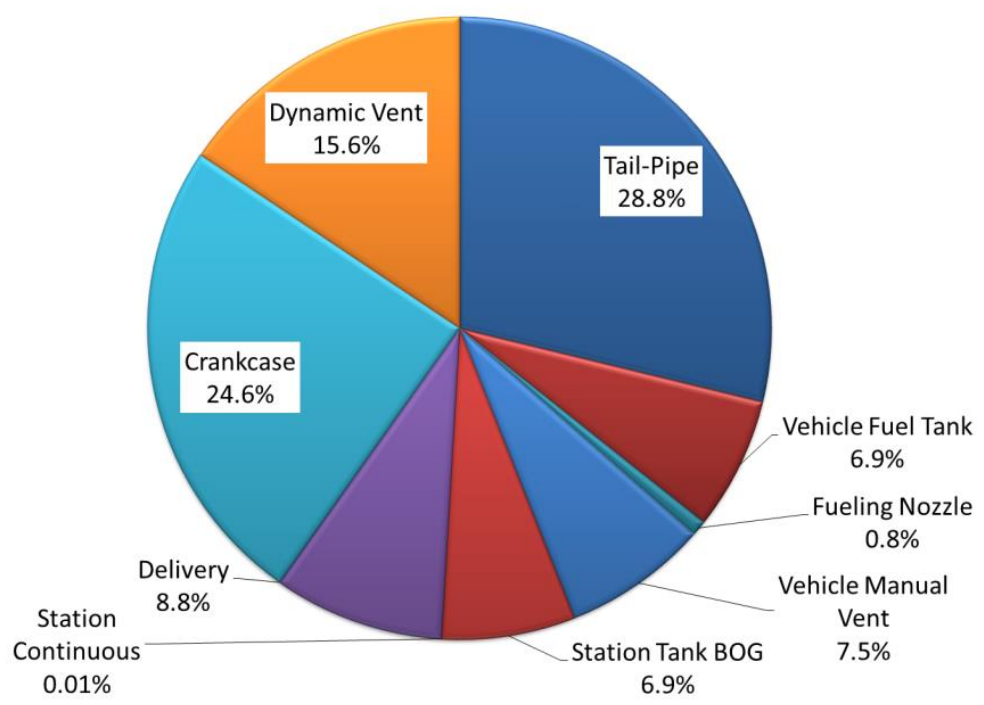

(b) All LNG Vehicles* $($ FSME $=14.47 \mathrm{~g} / \mathrm{kg}$ fuel $)$

Figure 20: Methane Emissions Sources from (a) All CNG Vehicles; (b) All LNG Vehicles*

*Note: dynamic vent is due to HPDI engine pressure control and vehicle manual vent is due to operators manually purging pressure in storage tanks for faster refueling at stations

Figure 21 shows the percentage of methane emissions from each type of vehicles for the medium population, medium HPDI penetration, stasis emissions and fuel consumption scenarios for (a) LNG SI engine OTR tractors, including 9 liter SI engine OTR tractors and 12 liter SI engine OTR tractors; and (b) 15 liter LNG HPDI engine OTR tractor. Crankcase and tailpipe emissions were the highest emission sources for SI engine and HPDI engine OTR tractors, respectively.

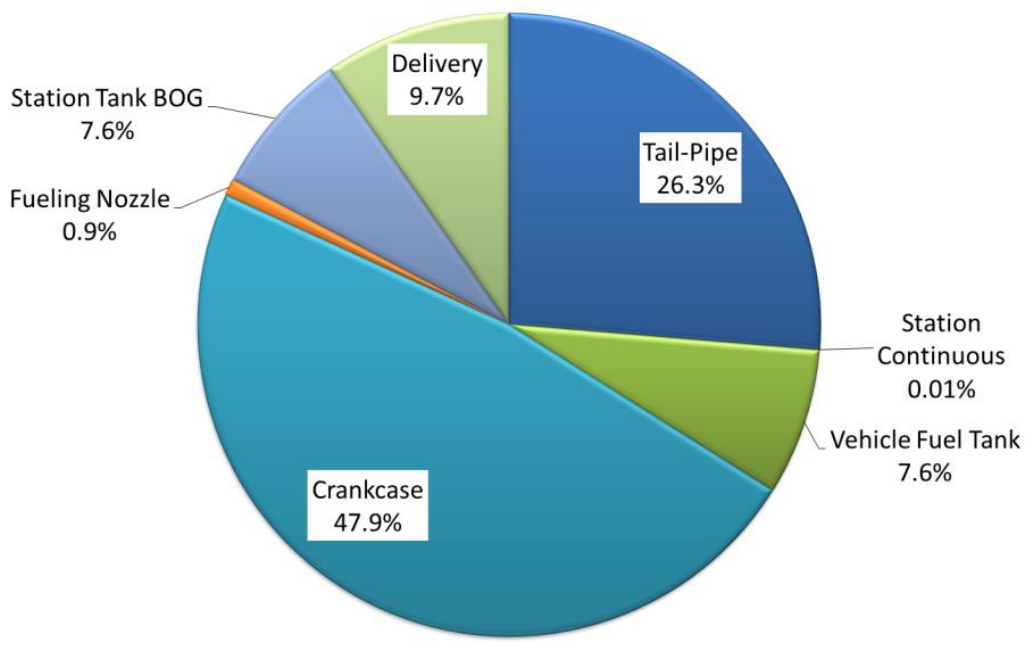

(a) LNG SI OTR Tractors* (FSME $=13.17 \mathrm{~g} / \mathrm{kg}$ fuel $)$ 


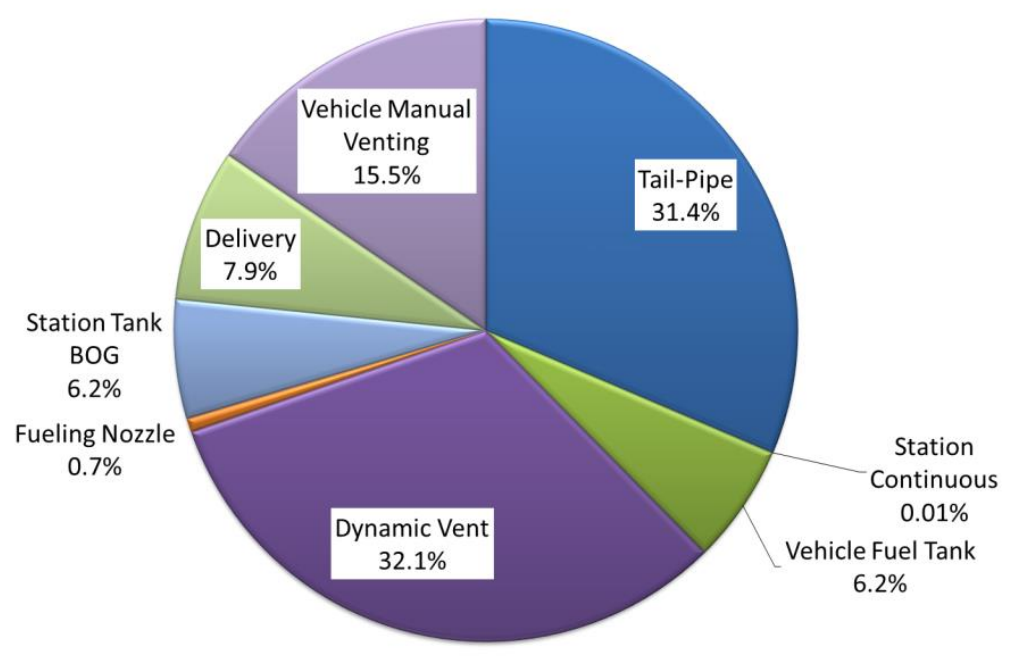

(b) LNG HPDI OTR Tractors* (FSME $=16.16 \mathrm{~g} / \mathrm{kg}$ fuel)

Figure 21: LNG OTR Tractor Methane Emissions Sources from (a) All LNG SI Vehicles; (b) All LNG HPDI Vehicles*

\section{Summary}

The FSME were calculated from the annual emissions and fuel consumption. The resulting output was the same as the FSME input. Therefore there is confidence that the model has no calculation errors. OTR tractors emitted the most emissions due to a higher population. Vehicle emissions $(82.8 \%)$ were higher than station emissions (17.2\%). Crankcase $(39.1 \%)$ and tailpipe (30.6\%) emissions were the highest sources. 15 liter HPDI engine long haul OTR tractors had the highest emissions $(28.4 \%)$. 


\section{Chapter 6 - 2035 Heavy-Duty Natural Gas Sector Methane Emissions Estimated by the Model}

The control set of scenarios analyzed was the medium population, medium HPDI penetration, and medium emissions and fuel consumption scenarios. The first variation analyzed was the emissions and fuel consumption scenarios with the medium population and medium HPDI penetration scenarios held constant. The second variation analyzed was the population scenarios with the HPDI penetration and emissions and fuel consumption scenarios held constant. The third variation analyzed was the HPDI penetration scenarios with the medium population and medium emissions and fuel consumption scenarios held constant. The effect of HPDI dynamic ventilation and manual ventilation, effect of CNG station utilization, and effect of the emissions scenario compared to the fuel consumption scenario were explored in respective case studies.

\section{Methane Emissions Estimated by the Control Scenario}

\section{Table Data Output Results for the Control Scenario}

Table 89 shows the annual methane emissions and percent of total methane for all of the vehicles and stations, classified by sources. The control scenarios were used in this table: medium population scenario; medium HPDI penetration scenario; and medium emissions and fuel consumption scenario. Tailpipe emissions contributed the highest portion of methane emissions $(43.19 \%)$. The stations contributed to $24.52 \%$ of the overall emissions, which is less than the emissions from vehicles $(75.48 \%)$.

Table 89: Methane Emissions from Each Source and Their Contributions (Control Scenarios)

\begin{tabular}{|c|c|r|r|}
\hline \multirow{4}{*}{ Vehicle Emissions } & Emissions Source & $\begin{array}{c}\text { Methane Emissions } \\
(\mathrm{kg} / \text { year })\end{array}$ & $\begin{array}{r}\text { \% of Total } \\
\text { Methane Emissions }\end{array}$ \\
\cline { 2 - 4 } & Tailpipe & $47,141,601$ & $43.19 \%$ \\
\cline { 2 - 4 } & Crankcase & $16,293,261$ & $14.93 \%$ \\
\cline { 2 - 4 } & Dynamic Ventilation & $9,687,993$ & $8.87 \%$ \\
\cline { 2 - 4 } Station Emissions & Vehicle Tank BOG & $9,272,128$ & $8.49 \%$ \\
\cline { 2 - 4 } & Fueling Nozzle & 591,683 & $0.54 \%$ \\
\cline { 2 - 4 } & Continuous & 993,761 & $0.91 \%$ \\
\cline { 2 - 4 } & Compressor & $2,157,955$ & $1.98 \%$ \\
\cline { 2 - 4 } & Delivery & $9,494,659$ & $8.70 \%$ \\
\cline { 2 - 4 } & Station Tank BOG & $1,854,426$ & $1.70 \%$ \\
\hline All Emissions & Manual Venting & $11,673,869$ & $10.69 \%$ \\
\hline
\end{tabular}

Table 90 shows the total fuel consumed for all of the vehicles for the medium population, medium HPDI penetration, and medium emissions and fuel consumption scenarios. Transit buses had the lowest annual methane emissions but the highest FSME, which led to the highest methane emissions to fuel consumption ratio or relative methane emissions (RME). The emissions from OTR tractors were weighted most heavily among the vehicle types $(92.2 \%$ of emissions), due to a higher population. The total FSME for the vehicles were $2.50 \mathrm{~g} / \mathrm{kg}$ fuel. 
Table 90: Total Fuel Consumption and Vehicle Only Methane Emissions for each Vehicle Type for the Control Scenarios

\begin{tabular}{|c|r|r|r|r|c|}
\hline Vehicle Type & $\begin{array}{c}\text { Annual Methane } \\
\text { Emissions (kg) }\end{array}$ & $\begin{array}{c}\text { Percent of } \\
\text { Total Emissions (\%) }\end{array}$ & $\begin{array}{c}\text { Total Fuel } \\
\text { Consumed (kg) }\end{array}$ & $\begin{array}{c}\text { FSME } \\
(\mathrm{g} / \mathrm{kg} \text { fuel) }\end{array}$ & $\begin{array}{c}\text { RME } \\
(\%)\end{array}$ \\
\hline Transit Buses & $3,143,237$ & $3.8 \%$ & $828,038,907$ & 3.80 & $0.38 \%$ \\
\hline Refuse Trucks & $4,530,194$ & $5.5 \%$ & $2,212,945,800$ & 2.05 & $0.20 \%$ \\
\hline 9L OTR Tractors & $27,439,066$ & $33.3 \%$ & $10,701,127,124$ & 2.56 & $0.26 \%$ \\
\hline 12L OTR Tractors & $16,326,654$ & $19.8 \%$ & $9,849,417,672$ & 1.66 & $0.17 \%$ \\
\hline 15L HPDI Tractors & $30,955,831$ & $37.6 \%$ & $9,339,095,594$ & 3.31 & $0.33 \%$ \\
\hline All Vehicles Total & $82,394,982$ & $100.0 \%$ & $32,930,625,097$ & 2.50 & $0.25 \%$ \\
\hline
\end{tabular}

Table 91 shows the total fuel consumed for all of the vehicles for the medium population, medium HPDI penetration, and medium emissions and fuel consumption scenarios. CNG stations had lower annual methane emissions and FSME, which led to lower RME. The emissions from LNG stations were weighted most heavily among the station types (88.5\% of station emissions) despite only a marginally higher fuel output (56.3\% of fuel consumed). This was mostly due to the high manual ventilation (43.9\% of station emissions) and delivery (35.7\% of station emissions) emissions. The total FSME for the stations were $0.81 \mathrm{~g} / \mathrm{kg}$ fuel.

Table 91: Total Fuel Consumption and Station Only Methane Emissions for each Station Type for the Control Scenarios

\begin{tabular}{|c|r|r|c|r|c|}
\hline Station Type & $\begin{array}{c}\text { Annual Methane } \\
\text { Emissions (kg) }\end{array}$ & $\begin{array}{c}\text { Percent of } \\
\text { Total Emissions (\%) }\end{array}$ & $\begin{array}{c}\text { Total Fuel } \\
\text { Consumed (kg) }\end{array}$ & $\begin{array}{c}\text { FSME } \\
(\mathrm{g} / \mathrm{kg} \text { fuel) }\end{array}$ & $\begin{array}{c}\text { RME } \\
(\%)\end{array}$ \\
\hline CNG & $3,239,368$ & $12.1 \%$ & $14,386,369,818$ & 0.23 & $0.02 \%$ \\
\hline LNG & $23,526,985$ & $87.9 \%$ & $18,544,255,280$ & 1.27 & $0.13 \%$ \\
\hline All Stations Total & $26,766,353$ & $100.0 \%$ & $32,930,625,097$ & 0.81 & $0.08 \%$ \\
\hline
\end{tabular}

Table 92 shows the overall (vehicles + stations) methane emissions for the medium population, medium HPDI penetration, and medium emissions and fuel consumption scenarios. The emissions in the table are a summation of Table 90 and Table 91.

Table 92: Total Fuel Consumption and Methane Emissions for each Station Type for the Control Scenarios

\begin{tabular}{|l|c|c|r|c|}
\hline Station Type & $\begin{array}{c}\text { Annual Methane } \\
\text { Emissions }(\mathrm{kg})\end{array}$ & $\begin{array}{c}\text { Total Fuel } \\
\text { Consumed }(\mathrm{kg})\end{array}$ & $\begin{array}{c}\text { FSME } \\
(\mathrm{g} / \mathrm{kg} \text { fuel) }\end{array}$ & $\begin{array}{c}\text { RME } \\
(\%)\end{array}$ \\
\hline All Vehicles and Stations Total & $109,161,335$ & $32,930,625,097$ & 3.31 & $0.33 \%$ \\
\hline
\end{tabular}

Visual Metrics Output Results for the Control Scenario

Figure 22 shows the percentage of the total methane emissions by contributing source for the assumed scenario for all natural gas vehicles. Tailpipe emissions were the largest source of methane (43.19\%). This is consistent with data shown in Table 89. The other vehicle emissions label is a combination of dynamic ventilation and vehicle tank BOG. 


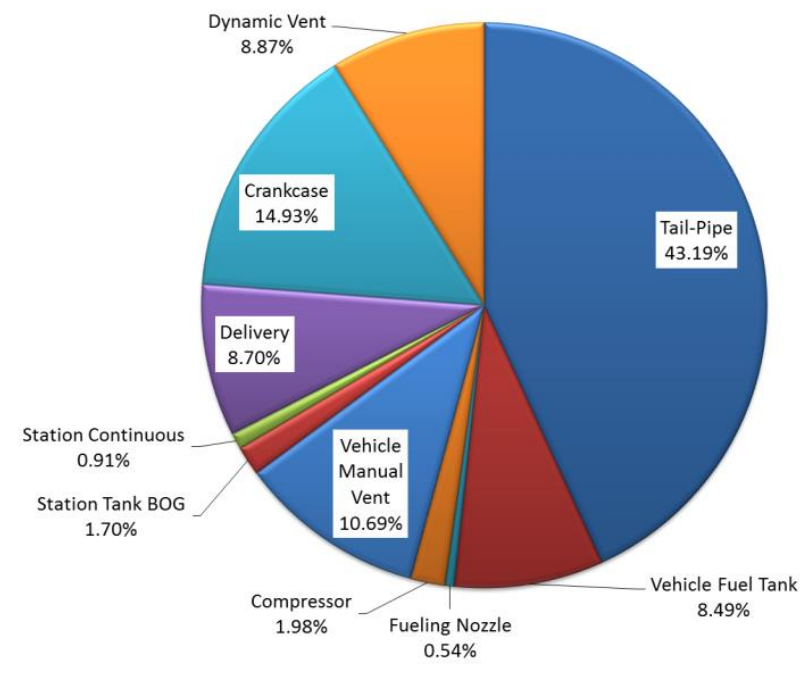

(a) all emission sources* $(\mathrm{FSME}=3.31 \mathrm{~g} / \mathrm{kg}$ fuel $)$

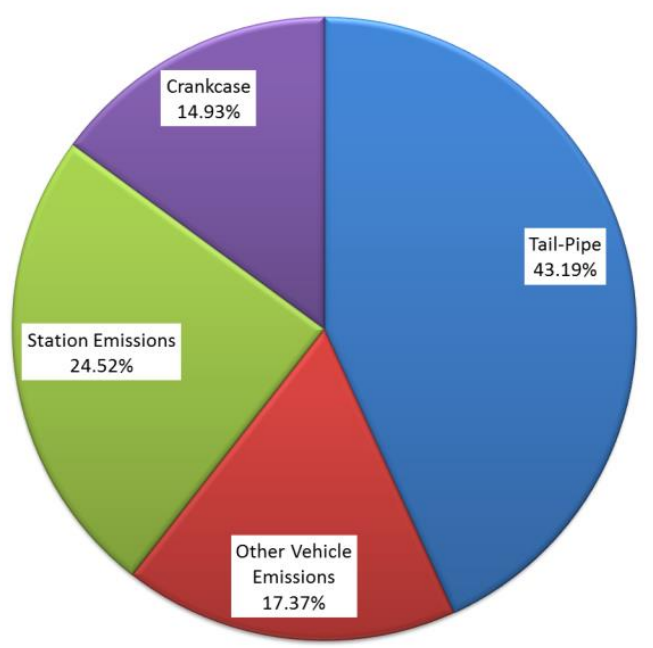

(b) top four emission sources* $(\mathrm{FSME}=3.31 \mathrm{~g} / \mathrm{kg}$ fuel $)$

Figure 22: Methane Emissions Sources (Control Scenarios) Grouped by: (a) All Sources and (b) Top Four Emission Sources

*Note: dynamic vent is due to HPDI engine pressure control and vehicle manual vent is due to operators manually purging pressure in storage tanks for faster refueling at stations

Figure 23 and Figure 24 show the total annual methane emissions and FSME, respectively, for the control scenario by source. This data is reflective of Table 89 and Figure 22. 


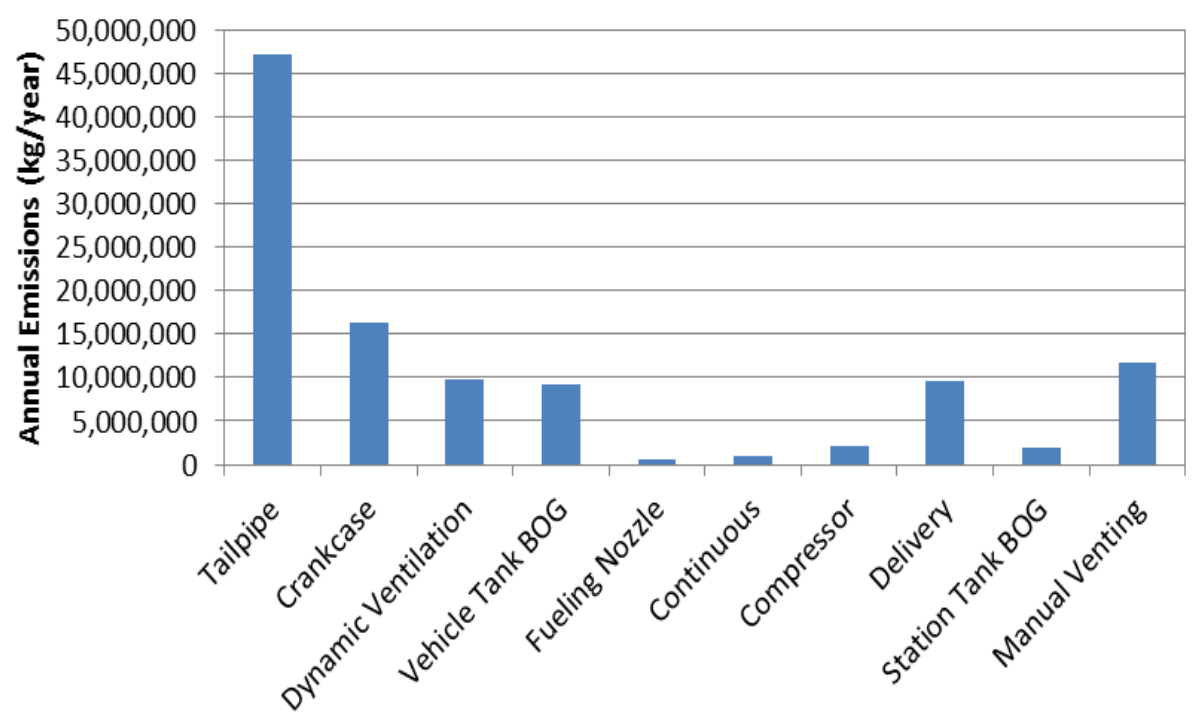

Figure 23: Annual Methane Emissions of Heavy-Duty Natural Gas Vehicles Estimated from the Control Scenarios

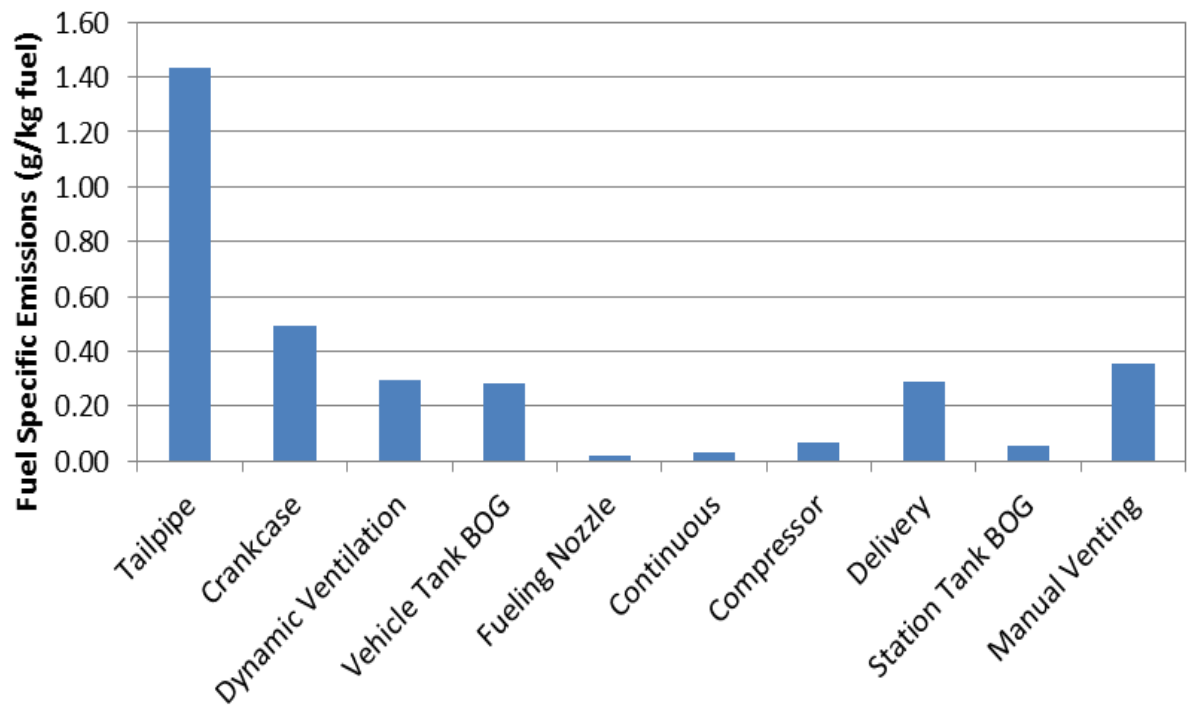

Figure 24: FSME of Heavy-Duty Natural Gas Vehicles Estimated from the Control Scenarios

Figure 25 shows the percentage of methane emissions from each type of vehicles for the medium population, medium HPDI penetration, medium emissions and fuel consumption scenarios for (a) CNG vehicles, including 9 liter SI engine transit buses, 9 liter SI engine refuse trucks, 9 liter SI engine OTR tractors, and 12 liter SI engine OTR tractors; (b) LNG vehicles, including 9 liter SI engine OTR tractors, 12 liter SI engine OTR tractors, and 15 liter HPDI engine OTR tractors. Tailpipe emissions were the highest emission sources for each respective fuel type. 


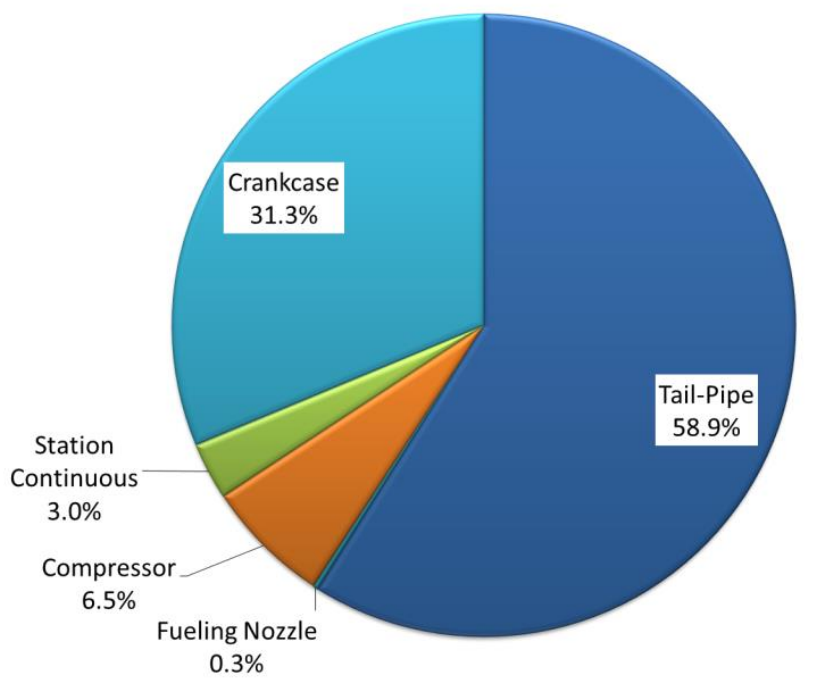

(a) All CNG Vehicles (FSME $=2.30 \mathrm{~g} / \mathrm{kg}$ fuel)

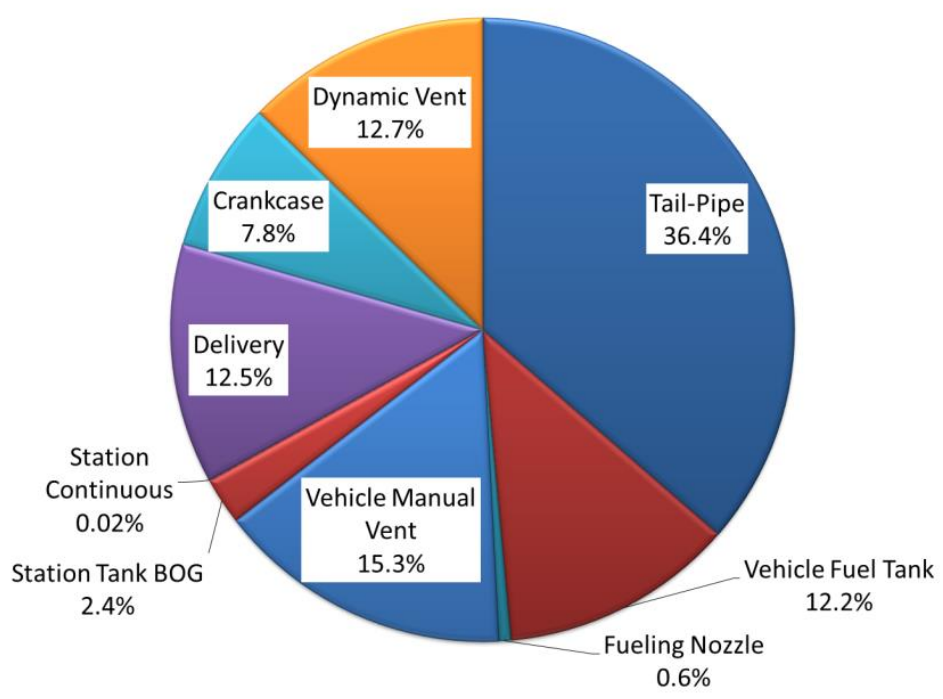

(b) All LNG Vehicles* (FSME $=4.11 \mathrm{~g} / \mathrm{kg}$ fuel)

Figure 25: Methane Emissions Sources (Control Scenarios) from (a) all CNG Vehicles; (b) all LNG Vehicles

*Note: dynamic vent is due to HPDI engine pressure control and vehicle manual vent is due to operators manually purging pressure in storage tanks for faster refueling at stations

Figure 26 shows the percentage of methane emissions from each type of vehicle for the medium population, medium HPDI penetration, medium emissions and fuel consumption scenarios for (a) LNG SI engine OTR tractors, including 9 liter SI engine OTR tractors and 12 liter SI engine OTR tractors; and (b) 15 liter LNG HPDI engine OTR tractor. Tailpipe emissions were the highest emission sources for each respective OTR tractor type. 


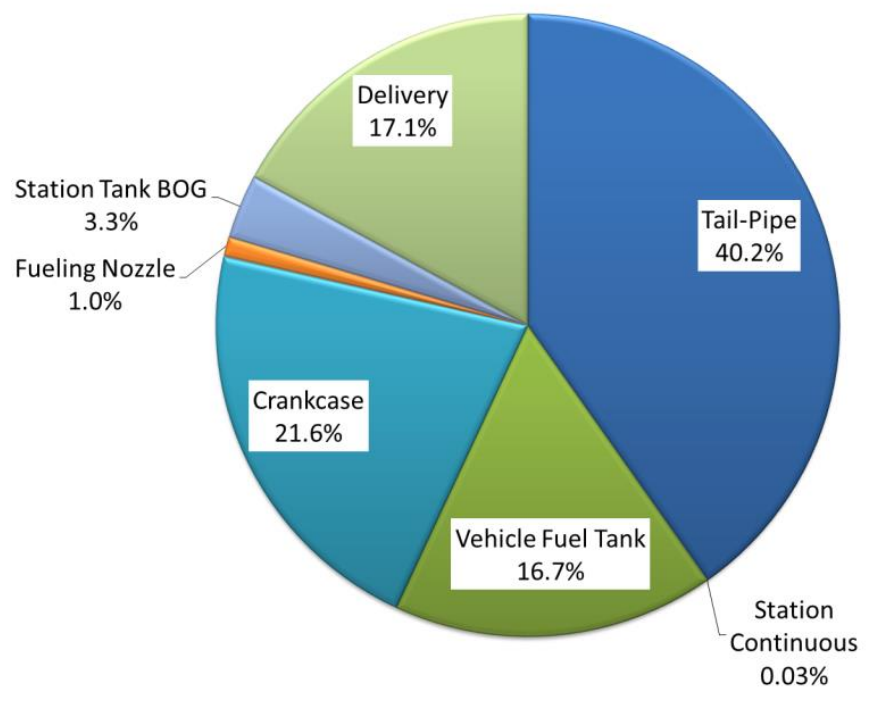

(a) LNG SI OTR Tractors* (FSME $=3.00 \mathrm{~g} / \mathrm{kg}$ fuel)

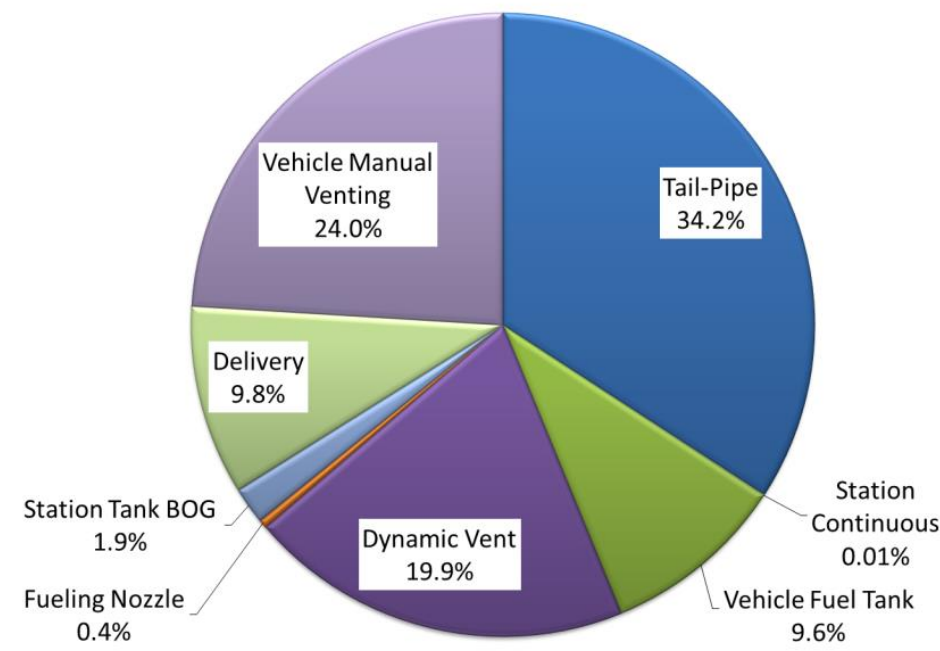

(b) LNG HPDI OTR Tractors* (FSME $=5.20 \mathrm{~g} / \mathrm{kg}$ fuel)

Figure 26: LNG OTR Tractor Methane Emissions Sources (Control Scenarios) from (a) all LNG SI vehicles; (b) all LNG HPDI vehicles

*Note: dynamic vent is due to HPDI engine pressure control and vehicle manual vent is due to operators manually purging pressure in storage tanks for faster refueling at stations

\section{Impact of Emissions and Fuel Consumption Scenarios on Estimated Methane Emissions}

The estimation model was used to simulate four scenario cases: Case 1: Medium vehicle population, medium HPDI penetration, and stasis emissions; Case 2: Medium vehicle population, medium HPDI penetration, and high emissions; Case 3: Medium population, medium HPDI penetration, and medium emissions; Case 4: Medium population, medium HPDI penetration, and 
low emissions. All tables and figures in this section were calculated with medium population and medium HPDI penetration scenarios. Table 93 and Table 94 show the high, medium, and low emissions and fuel consumption scenarios for vehicles and stations.

Table 93: Stasis, High, Medium, and Low Scenarios of Methane Emissions and Fuel Consumption for Vehicles

\begin{tabular}{|c|c|c|c|c|c|c|}
\hline & $\begin{array}{c}\text { Tailpipe } \\
\text { Methane }\end{array}$ & $\begin{array}{c}\text { Crankcase } \\
\text { Methane }\end{array}$ & $\begin{array}{c}\text { HPDI } \\
\text { Dynamic } \\
\text { Ventilation }\end{array}$ & $\begin{array}{c}\text { Vehicle } \\
\text { On-board } \\
\text { Tank BOG }\end{array}$ & $\begin{array}{c}\text { Fuel } \\
\text { Consumption } \\
\text { Non-idle } \\
\text { Operation }\end{array}$ & $\begin{array}{c}\text { Fuel } \\
\text { Consumption } \\
\text { During Idle } \\
\text { Operation }\end{array}$ \\
\hline Stasis & \multicolumn{7}{|c|}{$100 \%$ Average of current measurement } \\
\hline High & $75 \%$ & $25 \%$ & $50 \%$ & $75 \%$ & $90 \%$ & $100 \%$ \\
\hline Medium & $35 \%$ & $10 \%$ & $20 \%$ & $50 \%$ & $75 \%$ & $90 \%$ \\
\hline Low & $15 \%$ & $2 \%$ & $10 \%$ & $25 \%$ & $50 \%$ & $60 \%$ \\
\hline
\end{tabular}

Table 94: Stasis, High, Medium, and Low Scenarios of Methane Emissions and Fuel Consumption for Stations

\begin{tabular}{|c|c|c|c|c|c|c|}
\hline Scenario & $\begin{array}{l}\text { Dispenser } \\
\text { Nozzle }{ }^{L, C}\end{array}$ & $\begin{array}{c}\text { Continuous } \\
\text { Station } \\
\text { Emissions }\end{array}$ & $\begin{array}{l}\text { Emissions from } \\
\text { Compressor }\end{array}$ & $\begin{array}{c}\text { Station } \\
\text { Storage Tank } \\
\text { BOG }^{\mathrm{L}}\end{array}$ & Delivery & $\begin{array}{c}\text { Vehicle Manual } \\
\text { Ventilation }{ }^{\mathrm{L}, \mathrm{H}}\end{array}$ \\
\hline Stasis & \multicolumn{6}{|c|}{$100 \%$ Average of the current measurement } \\
\hline High & $50 \%$ & $80 \%$ & $50 \%$ & $20 \%$ & $60 \%$ & $50 \%$ \\
\hline Medium & $20 \%$ & $50 \%$ & $20 \%$ & $10 \%$ & $40 \%$ & $25 \%$ \\
\hline Low & $10 \%$ & $20 \%$ & $5 \%$ & $2 \%$ & $20 \%$ & $3 \%$ \\
\hline
\end{tabular}

${ }^{\mathrm{L}}$ for LNG stations

C for CNG stations

${ }^{\mathrm{H}}$ for HPDI engine vehicles only

Table 95 shows the annual methane emissions, annual fuel consumption, and FSME estimated with an assumed medium vehicle population, medium HPDI penetration, and stasis, high, medium, and low emissions and fuel consumption scenarios, respectively. Case 1 results agree with Table 87 for the stasis emissions and fuel consumption scenario and Case 3 results agree with Table 92 for the medium emissions and fuel consumption scenario.

Table 95: Effect of Variable Emissions and Fuel Consumption Scenarios on Combined Methane Emissions and Fuel Consumption

\begin{tabular}{|c|r|r|r|r|}
\hline $\begin{array}{c}\text { Emissions/Fuel } \\
\text { Consumption } \\
\text { Scenario }\end{array}$ & $\begin{array}{c}\text { Methane } \\
\text { Emissions (g) }\end{array}$ & $\begin{array}{c}\text { Fuel Consumption, } \\
(\mathrm{kg})\end{array}$ & $\begin{array}{c}\text { FSME } \\
(\mathrm{g} / \mathrm{kg} \text { fuel) }\end{array}$ & $\begin{array}{c}\text { FSME \% } \\
\text { Relative to } \\
\text { Stasis }\end{array}$ \\
\hline Stasis & $532,143,455,180$ & $40,292,124,671$ & 13.21 & $100.0 \%$ \\
\hline High & $249,103,770,491$ & $37,447,993,560$ & 6.65 & $50.4 \%$ \\
\hline Medium & $109,161,335,168$ & $32,930,625,097$ & 3.31 & $25.1 \%$ \\
\hline Low & $36,719,504,241$ & $25,066,781,930$ & 1.46 & $11.1 \%$ \\
\hline
\end{tabular}

Table 96 shows the ratio of methane emissions, fuel consumption, and FSME relative to that estimated with the stasis emissions and fuel consumption scenario. The methane emissions 
estimated by the medium emissions and fuel consumption scenario were $25.1 \%$ of that estimated at stasis emissions and fuel consumption scenario, by a combination of both FSME and fuel consumption reduction. The reduction in fuel consumption reduces the amount of fuel distributed by the station. The reduction in fuel consumption does not affect fuel nozzle emissions.

Table 96: Percent of Combined Methane Emissions, Fuel Consumption, and FSME Relative to Stasis Emissions and Fuel Consumption Scenarios

\begin{tabular}{|c|r|r|r|}
\hline Emissions/Fuel Consumption Scenario & Methane Emissions & Fuel Consumption & FSME \\
\hline Stasis & $100.0 \%$ & $100.0 \%$ & $100.0 \%$ \\
\hline High & $46.8 \%$ & $92.9 \%$ & $50.4 \%$ \\
\hline Medium & $20.5 \%$ & $81.7 \%$ & $25.1 \%$ \\
\hline Low & $6.9 \%$ & $62.2 \%$ & $11.1 \%$ \\
\hline
\end{tabular}

Table 97 shows the FSME for each type of vehicle estimated for stasis, high, medium, and low emissions and fuel consumption scenarios. The transit buses had the highest FSME for all scenarios. The 12 liter OTR tractors had the lowest FSME for all scenarios. Table 98 shows the relative ratio of the FSME estimated relative to that of the high emissions ratio. The FSME for the SI engine vehicles decreased more than the HPDI engine vehicles for each respective emissions and fuel consumption scenario. This is mostly due to crankcase emissions (the largest source for the stasis emissions and fuel consumption scenario) being reduced by the highest percentages in the high, medium, and low emissions and fuel consumption scenarios.

Table 97: Effect of Variable Emissions and Fuel Consumption Scenarios on Vehicle FSME

\begin{tabular}{|c|r|r|r|r|}
\hline & \multicolumn{1}{|c|}{$\begin{array}{c}\text { Stasis } \\
\text { Emissions }\end{array}$} & $\begin{array}{c}\text { High } \\
\text { Emissions }\end{array}$ & $\begin{array}{c}\text { Medium } \\
\text { Emissions }\end{array}$ & $\begin{array}{c}\text { Low } \\
\text { Emissions }\end{array}$ \\
\cline { 2 - 5 } & \multicolumn{5}{|c|}{$\mathrm{g} / \mathrm{kg}$ fuel } \\
\hline 9L CNG Transit Bus & 18.06 & 8.96 & 4.03 & 1.51 \\
\hline 9L SI CNG Refuse Truck & 13.46 & 5.31 & 2.35 & 0.79 \\
\hline 9L SI CNG Short Haul OTR Tractor & 12.59 & 5.80 & 2.59 & 0.93 \\
\hline 9L SI LNG Short Haul OTR Tractor & 15.14 & 7.12 & 3.52 & 1.41 \\
\hline 12L SI CNG Long Haul OTR Tractor & 8.94 & 3.65 & 1.60 & 0.53 \\
\hline 12L SI LNG Long Haul OTR Tractor & 11.48 & 4.98 & 2.54 & 1.01 \\
\hline 15L HPDI LNG Long Haul OTR Tractor & 16.16 & 10.18 & 5.20 & 2.32 \\
\hline Overall & 13.21 & 6.65 & 3.31 & 1.46 \\
\hline
\end{tabular}

Table 98: Ratio of Vehicle FSME Relative to Stasis FSME and Fuel Consumption Scenario

\begin{tabular}{|c|c|c|r|r|}
\hline & Stasis & High & Medium & Low \\
\hline 9L CNG Transit Bus & $100.0 \%$ & $49.6 \%$ & $22.3 \%$ & $8.4 \%$ \\
\hline 9L SI CNG Refuse Truck & $100.0 \%$ & $39.5 \%$ & $17.4 \%$ & $5.9 \%$ \\
\hline 9L SI CNG Short Haul OTR Tractor & $100.0 \%$ & $46.0 \%$ & $20.6 \%$ & $7.4 \%$ \\
\hline 9L SI LNG Short Haul OTR Tractor & $100.0 \%$ & $47.0 \%$ & $23.2 \%$ & $9.3 \%$ \\
\hline 12L SI CNG Long Haul OTR Tractor & $100.0 \%$ & $40.9 \%$ & $17.9 \%$ & $6.0 \%$ \\
\hline 12L SI LNG Long Haul OTR Tractor & $100.0 \%$ & $43.4 \%$ & $22.1 \%$ & $8.8 \%$ \\
\hline 15L HPDI LNG Long Haul OTR Tractor & $100.0 \%$ & $63.0 \%$ & $32.2 \%$ & $14.3 \%$ \\
\hline Overall & $100.0 \%$ & $50.4 \%$ & $25.1 \%$ & $11.1 \%$ \\
\hline
\end{tabular}


Figure 27 compares the FSME estimated with the medium population, medium HPDI penetration, and stasis, high, medium, and low methane emissions and fuel consumption scenarios, respectively. The data is reflective of Table 97.

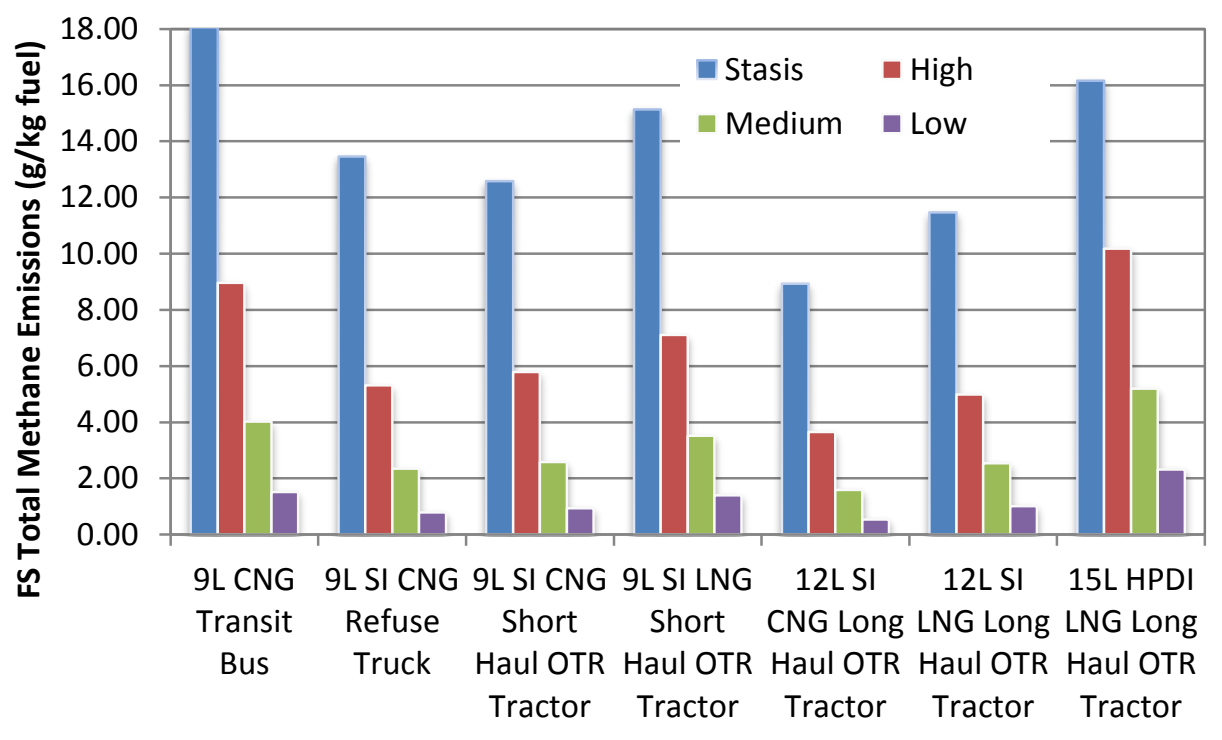

Figure 27: Effect of Emissions and Fuel Consumption Scenarios on Vehicle FSME

Table 99 shows the total annual vehicle methane emissions for each type of vehicle estimated for stasis, high, medium, and low emissions and fuel consumption scenarios. The 9 liter CNG OTR tractors had the highest methane emissions for the stasis scenario. Even though transit buses had the highest FSME, their relatively low population causes the lowest methane emissions for the stasis scenarios.

Table 99: Effect of Emissions and Fuel Consumption Scenarios on Total Annual Vehicle Methane Emissions

\begin{tabular}{|c|r|r|r|r|}
\hline \multirow{2}{*}{} & \multicolumn{3}{|c|}{ Stasis Emissions } & \multicolumn{3}{|c|}{ High Emissions } & \multicolumn{1}{|c|}{ Medium Emissions } & Low Emissions \\
\cline { 2 - 5 } & \multicolumn{3}{|c|}{$\mathrm{y}$} \\
\hline 9L CNG Transit Bus & $19,456,002,816$ & $8,811,357,513$ & $3,333,216,043$ & $834,350,395$ \\
\hline 9L SI CNG Refuse Truck & $38,373,447,320$ & $13,889,098,262$ & $5,191,624,541$ & $1,163,885,702$ \\
\hline 9L SI CNG Short Haul OTR Tractor & $105,636,041,298$ & $44,264,738,124$ & $16,626,747,202$ & $3,994,040,772$ \\
\hline 9L SI LNG Short Haul OTR Tractor & $84,691,385,950$ & $36,233,976,363$ & $15,054,712,869$ & $4,011,258,611$ \\
\hline 12L SI CNG Long Haul OTR Tractor & $58,250,827,828$ & $21,505,684,530$ & $7,872,665,147$ & $1,746,041,795$ \\
\hline 12L SI LNG Long Haul OTR Tractor & $74,813,350,162$ & $29,345,634,041$ & $12,517,998,183$ & $3,321,458,183$ \\
\hline 15L HPDI LNG Long Haul OTR Tractor & $150,922,399,806$ & $95,053,281,656$ & $48,564,371,183$ & $21,648,468,785$ \\
\hline Overall & $532,143,455,180$ & $249,103,770,491$ & $109,161,335,168$ & $36,719,504,241$ \\
\hline
\end{tabular}

Figure 28 compares the total annual vehicle methane emissions estimated with the medium population, medium HPDI penetration, and stasis, high, medium, and low methane emissions and fuel consumption scenarios, respectively. The data is reflective of Table 99. 


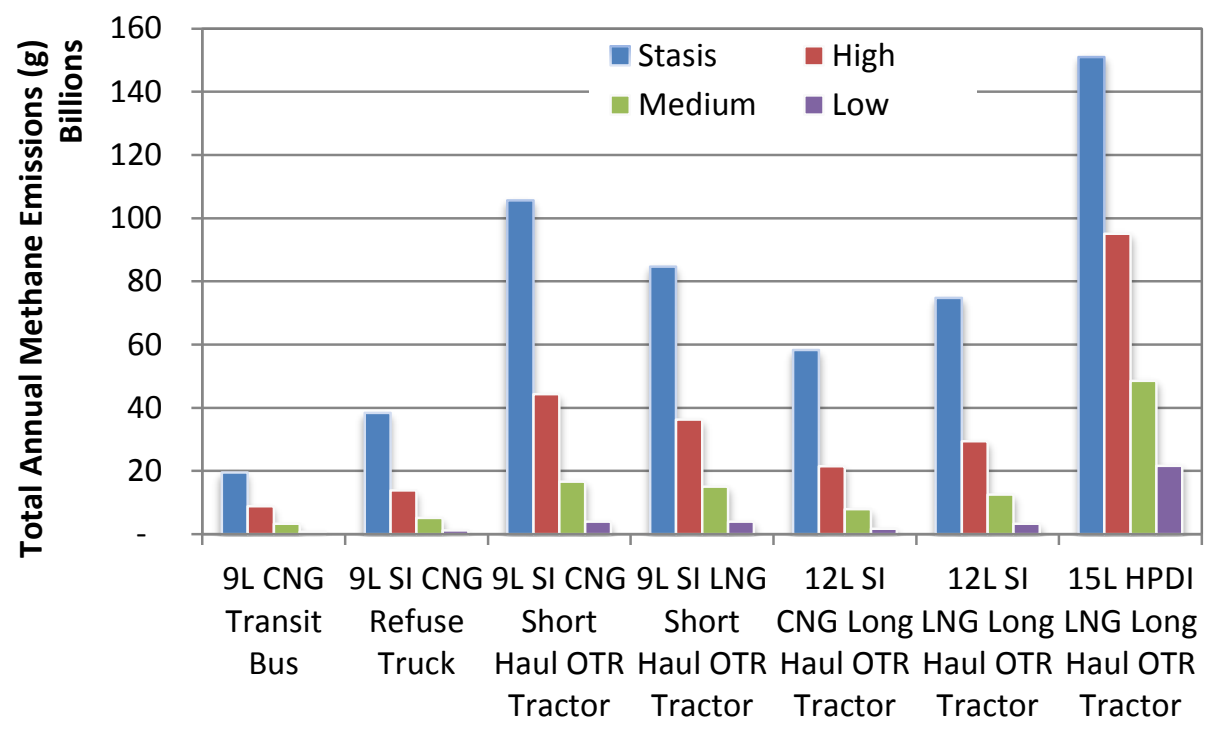

Figure 28: Effect of Emissions and Fuel Consumption Scenarios on Total Annual Vehicle Methane Emissions Impact of Population Scenarios on Estimated Methane Emissions

The estimation model was used to simulate three scenario cases: Case 1: High vehicle population, medium HPDI penetration, and medium emissions and fuel consumption scenarios; Case 2: Medium vehicle population, medium HPDI penetration, and medium emissions and fuel consumption scenarios; Case 3: Low vehicle population, medium HPDI penetration, and medium emissions and fuel consumption scenarios. The low, medium, and high population scenarios are shown in Table 100. Appendix K shows details of vehicle population.

Table 100: Population Scenarios for Heavy-duty NG Vehicle Sector in 2035

\begin{tabular}{|c|c|r|r|r|r|}
\hline \multicolumn{2}{|c|}{ Vehicle Type } & $\begin{array}{r}\text { Refuse Truck } \\
\text { (CNG only) }\end{array}$ & $\begin{array}{r}\text { Transit Bus } \\
\text { (CNG only) }\end{array}$ & $\begin{array}{r}\text { OTR Tractor } \\
\text { (CNG/LNG) }\end{array}$ & \multicolumn{1}{|c|}{ Total $^{\mathbf{A}}$} \\
\hline $\begin{array}{c}\text { Projected population of each type } \\
\text { of vehicle (includes all fuel types) }\end{array}$ & $\mathbf{1 6 0 , 0 0 0}$ & $\mathbf{7 0 , 0 0 0}$ & $\mathbf{2 , 2 7 0 , 0 0 0}$ & $\mathbf{2 , 5 0 0 , 0 0 0}$ \\
\hline \multirow{2}{*}{ Low } & \% of population & $50.00 \%$ & $30.00 \%$ & $19.44 \%$ & $21.69 \%$ \\
\cline { 2 - 6 } & Projected population & $\mathbf{8 0 , 0 0 0}$ & $\mathbf{2 1 , 0 0 0}$ & $\mathbf{4 4 1 , 2 0 0}$ & $\mathbf{5 4 2 , 2 0 0}$ \\
\hline \multirow{2}{*}{ Medium } & \% of population & $65.00 \%$ & $45.00 \%$ & $34.06 \%$ & $36.35 \%$ \\
\cline { 2 - 6 } & Projected population & $\mathbf{1 0 4 , 0 0 0}$ & $\mathbf{3 1 , 5 0 0}$ & $\mathbf{7 7 3 , 2 0 0}$ & $\mathbf{9 0 8 , 7 0 0}$ \\
\hline \multirow{2}{*}{ High } & \% of population & $\mathbf{8 0 . 0 0 \%}$ & $60.00 \%$ & $48.69 \%$ & $51.01 \%$ \\
\cline { 2 - 6 } & Projected population & $\mathbf{1 2 8 , 0 0 0}$ & $\mathbf{4 2 , 0 0 0}$ & $\mathbf{1 , 1 0 5 , 3 0 0}$ & $\mathbf{1 , 2 7 5 , 3 0 0}$ \\
\hline
\end{tabular}

A The percentage of NG vehicles was calculated with an assumed heavy-duty vehicle population of 2,500,000 excluding school buses $(500,000)$

Table 101 shows the annual combined (vehicle + station) methane emissions, annual fuel consumption, and FSME estimated with an assumed high, medium, and low vehicle population, medium HPDI penetration, and medium emissions and fuel consumption scenarios, respectively. Table 102 shows the ratio of methane emissions, fuel consumption, and FSME relative to that estimated with the medium population scenario (control case). The FSME were relatively 
constant because the annual emissions and the fuel consumption decreased at the same rate. There were differences in relative FSME because the populations of each vehicle type did not increase or decrease proportionally to each other. Case 2 results agree with Table 92 for the medium population scenario.

Table 101: Effect of Population Scenarios on Combined Methane Emissions and Fuel

\begin{tabular}{|c|r|r|r|r|}
\hline $\begin{array}{c}\text { Population } \\
\text { Scenario }\end{array}$ & $\begin{array}{c}\text { Methane } \\
\text { Emissions (g) }\end{array}$ & $\begin{array}{c}\text { Fuel Consumption, } \\
(\mathrm{kg})\end{array}$ & $\begin{array}{c}\text { FSME } \\
(\mathrm{g} / \mathrm{kg} \text { fuel) }\end{array}$ & $\begin{array}{c}\text { FSME \% } \\
\text { Relative to } \\
\text { Medium }\end{array}$ \\
\hline High & $154,695,122,972$ & $46,555,277,225$ & 3.32 & $100.2 \%$ \\
\hline Medium & $109,161,335,168$ & $32,930,625,097$ & 3.31 & $100.0 \%$ \\
\hline Low & $63,640,457,460$ & $19,309,787,722$ & 3.30 & $99.4 \%$ \\
\hline
\end{tabular}

Table 102: Percent of the Combined Methane Emissions, Fuel Consumption, and FSME Relative to Medium Population Scenario

\begin{tabular}{|c|r|r|c|}
\hline Population Scenario & Methane Emissions & Fuel Consumed & FSME \\
\hline High & $141.7 \%$ & $141.4 \%$ & $100.2 \%$ \\
\hline Medium & $100.0 \%$ & $100.0 \%$ & $100.0 \%$ \\
\hline Low & $58.3 \%$ & $58.6 \%$ & $99.4 \%$ \\
\hline
\end{tabular}

Table 103 shows the vehicle FSME for each type of vehicle estimated for high, medium, and low population scenarios. Table 104 shows the relative ratio of the FSME estimated relative to that of the medium population ratio (control scenario). The FSME for all vehicles were the same since the FSME for each vehicle type were independent of the population.

Table 103: Effect of Population Scenarios on Total Vehicle FSME

\begin{tabular}{|c|r|r|r|}
\hline & \multicolumn{1}{|c|}{$\begin{array}{c}\text { High } \\
\text { Population }\end{array}$} & $\begin{array}{c}\text { Medium } \\
\text { Population }\end{array}$ & $\begin{array}{c}\text { Low } \\
\text { Population }\end{array}$ \\
\hline 9L CNG Transit Bus & 4.03 & 4.03 & 4.03 \\
\hline 9L SI CNG Refuse Truck & 2.35 & 2.35 & 2.35 \\
\hline 9L SI CNG Short Haul OTR Tractor & 2.59 & 2.59 & 2.59 \\
\hline 9L SI LNG Short Haul OTR Tractor & 3.52 & 3.52 & 3.52 \\
\hline 12L SI CNG Long Haul OTR Tractor & 1.60 & 1.60 & 1.60 \\
\hline 12L SI LNG Long Haul OTR Tractor & 2.54 & 2.54 & 2.54 \\
\hline 15L HPDI LNG Long Haul OTR Tractor & 5.20 & 5.20 & 5.20 \\
\hline Overall & 3.32 & 3.31 & 3.30 \\
\hline
\end{tabular}


Table 104: Ratio of FS Total Vehicle Methane Emissions Relative to Medium Population Scenario

\begin{tabular}{|c|r|r|r|}
\hline \multirow{2}{*}{} & \multicolumn{3}{|c|}{ Population Scenario } \\
\cline { 2 - 4 } & \multicolumn{1}{|c|}{ High } & Medium & \multicolumn{1}{c|}{ Low } \\
\hline 9L CNG Transit Bus & $100 \%$ & $100 \%$ & $100 \%$ \\
\hline 9L SI CNG Refuse Truck & $100 \%$ & $100 \%$ & $100 \%$ \\
\hline 9L SI CNG Short Haul OTR Tractor & $100 \%$ & $100 \%$ & $100 \%$ \\
\hline 9L SI LNG Short Haul OTR Tractor & $100 \%$ & $100 \%$ & $100 \%$ \\
\hline 12L SI CNG Long Haul OTR Tractor & $100 \%$ & $100 \%$ & $100 \%$ \\
\hline 12L SI LNG Long Haul OTR Tractor & $100 \%$ & $100 \%$ & $100 \%$ \\
\hline 15L HPDI LNG Long Haul OTR Tractor & $100 \%$ & $100 \%$ & $100 \%$ \\
\hline
\end{tabular}

Figure 29 compares the vehicle FSME estimated with the high, medium, and low population, medium HPDI penetration, and medium methane emissions and fuel consumption scenarios, respectively. The data is reflective of Table 103.

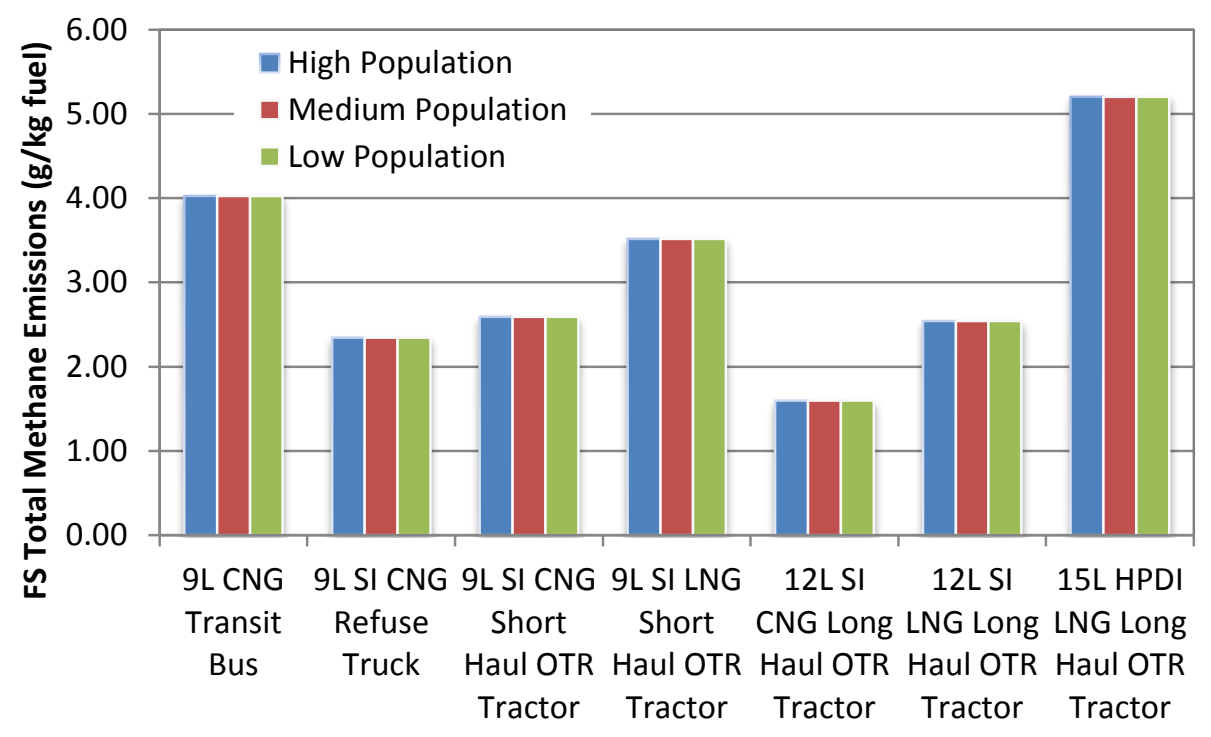

Figure 29: Effect of Population Scenarios on Vehicle FSME

Table 105 shows the total annual vehicle methane emissions for each type of vehicle estimated for high, medium, and low population scenarios. The total annual methane emissions were reduced proportional to the vehicle population.

Figure 30 compares the total annual vehicle methane emissions estimated with the high, medium, and low population, medium HPDI penetration, and medium methane emissions and fuel consumption scenarios, respectively. The data is reflective of Table 105. 
Table 105: Effect of Population Scenarios on Total Annual Vehicle Methane Emissions

\begin{tabular}{|c|c|c|c|}
\hline & High Population & Medium Population & Low Population \\
\hline & \multicolumn{3}{|c|}{ g/year } \\
\hline 9L CNG Transit Bus & $4,444,288,057$ & $3,333,216,043$ & $2,222,144,029$ \\
\hline 9L SI CNG Refuse Truck & $6,389,691,742$ & $5,191,624,541$ & $3,993,557,339$ \\
\hline 9L SI CNG Short Haul OTR Tractor & $23,768,163,065$ & $16,626,747,202$ & $9,487,481,719$ \\
\hline 9L SI LNG Short Haul OTR Tractor & $21,520,918,435$ & $15,054,712,869$ & $8,590,454,369$ \\
\hline 12L SI CNG Long Haul OTR Tractor & $11,254,042,029$ & $7,872,665,147$ & $4,492,265,731$ \\
\hline 12L SI LNG Long Haul OTR Tractor & $17,894,585,256$ & $12,517,998,183$ & $7,142,965,337$ \\
\hline 15L HPDI LNG Long Haul OTR Tractor & $69,423,434,387$ & $48,564,371,183$ & $27,711,588,937$ \\
\hline Overall & $154,695,122,972$ & $109,161,335,168$ & $63,640,457,460$ \\
\hline
\end{tabular}

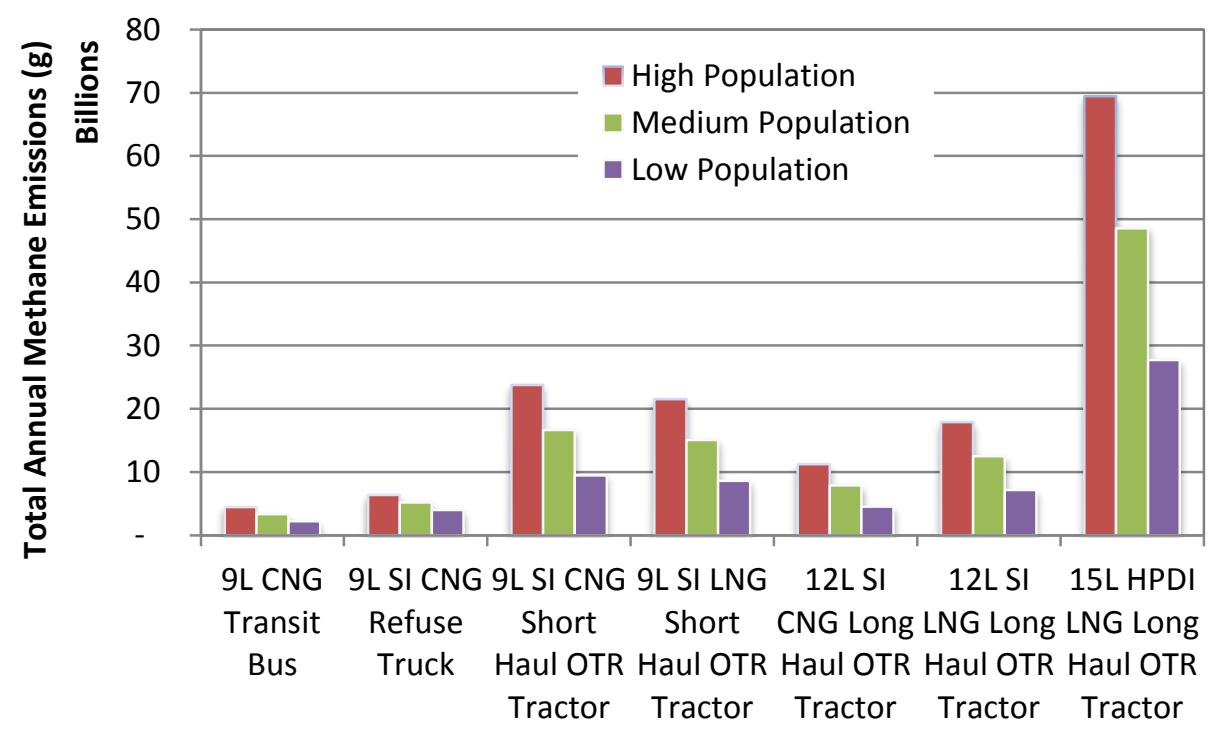

Figure 30: Effect of Population Scenarios on Total Annual Vehicle Methane Emissions

\section{Impact of HPDI Penetration Scenarios on Estimated Methane Emissions}

The estimation model was used to simulate three scenario cases: Case 1: Medium vehicle population, high HPDI penetration, and medium emissions and fuel consumption; Case 2: Medium vehicle population, medium HPDI penetration, and medium emissions and fuel consumption; Case 3: Medium population, low HPDI penetration, and medium emissions and fuel consumption. All tables and figures in this section were calculated with medium population and medium emissions and fuel consumption scenarios. Table 106 shows the percent penetration and population for long haul OTR tractors based on the HPDI penetration scenarios.

Table 106: HPDI Penetration Scenarios for Long Haul OTR Tractors

\begin{tabular}{|c|r|r|r|r|r|r|}
\hline & \multicolumn{2}{|c|}{ HPDI Long Haul OTR Tractors } & \multicolumn{2}{c|}{ SI Long Haul OTR Tractors } & \multicolumn{2}{c|}{ Total Long Haul OTR Tractors } \\
\cline { 2 - 7 } & \% Population & Population & \% Population & Population & \% Population & Population \\
\hline High & $80 \%$ & 309,280 & $20 \%$ & 77,320 & $100 \%$ & 386,600 \\
\hline Medium & $50 \%$ & 193,300 & $50 \%$ & 193,300 & $100 \%$ & 386,600 \\
\hline Low & $20 \%$ & 77,320 & $80 \%$ & 309,280 & $100 \%$ & 386,600 \\
\hline
\end{tabular}

Table 107 shows the effect of HPDI penetration on the annual methane emissions, annual fuel consumption, and FSME estimated with an assumed medium vehicle population and medium 
emissions and fuel consumption scenarios. Table 108 shows the ratio of methane emissions, fuel consumption, and FSME relative to that estimated with the medium HPDI penetration scenario (control case). The FSME increased as the HPDI penetration increased, as supported by Table 90 of the control case. Case 2 results agree with Table 92 for the medium HPDI penetration scenario.

Table 107: Effect of HPDI Penetration Scenarios on Combined Methane Emissions and Fuel

\begin{tabular}{|c|c|r|r|r|}
\hline $\begin{array}{c}\text { HPDI Penetration } \\
\text { Scenario }\end{array}$ & $\begin{array}{c}\text { Methane } \\
\text { Emissions }(\mathrm{g})\end{array}$ & $\begin{array}{c}\text { Fuel Consumption, } \\
(\mathrm{kg})\end{array}$ & $\begin{array}{c}\text { FSME } \\
(\mathrm{g} / \mathrm{kg} \text { fuel) }\end{array}$ & $\begin{array}{c}\text { FSME \% Relative } \\
\text { to Medium }\end{array}$ \\
\hline High & $126,065,559,879$ & $32,624,431,851$ & 3.86 & $116.6 \%$ \\
\hline Medium & $109,161,335,168$ & $32,930,625,097$ & 3.31 & $100.0 \%$ \\
\hline Low & $92,257,110,457$ & $33,236,818,344$ & 2.78 & $83.7 \%$ \\
\hline
\end{tabular}

Table 108: Percent of the Combined Methane Emissions, Fuel Consumption, and FSME Relative to High HPDI Penetration Scenario

\begin{tabular}{|c|r|r|c|}
\hline HPDI Penetration Scenario & Methane Emissions & Fuel Consumed & FSME \\
\hline High & $115.5 \%$ & $99.1 \%$ & $116.6 \%$ \\
\hline Medium & $100.0 \%$ & $100.0 \%$ & $100.0 \%$ \\
\hline Low & $84.5 \%$ & $100.9 \%$ & $83.7 \%$ \\
\hline
\end{tabular}

Table 109 shows the vehicle FSME for each type of vehicle estimated with high, medium, and low HPDI penetration scenarios. Table 110 shows the relative ratio of the FSME estimated relative to that of the medium HPDI penetration ratio (control case). The FSME for all vehicles were the same since the FSME for each vehicle type were independent of the HPDI penetration.

Figure 31 compares the vehicle FSME estimated with the high, medium, and low population, medium HPDI penetration, and medium methane emissions and fuel consumption scenarios, respectively. The data is reflective of Table 109.

Table 109: Effect of HPDI Penetration Scenarios on Total Vehicle FSME (g/kg fuel)

\begin{tabular}{|c|r|r|r|}
\hline \multirow{2}{*}{} & \multicolumn{3}{|c|}{ HPDI Penetration Scenario } \\
\cline { 2 - 4 } & \multicolumn{1}{|c|}{ High } & Medium & \multicolumn{1}{c|}{ Low } \\
\hline 9L CNG Transit Bus & 4.03 & 4.03 & 4.03 \\
\hline 9L SI CNG Refuse Truck & 2.35 & 2.35 & 2.35 \\
\hline 9L SI CNG Short Haul OTR Tractor & 2.59 & 2.59 & 2.59 \\
\hline 9L SI LNG Short Haul OTR Tractor & 3.52 & 3.52 & 3.52 \\
\hline 12L SI CNG Long Haul OTR Tractor & 1.60 & 1.60 & 1.60 \\
\hline 12L SI LNG Long Haul OTR Tractor & 2.54 & 2.54 & 2.54 \\
\hline 15L HPDI LNG Long Haul OTR Tractor & 5.20 & 5.20 & 5.20 \\
\hline Combined & 3.86 & 3.31 & 2.78 \\
\hline
\end{tabular}


Table 110: Ratio of FS Total Vehicle Methane Emissions Relative to High HPDI Penetration Scenario

\begin{tabular}{|c|r|r|r|}
\hline \multirow{2}{*}{} & \multicolumn{3}{|c|}{ HPDI Penetration Scenario } \\
\cline { 2 - 4 } & \multicolumn{1}{|c|}{ High } & Medium & \multicolumn{1}{c|}{ Low } \\
\hline 9L CNG Transit Bus & $100 \%$ & $100 \%$ & $100 \%$ \\
\hline 9L SI CNG Refuse Truck & $100 \%$ & $100 \%$ & $100 \%$ \\
\hline 9L SI CNG Short Haul OTR Tractor & $100 \%$ & $100 \%$ & $100 \%$ \\
\hline 9L SI LNG Short Haul OTR Tractor & $100 \%$ & $100 \%$ & $100 \%$ \\
\hline 12L SI CNG Long Haul OTR Tractor & $100 \%$ & $100 \%$ & $100 \%$ \\
\hline 12L SI LNG Long Haul OTR Tractor & $100 \%$ & $100 \%$ & $100 \%$ \\
\hline 15L HPDI LNG Long Haul OTR Tractor & $100 \%$ & $100 \%$ & $100 \%$ \\
\hline Overall & $100 \%$ & $89 \%$ & $79 \%$ \\
\hline
\end{tabular}

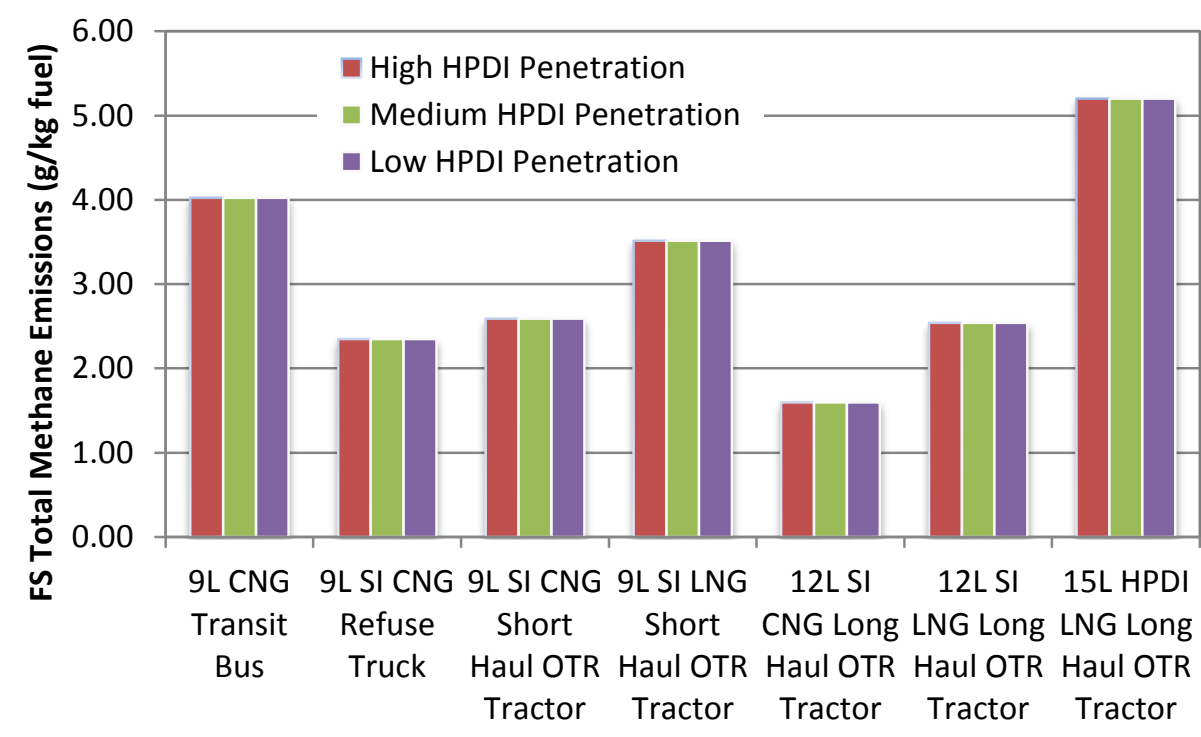

Figure 31: Effect of HPDI Penetration Scenarios on Vehicle FSME

Table 111 shows the total annual vehicle methane emissions for each type of vehicle estimated for high, medium, and low HPDI penetration scenarios. The total annual methane emissions increase for the HPDI engine vehicles and decrease for the SI engine vehicles as the HPDI penetration increases. The HPDI penetration does not affect transit bus, refuse truck, or short haul OTR tractor emissions.

Table 111: Effect of HPDI Penetration Scenarios on Total Annual Vehicle Methane Emissions (g/year)

\begin{tabular}{|c|r|r|r|}
\hline & \multicolumn{2}{|c|}{ HPDI Penetration Scenario } \\
\cline { 2 - 4 } & \multicolumn{1}{|c|}{ High } & \multicolumn{1}{c|}{ Medium } & \multicolumn{1}{c|}{ Low } \\
\hline 9L CNG Transit Bus & $3,333,216,043$ & $3,333,216,043$ & $3,333,216,043$ \\
\hline 9L SI CNG Refuse Truck & $5,191,624,541$ & $5,191,624,541$ & $5,191,624,541$ \\
\hline 9L SI CNG Short Haul OTR Tractor & $16,626,747,202$ & $16,626,747,202$ & $16,626,747,202$ \\
\hline 9L SI LNG Short Haul OTR Tractor & $15,054,712,869$ & $15,054,712,869$ & $15,054,712,869$ \\
\hline 12L SI CNG Long Haul OTR Tractor & $3,149,066,059$ & $7,872,665,147$ & $12,596,264,236$ \\
\hline 12L SI LNG Long Haul OTR Tractor & $5,007,199,273$ & $12,517,998,183$ & $20,028,797,093$ \\
\hline 15L HPDI LNG Long Haul OTR Tractor & $77,702,993,892$ & $48,564,371,183$ & $19,425,748,473$ \\
\hline Overall & $126,065,559,879$ & $109,161,335,168$ & $92,257,110,457$ \\
\hline
\end{tabular}


Figure 32 shows the effect of HPDI penetration on the total annual vehicle methane emissions estimated with the medium population and medium methane emissions and fuel consumption scenarios. The data is reflective of Table 111.

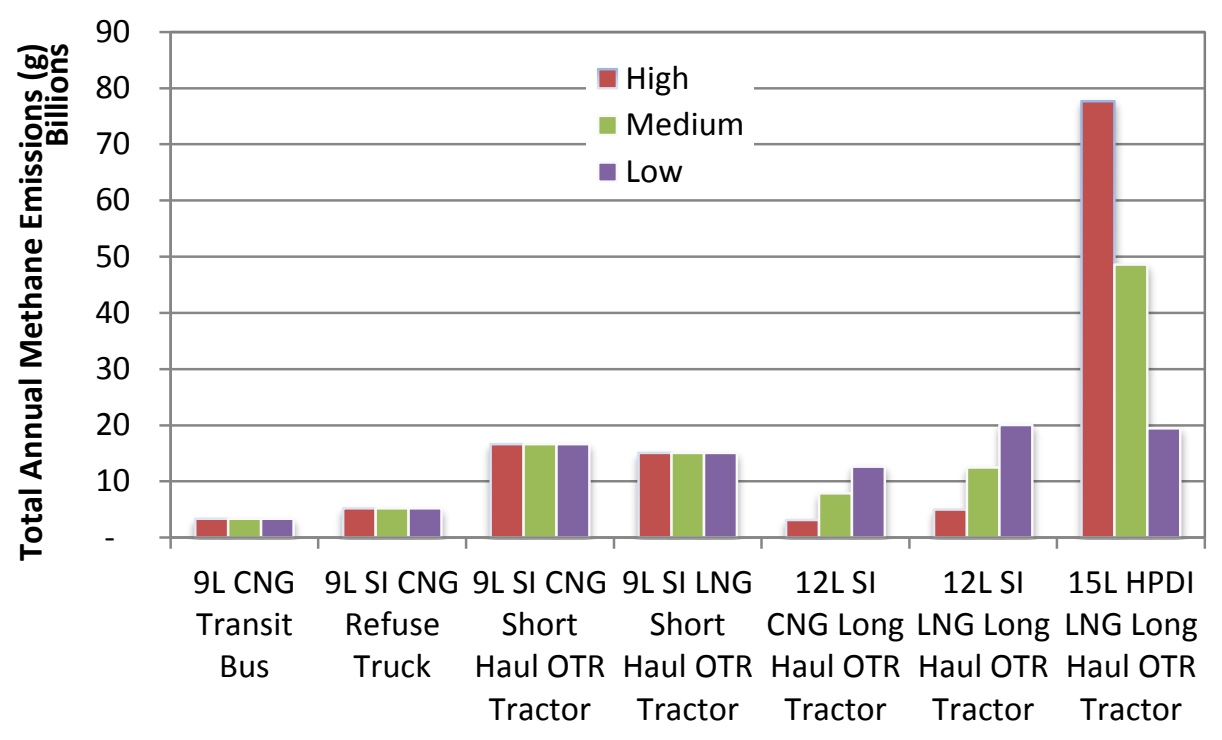

Figure 32: Effect of HPDI Penetration Scenarios on Total Annual Vehicle Methane Emissions

\section{Case Study: Effect of Dynamic Ventilation and Manual Ventilation on HPDI Engine OTR Tractor Emissions}

The largest emissions sources of 15L HPDI engine OTR tractors were dynamic ventilation (32.1\% of total emissions), tailpipe (31.4\% of total emissions), and manual ventilation (15.5\% of total emissions). Eliminating dynamic ventilation and manual ventilation had a profound reduction in the 15 liter HPDI engine OTR tractor methane emissions. Table 112 shows the emissions and FSME of long haul OTR tractors. By removing the dynamic ventilation and manual ventilation (47.6\% of total emissions), the 15 liter HPDI engine long haul OTR tractors were lower than the CNG and LNG 12 liter SI engine long haul OTR tractors.

Table 112: Effect of Eliminating Dynamic Ventilation and Manual Ventilation on 15L OTR Tractors

\begin{tabular}{|c|c|r|r|}
\hline Vehicle Type & Emissions Sources & $\begin{array}{c}\text { Methane } \\
\text { Emissions (g) }\end{array}$ & $\begin{array}{r}\text { FSME } \\
\text { (g/kg fuel) }\end{array}$ \\
\hline 12L SI CNG Long Haul OTR Tractor & N/A & $58,250,827,828$ & 8.94 \\
\hline 12L SI LNG Long Haul OTR Tractor & N/A & $74,813,350,162$ & 11.48 \\
\hline Average 12L SI Long Haul OTR Tractor & N/A & $\mathbf{6 6 , 5 3 2 , 0 8 8 , 9 9 5}$ & 10.21 \\
\hline 15L HPDI LNG Long Haul OTR Tractor & All Emissions & $\mathbf{1 5 0 , 9 2 2 , 3 9 9 , 8 0 6}$ & 16.16 \\
\hline 15L HPDI LNG Long Haul OTR Tractor & $\begin{array}{c}\text { Dynamic Vent and } \\
\text { Manual Vent Removed }\end{array}$ & $\mathbf{7 9 , 1 3 4 , 6 9 6 , 5 8 3}$ & $\mathbf{8 . 4 7}$ \\
\hline
\end{tabular}

\section{Case Study: Effect of CNG Station Utilization on Methane Emissions}

The medium population, medium HPDI penetration, and stasis emissions and fuel consumption scenarios were used for this case study. An assumption of 80 vehicles per day (50 for refuse trucks) was used as the default input for the estimation model. This section outlines the impact of 
changing that assumption. The number of refuse trucks was calculated by the default ratio of refuse trucks to other vehicles, 50:80. The estimation model was used to simulate five utilization cases: Case 1: Very Low Utilization (40 transit buses, 40 OTR tractors, or 25 refuse trucks); Case 2: Low Utilization (60 transit buses, 60 OTR tractors, or 38 refuse trucks); Case 3: Default Utilization (80 transit buses, 80 OTR tractors, or 50 refuse trucks); Case 4: High Utilization (100 transit buses, 100 OTR tractors, or 63 refuse trucks); and Case 5: Very High Utilization (120 transit buses, 120 OTR tractors, or 75 refuse trucks). The stasis emissions and fuel consumption, medium population, and medium HPDI penetration were used in this section. It is important to note that only the CNG compressor and continuous emissions change. The nozzle emissions had a fixed number of refueling events per vehicle and all other emissions had fuel based inputs. There was a lack of resources to fully explore LNG station utilization, as some LNG station components like fuel tank BOG were complex.

Table 113 shows the annual methane emissions, annual fuel consumption, and FSME estimated with the very low, low, default, high, and very high utilization cases, respectively, of CNG stations. Table 114 shows the ratio of methane emissions, fuel consumption, and FSME relative to that estimated with the default $\mathrm{CNG}$ station utilization. The change in emissions was not linear, though the change in vehicle population per station was. There was less than a $5 \%$ change in overall emissions between the default and most extreme case, very low utilization. The medium population, medium HPDI penetration, and stasis emissions and fuel consumption scenarios were used

Table 113: Effect of CNG Station Utilization on Methane Emissions and Fuel Consumption

\begin{tabular}{|c|r|r|r|}
\hline $\begin{array}{c}\text { CNG Station } \\
\text { Utilization Case }\end{array}$ & $\mathrm{CH}_{4}$ Emissions (g) & Fuel Consumption (kg) & $\begin{array}{c}\text { FSME } \\
\left(\mathrm{g} \mathrm{CH}_{4} / \mathrm{kg} \text { fuel) }\right.\end{array}$ \\
\hline Very Low & $232,720,919,276$ & $18,839,709,757$ & 12.35 \\
\hline Low & $225,185,246,178$ & $18,839,709,757$ & 11.95 \\
\hline Default & $221,716,319,262$ & $18,839,709,757$ & 11.77 \\
\hline High & $219,436,104,347$ & $18,839,709,757$ & 11.65 \\
\hline Very High & $218,048,119,258$ & $18,839,709,757$ & 11.57 \\
\hline
\end{tabular}

Table 114: Percent of the Combined Methane Emissions, Fuel Consumption, and FSME Relative to the Default Utilization Case

\begin{tabular}{|c|r|r|r|}
\hline $\begin{array}{c}\text { CNG Station } \\
\text { Utilization Case }\end{array}$ & $\mathrm{CH}_{4}$ Emissions & Fuel Consumption & $\mathrm{FS} \mathrm{CH}_{4}$ Emissions \\
\hline Very Low & $105.0 \%$ & $100.0 \%$ & $105.0 \%$ \\
\hline Low & $101.6 \%$ & $100.0 \%$ & $101.6 \%$ \\
\hline Default & $100.0 \%$ & $100.0 \%$ & $100.0 \%$ \\
\hline High & $99.0 \%$ & $100.0 \%$ & $99.0 \%$ \\
\hline Very High & $98.3 \%$ & $100.0 \%$ & $98.3 \%$ \\
\hline
\end{tabular}

Table 115 shows the annual combined methane emissions, annual fuel consumption, and FSME estimated with the very low, low, default, high, and very high utilization cases, respectively. 
Table 115: Effect of Station Utilization on CNG Station Methane Emissions and Fuel Consumption

\begin{tabular}{|c|r|r|r|}
\hline Utilization Case & $\mathrm{CH}_{4}$ Emissions (g) & Fuel Consumption (kg) & $\begin{array}{c}\text { FSME } \\
\left(\mathrm{g} \mathrm{CH}_{4} / \mathrm{kg} \text { fuel) }\right.\end{array}$ \\
\hline Very Low & $27,599,135,157$ & $18,839,709,757$ & 1.46 \\
\hline Low & $20,063,462,059$ & $18,839,709,757$ & 1.06 \\
\hline Default & $16,594,535,143$ & $18,839,709,757$ & 0.88 \\
\hline High & $14,314,320,228$ & $18,839,709,757$ & 0.76 \\
\hline Very High & $12,926,335,139$ & $18,839,709,757$ & 0.69 \\
\hline
\end{tabular}

Figure 33 shows the CNG station only FSME with respect to the utilization factor. The utilization factor is the ratio of the number of vehicles over the number of vehicles per CNG station for the default utilization (80 vehicles per CNG station). 100\% CNG station utilization represents the default utilization. As the utilization factor (and the number of vehicles per station by definition) increases, the FSME of the CNG station decreases.

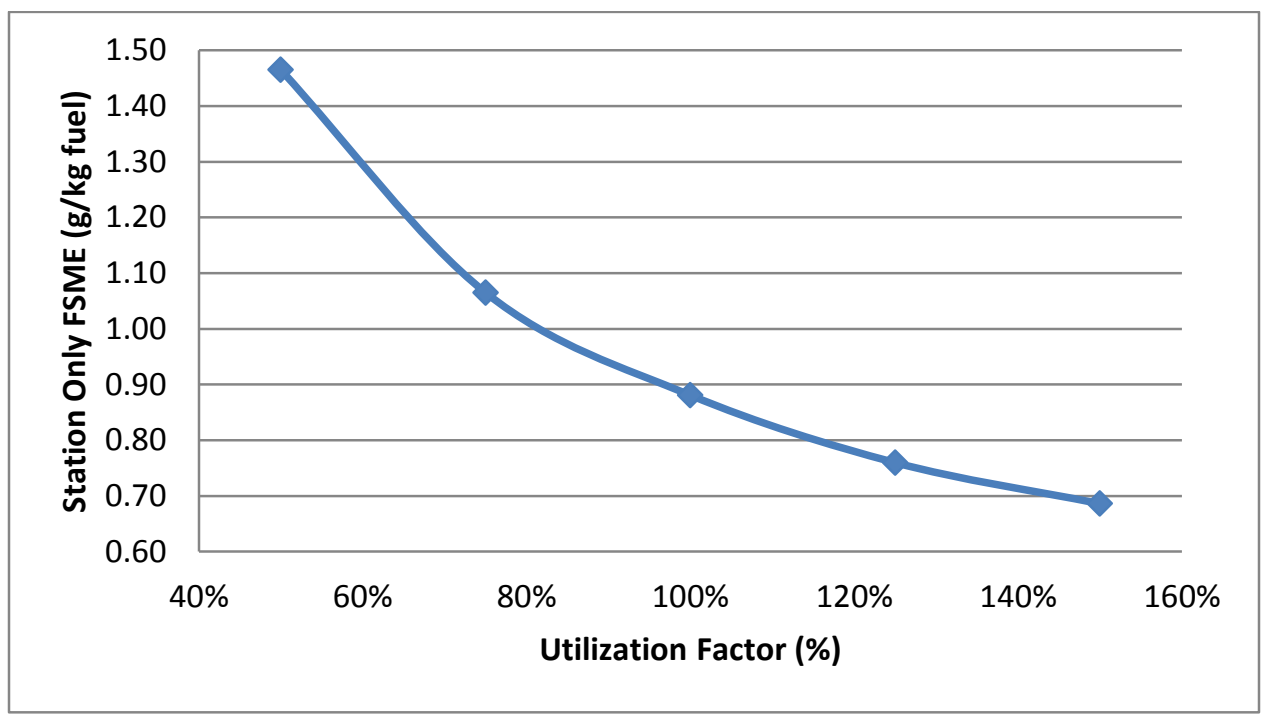

Figure 33: CNG Station FSME with Respect to Utilization Factor

Table 116 shows the ratio of methane emissions, fuel consumption, and FSME relative to that estimated with the default station utilization. The CNG station emissions showed the largest change, $66.3 \%$ increase for the very low utilization case. The station utilization only affected $\mathrm{CNG}$ station emissions. The rate of change for the combined emissions was less because the vehicle emissions were the dominant emissions sources. 
Table 116: Percent of the CNG Station Methane Emissions, Fuel Consumption, and FSME Relative to the Default Utilization Case

\begin{tabular}{|c|r|r|r|}
\hline Utilization Case & $\mathrm{CH}_{4}$ Emissions & Fuel Burned & FSME \\
\hline Very Low & $166.3 \%$ & $100.0 \%$ & $166.3 \%$ \\
\hline Low & $120.9 \%$ & $100.0 \%$ & $120.9 \%$ \\
\hline Default & $100.0 \%$ & $100.0 \%$ & $100.0 \%$ \\
\hline High & $86.3 \%$ & $100.0 \%$ & $86.3 \%$ \\
\hline Very High & $77.9 \%$ & $100.0 \%$ & $77.9 \%$ \\
\hline
\end{tabular}

Table 117 shows the FSME for each type of vehicle estimated for very low, low, default, high, and very high station utilization. Table 118 shows the relative ratio of the FSME estimated relative to that of the default utilization case. The 12 liter OTR tractor had the highest relative change. The changes in emissions were relatively small because CNG station utilization only affects CNG station emissions and vehicle emissions were the dominant sources. The medium population, medium HPDI penetration, and stasis emissions and fuel consumption scenarios were used

Table 117: Effect of CNG Station Utilization on FSME

\begin{tabular}{|c|c|c|c|c|c|}
\hline & Very Low & Low & Default & High & Very High \\
\cline { 2 - 6 } & \multicolumn{5}{|c|}{ g/kg fuel } \\
\hline 9L CNG Transit Bus & 18.65 & 18.24 & 18.06 & 17.94 & 17.86 \\
\hline 9L SI CNG Refuse Truck & 14.15 & 13.68 & 13.46 & 13.31 & 13.22 \\
\hline 9L SI CNG Short Haul OTR Tractor & 13.17 & 12.77 & 12.59 & 12.47 & 12.39 \\
\hline 12L SI CNG Long Haul OTR Tractor & 9.47 & 9.10 & 8.94 & 8.83 & 8.76 \\
\hline Overall & 12.35 & 11.95 & 11.77 & 11.65 & 11.57 \\
\hline
\end{tabular}

Table 118: Ratio of FSME Relative Default CNG Station Utilization

\begin{tabular}{|c|c|c|c|c|c|}
\hline & Very Low & Low & Default & High & Very High \\
\hline 9L CNG Transit Bus & $103 \%$ & $101 \%$ & $100 \%$ & $99 \%$ & $99 \%$ \\
\hline 9L SI CNG Refuse Truck & $105 \%$ & $102 \%$ & $100 \%$ & $99 \%$ & $98 \%$ \\
\hline 9L SI CNG Short Haul OTR Tractor & $105 \%$ & $101 \%$ & $100 \%$ & $99 \%$ & $98 \%$ \\
\hline 12L SI CNG Long Haul OTR Tractor & $106 \%$ & $102 \%$ & $100 \%$ & $99 \%$ & $98 \%$ \\
\hline Overall & $105 \%$ & $102 \%$ & $100 \%$ & $99 \%$ & $98 \%$ \\
\hline
\end{tabular}

Figure 34 compares the vehicle FSME estimated with very low, low, default, high, and very high station utilization, respectively. The data is reflective of Table 117. 


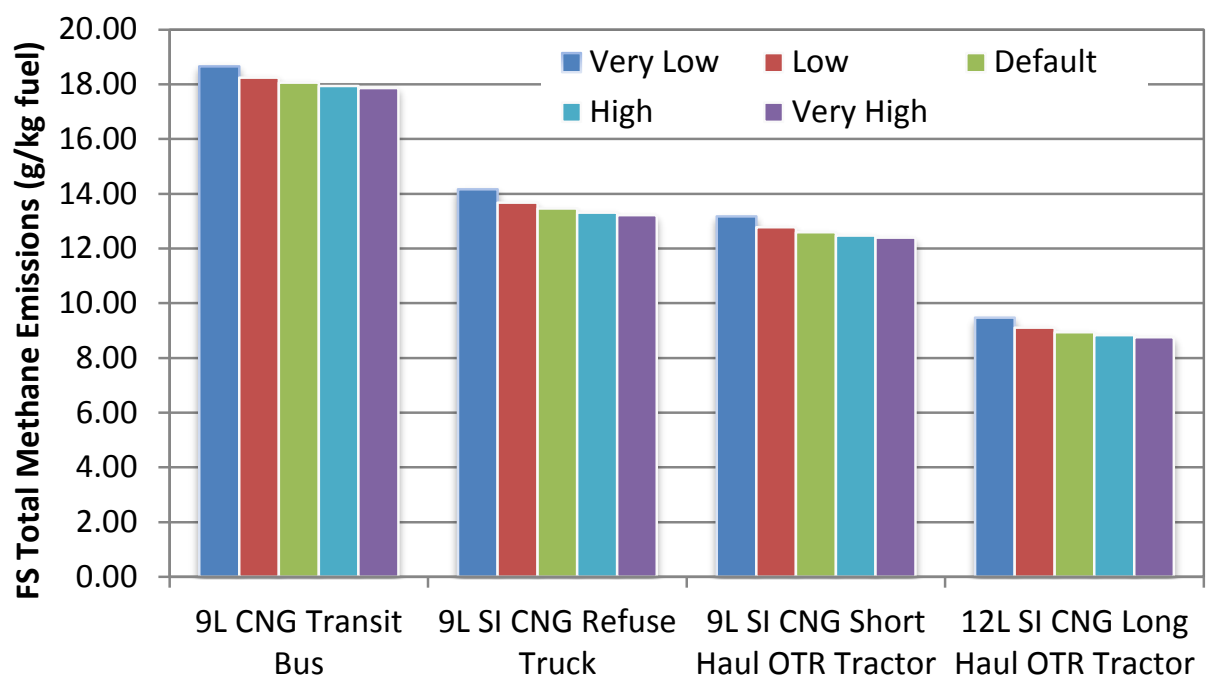

Figure 34: Effect of CNG Station Utilization on FSME

Table 119 shows the total annual vehicle methane emissions for each type of vehicle estimated for very low, low, default, high, and very high station utilization. The 9 liter OTR tractor had the highest annual emissions. The medium population, medium HPDI penetration, and stasis emissions and fuel consumption scenarios were used

Table 119: Effect of CNG Station Utilization on Combined Annual Methane Emissions

\begin{tabular}{|c|c|c|c|c|c|}
\hline & Very Low & Low & Default & High & Very High \\
\hline 9L CNG Transit Bus & $20,090,511,864$ & $19,656,731,786$ & $19,456,002,816$ & $19,324,791,388$ & $19,244,499,800$ \\
\hline 9L SI CNG Refuse Truck & $40,362,160,280$ & $38,996,959,368$ & $38,373,447,320$ & $37,960,362,143$ & $37,710,543,000$ \\
\hline 9L SI CNG Short Haul OTR Tractor & $110,528,415,116$ & $107,182,911,837$ & $105,636,041,298$ & $104,623,998,241$ & $104,005,250,025$ \\
\hline 12L SI CNG Long Haul OTR Tractor & $61,739,832,016$ & $59,348,643,187$ & $58,250,827,828$ & $57,526,952,576$ & $57,087,826,432$ \\
\hline Overall & $232,720,919,276$ & $225,185,246,178$ & $221,716,319,262$ & $219,436,104,347$ & $218,048,119,258$ \\
\hline
\end{tabular}

Figure 35 compares the total annual vehicle methane emissions estimated with very low, low, default, high, and very high station utilization, respectively. The data is reflective of Table 119.

The 9 liter OTR tractors had the highest overall emissions for all respective utilization cases. The transit buses had the highest FSME for all respective utilization cases. The 12 liter OTR tractor had the largest relative change in emissions due to change in station utilization. The relative changes in emissions were not significant because CNG station utilization only affects CNG station emissions and $\mathrm{CNG}$ vehicle emissions were the dominant sources. 


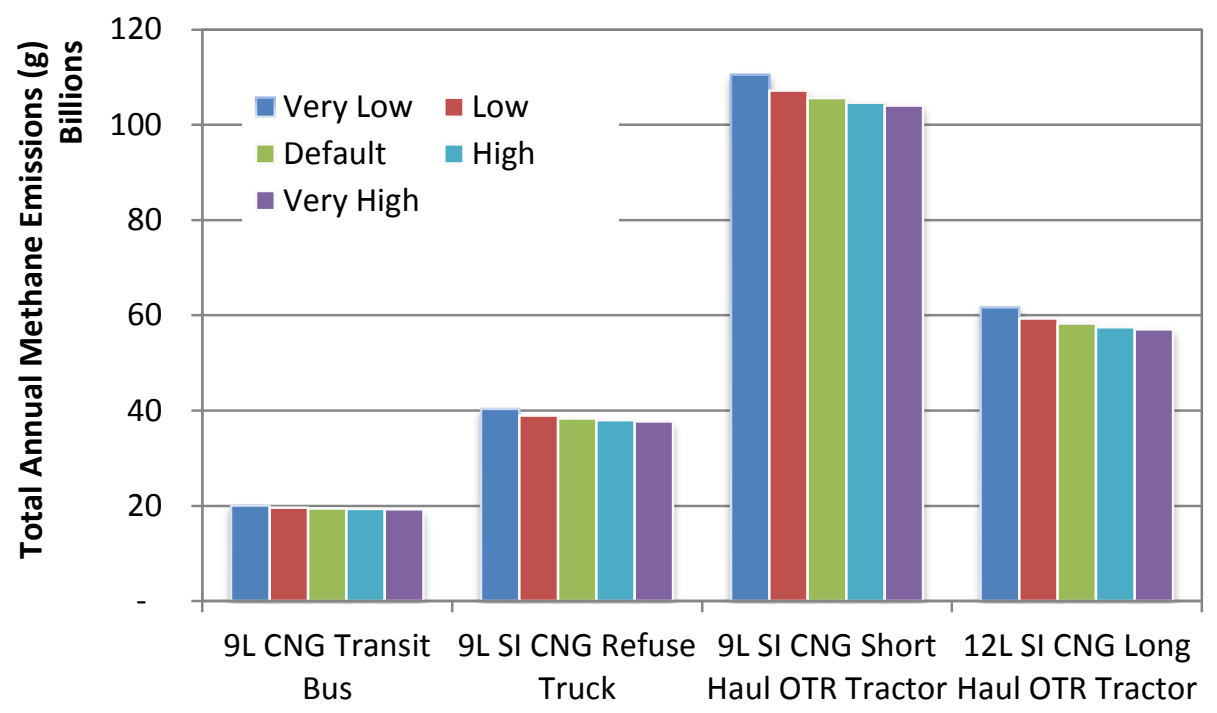

Figure 35: Effect of CNG Station Utilization on Combined Annual Methane Emissions

\section{Case Study: Effect of Emissions and/or Fuel Consumption Scenario on Overall Emissions}

Table 120, Table 121, and Table 122 show the separate effects of the emissions and fuel consumption scenarios on overall annual methane emissions, fuel consumption, and FSME. As shown in the tables, the annual emissions decreased as the emissions and fuel consumption were reduced. The reduction in emissions had a much larger impact on methane emissions than the reduction in fuel consumption for the overall emissions. The reduction in emissions only had no impact on the fuel consumption. The FSME decreased as the emissions were reduced, with a constant fuel consumption scenario. The FSME increased as the fuel consumption was reduced, with a constant emissions scenario. The reduction in emissions had a much larger impact on the FSME than the reduction in fuel consumption.

Table 120: Effect of Emissions and/or Fuel Consumption Scenarios on Overall Annual Methane Emissions (g)

\begin{tabular}{|c|c|c|c|c|c|}
\hline & & \multicolumn{4}{|c|}{ Fuel Consumption Scenario } \\
\hline & & Stasis & High & Medium & Low \\
\hline \multirow{4}{*}{ 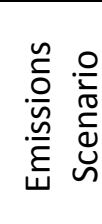 } & Stasis & $532,143,455,180$ & $499,852,392,417$ & $445,971,471,710$ & $348,910,835,111$ \\
\hline & High & $264,069,071,597$ & $249,103,770,491$ & $224,972,185,790$ & $182,508,033,902$ \\
\hline & Medium & $127,446,211,838$ & $120,423,996,779$ & $109,161,335,168$ & $89,417,780,452$ \\
\hline & Low & $50,793,323,093$ & $48,143,710,491$ & $43,962,852,628$ & $36,719,504,241$ \\
\hline
\end{tabular}


Table 121: Effect of Emissions and/or Fuel Consumption Scenarios on Overall Fuel Consumption (kg)

\begin{tabular}{|c|c|c|c|c|c|}
\hline & & \multicolumn{4}{|c|}{ Fuel Consumption Scenario } \\
\hline & & Stasis & High & Medium & Low \\
\hline \multirow{4}{*}{ 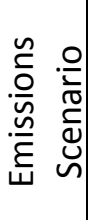 } & Stasis & $40,292,124,671$ & $37,447,993,560$ & $32,930,625,097$ & $25,066,781,930$ \\
\hline & High & $40,292,124,671$ & $37,447,993,560$ & $32,930,625,097$ & $25,066,781,930$ \\
\hline & Medium & $40,292,124,671$ & $37,447,993,560$ & $32,930,625,097$ & $25,066,781,930$ \\
\hline & Low & $40,292,124,671$ & $37,447,993,560$ & $32,930,625,097$ & $25,066,781,930$ \\
\hline
\end{tabular}

Table 122: Effect of Emissions and/or Fuel Consumption Scenarios on Overall FSME (g/kg fuel)

\begin{tabular}{|c|c|c|c|c|c|}
\hline & & \multicolumn{4}{|c|}{ Fuel Consumption Scenario } \\
\hline & & Stasis & High & Medium & Low \\
\hline \multirow{4}{*}{ 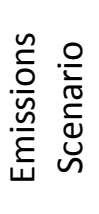 } & Stasis & 13.21 & 13.35 & 13.54 & 13.92 \\
\hline & High & 6.55 & 6.65 & 6.83 & 7.28 \\
\hline & Medium & 3.16 & 3.22 & 3.31 & 3.57 \\
\hline & Low & 1.26 & 1.29 & 1.34 & 1.46 \\
\hline
\end{tabular}

\section{Methane Emissions Summary}

Crankcase emissions were the largest source of emissions for the stasis emissions and fuel consumption scenarios. However, the tailpipe emissions are expected to be the largest source in 2035 (control case). Annual methane emissions for the stasis scenario were roughly four times the control scenarios. The emissions reduction scenarios had a larger effect on the annual emissions than the fuel consumption reduction scenarios. Vehicle emissions were larger than CNG station emissions for all scenarios. Increasing the population by changing the population scenario had no effect of the FSME, although the total methane released increased proportionally. Increasing the percentage of HPDI engine vehicles in the HPDI penetration scenario increased the overall emissions as the HPDI penetration increased, since 15 liter HPDI engine long haul OTR tractors had higher emissions than 12 liter SI engine long haul OTR tractors. 15 liter HPDI engine OTR tractors had higher emissions due in large part to the presence of manual ventilation and dynamic ventilation that 12 liter SI engine OTR tractors did not have. The CNG station utilization had a large impact on the CNG station FSME. However the impact on the overall FSME was not as significant because vehicle emissions were the dominant emissions sources. 


\section{Chapter 7 - Conclusion and Future Work}

\section{Conclusion}

The estimation model has inputs of future fleets (such as vehicle types, operation activities of each vehicle type, station types, and population of vehicles and stations) and experimental data (such as fuel consumption and tailpipe, crankcase, vehicle fuel tank BOG, nozzle, compressor, continuous, manual ventilation, station fuel tank BOG, and delivery emissions). The model compares these inputs to estimate the fuel and emissions rates for the fleet in 2035. The model outputs the methane emissions in grams of annual emissions and FSME. The model also provides metrics (such as pie charts and column charts) to help interpret the results visually. The estimation model lays a great foundation for future estimation models, especially for tailpipe and crankcase emissions. Moreover this model helps to provide more knowledge of natural gas fuels, builds upon previous models such as GREET, MOBILE, and EMFAC, and provides a source for further understanding a developing technology. The model has been checked for errors by comparing the inputs to the outputs for each source and verifying that the FSME of each source are the same.

(1) For the stasis emissions and fuel consumption scenario (measured data) with medium population and medium HPDI penetration scenarios, the model estimated:

- FSME from the heavy-duty natural gas sector, estimated with the stasis scenario, were $13.21 \mathrm{~g} / \mathrm{kg}$ fuel consumed. The contributions of the station and vehicle emissions were $24.5 \%$ and $75.5 \%$, respectively.

- FSME of LNG and CNG vehicles were $14.46 \mathrm{~g} / \mathrm{kg}$ and $11.77 \mathrm{~g} / \mathrm{kg}$ fuel consumed, respectively. The higher FSME from the LNG sector were mostly due to methane emissions from LNG bulk delivery (1.28 g/ $/ \mathrm{kg}$ fuel), manual ventilation (1.08 g/kg fuel), vehicle tank BOG $(1.00 \mathrm{~g} / \mathrm{kg}$ fuel $)$, and station tank BOG $(1.00 \mathrm{~g} / \mathrm{kg}$ fuel $)$.

- The measured crankcase (39.1\%) and tailpipe (30.6\%) emissions were dominant compared to the measured continuous $(0.4 \%)$, fueling nozzles $(0.6 \%)$, LNG delivery (5.2\%), LNG station fuel tank BOG (4.0\%), manual ventilation (4.4\%), CNG compressor $(2.7 \%)$, dynamic ventilation $(9.1 \%)$, and vehicle fuel tank BOG $(4.0 \%)$ emissions.

- Methane emissions from LNG vehicles (14.46 $\mathrm{g} / \mathrm{kg}$ fuel) accounted for $58.3 \%$ of total emissions. The largest sources of LNG emissions were tailpipe (28.8\%), crankcase (24.6\%), and dynamic ventilation (15.6\%). The vehicle tank BOG and combined station emissions accounted for the remaining $6.9 \%$ and $24.1 \%$ of LNG emissions, respectively.

- Methane emissions from CNG vehicles $(11.77 \mathrm{~g} / \mathrm{kg}$ fuel) accounted for $41.7 \%$ of total emissions. The largest sources of CNG emissions were crankcase (59.4\%) and tailpipe emissions (33.2\%). The combined station emissions accounted for the remaining $7.4 \%$ CNG emissions.

- $\mathrm{CNG}(3.1 \%)$ and LNG (14.0\%) station emissions accounted for $17.2 \%$ of total emissions.

- Crankcase emissions were the largest source of methane emissions $(39.1 \%$ percent of the overall emissions). 208,011,099,924 grams of methane per year $(5.16 \mathrm{~g} / \mathrm{kg}$ fuel $)$ were due to crankcase blow-by. 
- Manual ventilation of HPDI engine vehicle fuel tanks prior to refueling accounted for $15.5 \%$ of HPDI engine vehicle emissions and $4.4 \%$ of the overall emissions. $23,347,738,985$ grams of methane per year $(0.58 \mathrm{~g} / \mathrm{kg}$ fuel $)$ were due to manual ventilation. Manual ventilation was performed to expedite the refueling process and can be removed with regulations and improved training.

- Transit busses had the highest FSME (18.06 g/kg fuel). However 15 liter long haul HPDI engine OTR tractors produced the most methane overall (28.4\%) due to its high population.

- A 52.4\% reduction in FSME can be achieved if dynamic ventilation and manual ventilation were removed (from $16.16 \mathrm{~g} / \mathrm{kg}$ fuel to $8.47 \mathrm{~g} / \mathrm{kg}$ fuel) for the 15 liter long haul HPDI engine OTR tractors The 15 liter long haul HPDI engine OTR tractors would have lower FSME than 12 liter long haul SI engine OTR tractors (11.48 for LNG and $8.94 \mathrm{~g} / \mathrm{kg}$ for $\mathrm{CNG})$.

(2) For the medium emissions and fuel consumption, medium population, and medium HPDI penetration scenarios (control case), the model estimated:

- FSME were reduced by nearly 4 fold between the stasis emissions and fuel scenario $(13.21 \mathrm{~g} / \mathrm{kg}$ fuel $)$ and the medium emissions and fuel scenario $(3.31 \mathrm{~g} / \mathrm{kg}$ fuel $)$.

- The estimation model predicts a FSME of $3.31 \mathrm{~g} / \mathrm{kg}$ fuel $(0.33 \%$ of fuel consumed) in year 2035 with the control scenarios. CNG vehicles $(2.30 \mathrm{~g} / \mathrm{kg}$ fuel $)$ had lower emissions than LNG vehicles ( $4.11 \mathrm{~g} / \mathrm{kg}$ fuel), mostly due to higher station emissions and manual ventilation of HPDI engine vehicles.

- OTR tractors were the largest contributor (92.2\%) due to a larger population of vehicles.

- 15 liter HPDI engine OTR tractors had the highest FSME (5.20 g/kg fuel), mostly due to manual ventilation of HPDI engine vehicle fuel tanks.

- Tailpipe emissions were the largest source of methane (43.2\%).

(3) The impact of the population scenario was the following:

- Increasing the population by changing the population scenario had no effect of the FSME of each vehicle type, although the total methane released increased proportionally.

(4) The impact of the HPDI penetration scenario was the following:

- Increasing the percentage of HPDI engine vehicles in the HPDI penetration scenario weighted the HPDI engine OTR tractors more heavily amongst the long haul OTR tractors, which also includes CNG and LNG 12L OTR tractors. The overall population was fixed. Since HPDI engine OTR tractors had higher emissions, the overall emissions increased as the HPDI penetration increased.

(5) The impact of CNG station utilization was the following:

- The CNG station utilization had a large impact on the CNG station FSME. The station FSME of the very low utilization (40 vehicles/station) and very high utilization (120 vehicles/station) were $166.3 \%$ and $77.9 \%$, respectively, of the default utilization (80 
vehicles/station). However the impact on the overall FSME was not as significant because vehicle emissions were the dominant emissions sources. The overall FSME of the very low utilization and were $105.0 \%$ and $98.3 \%$, respectively, of the default utilization.

\section{Future Work}

- A maintenance input was not included due to internal and external limitations. The emissions are due to planned or unplanned maintenances performed on natural gas vehicles. The maintenance service provider's ability to mitigate natural gas release (ability to capture natural gas or procedure to vent to atmosphere) and the type of maintenance required (ability to isolate the fuel tank) contribute to the amount of methane released. Emissions related to maintenances should be developed for more accuracy.

- The granularity for dynamic ventilation, station BOG, vehicle BOG, manual vent, and delivery emissions needs to be expanded upon and researched further.

- The justification for the emissions and fuel reduction scenarios, such as tailpipe reductions and improvement in fuel economy, needs to be explored further to determine how feasible the estimated reductions are and analyze the progress of their implementation.

- Three retrofit OTR tractors were examined in this study. The current measurements of retrofit OTR tractors were not representative of possible emissions in 2035. A complete examination of retrofit vehicles should be made to determine the feasibility of future use.

- The annual number of operational days for each vehicle type and number of times a vehicle refuels per day needs to be investigated in more detail. The OTR tractors need more information for the activity scenario as well, short haul in particular.

- The number of observations for the entire research effort should be increased in future work. Some vehicle types only had three observed vehicles: one vehicle with a set of chassis dynamometer driving schedules; one vehicle with a set of on-road tests; and one vehicle with both chassis dynamometer and on-road tests. Differences in model year or effect of different aftertreatment systems, if any, on vehicle emissions were not explored due to a limited number of vehicles tested.

- The current designs of stations were inconsistent. Even with a higher number of observations (relative to each vehicle type), the station data acquisition needs to be more thorough.

- The lost emissions were not considered when calculating the fuel being delivered by the stations. The fuel entering the engine was assumed to be the fuel delivered by the stations. Since most emission loss inputs were based on fuel consumed, this would need to be an iterative process to get the added fuel consumption due to total emissions loss to converge.

- A future study should be conducted to determine the effect of the fuel consumption increase (by accounting for the lost fuel) or reduction (by assuming fuel economy will improve) on station utilization and the standardization of station designs. 
- A comparison of the estimation model with current estimation models, such as GREET, should be made to determine the accuracy of the estimation model compared to previous models. 


\section{References}

Abramek, K. F. (2007). An Attempt at an Analytical Description of Blow-by Intensity to a Crankcase, Teka Komisji Motoryzacji i Energetyki Rolnictwa Polskiej Akademii Nauk Oddział w Lublinie. Lublin, 7.

ACT Research. (2012). The Future of Natural Gas Engines in Heavy Duty Trucks: The Diesel of Tomorrow? Retrieved May 30, 2014 from http://www.actresearch.net/wpcontent/uploads/2013/04/ACT_NGP.pdf

Adger, W. N., \& Brown, K. (1994). Land use and the causes of global warming. John Wiley \& Sons, Chichester, UK.

Allen, D. T., Torres, V. M., Thomas, J., Sullivan, D. W., Harrison, M., Hendler, A., Herndon, S., Kolb, C., Fraser, M., Hill, A. D., Lamb, B., Miskimins, J., Sawyer, R., and Seinfeld, J. H. (2013). Measurements of methane emissions at natural gas production sites in the United States. Proceedings of the National Academy of Sciences, 110(44), 17768-17773.

Alvarez, R. A., Pacala, S. W., Winebrake, J. J., Chameides, W. L., and Hamburg, S. P. (2012). Greater Focus Needed on Methane Leakage from Natural Gas Infrastructure. Proceedings of the National Academy of Sciences, 109(17), 6435-6440.

ANGA. (2012 a). U.S. and Canadian Natural Gas Vehicle Market Analysis: Market Segmentation. Obtained from Dr. Hailin Li.

ANGA. (2012 b). U.S. and Canadian Natural Gas Vehicle Market Analysis: Natural Gas Vehicle Industry Overview. Obtained from Dr. Hailin Li.

APTA. (2011). 2011 Public Transportation Fact Book, 62th Edition. America Public Transportation Association, April 2011. Retrieved May 30, 2014 from http://www.apta.com/resources/statistics/Documents/FactBook/APTA_2011_Fact_Book.pdf

APTA, (2013). 2013 Public Transportation Fact Book, 64th Edition. America Public Transportation Association, October 2013. Retrieved May 30, 2014 from http://www.apta.com/resources/statistics/Documents/FactBook/2013-APTA-Fact-Book.pdf

Arrhenius, S. (1896). XXXI. On the Influence of Carbonic Acid in the Air Upon the Temperature of the Ground. The London, Edinburgh, and Dublin Philosophical Magazine and Journal of Science, 41(251), 237-276.

Bata, R., Clark, N., Gautam, M., Howell, A., Long, T., Loth, J., Lyons, D. (PI), Palmer, M., Rapp, B., Smith, J., and Wang, W. (1991). The First Transportable Heavy Duty Vehicle Emissions Testing Laboratory. SAE Paper 912668.

Beer, T., Grant, T., Williams, D., and Watson, H. (2002). Fuel-Cycle Greenhouse Gas Emissions from Alternative Fuels in Australian Heavy Vehicles. Atmospheric Environment, 36(4), 753763. 
Boriboonsomsin, K., Scora, G., Wu, G., and Barth, M., (2011). Improving Vehicle Fleet, Activity, and Emissions Data for On-Road Mobile Sources Emissions Inventories. Center for Environmental Research and Technology, University of California at Riverside.

Boucher, O., Friedlingstein, P., Collins, B., and Shine, K. P. (2009). The indirect global warming potential and global temperature change potential due to methane oxidation. Environmental Research Letters, 4(4), 044007.

Burnette, A. (2014). Comparison of PEMS, PAMS, and Daily Logged Fuel Efficiency Data for Refuse Haulers in a Municipal Fleet. In PEMS 2014 International Conference and Workshop at CE-CERT, April 3-4, 2014.

Burnham, A., Wang, M. Q., \& Wu, Y. (2006). Development and Applications of GREET 2.7-The Transportation Vehicle-Cycle Model (No. ANL/ESD/06-5). Argonne National Labratory.

Byers, J. W. (2006). Commodity Storage Valuation: A Linear Optimization Based on Traded Instruments. Energy Economics, 28(3), 275-287.

Cadle, S. H., Ayala, A., Black, K. N., Fulper, C. R., Graze, R. R., Minassian, F., Marray H. B., Natarajan, M., Tennant, C. J., and Lawson, D. R. (2007). Real-world Vehicle Emissions: A Summary of the Sixteenth Coordinating Research Council On-road Vehicle Emissions Workshop. Journal of the Air and Waste Management Association, 57(2), 139-145.

Calcagno, J. A. (2005). Evaluation of Heavy-duty Diesel Vehicle Emissions During Cold-start and Steady-state Idling Conditions and Reduction of Emissions from a Truck-stop Electrification Program.

Capps, G., Franzese, O., Knee, B., Lascurain, M.B., and Otaduy, P., (2008). Class-8 Heavy Truck Duty Cycle Project Final Report. Oak Ridge National Laboratory, ORNL/TM-2008/122.

Cardwell, D., and Krauss, C. (2013). Natural Gas Use in the Long-Haul. Retrieved September 29, 2013, from New York Times: http://www.nytimes.com/2013/04/23/business/energyenvironment/natural-gas-use-in-long-haul-trucks-expected-to-rise.html?pagewanted=all\&_r=0

Caterpillar (2006). Understanding Tractor-Trailer Performance. LEGT6380. Retrieved May 29, 2013, from http://pdf.cat.com/cda/files/2222280/7/legt6380.pdf

Caulton, D. R., Shepson, P. B., Santoro, R. L., Sparks, J. P., Howarth, R. W., Ingraffea, A. R., Cambaliza, M. O. L., Sweeney, C., Karion, A., Davis, K. J., Stirm, B. H., Montzka, S. A., and Miller, B. R. (2014). Toward a Better Understanding and Quantification of Methane Emissions from Shale Gas Development. Proceedings of the National Academy of Sciences, 111(17), 62376242.

Chen, Q. S., Wegrzyn, J., and Prasad, V. (2004). Analysis of Temperature and Pressure Changes in Liquefied Natural Gas (LNG) Cryogenic Tanks. Cryogenics, 44(10), 701-709.

Chesapeake Energy. (n.d.). Natural Gas Vehicles Are the Solution to Lower School Bus Emissions. $\quad$ Retrieved May 30, 2013, from http://www.cngnow.com/Tagged\%20PDFs/CHK_Solution.pdf 
Chiu, J.P., Wegrzyn, J., and Murphy, K.E., (2004). Low Emissions Class 8 Heavy-Duty OnHighway Natural Gas and Gasoline Engine. SAE Paper 2004-01-2982

Clark, N. N., Gautam, M., Bata, R. M., Loth, J. L., Palmer, G. M., and Lyons, D. W. (1995). Technical Report: Design and Operation of a New Transportable Laboratory for Emissions Testing of Heavy Duty Trucks and Buses. Heavy Vehicle Systems: A Special Series of the International Journal of Vehicle Design, 2(3/4).

Clark, N. N., Tatli, E., Barnett, R., Wayne, W. S., and McKain, D. L. (2006). Characterization and Abatement of Diesel Crankcase Emissions. SAE Paper 2006-01-3372.

Clark, N.N., Zhen, F., Wayne, S., and Lyons, D.W., (2007). "Transit Bus Life Cycle Cost and Year 2007 Emissions Estimation Final Report," FTA-WV-26-7004.2007.1,

Code of Federal Regulations. CFR Title 40 Part 86. (1990). Office of the Federal Register National Archives and Records Administration, Washington, DC.

Code of Federal Regulations. CFR Title 40 Part 1036.108. (2014). Office of the Federal Register National Archives and Records Administration, Washington, DC.

Cooper, E., Arioli, M., Carrigan, A., and Jain, U. (2012). Exhaust Emissions of Transit BusesSustainable Urban Transportation Fuels and Vehicles. Working paper. Np: EMBARQ, 2012. Print.

Davis, N., Lents, J., Osses, M., Nikkila, N., and Barth, M. (2005). Part 3: Developing Countries: Development and Application of an International Vehicle Emissions Model. Transportation Research Record: Journal of the Transportation Research Board, 1939(1), 155-165.

de la Houssaye, M., and White, A. (n.d.). Economics of Composting and MSW. Retrieved November 112013 from Coalition for Resource Recovery: http://thecorr.org/EconomicsofCompostingandMSW.pdf

DieselNet. (n.d.). Emission Test Cycles. Retrieved May 28, 2013, from DieselNet: http://www.dieselnet.com/standards/cycles/

EDF. (2015). Natural gas: Five areas of concern. Retrieved March 30, 2015, from http://www.edf.org/climate/five-areas-of-concern

EIA. (2014). U.S. Natural Gas Vehicle Fuel Consumption (Million Cubic Feet). Retrieved April 23, 2014, from http://www.eia.gov/dnav/ng/hist/n3025us2M.htm

Eilbert, A. (2013). Update to MOVES Vehicle Populations. FACA MOVES Review Workgroup July 9, 2013. $\quad$ Retrieved $\quad$ May $30, \quad 2014$ from http://www.epa.gov/otaq/models/moves/documents/faca-meeting-jul2013/02-population-201307-09.pdf

Einewall, P., Tunestål, P., and Johansson, B. (2005). Lean Burn Natural Gas Operation vs. Stoichiometric Operation with EGR and a Three Way Catalyst. SAE Paper 2005-01-0250.

EPA. (2010). Methane and Nitrous Oxide Emissions from Natural Sources, EPA 430-R-10-001 
EPA. (2013 a). Inventory of U.S. Greenhouse Gas Emissions and Sinks: 1990-2011, EPA 430-R13-001

EPA. (2013 b). Methane Emissions Climate Change US EPA. Retrieved November 16, 2013, from United States Environmental Protection Agency: http://epa.gov/climatechange/ghgemissions/gases/ch4.html

FairTran. (2010). National FairTran Rates. Retrieved November 10, 2013, from FairTran: http://www.fairtran.com/fairtrans/ResearchMethod.aspx

Feist, M. D., Landau, M., and Harte, E. (2010). The Effect of Fuel Composition on Performance and Emissions of a Variety of Natural Gas Engines. SAE Paper 2010-01-1476.

Fishman, J., Ramanathan, V., Crutzen, P.J., and Liu, S.C. (1980). Tropospheric Ozone and Climate. Nature 282, 818-820.

Fisk, M. (2013). Trucks Get a Second (or Third) Life. Waste and Recycling News.

Fontaras, G., Martini, G., Manfredi, U., Marotta, A., Krasenbrink, A., Maffioletti, F., Terenghi, R., and Colombo, M. (2012). Assessment of On-road Emissions of Four Euro V Diesel and CNG Waste Collection Trucks for Supporting Air-quality Improvement Initiatives in the City of Milan. Science of the Total Environment, 426, 65-72.

Gaines, L., Vyas, A., and Anderson, J. L. (2006). Estimation of Fuel Use by Idling Commercial Trucks. Transportation Research Record: Journal of the Transportation Research Board, 1983(1), 91-98.

Gallagher, M. (2013). The Future of Natural Gas as a Transportation Fuel - Findings of the NPC Study. A Presentation for the Transportation Research Board. Washington, D.C.

Gao, Z., LaClair, T. J., Daw, C. S., Smith, D. E., and Franzese, O. (2014). Simulations of the Fuel Economy and Emissions of Hybrid Transit Buses over Planned Local Routes. SAE Paper 2014-01-1562.

Gordon, D., Burdelski, J., and Cannon, J. S. (2003). Greening Garbage Trucks: New Technologies for Cleaner Air. INFORM.

Graboski, M. S., McCormick, R. L., Newlin, A. W., Dunnuck, D. L., Kamel, M. M., and Ingle, W. D. (1997). Effect of Fuel Composition and Altitude on Regulated Emissions from a LeanBurn, Closed Loop Controlled Natural Gas Engine. SAE Paper 971707.

Greenwood, S. J., Coxon, J. E., Biddulph, T., and Bennett, J. (1996). An Investigation to Determine the Exhaust Particulate Size Distributions for Diesel, Petrol, and Compressed Natural Gas Fuelled Vehicles. SAE Paper 961085.

Greyhound. (n.d.). Greyhound Facts and Figures. Retrieved November 10, 2013, from Greyhound: https://www.greyhound.com/en/about/factsandfigures.aspx

Harrison MR, Galloway KE, Hendler A, Shires TM, Allen D, Foss M, Thomas J, Spinhirne J. (2011). Natural Gas Industry Methane Emission Factor Improvement Study, Final Report, 
Cooperative Agreement (with US EPA) XA-83376101. Austin, TX: University of Texas; In: http://www.utexas.edu/research/ceer/GHG/files/FReports/XA_83376101_Final_Report.pdf

Hayes, R. E. (2004). Catalytic Solutions for Fugitive Methane Emissions in the Oil and Gas Sector. Chemical Engineering Science, 59(19), 4073-4080.

Heck, R. M., and Farrauto, R. J. (2001). Automobile Exhaust Catalysts. Applied Catalysis A: General, 221(1), 443-457.

Houghton, J. T. (Ed.). (1995). Climate change, 1994: Radiative forcing of climate change and an evaluation of the IPCC IS92 emission scenarios. Cambridge University Press.

Huai, T., Shah, S.D., Miller, J.W., Younglove, T., Chernich, D.J., and Ayala, A., (2006). "Analysis of Heavy-duty Diesel Truck Activity and Emissions Data," Atmospheric Environment, 40, pp. 2333-2334

IMechE. (2013). Internal Combustion Engines: Improving Performance, Fuel Economy and Emissions: 27-28 November 2013, (p. 130). Woodhead Publishing Limited, Cambridge, UK.

Intergovernmental Panel on Climate Change. (2001). Climate change 2001: The Scientific Basis. In: Houghton, J.T. (Ed.), Contribution of Working Group I to the Third Assessment Report of the Intergovernmental Panel on Climate Change. Cambridge Univ. Press, New York, p. 881.

Karakurt, I., Aydin, G., and Aydiner, K. (2012). Sources and Mitigation of Methane Emissions by Sectors: A Critical Review. Renewable energy, 39(1), 40-48.

Karavalakis, G., Hajbabaei, M., Durbin, T. D., Johnson, K. C., Zheng, Z., and Miller, W. J. (2013). The Effect of Natural Gas Composition on the Regulated Emissions, Gaseous Toxic Pollutants, and Ultrafine Particle Number Emissions from a Refuse Hauler Vehicle. Energy, 50, 280-291.

Krishnamurthy, M. (2003). Characterization of In-Use Emissions from On-Highway Heavy-Duty Diesel Engines (Doctoral dissertation, West Virginia University).

Kruse, R. E., \& Huls, T. A. (1973). Development of the Federal Urban Driving Schedule. SAE Paper 730553.

Lashof, D. A., and Ahuja, D. R. (1990). Relative Contributions of Greenhouse Gas Emissions to Global Warming. Nature 344, 529-531. doi:10.1038/344529a0.

Laver, R., Schneck, D., Skorupski, D., Brady, S., and Cham, L. (2007). Useful Life of Transit Buses and Vans (No. FTA-VA-26-7229-07.1).

Li, H., and Karim, G. A. (2005 a). Exhaust Emissions from an SI Engine Operating on Gaseous Fuel Mixtures Containing Hydrogen. International Journal of Hydrogen Energy, 30(13), 14911499.

Li, H., and Karim, G. A. (2005 b). An Experimental Investigation of SI Engine Operation on Gaseous Fuels Lean Mixtures. SAE Paper 2005-01-3765. 
Li, J. M., Lin, Z., LaClair, T., Davidson, D., Xu, A., Guensler, R. L., Rodgers, M., O., and Lee, D. Y. (2014). Evaluation of GHG Emission across Transit Bus Technologies with Real-World Driving Schedules. In Transportation Research Board 93rd Annual Meeting (No. 14-0680).

Liss, W. (2012). Demand Outlook: A Golden Age of Natural Gas. Chemical Engineering Progress, 108(8), 35-40.

Manabe, S., and Wetherald, R. T. (1967). Thermal Equilibrium of the Atmosphere with a Given Distribution of Relative Humidity.

McKain, D. L., Clark, N., Balon, T. H., Moynihan, P. J., Lynch, S. A., and Webb, T. C. (2000). Characterization of Emissions from Hybrid-electric and Conventional Transit Buses. SAE Paper 2000-01-2011.

Melendez, M., Taylor, J., Zuboy, J., Wayne, W. S., and Smith, D. (2005). Emission Testing of Washington Metropolitan Area Transit Authority (WMATA) Natural Gas and Diesel Transit Buses (No. NREL/TP-540-36355). Golden, CO: National Renewable Energy Laboratory.

Milich, L. (1999). The Role of Methane in Global Warming: Where Might Mitigation Strategies be Focused?, Global Environmental Change, 9, 179-201.

Molina, M.J., and Rowland, F.S. (1974). Stratospheric Sink for Chlorofluorocarbons: Chlorine Atom Catalysed Destruction of Ozone. Nature 249, 810.

Navigant Research. (2013). Global Natural Gas Vehicle Sales and Refueling Infrastructure Forecasts: 2013-2020.

NGV America. (2013 a). About NGVs. Retrieved September 28, 2013, from Natural Gas Vehicles for America: http://www.ngvc.org/about_ngv/

NGV America. (2013 b). Federal NGV Tax Incentives. Retrieved April 2, 2014, from NGV America: http://www.ngvamerica.org/incentives/federalTax.html

NRC. (2010). Technologies and Approaches to Reducing the Fuel Consumption of Medium- and Heavy-Duty Vehicles. Washington DC: National Academies Press.

Ostria, S. J. (1996). Assessing Emissions Contribution of Intercity Trucking. Transportation Research Record: Journal of the Transportation Research Board, 1520(1), 35-43.

Pastorello, C., Dilara, P., and Martini, G. (2011). Effect of a Change Towards Compressed Natural Gas Vehicles on the Emissions of the Milan Waste Collection Fleet. Transportation Research Part D: Transport and Environment,16(2), 121-128.

Querol, E., Gonzalez-Regueral, B., García-Torrent, J., and García-Martínez, M. J. (2010). Boil Off Gas (BOG) Management in Spanish Liquid Natural Gas (LNG) Terminals. Applied Energy, 87(11), 3384-3392.

Rakha, Hesham, Kyoungho Ahn, and Antonio Trani (2003). "Comparison of MOBILE5a, MOBILE6, VT-MICRO, and CMEM Models for Estimating Hot-stabilized Light-duty Gasoline Vehicle Emissions." Canadian Journal of Civil Engineering 30.6: 1010-1021. 
Ramanathan, V. and Feng, Y. (2009). Air pollution, Greenhouse Gases and Climate Change: Global and Regional Perspectives, Atmospheric Environment, Volume 43, Issue 1, pp. 37-50, http://dx.doi.org/10.1016/j.atmosenv.2008.09.063.

Raval, A. and Ramanathan, V. (1989). Observational Determination of the Greenhouse Effect. Nature, 342(6251), 758-761.

Shah, S. D., Cocker, D. R., Miller, J. W., and Norbeck, J. M. (2004). Emission Rates of Particulate Matter and Elemental and Organic Carbon from In-Use Diesel Engines. Environmental Science \& Technology, 38(9), 2544-2550.

Shin, Y., and Lee, Y. P. (2009). Design of a Boil-off Natural Gas Reliquefaction Control System for LNG Carriers. Applied Energy, 86(1), 37-44.

Solomon, S., Plattner, G., Knutti, R., and Friedlingstein, P. (2009). Irreversible Climate Change Due to Carbon Dioxide Emissions, PNAS, Volume 106, Issue 6

Targa Resources and the Gas Processors Association. (2006). Methane Savings from Compressors and VRUs. Retrieved March 27, 2015 from http://www.oilandgasbmps.org/docs/GEN17-EPAStarMethaneSavings.pdf

Texas Transport Institute. (2009). Application of Landfill Gas as a Liquefied Natural Gas Fuel for Refuse Trucks in Texas. Retrieved October 16, 2013 http://tti.tamu.edu/group/airquality/files/2010/11/Application-of-Landfill-Gas-as-a-LiquefiedNatural-Gas-for-Refuse-Trucks-in-Texas.pdf

Thiruvengadam, A., Carder, D. K., Krishnamurthy, M., Oshinuga, A., and Gautam, M. (2011). Effect of an Economical Oxidation Catalyst Formulation on Regulated and Unregulated Pollutants from Natural Gas Fueled Heavy Duty Transit Buses. Transportation Research Part D: Transport and Environment, 16(6), 469-473.

U.S. Energy Information Administration. (2013). Annual Energy Outlook 2013. Retrieved November 25, 2014 http://www.eia.gov/forecasts/aeo/pdf/0383(2013).pdf

US DOT. (n.d.). Table 1-11: Number of U.S. Aircraft, Vehicles, Vessels, and Other Conveyances. Retrieved October 28, 2013, from United States Department of Transportation: http://www.rita.dot.gov/bts/sites/rita.dot.gov.bts/files/publications/national_transportation_statist ics/html/table_01_11.html

US Environmental Protection Agency, United States. MOVES2010 Highway Vehicle: Population and Activity Data. EPA420-R-10-026 2010.

Vieth, K. (2013). U.S. Class 8 Truck Transportation and Natural Gas: Evolution, Revolution or Bust? New Access to Energy Conference. Chicago: Federal Reserve Bank of Chicago.

Wagner, F. (2007). Heavy-Duty Truck Idle Reduction Technology Demonstrations. Retrieved November 18, 2014, from the U.S. Department of Energy: https://www1.eere.energy.gov/vehiclesandfuels/avta/pdfs/heavy/2006_idle_reduction_rpt.pdf 
Walkowicz, K., Wayne, S., Nine, R., Campbell, K., and Wiedemeier, G. (2003). Chassis Dynamometer Emission Measurements from Refuse Trucks Using Dual-Fuel ${ }^{\mathrm{TM}}$ Natural Gas Engines. SAE Paper 2003-01-3366.

Wang, M. Q. (1996). GREET 1.0--Transportation Fuel Cycles Model: Methodology and Use. 1996, Argonne National Laboratory. Center for Transportation Research: Argonne, IL, 78.

Wang, M. Q. (1999). GREET 1.5-Transportation Fuel-cycle Model-Vol. 1: Methodology, Development, Use, and Results. Argonne National Lab., IL (United States). Funding Organization: US Department of Energy (United States).

Wang, M. Q. (2001). Development and Use of GREET 1.6 Fuel-cycle Model for Transportation Fuels and Vehicle Technologies. Argonne National Lab., IL (United States). Funding Organization: US Department of Energy (United States).

Wang, M. Q., and Huang, H. S. (2000). A Full Fuel-cycle Analysis of Energy and Emissions Impacts of Transportation Fuels Produced from Natural Gas (No. ANL/ESD--40). Argonne National Lab., IL (US).

Wang, W. G., Clark, N. N., Lyons, D. W., Yang, R. M., Gautam, M., Bata, R. M., and Loth, J. L. (1997). Emissions Comparisons from Alternative Fuel Buses and Diesel Buses with a Chassis Dynamometer Testing Facility. Environmental science and technology, 31(11), 3132-3137.

Wang,W.-C., Yung, Y.L., Lacis, A.A., Mo, T., and Hansen, J.E. (1976). Greenhouse Effects Due to Man-made Perturbation of Trace Gases. Science, 194, 685-690.

Wayne, W. S., Clark, N. N., Nine, R. D., and Elefante, D. (2004). A Comparison of Emissions and Fuel Economy from Hybrid-Electric and Conventional-Drive Transit Buses. Energy \& fuels, 18(1), 257-270.

Wegrzyn, J., and Gurevich, M. (2000). Liquefied Natural Gas for Trucks and Buses. SAE Paper 2000-01-2210.

Wiedmann, T. and Minx, J. (2008). A Definition of 'Carbon Footprint'. In: C. C. Pertsova, Ecological Economics Research Trends: Chapter 1, pp. 1-11, Nova Science Publishers, Hauppauge NY, USA.

William. (2012). ECUA Gets New Natural Gas Garbage Trucks, ESP To Build Fueling Stations. Retrieved November 11, 2013, from NorthEscambia: http://www.northescambia.com/2012/06/ecua-gets-new-natural-gas-garbage-trucks-esp-to-buildfueling-stations

Willner, K. (2013). "Testing of Unregulated Emissions from Heavy Duty Natural Gas Vehicles," SGC Report 2013:289, Swedish Gas Technology Centre,

Wuebbles, D. J., and Hayhoe, K. (2000). Atmospheric Methane: Trends and Impacts. In Non$\mathrm{CO}_{2}$ Greenhouse Gases: Scientific Understanding, Control and Implementation (pp. 1-44). Springer Netherlands. 
Yusuf, R. O., Noor, Z. Z., Abba, A. H., Hassan, M. A. A., and Din, M. F. M. (2012). Methane Emission by Sectors: A Comprehensive Review of Emission Sources and Mitigation Methods. Renewable and Sustainable Energy Reviews,16(7), 5059-5070.

Zielinska, B., Campbell, D., Lawson, D. R., Ireson, R. G., Weaver, C. S., Hesterberg, T. W., Larson, T., Davey, M., \& Liu, L. J. S. (2008). Detailed Characterization and Profiles of Crankcase and Diesel Particulate Matter Exhaust Emissions Using Speciated Organics. Environmental Science \& Technology, 42(15), 5661-5666. 


\section{Appendix}

\section{Appendix Table of Contents}

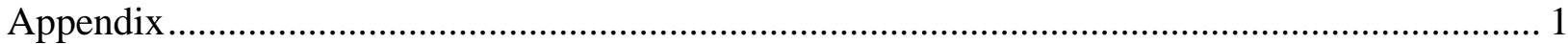

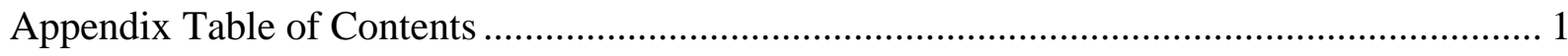

List of Appendix Tables............................................................................................... 2

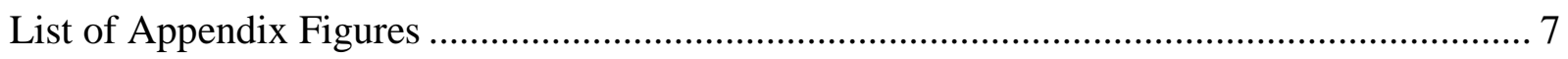

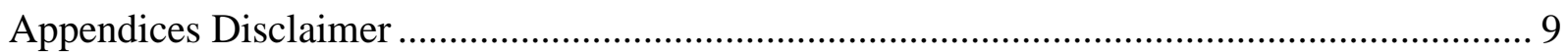

Appendix A Chassis Dynamometer Driving Schedules Tested ......................................... A-10

Appendix B Methane Emissions from Tailpipe, Crankcase, and HPDI Ventilation........... B-14

Appendix C CNG Station Data Processing ............................................................... C-20

Appendix D Effect of CNG Station Utilization on Methane Emissions ........................... D-27

Appendix E Effect of Using a Standard CNG Station on Methane Emissions ....................E-45

Appendix F LNG Station Data Processing .....................................................................5-50

Appendix G Effect of LNG Station Utilization on Methane Emissions ............................ G-54 


\section{List of Appendix Tables}

Table A-1: Operational Data of Chassis Dynamometer Cycles Tested..................................... A-13

Table B-1: Summary of Vehicles Measured and Measurement Methods ................................ B-14

Table B-2: Methane Emissions from 9L SI NG Vehicles with Tailpipe Methane Emissions Measured Crankcase Methane Emissions Modeled ……………………………………...... B-15

Table B-3: Methane Emissions from 9L SI NG Vehicles with Tailpipe and Crankcase Methane Emissions Measured Separately ........................................................................................ B-15

Table B-4: Methane Emissions from SI NG Vehicles with Tailpipe and Crankcase Methane Measured Together …………………………………............................................... B-15

Table B-5: Methane Emissions from 15L HPDI Vehicles with Tailpipe and Dynamic Vent Methane Emissions Measured ……………………................................................... B-16

Table B-6: Methane Emissions from 12L SI NG Vehicles with Tailpipe Methane Emissions Measured and Crankcase Methane Emissions Modeled...................................................... B-16

Table B-7: Methane Emissions from 12L SI NG Vehicles with Tailpipe and Crankcase Methane Emissions Measured Separately .................................................................................. B-16

Table B-8: Methane Emissions from SI NG Vehicles with Tailpipe and Crankcase Methane

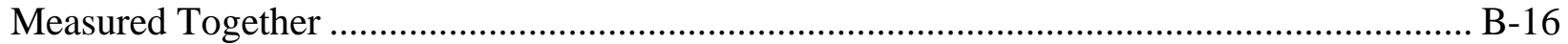

Table B-9: Tailpipe and Crankcase Emissions and DSEC for Three 9L Stoichiometric Transit

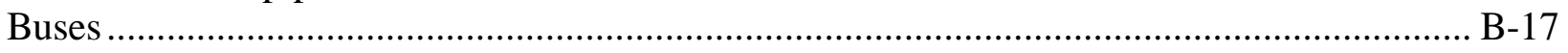

Table B-10: Tailpipe and Crankcase Emissions and DSEC for Five 9L Stoichiometric Refuse

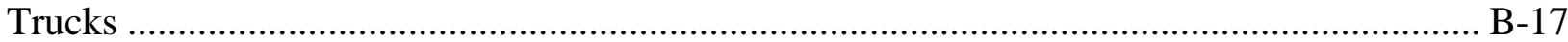

Table B-11: Tailpipe and Crankcase Emissions and DSEC for Three 9L Stoichiometric OTR

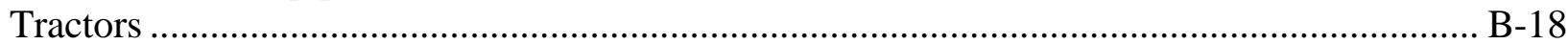

Table B-12: Tailpipe and Crankcase Emissions and DSEC for Three 12 L Stoichiometric OTR

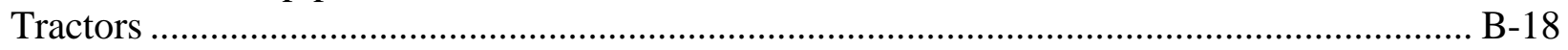

Table B-13: Tailpipe and Crankcase Emissions and DSEC for Four 15 L HPDI Engine OTR Tractors ........................................................................................................... B-19

Table C-1: Fuel Distribution Scenario Derived from the Estimation Model............................ C-20

Table C-2: Average Methane Emissions from CNG Stations …………………………….... C-21

Table C-3: Average FSME from CNG Station................................................................. C-21

Table C-4: Methane Emissions from Dispensing Nozzles Measured (Nozzle Dead Space and

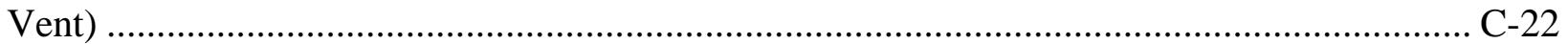

Table C-5: Actuator Emissions Associated with Vehicle Refueling Events ........................... C-22

Table C-6: Total Nozzle Emissions from CNG Stations ......................................................... C-23

Table C-7: The Compressor on/off Time (Station ID \#4) ………………………………….... C-23

Table C-8: Methane Emissions from Compressors (Station ID \#4) ....................................... C-24 
Table C-9: Methane Emissions from Continuous Emissions Sources (Station ID\#4) C-24

Table C-10: Summary of Methane Emissions from CNG Station (ID\#4)............................. C-24

Table C-11: Estimated Methane Emissions from Each CNG Station ................................... C-25

Table C-12: Average Methane Emissions from CNG Station ............................................ C-26

Table C-13: Average FSME from CNG Stations ............................................................ C-26

Table D-1: Total Station Methane Emissions Comparison of Transit Buses and 12 Liter OTR

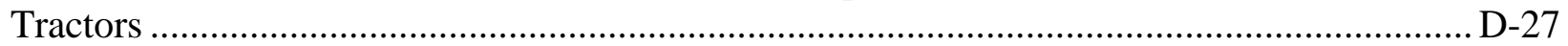

Table D-2: Methane Emissions from CNG Stations.......................................................... D-28

Table D-3: FSME (g/kg fuel) from CNG Stations......................................................... D-29

Table D-4: Impact of CNG Station Utilization (Number of Refueling Events) on Methane Emissions from CNG Stations for Transit Buses ............................................................ D-30

Table D-5: Impact of CNG Station Utilization (Number of Refueling Events) on Methane Emissions from CNG Stations for 12 Liter OTR Tractors ................................................. D-32

Table D-6: FSME from CNG Station Emissions for Transit Buses and 12L OTR Tractors... D-35

Table D-7: Summary of Case Studies for Effect of Over-Utilization and Under-Utilization .. D-37

Table D-8: Total Methane Emissions from 10 CNG Station Refueling 800 Transit Buses. Case 1: Evenly Utilized CNG Stations Refueling 80 Transit Buses in Each Station ......................... D-37

Table D-9: Total Methane Emissions from 10 CNG Station Refueling 800 Transit Buses. Case 2: Seriously Unevenly Utilized CNG Stations................................................................

Table D-10: Total Methane Emissions from 10 CNG Station Refueling 800 Transit Buses. Case 3: Medium Unevenly Utilized CNG Stations .................................................................. D-38

Table D-11: FSME from Each Source for Different Utilization Types for Transit Buses ....... D-38

Table D-12: Contribution of Each Source to Methane Emissions from CNG Stations for Each

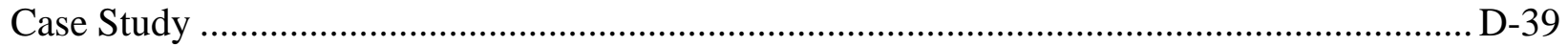

Table D-13: Total Methane Emissions from 10 CNG Station Refueling 800 OTR Tractors. Case 1: Evenly Utilized CNG Stations Refueling 80 OTR Tractors in Each Station ..................... D-39

Table D-14: Total Methane Emissions from 10 CNG Station Refueling 800 OTR Tractors. Case 2: Seriously Unevenly Utilized CNG Stations......................................................... D-39

Table D-15: Total Methane Emissions from 10 CNG Station Refueling 800 OTR Tractors. Case 3: Medium Unevenly Utilized CNG Stations ............................................................... D-40

Table D-16: Contribution of Each Source to Methane Emissions from CNG Stations for Each Case Study ....................................................................................................... D-40

Table D-17: Number of Vehicles and Stations for the Multiple Vehicle Types Case Study ... D-41

Table D-18: Total Methane Emissions from 60 CNG Station Refueling 4800 CNG Vehicles. Case 1: Each Type CNG Station Normally Utilized to Serve Specific Type of CNG Vehicles Only...... D-41 
Table D-19: Total Emissions from One Fully Utilized Station Type Refueling Three Different Vehicle Types per Station (60 Total)...... D-41

Table E-1: Compressor, Continuous, and Nozzle Emissions for an Average of All Measured Stations and the Standard Station E-45

Table E-2: Compressor, Continuous, and Nozzle FSME for an Average of All Measured Stations and the Standard Station E-46

Table E-3: Compressor Flow Rate and Emissions Rate for Each Station and Standard Station for Transit Buses..... E-46

Table E-4: Compressor, Continuous, and Nozzle Emissions for each Transit Bus Station and the Standard Transit Bus Station (kg/day). E-47

Table E-5: Compressor, Continuous, and Nozzle Emissions for an Average of All Measured Stations and the Standard Station E-47

Table E-6: Compressor, Continuous, and Nozzle FSME for an Average of All Measured Stations and the Standard Station .E-48

Table F-1: Average Methane Emissions from LNG Stations. .F-50

Table F-2: Average FSME from LNG Stations. F-50

Table F-3: Total Nozzle Emissions from All LNG Stations. F-51

Table F-4: Total Nozzle Emissions from LNG Stations. F-51

Table F-5: Methane Emissions from Continuous Emissions Sources F-52

Table F-6: Estimated Methane Emissions from All LNG Stations F-53

Table F-7: Average FSME from LNG Stations .F-53

Table G-1: Total LNG Station Methane Emissions Comparison of 15 Liter HPDI and 12 Liter SI OTR Tractors G-54

Table G-2: Methane Emissions from LNG Stations G-55

Table G-3: FSME (g/kg fuel) from LNG Station G-56

Table G-4: Impact of LNG Station Utilization (Number of Refueling Events) on Methane Emissions from LNG Stations for 15L HPDI OTR Tractors G-57

Table G-5: FSME from LNG Station Emissions for 15L HPDI and 12L SI OTR Tractors .... G-58 Table G-6: Summary of Case Studies for Effect of Over-Utilization and Under-Utilization .. G-59 Table G-7: Total Emissions from a Distribution of Ten Fully Utilized Stations Refueling 15L HPDI OTR Tractors (10 Total)..... G-59

Table G-8: Total Methane Emissions from 10 LNG Station Refueling 80015 Liter HPDI OTR Tractors. Case 1: Evenly Utilized LNG Stations Refueling 8015 Liter HPDI OTR Tractors in Each Station .... G-59

Table G-9: Total Methane Emissions from 10 LNG Station Refueling 80015 Liter HPDI OTR Tractors. Case 2: Seriously Unevenly Utilized LNG Stations. G-60 
Table G-10: FSME from Each Source for Different Utilization Types for 15L HPDI OTR

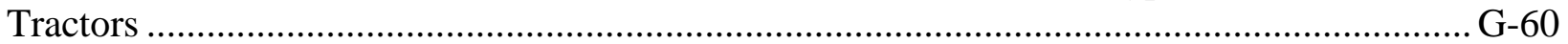

Table G-11: Methane Emissions from Each Source for Each Case Study ............................. G-60

Table G-12: Total Methane Emissions from 10 LNG Station Refueling 800 12L OTR Tractors. Case 1: Evenly Utilized LNG Stations Refueling 80 OTR Tractors in Each Station.............. G-61

Table G-13: Total Methane Emissions from 10 LNG Station Refueling 800 12L OTR Tractors. Case 2: Seriously Unevenly Utilized LNG Stations ..................................................... G-61

Table G-14: Total Methane Emissions from 10 LNG Station Refueling 800 12L OTR Tractors. Case 3: Medium Unevenly Utilized LNG Stations..... G-61

Table G-15: Number of Vehicles and Stations for the Multiple Vehicle Types Case Study ... G-62

Table G-16: Total Methane Emissions from 60 LNG Station Refueling 4800 LNG Vehicles. Case 1: Each Type LNG Station Normally Utilized to Serve Specific Type of LNG Vehicles Only...... G-62

Table G-17: Total Emissions from One Fully Utilized Station Type Refueling Three Different Vehicle Types per Station (60 Total) ............................................................................... G-63

Table H-1: Bins of Average Speed for Each Activity ......................................................63

Table H-2: Distance and Duration of Refuse Truck Operation in Each Activity .................... H-64

Table H-3: Percentage of Distance and Duration in Each Activity ........................................64

Table H-4: Driving Schedules Used in this Study ...............................................................64

Table H-5: Bins of Average Speed for Each Activity ...................................................

Table H-6: Original Distance of Refuse Truck Operation in Each Activity.............................-66

Table H-7: Original Duration of Refuse Truck Operation in Each Activity ......................... H-66

Table H-8: Scaled Distance of Refuse Truck Operation in Each Activity .............................H-67

Table H-9: Scaled Duration of Refuse Truck Operation in Each Activity ................................-67

Table H-10: Distance and Duration of Refuse Truck Operation in Each Activity ..................H-68

Table H-11: Refuse Truck Average Speed (mph) for Each Activity.................................... H-68

Table H-12: Percentage of Distance (\%) Driven for Each Activity .......................................6-69

Table H-13: Percentage of Duration (\%) for Each Activity ................................................ H-69

Table H-14: Percentage of Distance and Duration of Refuse Truck Operation Each Activity H-70

Table I-1: Bins of Average Speed for Each Activity ............................................................. I-71

Table I-2: Distance and Duration of Transit Bus Operation in Each Activity.......................... I-71

Table I-3: Percentage of Distance and Duration in Each Activity.........................................

Table I-4: Driving Schedules Used in this Study..............................................................

Table I-5: Bins of Average Speed for Each Activity ...........................................................

Table I-6: Distance of Transit Bus Operation in Each Activity.............................................. I-74 
Table I-7: Duration of Transit Bus Operation in Each Activity ……......................................-75

Table I-8: Distance and Duration of Transit Bus Operation in Each Activity............................. I-75

Table I-9: Transit Bus Average Speed (mph) for Each Activity .................................................

Table I-10: Percentage of Distance (\%) Driven for Each Activity .............................................-76

Table I-11: Percentage of Duration (\%) for Each Activity ........................................................

Table I-12: Percentage of Distance and Duration of Transit Bus Operation in Each Activity...I-77

Table J-1: Fraction of VMT and Total Annual Distance of Long Haul Heavy-duty OTR Tractors $\mathrm{J}-79$

Table J-2: Time Fraction of Heavy-duty OTR Tractor Operation for Each Speed Bin [Huai et al., 2006] $\mathrm{J}-80$

Table J-3: Fraction of VMT of Heavy-duty OTR Tractor Operation for Each Speed Bin [Huai et al., 2006] $\mathrm{J}-80$

Table J-4: Percentage of Idle and Total Idle Time for Long Haul heavy-Duty OTR Tractors [Wagner, 2007] $\mathrm{J}-80$

Table J-5: Fraction of VMT and Total Annual Distance of Short Haul Heavy-duty OTR Tractors [Boriboonsomsin et al., 2011] .................................................................................... J-81

Table J-6: Percentage of Time During Idle and Percentage of Miles During All Activities for Long Haul and Short Haul OTR Tractors ......................................................................... J-81

Table K-1: Current U.S. Natural Gas Vehicle Population ....................................................... K-82

Table K-2: Current U.S. Heavy-duty Natural Gas Vehicle Population [ANGA a, 2012] ......... K-82

Table K-3: U.S. Natural Gas Vehicle Future Projections ......................................................... K-83

Table K-4: EIA Natural Gas Consumption Projection for 2030 and 2040 in the Transportation

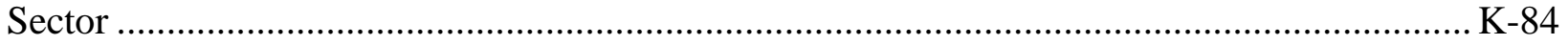

Table K-5: The Scenarios for USA Heavy-duty NG Vehicle Sector in 2035 .......................... K-88

Table K-6: The Scenarios for USA HD OTR Tractors in 2035 ............................................ K-89

Table K-7: Future Station Population ............................................................................... K-89

Table K-8: Projected Population of NG Fuel Stations for HD Natural Gas Refuse Tuck and

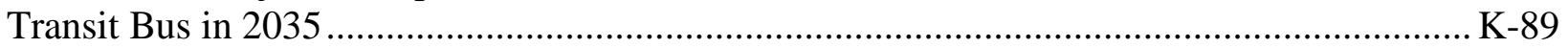

Table K-9: Projected Population of NG Fuel Stations for HD OTR Tractors in 2035 ............. K-90

Table K-10: Projected Population of NG Fuel Stations for HD NG Vehicle Sector in 2035 ... K-90 


\section{List of Appendix Figures}

Figure A-1: AQMD Refuse Truck Driving Schedule ..................................................... A-10

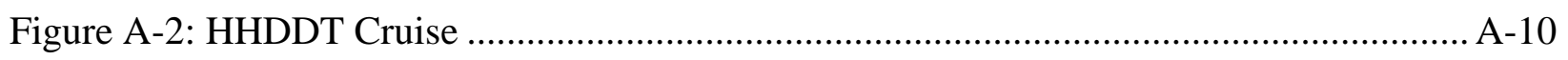

Figure A-3: HHDDT Transient Driving Schedule ....................................................... A-11

Figure A-4: UDDS Driving Schedule ...................................................................... A-11

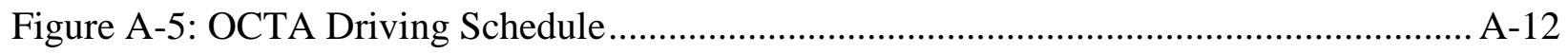

Figure A-6: Manhattan Driving Schedule................................................................. A-12

Figure D-1: Effect of Station Utilization on FSME from Compressors in CNG Stations for 12L

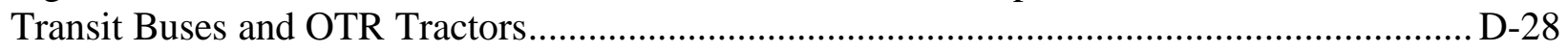

Figure D-2: Effect of Station Utilization on FSME from CNG Stations for Transit Buses ..... D-30

Figure D-3: Effect of Station Utilization on FSME from Compressors in CNG Stations for

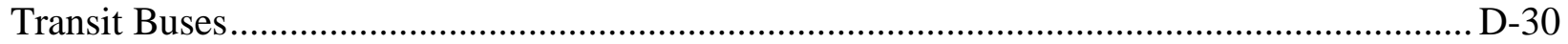

Figure D-4: Station Methane Emissions by Source for an Under-Utilized Transit Bus Station (20 Vehicles per Station) ...................................................................................... D-31

Figure D-5: Station Methane Emissions by Source for a Fully Utilized Transit Bus Station (80

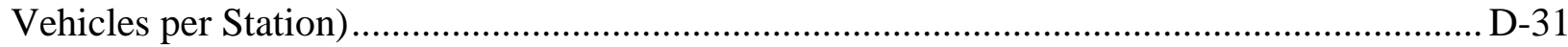

Figure D-6: Station Methane Emissions by Source for an Over-Utilized Transit Bus Station (160

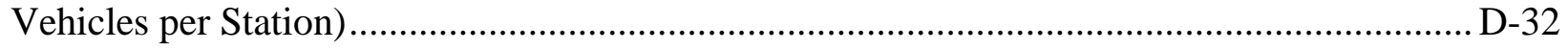

Figure D-7: Effect of Station Utilization on FSME from CNG Stations for 12 Liter OTR Tractors D-33

Figure D-8: Effect of Station Utilization on FSME from Compressors in CNG Stations for 12L

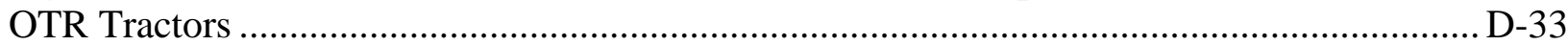

Figure D-9: Station Methane Emissions by Source for an Under-Utilized 12L OTR Tractor

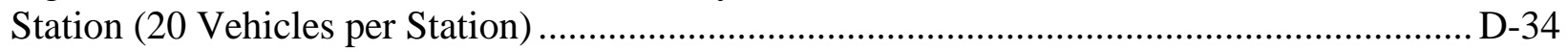

Figure D-10: Station Methane Emissions by Source for a Fully Utilized 12L OTR Tractor Station

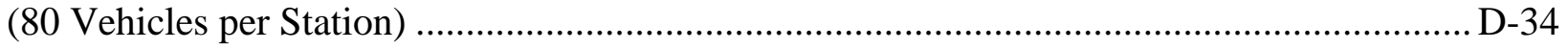

Figure D-11: Station Methane Emissions by Source for an Over-Utilized 12L OTR Tractor

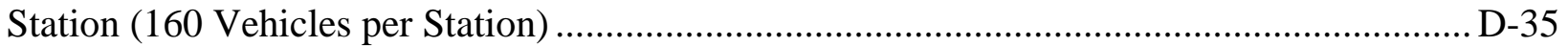

Figure D-12: Effect of Station Utilization on FSME from Compressors in CNG Stations for Transit Buses and 12L OTR Tractors ...................................................................... D-36

Figure D-13: Contributions of Compressor Emissions to Methane Emissions from Compressors

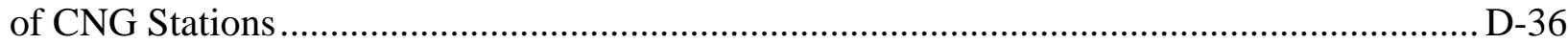

Figure G-1: Effect of Station Utilization on FSME from LNG Stations for 12L SI and 15L HPDI

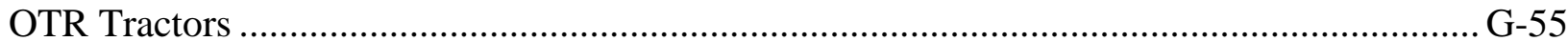

Figure G-2: Effect of Station Utilization on FSME from LNG Stations for 15L HPDI OTR

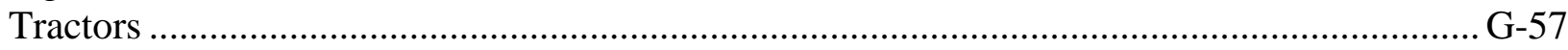

Figure H-1: Collection Route Measured by WVU .......................................................65 
Figure I-1: KAT Driving Schedule Reported in Literature [Gao, et al., 2014] ..... I-72

Figure I-2: KAT Driving Schedule with the Long Idle Operation Period Removed [Gao, et al., 2014]. I-73

Figure I-3: Commuter Driving Schedule Developed by WVU I-73

Figure J-1: VMT and Accumulated Fraction of VMT for Heavy-duty OTR Tractors Operated on Urban Restricted Roads. [Boriboonsomsin et al., 2011] $\mathrm{J}-78$

Figure J-2: Fraction of VMT and Accumulated Fraction of VMT of Heavy-duty OTR Tractor Operation. [Table 24, page 97, Capps, et al., 2008] .... J-79

Figure K-1: EIA Natural Gas Vehicle Projection [EIA, 2013] ........................................... K-83

Figure K-2: ACT Research Vehicle Projection Until 2030 [ACT, 2013] ............................. K-84

Figure K-3: NPC Projected HD NGV Market Share for Low, Medium (Reference Case), and high Penetration [NPC, 2012]. K-85

Figure K-4: Market Share of HD Natural Gas Vehicles Projected by ACT, ACFS, and NPC (reference case) [ACT 2012, ACSF 2013, and NPC 2012]...... $\mathrm{K}-86$

Figure K-5: Market Share of HD Natural Gas Vehicles Projected by ACT, ACFS, and NPC (reference case) [ACT 2012, ACSF 2013, and NPC 2012]..... $\mathrm{K}-86$

Figure K-6: Comparison of the Populations of Heavy-duty NG Vehicles Projected by EIA, NPC, ACSF, and ACT. [EIA, 2013, ACT 2012, ACSF 2013, and NPC 2012] ............................... K-87

Figure K-7: The Projected Low, Medium, and High Penetration Scenario. K-87 


\section{Appendices Disclaimer}

Each appendix represents a document presented to the steering committee, whose task was to guide the study. Any instance of "this document" refers to the appendix which the text is written. The purpose of each appendix was to provide more details for the data presented in this thesis. Less importance was placed on correcting grammatical errors than verifying that the data were correct. Some of these documents were co-authored by other research members, so formatting and writing styles may differ between appendices. 


\section{Appendix A Chassis Dynamometer Driving Schedules Tested}

The AQMD Refuse Truck Driving Schedule represents the collection portion of a refuse truck operation (Walkowicz et al., 2003). The AQMD Refuse Truck Driving Schedule is shown in Figure A-1.

\section{AQMD Refuse Truck}

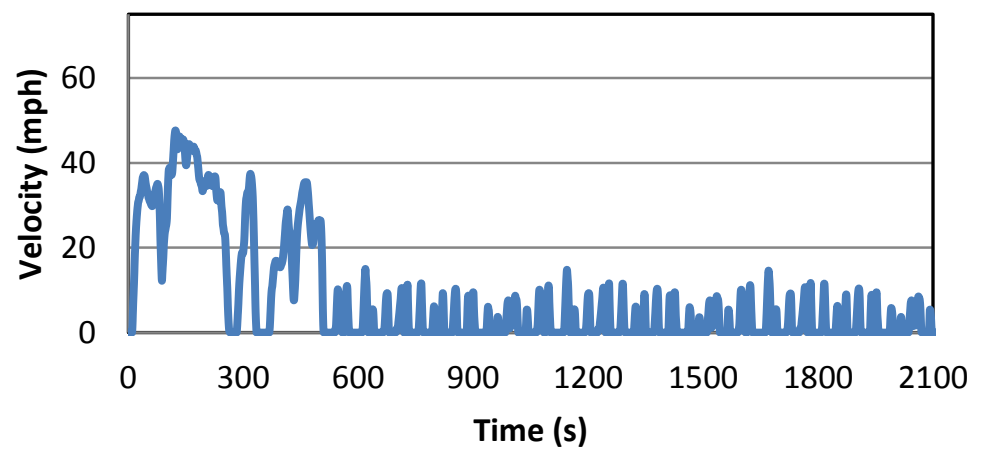

Figure A-1: AQMD Refuse Truck Driving Schedule

The HHDDT Cruise Driving Schedule represents a vehicle maintained at high speed over a period of time (Shah et al., 2004). This is representative of interstate travel, usually for OTR tractors. The HHDDT High Speed Cruise Driving Schedule is shown in Figure A-2.

\section{HHDDT High Speed Cruise}

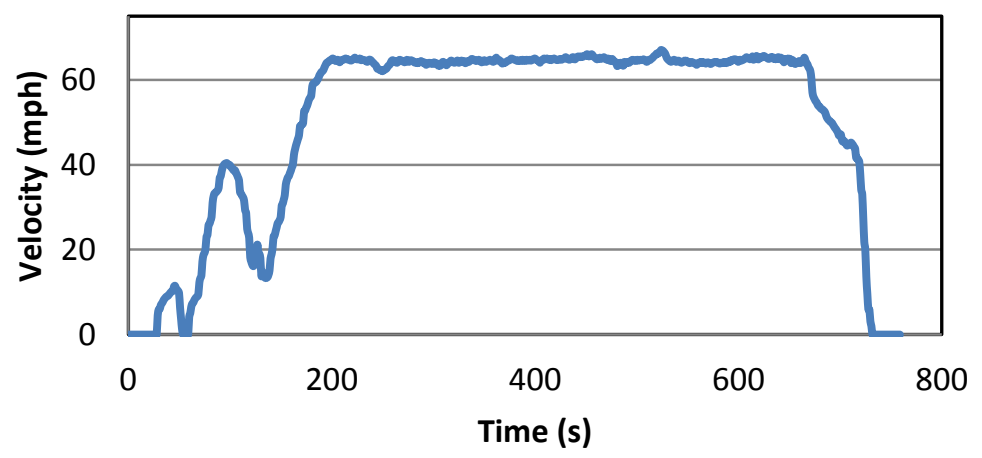

Figure A-2: HHDDT Cruise

The HHDDT Transient Driving Schedule represents rapid accelerations and decelerations over a period of time (Shah et al., 2004). The Transient Driving Schedule is shown in Figure A-3. 


\section{HHDDT Transient}

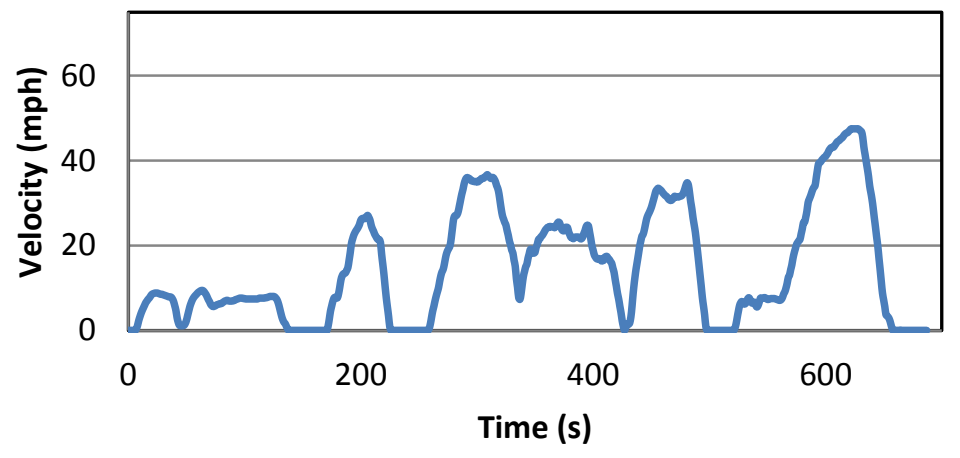

Figure A-3: HHDDT Transient Driving Schedule

The urban dynamometer driving schedule (UDDS) driving schedule was developed for testing heavy-duty vehicles on a chassis dynamometer (Kruse and Huls, 1973; CFR 40 Part 86, 1990). It is sometimes referred to as 'cycle D' (DieselNet). The UDDS is shown in Figure A-4.

\section{UDDS}

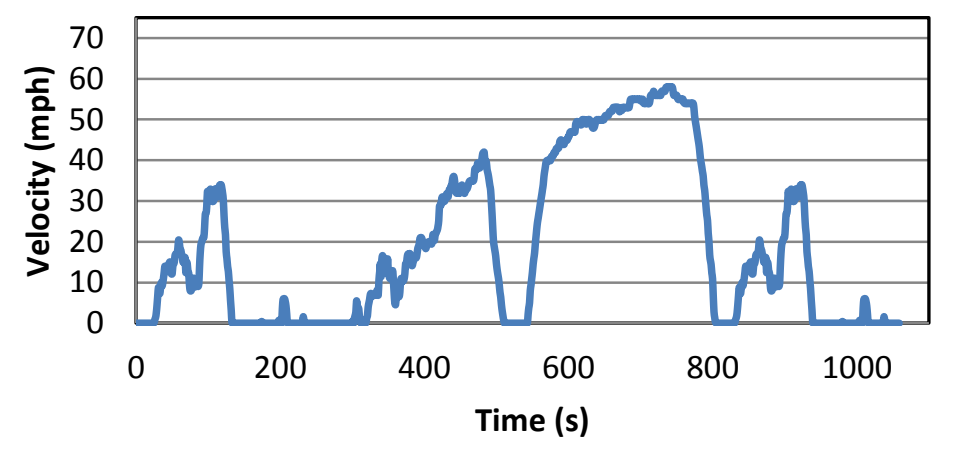

Figure A-4: UDDS Driving Schedule

The OCTA Driving Schedule was developed by West Virginia University from Orange County Transportation Authority test data to represent urban transit buses in the Los Angeles, California area (Wayne et al. 2004; DieselNet). The OCTA Driving Schedule is shown in Figure A-5. 


\section{OCTA}

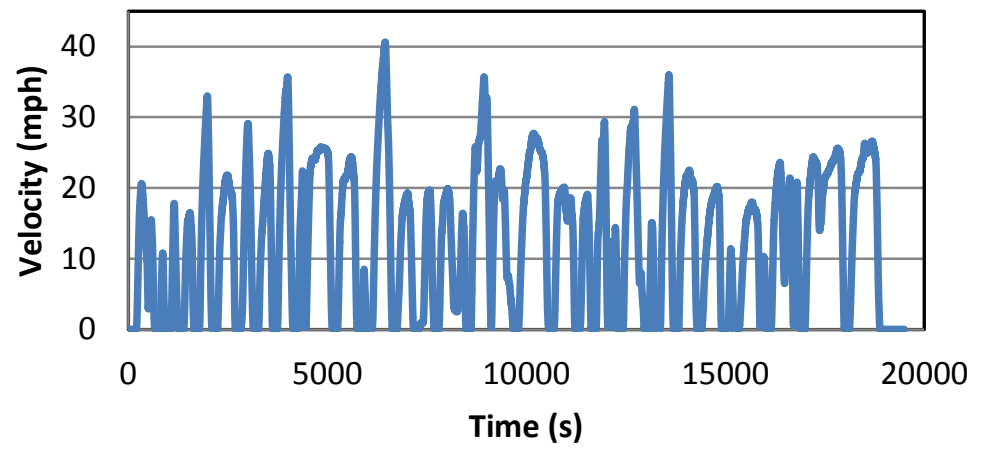

Figure A-5: OCTA Driving Schedule

The Manhattan Driving Schedule was developed by West Virginia University to represent urban transit buses in the Manhattan core of New York City, based on observed patterns (McKain et al., 2000). The Driving Schedule includes frequent stops and speeds below $25 \mathrm{mph}$ (DieselNet). The Manhattan Driving Schedule is shown in Figure A-6.

\section{Manhattan}

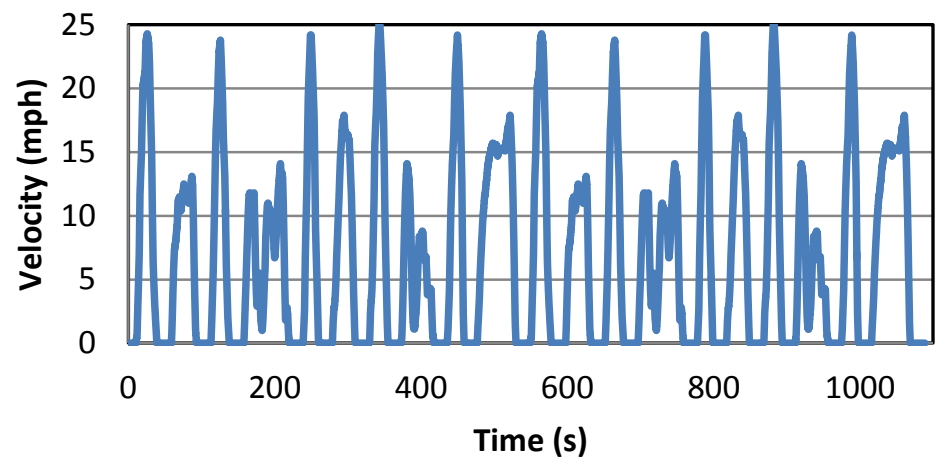

Figure A-6: Manhattan Driving Schedule

Table A-1 shows the operational data of the driving schedules tested on the chassis dynamometer. 
Table A-1: Operational Data of Chassis Dynamometer Cycles Tested

\begin{tabular}{|c|r|r|r|r|r|r|}
\hline \multicolumn{7}{|c|}{ Chassis Dynamometer } \\
\hline & $\begin{array}{c}\text { Distance } \\
\text { Traveled (mile) }\end{array}$ & $\begin{array}{c}\text { Average Speed } \\
(\mathrm{mph})\end{array}$ & $\begin{array}{c}\text { Total } \\
\text { Time }(\mathrm{s})\end{array}$ & $\begin{array}{c}\text { Idle } \\
\text { Time (s) }\end{array}$ & $\begin{array}{c}\text { Percent Idle } \\
\text { (\%) }\end{array}$ & $\begin{array}{c}\text { Average Non-idle } \\
\text { Speed (mph) }\end{array}$ \\
\hline AQMD Refuse Truck & 4.4 & 7.6 & 2116 & 964 & $46 \%$ & 13.9 \\
\hline HHDDT Cruise & 10.5 & 49.9 & 759 & 62 & $8 \%$ & 54.4 \\
\hline HHDDT Transient & 2.9 & 14.9 & 687 & 128 & $19 \%$ & 18.4 \\
\hline UDDS & 5.5 & 18.8 & 1059 & 349 & $33 \%$ & 28.1 \\
\hline Manhattan & 2.1 & 6.8 & 1089 & 389 & $36 \%$ & 10.6 \\
\hline OCTA & 6.5 & 12.1 & 1950 & 433 & $22 \%$ & 15.5 \\
\hline
\end{tabular}




\section{Appendix B Methane Emissions from Tailpipe, Crankcase, and HPDI Ventilation}

Table B-1: Summary of Vehicles Measured and Measurement Methods

\begin{tabular}{|c|c|c|c|c|c|c|}
\hline Vehicle & $\begin{array}{c}\text { Engine } \\
\text { Technology }\end{array}$ & $\begin{array}{l}\text { Test } \\
\text { Type }\end{array}$ & $\begin{array}{l}\text { Tailpipe } \\
\text { Measured }\end{array}$ & $\begin{array}{l}\text { Crankcase } \\
\text { Measured }\end{array}$ & $\begin{array}{l}\text { Crankcase } \\
\text { Modeled }\end{array}$ & $\begin{array}{c}\text { Tailpipe and } \\
\text { Crankcase Measured } \\
\text { Together }\end{array}$ \\
\hline OTR Tractor (V3) & SI Dedicated & Chassis & $\mathrm{x}$ & & $\mathrm{x}$ & \\
\hline OTR Tractor (V10) & SI Dedicated & On-Road & $x$ & & $\mathrm{x}$ & \\
\hline OTR Tractor (V10) & SI Dedicated & Chassis & $x$ & $x$ & & \\
\hline OTR Tractor (V10) & SI Dedicated & On-Road & & & & $x$ \\
\hline OTR Tractor (V11) & SI Dedicated & On-Road & $x$ & & $x$ & \\
\hline OTR Tractor (V11) & SI Dedicated & On-Road & & & & $x$ \\
\hline OTR Tractor (V17) & HPDI & Chassis & $x$ & & & \\
\hline OTR Tractor (V17) & $\mathrm{HPDI}$ & On-Road & $x$ & & & \\
\hline OTR Tractor (V18*) & $\mathrm{HPDI}$ & On-Road & $x$ & & & \\
\hline OTR Tractor (V19*) & $\mathrm{HPDI}$ & On-Road & $\mathrm{X}$ & & & \\
\hline OTR Tractor (V20) & $\mathrm{HPDI}$ & Chassis & $x$ & & & \\
\hline OTR Tractor (V20) & HPDI & On-Road & $x$ & & & \\
\hline OTR Tractor (V23) & SI Dedicated & Chassis & $x$ & $x$ & & \\
\hline OTR Tractor (V25) & SI Dedicated & Chassis & $\mathrm{X}$ & $\mathrm{x}$ & & \\
\hline OTR Tractor (V25) & SI Dedicated & On-Road & $x$ & & $\mathrm{x}$ & $\mathrm{x}$ \\
\hline OTR Tractor (V25) & SI Dedicated & On-Road & & & & $x$ \\
\hline OTR Tractor (V26) & SI Dedicated & Chassis & $x$ & $\mathrm{x}$ & & \\
\hline OTR Tractor (V26) & SI Dedicated & On-Road & $x$ & & $\mathrm{x}$ & \\
\hline Refuse Truck (V5) & SI Dedicated & Chassis & $x$ & & $\mathrm{X}$ & \\
\hline Refuse Truck (V6) & SI Dedicated & Chassis & $x$ & & $\mathrm{X}$ & \\
\hline Refuse Truck (V7) & SI Dedicated & Chassis & $x$ & & $\mathrm{X}$ & \\
\hline Refuse Truck (V7) & SI Dedicated & On-Road & $x$ & & $x$ & \\
\hline Refuse Truck (V7) & SI Dedicated & On-Road & & & & $x$ \\
\hline Refuse Truck (V7) & SI Dedicated & Chassis & $\mathrm{x}$ & $\mathrm{x}$ & & \\
\hline Refuse Truck (V12) & SI Dedicated & On-Road & & & & $\mathrm{x}$ \\
\hline Refuse Truck (V12) & SI Dedicated & On-Road & $x$ & & $x$ & \\
\hline Refuse Truck (V13) & SI Dedicated & On-Road & $x$ & & $\mathrm{X}$ & \\
\hline Refuse Truck (V13) & SI Dedicated & On-Road & & & & $x$ \\
\hline Transit Bus (V14) & SI Dedicated & Chassis & $\mathrm{X}$ & $\mathrm{x}$ & & \\
\hline Transit Bus (V15) & SI Dedicated & Chassis & $x$ & $x$ & & \\
\hline Transit Bus (V15) & SI Dedicated & On-Road & $x$ & & $\mathrm{x}$ & \\
\hline Transit Bus (V15) & SI Dedicated & On-Road & & & & $x$ \\
\hline Transit Bus (V16) & SI Dedicated & On-Road & $\mathrm{X}$ & & $\mathrm{X}$ & \\
\hline Transit Bus (V16) & SI Dedicated & On-Road & & & & $\mathrm{x}$ \\
\hline
\end{tabular}


Table B-2: Methane Emissions from 9L SI NG Vehicles with Tailpipe Methane Emissions Measured Crankcase Methane Emissions Modeled

\begin{tabular}{|c|c|r|r|r|r|r|r|}
\hline Vehicle & Test Type & $\begin{array}{c}\text { Total } \\
\text { Distance } \\
\text { (miles) }\end{array}$ & $\begin{array}{c}\text { Total } \\
\text { Duration } \\
\text { (hours) }\end{array}$ & $\begin{array}{c}\text { Fuel } \\
\text { Consumed } \\
(\mathrm{kg})\end{array}$ & $\begin{array}{c}\text { Tailpipe } \\
\text { Methane } \\
\text { (g) }\end{array}$ & $\begin{array}{c}\text { Crankcase } \\
\text { Methane } \\
(\mathrm{g})\end{array}$ & FSME (g/kg) \\
\hline OTR Tractor (V3) & Chassis & 28.8 & 0.9 & 20.7 & 128.2 & 96.2 & 10.9 \\
\hline OTR Tractor (V10) & On-Road & 115.0 & 3.4 & 66.8 & 256.6 & 443.9 & 10.5 \\
\hline OTR Tractor (V11) & On-Road & 155.2 & 5.1 & 95.8 & 336.1 & 620.7 & 10.0 \\
\hline Refuse Truck (V5) & Chassis & 21.2 & 1.7 & 18.3 & 79.1 & 169.1 & 13.6 \\
\hline Refuse Truck (V6) & Chassis & 28.0 & 2.0 & 21.9 & 99.1 & 192.3 & 13.3 \\
\hline Refuse Truck (V7) & Chassis & 20.9 & 1.7 & 17.0 & 77.9 & 170.1 & 14.6 \\
\hline Refuse Truck (V7) & On-Road & 135.4 & 5.6 & 81.8 & 206.2 & 638.1 & 10.3 \\
\hline Refuse Truck (V12) & On-Road & 38.9 & 5.3 & 58.4 & 100.9 & 502.7 & 10.3 \\
\hline Refuse Truck (V13) & On-Road & 42.4 & 3.7 & 37.7 & 63.2 & 341.7 & 10.7 \\
\hline Transit Bus (V15) & On-Road & 41.8 & 2.4 & 26.6 & 199.2 & 233.1 & 16.2 \\
\hline Transit Bus (V16) & On-Road & 42.0 & 2.2 & 27.5 & 250.4 & 229.5 & 17.4 \\
\hline
\end{tabular}

Table B-3: Methane Emissions from 9L SI NG Vehicles with Tailpipe and Crankcase Methane Emissions Measured Separately

\begin{tabular}{|c|c|r|r|r|r|r|r|}
\hline Vehicle & Test Type & $\begin{array}{c}\text { Total } \\
\text { Distance } \\
\text { (miles) }\end{array}$ & $\begin{array}{c}\text { Total } \\
\text { Duration } \\
\text { (hours) }\end{array}$ & $\begin{array}{c}\text { Fuel } \\
\text { Consumed } \\
(\mathrm{kg})\end{array}$ & $\begin{array}{c}\text { Tailpipe } \\
\text { Methane } \\
(\mathrm{g})\end{array}$ & $\begin{array}{c}\text { Crankcase } \\
\text { Methane } \\
(\mathrm{g})\end{array}$ & FSME (g/kg) \\
\hline OTR Tractor (V10) & Chassis & 28.9 & 0.9 & 21.5 & 101.8 & 120.2 & 10.3 \\
\hline Refuse Truck (V7) & Chassis & 27.8 & 2.0 & 22.2 & 101.4 & 213.5 & 14.2 \\
\hline Transit Bus (V14) & Chassis & 20.5 & 1.7 & 21.1 & 163.4 & 182.7 & 16.4 \\
\hline Transit Bus (V15) & Chassis & 20.6 & 1.7 & 18.5 & 175.9 & 150.5 & 17.7 \\
\hline
\end{tabular}

Table B-4: Methane Emissions from SI NG Vehicles with Tailpipe and Crankcase Methane Measured Together

\begin{tabular}{|c|r|r|r|r|r|r|}
\hline Vehicle & Test Type & $\begin{array}{c}\text { Total } \\
\text { Distance } \\
\text { (miles) }\end{array}$ & $\begin{array}{c}\text { Total } \\
\text { Duration } \\
\text { (hours) }\end{array}$ & $\begin{array}{c}\text { Fuel } \\
\text { Consumed } \\
\text { (kg) }\end{array}$ & $\begin{array}{c}\text { Total } \\
\text { Methane } \\
\text { (g) }\end{array}$ & FSME (g/kg) \\
\hline OTR Tractor (V10) & On-Road & 235.2 & 6.4 & 132.7 & 1186.4 & 8.9 \\
\hline OTR Tractor (V11) & On-Road & 233.3 & 6.8 & 133.9 & 1328.4 & 9.9 \\
\hline Refuse Truck (V7) & On-Road & 83.9 & 3.2 & 52.8 & 441.8 & 8.4 \\
\hline Refuse Truck (V12) & On-Road & 142.6 & 8.5 & 114.6 & 1022.2 & 8.9 \\
\hline Refuse Truck (V13) & On-Road & 64.3 & 3.2 & 50.0 & 726.5 & 14.5 \\
\hline Transit Bus (V15) & On-Road & 41.6 & 2.3 & 27.6 & 435.2 & 15.8 \\
\hline Transit Bus (V16) & On-Road & 41.8 & 2.3 & 28.1 & 534.3 & 19.0 \\
\hline
\end{tabular}


Table B-5: Methane Emissions from 15L HPDI Vehicles with Tailpipe and Dynamic Vent Methane Emissions Measured

\begin{tabular}{|c|c|r|r|r|r|r|r|}
\hline Vehicle & Test Type & $\begin{array}{c}\text { Total } \\
\text { Distance } \\
\text { (miles) }\end{array}$ & $\begin{array}{c}\text { Total } \\
\text { Duration } \\
\text { (hours) }\end{array}$ & $\begin{array}{c}\text { Fuel } \\
\text { Consumed } \\
(\mathrm{kg})\end{array}$ & $\begin{array}{c}\text { Tailpipe } \\
\text { Methane } \\
(\mathrm{g})\end{array}$ & $\begin{array}{c}\text { Dynamic Vent } \\
\text { Methane }(\mathrm{g})\end{array}$ & $\begin{array}{c}\text { FSME } \\
(\mathrm{g} / \mathrm{kg})^{* *}\end{array}$ \\
\hline OTR Tractor (V17) & Chassis & 31.7 & 1.0 & 18.5 & 107.4 & $\mathrm{n} / \mathrm{a}$ & 5.8 \\
\hline OTR Tractor (V17) & On-Road & 125.3 & 3.9 & 55.3 & 311.7 & $\mathrm{n} / \mathrm{a}$ & 5.6 \\
\hline OTR Tractor (V18*) & On-Road & 322.5 & $7.0^{1}$ & 133.3 & 625.3 & $\mathrm{n} / \mathrm{a}$ & 4.7 \\
\hline OTR Tractor (V19*) & On-Road & 230.5 & $4.5^{1}$ & 107.9 & 589.9 & $\mathrm{n} / \mathrm{a}$ & 5.5 \\
\hline OTR Tractor (V20) & Chassis & 20.6 & 0.4 & 9.9 & 35.4 & $\mathrm{n} / \mathrm{a}$ & 3.6 \\
\hline OTR Tractor (V20) & On-Road & 210.8 & 5.3 & 120.1 & 461.2 & $\mathrm{n} / \mathrm{a}$ & 3.8 \\
\hline
\end{tabular}

Note: * The measurement to V18 and V19 include some long idle periods for vehicle weighing and LNG tank analyses.

** HPDI FSME was tailpipe emissions only

Table B-6: Methane Emissions from 12L SI NG Vehicles with Tailpipe Methane Emissions Measured and Crankcase Methane Emissions Modeled

\begin{tabular}{|c|c|c|c|r|r|r|r|}
\hline Vehicle & Test Type & $\begin{array}{c}\text { Total } \\
\text { Distance } \\
\text { (miles) }\end{array}$ & $\begin{array}{c}\text { Total } \\
\text { Duration } \\
\text { (hours) }\end{array}$ & $\begin{array}{c}\text { Fuel } \\
\text { Consumed } \\
(\mathrm{kg})\end{array}$ & $\begin{array}{c}\text { Tailpipe } \\
\text { Methane } \\
(\mathrm{g})\end{array}$ & $\begin{array}{c}\text { Crankcase } \\
\text { Methane } \\
(\mathrm{g})\end{array}$ & FSME (g/kg) \\
\hline OTR Tractor (V25) & On-Road & 161.8 & 4.2 & 100.1 & 303.9 & 562.9 & 8.7 \\
\hline OTR Tractor (V26) & On-Road & 118.3 & 2.9 & 83.7 & 76.2 & 326.2 & 4.8 \\
\hline
\end{tabular}

Table B-7: Methane Emissions from 12L SI NG Vehicles with Tailpipe and Crankcase Methane Emissions Measured Separately

\begin{tabular}{|l|c|r|r|r|r|r|r|}
\hline Vehicle & Test Type & $\begin{array}{c}\text { Total } \\
\text { Distance } \\
\text { (miles) }\end{array}$ & $\begin{array}{c}\text { Total } \\
\text { Duration } \\
\text { (hours) }\end{array}$ & $\begin{array}{c}\text { Fuel } \\
\text { Consumed } \\
\text { (kg) }\end{array}$ & $\begin{array}{c}\text { Tailpipe } \\
\text { Methane } \\
\text { (g) }\end{array}$ & $\begin{array}{c}\text { Crankcase } \\
\text { Methane } \\
\text { (g) }\end{array}$ & FSME (g/kg) \\
\hline OTR Tractor (V23) & Chassis & 28.9 & 0.9 & 21.0 & 68.2 & 62.1 & 6.2 \\
\hline OTR Tractor (V25) & Chassis & 29.1 & 0.9 & 14.9 & 26.3 & 25.1 & 3.4 \\
\hline OTR Tractor (V26) & Chassis & 28.7 & 0.9 & 23.1 & 62.9 & 59.8 & 5.3 \\
\hline
\end{tabular}

Table B-8: Methane Emissions from SI NG Vehicles with Tailpipe and Crankcase Methane Measured Together

\begin{tabular}{|c|c|c|c|c|c|r|}
\hline Vehicle & Test Type & $\begin{array}{c}\text { Total } \\
\text { Distance } \\
\text { (miles) }\end{array}$ & $\begin{array}{c}\text { Total } \\
\text { Duration } \\
\text { (hours) }\end{array}$ & $\begin{array}{c}\text { Fuel } \\
\text { Consumed } \\
(\mathrm{kg})\end{array}$ & $\begin{array}{c}\text { Total } \\
\text { Methane } \\
(\mathrm{g})\end{array}$ & FSME (g/kg) \\
\hline OTR Tractor (V25) & On-Road & 98.1 & 2.5 & 60.3 & 553.2 & 9.2 \\
\hline
\end{tabular}


Table B-9: Tailpipe and Crankcase Emissions and DSEC for Three 9L Stoichiometric Transit Buses

\begin{tabular}{|c|l|r|r|r|r|c|}
\hline & Vehicle & \multicolumn{1}{c|}{ Idle } & \multicolumn{1}{c|}{ City } & Arterial & Highway & Test Methods \\
\hline \multirow{4}{*}{$\begin{array}{c}\text { Tailpipe Methane } \\
\text { (g/kg fuel) }\end{array}$} & Transit Bus (V14) & 2.08 & 10.48 & 8.54 & 6.42 & Chassis Only \\
\cline { 2 - 7 } & Transit Bus (V15) & 3.67 & 10.21 & 8.92 & 8.87 & Chassis/On-Road \\
\cline { 2 - 7 } & Transit Bus (V16) & 5.80 & 10.01 & 9.53 & 9.43 & On-Road Only \\
\cline { 2 - 7 } & Average & $\mathbf{3 . 8 5}$ & $\mathbf{1 0 . 2 3}$ & $\mathbf{9 . 0 0}$ & $\mathbf{8 . 2 4}$ & N.A. \\
\hline \multirow{4}{*}{$\begin{array}{c}\text { Crankcase Methane } \\
\text { (g/kg fuel) }\end{array}$} & Transit Bus (V14) & 14.09 & 10.04 & 7.94 & 6.38 & Chassis Only \\
\cline { 2 - 7 } & Transit Bus (V15) & 13.01 & 9.38 & 7.88 & 6.74 & Chassis/On-Road \\
\cline { 2 - 7 } & Transit Bus (V16) & 11.34 & 11.72 & 8.19 & 6.64 & On-Road Only \\
\cline { 2 - 7 } & Average & $\mathbf{1 2 . 8 1}$ & $\mathbf{1 0 . 3 8}$ & $\mathbf{8 . 0 0}$ & $\mathbf{6 . 6 3}$ & N.A. \\
\hline \multirow{2}{*}{$\begin{array}{c}\text { Distance Specific } \\
\text { Energy Consumption } \\
\text { (MJ/mile) }\end{array}$} & Transit Bus (V14) & 259.12 & 64.77 & 43.70 & 28.73 & Chassis Only \\
\cline { 2 - 7 } *Idle (MJ/hr) & Transit Bus (V15) & 256.62 & 58.87 & 30.97 & 18.33 & Chassis/On-Road \\
\cline { 2 - 7 } & Transit Bus (V16) & 321.19 & 44.87 & 30.58 & 20.76 & On-Road Only \\
\cline { 2 - 7 } & Average & $\mathbf{2 7 8 . 9 8}$ & $\mathbf{5 6 . 0 3}$ & $\mathbf{3 5 . 0 8}$ & $\mathbf{2 2 . 6 1}$ & N.A. \\
\hline
\end{tabular}

Table B-10: Tailpipe and Crankcase Emissions and DSEC for Five 9L Stoichiometric Refuse Trucks

\begin{tabular}{|c|c|c|c|c|c|c|}
\hline & Vehicle & Idle & City & Arterial & Highway & Test Methods \\
\hline \multirow{6}{*}{$\begin{array}{l}\text { Tailpipe Methane } \\
\text { (g/kg fuel) }\end{array}$} & Refuse Truck (V6) & 0.32 & 3.70 & 9.79 & 2.05 & Chassis Only \\
\hline & Refuse Truck (V7) & 1.15 & 4.96 & 4.26 & 2.82 & Chassis/On-Road \\
\hline & Refuse Truck (V13) & 0.39 & 2.03 & 1.56 & 3.04 & On-Road Only \\
\hline & Refuse Truck (V5) & 0.88 & 2.63 & 9.00 & 1.08 & Chassis Only \\
\hline & Refuse Truck (V12) & 0.61 & 1.62 & 2.36 & 2.03 & On-Road Only \\
\hline & Average & 0.67 & 2.99 & 5.39 & 2.20 & N.A. \\
\hline \multirow{6}{*}{$\begin{array}{l}\text { Crankcase Methane } \\
\text { (g/kg fuel) }\end{array}$} & Refuse Truck (V6) & 20.93 & 8.12 & 6.99 & 5.41 & Chassis Only \\
\hline & Refuse Truck (V7) & 18.06 & 10.54 & 7.89 & 5.64 & Chassis/On-Road \\
\hline & Refuse Truck (V13) & 14.99 & 9.07 & 7.55 & 5.75 & On-Road Only \\
\hline & Refuse Truck (V5) & 19.08 & 9.13 & 7.17 & 5.37 & Chassis Only \\
\hline & Refuse Truck (V12) & 10.41 & 8.42 & 7.37 & 5.62 & On-Road Only \\
\hline & Average & 16.62 & 9.06 & 7.39 & 5.56 & N.A. \\
\hline \multirow{6}{*}{$\begin{array}{l}\text { Distance Specific } \\
\text { Energy Consumption } \\
\text { (MJ/mile) } \\
\text { *Idle (MJ/hr) }\end{array}$} & Refuse Truck (V6) & 186.97 & 103.88 & 37.10 & 29.16 & Chassis Only \\
\hline & Refuse Truck (V7) & 195.91 & 81.22 & 31.42 & 24.71 & Chassis/On-Road \\
\hline & Refuse Truck (V13) & 249.62 & 82.30 & 33.38 & 18.82 & On-Road Only \\
\hline & Refuse Truck (V5) & 197.31 & 98.35 & 34.58 & 29.97 & Chassis Only \\
\hline & Refuse Truck (V12) & 349.77 & 199.19 & 35.67 & 19.75 & On-Road Only \\
\hline & Average & 235.92 & 112.99 & 34.43 & 24.48 & N.A. \\
\hline
\end{tabular}


Table B-11: Tailpipe and Crankcase Emissions and DSEC for Three 9L Stoichiometric OTR Tractors

\begin{tabular}{|c|c|c|c|c|c|c|}
\hline & Vehicle & Idle & City & Arterial & Highway & Test Methods \\
\hline \multirow{4}{*}{$\begin{array}{l}\text { Tailpipe Methane } \\
\text { (g/kg fuel) }\end{array}$} & 9L Tractor (V3) & 3.49 & 13.35 & 7.61 & 5.66 & Chassis Only \\
\hline & 9L Tractor (V10) & 1.38 & 12.42 & 6.04 & 2.91 & Chassis/On-Road \\
\hline & 9L Tractor (V11) & 2.10 & 4.28 & 3.18 & 4.13 & On-Road Only \\
\hline & Average & 2.32 & 10.02 & 5.61 & 4.23 & N.A. \\
\hline \multirow{4}{*}{$\begin{array}{c}\text { Crankcase Methane } \\
\text { (g/kg fuel) }\end{array}$} & 9L Tractor (V3) & 22.26 & 10.84 & 5.30 & 3.61 & Chassis Only \\
\hline & 9L Tractor (V10) & 16.21 & 7.83 & 7.31 & 5.42 & Chassis/On-Road \\
\hline & 9L Tractor (V11) & 16.90 & 11.24 & 6.14 & 5.70 & On-Road Only \\
\hline & Average & 18.46 & 9.97 & 6.25 & 4.91 & N.A. \\
\hline \multirow{4}{*}{$\begin{array}{l}\text { Distance Specific } \\
\text { Energy Consumption } \\
\text { (MJ/mile) } \\
\text { *Idle (MJ/hr) }\end{array}$} & 9L Tractor (V3) & 164.04 & 61.86 & 46.00 & 30.15 & Chassis Only \\
\hline & 9L Tractor (V10) & 193.26 & 61.22 & 35.02 & 25.20 & Chassis/On-Road \\
\hline & 9L Tractor (V11) & 215.68 & 52.21 & 32.16 & 22.91 & On-Road Only \\
\hline & Average & 190.99 & 58.43 & 37.73 & 26.09 & N.A. \\
\hline
\end{tabular}

Table B-12: Tailpipe and Crankcase Emissions and DSEC for Three 12 L Stoichiometric OTR Tractors

\begin{tabular}{|c|c|r|r|r|r|c|}
\hline & Vehicle & \multicolumn{1}{c|}{ Idle } & \multicolumn{1}{c|}{ City } & Arterial & Highway & Test Methods \\
\hline \multirow{4}{*}{$\begin{array}{c}\text { Tailpipe Methane } \\
\text { (g/kg fuel) }\end{array}$} & 12L Tractor (V23) & 0.18 & 5.07 & 3.85 & 3.15 & Chassis Only \\
\cline { 2 - 7 } & 12L Tractor (V25) & 0.84 & 2.54 & 4.16 & 2.68 & Chassis/On-Road \\
\cline { 2 - 7 } & 12L Tractor (V26) & 0.63 & 3.23 & 1.96 & 1.16 & Chassis/On-Road \\
\cline { 2 - 7 } & Average & $\mathbf{0 . 5 5}$ & $\mathbf{3 . 6 1}$ & $\mathbf{3 . 3 2}$ & $\mathbf{2 . 3 3}$ & N.A. \\
\hline \multirow{4}{*}{$\begin{array}{c}\text { Crankcase Methane } \\
\text { (g/kg fuel) }\end{array}$} & 12L Tractor (V23) & 15.09 & 6.72 & 7.08 & 6.13 & Chassis Only \\
\cline { 2 - 7 } & 12L Tractor (V25) & 39.05 & 8.62 & 6.20 & 5.19 & Chassis/On-Road \\
\cline { 2 - 7 } & 12L Tractor (V26) & 10.42 & 7.96 & 6.10 & 3.72 & Chassis/On-Road \\
\cline { 2 - 7 } & Average & $\mathbf{2 1 . 5 2}$ & $\mathbf{7 . 7 7}$ & $\mathbf{6 . 4 7}$ & $\mathbf{5 . 0 1}$ & N.A. \\
\hline \multirow{2}{*}{$\begin{array}{c}\text { Distance Specific } \\
\text { Energy Consumption } \\
\text { (MJ/mile) }\end{array}$} & 12L Tractor (V23) & 200.34 & 65.84 & 42.23 & 30.03 & Chassis Only \\
\cline { 2 - 7 } *Idle (MJ/hr) & 12L Tractor (V25) & 81.08 & 63.26 & 40.27 & 27.61 & Chassis/On-Road \\
\cline { 2 - 7 } & 12L Tractor (V26) & 320.14 & 74.51 & 44.43 & 31.85 & Chassis/On-Road \\
\cline { 2 - 7 } & Average & $\mathbf{2 0 0 . 5 2}$ & $\mathbf{6 7 . 8 7}$ & $\mathbf{4 2 . 3 1}$ & $\mathbf{2 9 . 8 3}$ & N.A. \\
\hline
\end{tabular}


Table B-13: Tailpipe and Crankcase Emissions and DSEC for Four 15 L HPDI Engine OTR Tractors

\begin{tabular}{|c|c|c|c|c|c|c|}
\hline & Vehicle & Idle & City & Arterial & Highway & Test Methods \\
\hline \multirow{5}{*}{$\begin{array}{l}\text { Tailpipe Methane } \\
\text { (g/kg fuel) }\end{array}$} & 15L Tractor (V17) & 14.77 & 8.39 & 6.73 & 4.44 & Chassis/On-Road \\
\hline & 15L Tractor (V18) & 10.33 & 6.29 & 6.29 & 4.63 & On-Road Only \\
\hline & 15L Tractor (V19) & 10.44 & 5.94 & 8.16 & 5.40 & On-Road Only \\
\hline & 15L Tractor (V20) & 21.03 & 8.71 & 4.87 & 3.53 & Chassis/On-Road \\
\hline & Average & 14.14 & 7.33 & 6.51 & 4.50 & N.A. \\
\hline Vent Methane ( $\mathrm{g} / \mathrm{kg}$ fuel) & Average & 0.00 & 22.10 & 10.15 & 4.81 & N.A. \\
\hline \multirow{5}{*}{$\begin{array}{l}\text { NG Fuel energy } \\
\text { (MJ/mile) } \\
\text { *Idle (MJ/hr) }\end{array}$} & 15L Tractor (V17) & 136.87 & 45.78 & 26.93 & 19.47 & Chassis/On-Road \\
\hline & 15L Tractor (V18) & 184.76 & 81.94 & 19.92 & 19.98 & On-Road Only \\
\hline & 15L Tractor (V19) & 253.67 & 165.67 & 19.77 & 22.68 & On-Road Only \\
\hline & 15L Tractor (V20) & 170.11 & 47.78 & 34.62 & 26.22 & Chassis/On-Road \\
\hline & Average & 170.11 & 85.29 & 25.31 & 22.09 & N.A. \\
\hline \multirow{5}{*}{$\begin{array}{l}\text { Distance Specific } \\
\text { Energy Consumption } \\
\text { (MJ/mile) } \\
\text { *Idle (MJ/hr) }\end{array}$} & 15L Tractor (V17) & 221.96 & 54.39 & 29.74 & 21.52 & Chassis/On-Road \\
\hline & 15L Tractor (V18) & 304.21 & 90.09 & 22.02 & 22.16 & On-Road Only \\
\hline & 15L Tractor (V19) & 418.84 & 182.59 & 21.86 & 25.17 & On-Road Only \\
\hline & 15L Tractor (V20) & 177.29 & 54.44 & 37.70 & 29.10 & Chassis/On-Road \\
\hline & Average & 282.39 & 94.66 & 27.86 & 24.49 & N.A. \\
\hline
\end{tabular}




\section{Appendix C CNG Station Data Processing}

\section{Summary of Methane Emissions from CNG Station}

This document reports the procedure of estimating methane emissions from CNG fuel stations. The emissions sources include:

(1) Methane emissions from dispensing nozzles reported in $\mathrm{g} /$ refueling event;

(2) Methane emissions from compressors reported in $\mathrm{g} / \mathrm{kg}$ fuel. The emissions from compressor packing vents, actuators, and dryers were categorized into emissions associated with compressor operation;

(3) Continuous methane emissions (g/day) from sources other than dispensing nozzle and compressors

\section{The estimates presented were based on the following scenarios:}

(1) Each CNG station would refuel 50 refuse trucks, 80 transit buses, or 80 OTR tractors per operational day;

(2) Each vehicle would be refueled once each operational day with 6 operational days per week for transit buses and OTR tractors and 5 operational days per week for refuse trucks;

(3) Annual fuel consumption values were estimated by the estimation model;

(4) Each CNG station was equipped with two active compressors and one dryer;

(5) Methane emissions from the dryer and actuator valves, if applicable, were considered portions of compressor emissions;

Audits, which included detection and quantification of methane emissions, were performed at eight CNG stations. Estimates from the CNG fueling stations were incorporated into the methane emissions estimation model for the heavy-duty transportation sector.

Table $\mathrm{C}-1$ shows the fuel distribution results derived from the estimation model. The stasis nonidle fuel consumption and stasis idle fuel consumption scenarios (100\% of the measured data) were used to determine the amount of fuel delivered by each station.

Table C-1: Fuel Distribution Scenario Derived from the Estimation Model

\begin{tabular}{|c|r|r|r|r|r|}
\hline Vehicle Type & $\begin{array}{c}\text { Number of } \\
\text { Vehicles per } \\
\text { Station }\end{array}$ & $\begin{array}{c}\text { Annual Fuel } \\
\text { Mass per } \\
\text { Vehicle }\end{array}$ & $\begin{array}{c}\text { Total } \\
\text { Annual } \\
\text { Fuel Mass }\end{array}$ & $\begin{array}{c}\text { Operational } \\
\text { Days per } \\
\text { Year }\end{array}$ & $\begin{array}{c}\text { Daily } \\
\text { Total } \\
\text { Fuel Mass }\end{array}$ \\
\cline { 3 - 6 } & kg/year/vehicle & kg/year & days/year & $\mathrm{kg} /$ day \\
\hline Transit Bus & 80 & 26,286 & $2,102,880$ & 312 & 6,740 \\
\hline Refuse Truck & 50 & 21,287 & $1,064,350$ & 260 & 4,094 \\
\hline 9L OTR Tractor & 80 & 27,680 & $2,214,400$ & 312 & 7,097 \\
\hline 12L OTR Tractor & 80 & 50,954 & $4,076,320$ & 312 & 13,065 \\
\hline
\end{tabular}

Appendix C-20 
Table C-2 shows the estimated current methane emissions from CNG stations reported in units used in the methane estimation model. Table C-3 shows the current FSME from CNG stations refueling each type of CNG vehicles (in units of $\mathrm{g} / \mathrm{kg}$ fuel). The current estimated FSME were 0.49 to $1.12 \mathrm{~g} / \mathrm{kg}$ fuel consumed. As shown in Table C-3, the methane emissions from compressors contributed to over $80.4 \%$ of the methane emissions from CNG stations.

Table C-2: Average Methane Emissions from CNG Stations

\begin{tabular}{|c|c|c|c|}
\hline \multirow{2}{*}{ Vehicle Type } & Compressor & Continuous & Nozzle Emissions \\
\hline & $\mathrm{g} / \mathrm{kg}$ fuel & g/day & g/event \\
\hline Transit Bus & 0.70 & 816 & 3.61 \\
\hline Refuse Truck* & 1.12 & 816 & 3.61 \\
\hline 9L OTR Tractor & 0.68 & 816 & 3.61 \\
\hline 12L OTR Tractor & 0.49 & 816 & 3.61 \\
\hline Average & 0.75 & 816 & 3.61 \\
\hline
\end{tabular}

*Only 50 vehicles refueled (compared to 80 for all other vehicle types)

Table C-3: Average FSME from CNG Station

\begin{tabular}{|c|r|r|r|r|r|}
\hline \multirow{2}{*}{ Vehicle Type } & Compressor & Continuous & $\begin{array}{r}\text { Nozzle } \\
\text { Emissions }\end{array}$ & Total & $\begin{array}{r}\text { Contribution of } \\
\text { Compressors to } \\
\text { Methane Emissions } \\
\text { from CNG Stations }\end{array}$ \\
\cline { 2 - 6 } & $\mathrm{g} / \mathrm{kg}$ fuel & $\mathrm{g} / \mathrm{kg}$ fuel & $\mathrm{g} / \mathrm{kg}$ fuel & $\mathrm{g} / \mathrm{kg}$ fuel & $\%$ \\
\hline Transit Bus & 0.70 & 0.14 & 0.043 & 0.88 & $79.5 \%$ \\
\hline Refuse Truck & 1.12 & 0.28 & 0.044 & 1.44 & $77.8 \%$ \\
\hline 9L OTR Tractor & 0.68 & 0.13 & 0.041 & 0.85 & $80.0 \%$ \\
\hline 12L OTR Tractor & 0.49 & 0.07 & 0.022 & 0.59 & $84.1 \%$ \\
\hline Average & 0.75 & 0.16 & 0.038 & 0.94 & $79.8 \%$ \\
\hline
\end{tabular}

Major Conclusions:

(1) The current estimated FSME were 0.59 to $1.44 \mathrm{~g} / \mathrm{kg}$ fuel consumed.

(2) The CNG compressors were recognized as the largest contributor to methane emissions from CNG stations, about $80 \%$ of the methane emissions from CNG stations.

\section{Methane Emissions from CNG station Dispensing Nozzles}

Table C-4 shows the methane emissions measured from dispenser nozzles for all CNG stations audited. These emissions consisted of the fuel released from the physical dead space volume of the nozzle when disconnected, referred to as nozzle dead space emissions, and the excess fuel from the fueling hose manually released upon completion of fueling, referred to as hose vent emissions. These emissions were treated separately as it was not possible to measure both the nozzle dead space and hose vent emissions concurrently due to physical separation (the hose vent was typically routed to an elevated location). There was also one out of the eight stations with natural gas operated actuator valves, two opening emissions and two closing emissions per 
refueling event. Details of the actuators are shown in Table C-5. The average of the nozzle dead space emissions ( $0.46 \mathrm{~g} /$ event $)$, the average of the vent emissions ( $2.97 \mathrm{~g} / \mathrm{event})$, and the actuator emissions ( $0.25 \mathrm{~g} /$ event) were added together to get the $\mathrm{CNG}$ vehicle nozzle emissions (3.61 g/event).

Table C-4: Methane Emissions from Dispensing Nozzles Measured (Nozzle Dead Space and Vent)

\begin{tabular}{|c|c|c|c|}
\hline \multicolumn{2}{|c|}{ Nozzle Dead Space Emissions } & \multicolumn{2}{|c|}{ Hose Vent Emissions } \\
\hline \multirow{2}{*}{ Station ID } & Emissions & \multirow{2}{*}{ Station ID } & Emissions \\
\hline & g/event & & g/event \\
\hline \#4 & 0.28 & $\# 2$ & 3.80 \\
\hline \#4 & 0.43 & $\# 2$ & 4.10 \\
\hline$\# 4$ & 0.34 & $\# 2$ & 3.90 \\
\hline$\# 4$ & 0.41 & $\# 6$ & 2.02 \\
\hline$\# 5$ & 0.92 & $\# 6$ & 0.51 \\
\hline \#5 & 0.06 & $\# 6$ & 2.50 \\
\hline$\# 5$ & 0.02 & $\# 6$ & 2.48 \\
\hline$\# 6$ & 0.56 & $\# 6$ & 2.55 \\
\hline \#6 & 0.73 & $\# 6$ & 2.79 \\
\hline \#6 & 0.73 & \#6 & 2.35 \\
\hline \#6 & 0.89 & \#6 & 2.53 \\
\hline \#6 & 1.15 & \#8 & 6.54 \\
\hline$\# 7$ & 0.11 & \#8 & 2.41 \\
\hline$\# 7$ & 0.19 & \#8 & 3.11 \\
\hline$\# 7$ & 0.07 & & \\
\hline$\# 7$ & 0.18 & & \\
\hline$\# 7$ & 0.09 & & \\
\hline$\# 8$ & 0.11 & & \\
\hline$\# 8$ & 0.39 & & \\
\hline$\# 8$ & 0.22 & & \\
\hline Average & 0.39 & Average & 2.97 \\
\hline
\end{tabular}

Table C-5: Actuator Emissions Associated with Vehicle Refueling Events

\begin{tabular}{|c|c|}
\hline \multirow{2}{*}{ Event } & Emissions \\
\cline { 2 - 2 } & g/event \\
\hline Open & 0.46 \\
\hline Close & 0.52 \\
\hline Per Event & 1.96 \\
\hline Per Station & 0.25 \\
\hline
\end{tabular}

In this research, the methane emissions from CNG dispensing nozzles were calculated by averaging the methane emissions from CNG dispenser nozzles measured. The average nozzle emissions were considered as the nozzle emissions from each station. Table C-6 shows the total methane emissions from fuel dispenser nozzles of a CNG station refueling 80 vehicles each day. 
An assumption of one vehicle refueling event per vehicle per day was made. The total nozzle emissions calculated were $0.29 \mathrm{~kg} /$ day.

Table C-6: Total Nozzle Emissions from CNG Stations

\begin{tabular}{|c|c|c|}
\hline \multicolumn{3}{|c|}{ Nozzle Emissions } \\
\hline $\begin{array}{c}\text { Nozzle } \\
\text { Emissions }\end{array}$ & $\begin{array}{c}\text { Refueling } \\
\text { Events }\end{array}$ & $\begin{array}{c}\text { Total Nozzle } \\
\text { Emissions }\end{array}$ \\
\hline g/event & event/day & $\mathrm{kg} /$ day \\
\hline 3.61 & 80 & 0.29 \\
\hline
\end{tabular}

\section{Methane Emissions from Compressors (Station ID \#4) When Refueling 80 Transit Buses Each Day}

In this document, Station ID\#4 with the assumed 80 transit buses refueled per day was used as an example to demonstrate the procedure for calculating the FSME from compressors (on/off) and continuous emissions.

The methane emissions from compressors were estimated based on the assumption that each station had two working compressors and one dryer. The number of hours the compressor was in use (on) was calculated by dividing the total annual fuel dispensed (estimated from vehicle activity scenario model and CNG station population scenario model) by the total capacity of compressors. The rest of the hours in the day were considered the number of hours the compressor was off.

Table C-7 shows the fuel delivery estimated by the vehicle scenario model and the on/off time of compressors for one CNG station (station ID \#4) with the assumption of refueling 80 transit buses each day. The dryer and actuator emissions were added to the compressor emissions since all three were primarily fuel-use dependent.

Table C-7: The Compressor on/off Time (Station ID \#4)

\begin{tabular}{|r|c|r|r|r|r|r|}
\hline \multirow{2}{*}{$\begin{array}{c}\text { Number of } \\
\text { Vehicles }\end{array}$} & \multicolumn{2}{|c|}{ Fuel Consumed } & \multicolumn{2}{c|}{$\begin{array}{c}\text { Compressor } \\
\text { Capacity }\end{array}$} & $\begin{array}{c}\text { Hours On } \\
\text { (Each Compressor) }\end{array}$ & $\begin{array}{c}\text { Hours Off } \\
\text { (Each Compressor) }\end{array}$ \\
\cline { 2 - 7 } & $\mathrm{kg} /$ year & $\mathrm{kg} / \mathrm{day}$ & CFM & $\mathrm{kg} / \mathrm{hour}$ & $\mathrm{hr} / \mathrm{day}$ & $\mathrm{hr} /$ day \\
\hline 80 & $2,102,880$ & 6,740 & 800 & 970 & & 3.0 \\
\hline
\end{tabular}

The daily compressor-on emissions were calculated by multiplying the hourly emissions rate by the number of hours the compressor was operating. The dryer emissions were included in compressor-on emissions as the dryer only emitted methane when the compressor was operating. The daily compressor-off emissions were calculated by multiplying the hourly emissions rate by the number of hours the compressor was not operating. The total compressor emissions were calculated by adding the daily emissions from compressor when it was on (including dryer and actuators) and off. Table C-8 shows the estimated methane emissions from the compressors. The FSME from the compressor (including on/off) calculated with the annual fuel delivery estimated from vehicle scenarios and the assumed 80 refueling events each day were $0.50 \mathrm{~g} / \mathrm{kg}$ fuel. 
Table C-8: Methane Emissions from Compressors (Station ID \#4)

\begin{tabular}{|c|r|r|r|}
\hline & Compressor-On & Compressor-Off & Total \\
\hline Hours On (hr/day) & 3.0 & 21.0 & 24.0 \\
\hline Emissions (g/hr) & 74.7 & 13.4 & N/A \\
\hline Emissions (g/day) & 221.6 & 281.8 & 503.5 \\
\hline Fuel Delivery Estimated from Scenario Model (kg/day) & 5757.4 \\
\hline \multicolumn{2}{|c|}{ Compressor FSME (g/kg fuel) } & 0.5 \\
\hline
\end{tabular}

\section{Methane Emissions from Continuous Emissions of CNG Station (Station ID\#4) When Refueling 80 Transit Buses Each Day}

Table C-9 shows the continuous methane emissions from station (station ID \#4) emissions. Numerous emissions were quantified with the minimum, maximum, and average methane emissions rates of $0.8,13.5$, and $5.9 \mathrm{~g} / \mathrm{hr}$, respectively. The total continuous methane emissions from this station were $27.2 \mathrm{~g} /$ hour. The number of refueling events or fuel delivery does not affect rate of continuous emissions but affects the FSME.

Table C-9: Methane Emissions from Continuous Emissions Sources (Station ID\#4)

\begin{tabular}{|c|c|c|c|}
\hline \multicolumn{2}{|c|}{ Continuous Emissions } & Fuel Delivery & FSME \\
\hline $\mathrm{g} / \mathrm{hr}$ & $\mathrm{kg} / \mathrm{day}$ & $\mathrm{kg} / \mathrm{day}$ & $\mathrm{g} / \mathrm{kg}$ fuel \\
\hline 27.2 & 0.65 & 5,757 & 0.11 \\
\hline
\end{tabular}

Summary of Methane emissions from Station ID\#4 for Transit Buses

Table C-10 shows a summary of the methane emissions from fuel dispenser nozzles, compressors, and continuous emissions sources (station ID \#4) with the assumed 80 refueling events of transit buses.

Table C-10: Summary of Methane Emissions from CNG Station (ID\#4)

\begin{tabular}{|r|c|c|c|}
\hline $\begin{array}{c}\text { Compressor-On/Dryer } \\
\text { Emissions }\end{array}$ & $\begin{array}{c}\text { Compressor-Off } \\
\text { Emissions }\end{array}$ & $\begin{array}{c}\text { Continuous } \\
\text { Emissions }\end{array}$ & $\begin{array}{c}\text { Nozzle } \\
\text { Emissions }\end{array}$ \\
\hline $\mathrm{g} / \mathrm{kg}$ fuel & $\mathrm{g} / \mathrm{kg}$ fuel & $\mathrm{g} / \mathrm{day}$ & $\mathrm{g} / \mathrm{event}$ \\
\hline 0.22 & 0.28 & 816 & 3.61 \\
\hline
\end{tabular}

\section{Methane Emissions from Seven CNG Stations Estimated with the Assumed 80 Refueling Events for Transit Buses}

Table C-11 shows the methane emissions from eight CNG stations estimated with the assumed 80 refueling events for transit buses (CNG station population scenario model) and total fuel delivered by each station (estimated from vehicle activity scenario model). As shown in Table $\mathrm{C}-11$, the average compressor emissions were $0.70 \mathrm{~g} / \mathrm{kg}$ fuel. The compressors in CNG station ID \#2 and ID\#6 were the main stations contributing to the methane emissions from compressors. The average continuous emissions were $816 \mathrm{~g} /$ day. The average nozzle emissions were 3.61 g/event. The average of the methane emissions from each station, shown in Table $\mathrm{C}-11$, will be considered the current methane emissions from CNG stations when refueling 80 transit buses 
each day and considered the high scenario of methane emissions from CNG stations for transit buses in 2035.

Table C-11: Estimated Methane Emissions from Each CNG Station

\begin{tabular}{|c|r|r|r|}
\hline \multirow{2}{*}{ Station ID } & \multicolumn{1}{|c|}{ Compressor } & Continuous & Nozzle Emissions \\
\cline { 2 - 4 } & g/kg fuel & \multicolumn{1}{c|}{ g/day } & \multicolumn{1}{c|}{ g/event } \\
\hline $1^{*}$ & 0.15 & 22 & 3.61 \\
\hline 2 & 4.04 & 2160 & 3.61 \\
\hline 3 & 0.02 & 991 & 3.61 \\
\hline 4 & 0.09 & 653 & 3.61 \\
\hline $5^{* *}$ & 0.41 & 264 & 3.61 \\
\hline $6^{* * *}$ & 0.86 & 1627 & 3.61 \\
\hline $7^{*}$ & 0.01 & 14 & 3.61 \\
\hline 8 & 0.03 & 797 & 3.61 \\
\hline Average & 0.70 & 816 & 3.61 \\
\hline
\end{tabular}

* assumed compressor capacity of 800 CFM

**compressor related actuator emissions included in compressor emissions

*** assumed compressor capacity of 1088 (average of 800 and 1376) CFM

Note: (1) The valve actuators in station ID \#5 were operated by CNG and leaked methane during its operation. The actuators were calculated by assuming $12,300 \mathrm{~kg}$ of fuel was available from the station fuel tank, the station employed a 3 bank cascade system 20"D by 23'L with about 10,000 CF @ 5,000 PSI, 41\% cascade utilization with nominal vehicle pressure of 1,000 PSIG, $80 \%$ of vehicles refueled continuously over two time periods and the remaining $20 \%$ refueled in a dispersed pattern, facility control strategy implemented a recharge of the storage vessels after every vehicle during dispersed fueling (20\%), vehicles took 5 minutes to refuel. Actuator emissions were added to the compressor emissions for that station.

(2) A compressor capacity of 800 CFM per compressor was assumed for two stations (station ID \#1 and ID \#7) referencing CNG stations with similar vehicle refueling capacities, the latter being the CNG portion of a LCNG station. There was no success in the attempt to get the actual compressor capacities from the manufacturer and operators of these two CNG stations. An average of 800 and 1376 was assumed for one station (station ID \#6) since the capacity was between the two compressor sizes.

(3) The compressor housing vent (including packing) was included in the compressor-on value $(19.1 \mathrm{~g} / \mathrm{hr}$ for compressor-on and 0.5 for housing vent for station \#4) since majority of the emissions occurred when the compressor was on.

\section{Estimated Methane Emissions from All CNG Stations for Transit Buses, Refuses Trucks, and OTR Tractors}

Methane emissions from CNG stations based on the 2035 CNG station population scenario and fuel consumption scenario (current or stasis at 2035) were estimated for CNG fueled transit 
buses, refuse trucks, and OTR tractors by assuming each CNG station will serve 80 transit buses, 80 OTR tractors, or 50 refuse trucks, as suggested in the CNG station scenario model. Table $\mathrm{C}-12$ shows the estimated methane emissions from $\mathrm{CNG}$ stations serving each type of vehicle, in the units used in the estimation model.

Table C-12: Average Methane Emissions from CNG Station

\begin{tabular}{|c|r|r|r|}
\hline \multirow{2}{*}{ Vehicle Type } & Compressor & Continuous & Nozzle Emissions \\
\cline { 2 - 4 } & g/kg fuel & g/day & \multicolumn{1}{|c|}{ g/event } \\
\hline Transit Bus & 0.70 & 816 & 3.61 \\
\hline Refuse Truck* & 1.12 & 816 & 3.61 \\
\hline 9L OTR Tractor & 0.68 & 816 & 3.61 \\
\hline 12L OTR Tractor & 0.49 & 816 & 3.61 \\
\hline Average & 0.75 & 816 & 3.61 \\
\hline
\end{tabular}

*Only 50 vehicles refueled (compared to 80 for all other vehicle types)

Table C-13 shows the FSME from CNG stations refueling transit buses (80), refuse trucks (50), short haul OTR tractors (80), and long haul 12 L OTR tractors (80), respectively. The current estimated FSME were 0.59 to $1.44 \mathrm{~g} / \mathrm{kg}$ fuel consumed. The CNG compressors were the major contributor to the methane emissions from CNG stations.

Table C-13: Average FSME from CNG Stations

\begin{tabular}{|c|r|r|r|r|r|}
\hline \multirow{2}{*}{ Vehicle Type } & Compressor & Continuous & $\begin{array}{c}\text { Nozzle } \\
\text { Emissions }\end{array}$ & Total & $\begin{array}{r}\text { Contribution of } \\
\text { Compressors to } \\
\text { Methane Emissions } \\
\text { from CNG Stations }\end{array}$ \\
\cline { 2 - 6 } & $\mathrm{g} / \mathrm{kg}$ fuel & $\mathrm{g} / \mathrm{kg}$ fuel & $\mathrm{g} / \mathrm{kg}$ fuel & $\mathrm{g} / \mathrm{kg}$ fuel & $\%$ \\
\hline Transit Bus & 0.70 & 0.14 & 0.043 & 0.88 & $79.5 \%$ \\
\hline Refuse Truck & 1.12 & 0.28 & 0.044 & 1.44 & $77.8 \%$ \\
\hline 9L OTR Tractor & 0.68 & 0.13 & 0.041 & 0.85 & $80.0 \%$ \\
\hline 12L OTR Tractor & 0.49 & 0.07 & 0.022 & 0.59 & $84.1 \%$ \\
\hline Average & 0.75 & 0.16 & 0.038 & 0.94 & $79.8 \%$ \\
\hline
\end{tabular}




\section{Appendix D Effect of CNG Station Utilization on Methane Emissions}

\section{Summary}

This document reports the impact of CNG station utilization on FSME from CNG stations, using transit buses and long haul OTR tractors as an example. In this document, the utilization of CNG stations was represented by the number of CNG vehicles refueled each day. As described in the 2035 CNG station population scenario model, each CNG station would serve 80 transit buses, 80 OTR tractors, or 50 refuse trucks. A CNG station that refueled less than 80 transit buses, 80 OTR tractors, or 50 refuse trucks was defined as an under-utilized CNG station. By comparison, a CNG station that refueled more than 80 transit buses, 80 OTR tractors, or 50 refuse trucks was defined as an over-utilized CNG station. The impact of CNG station utilization on methane emissions from CNG stations was investigated by examining the impact of the number of refueling events on the FSME from CNG stations.

Table D-1 compares the impact of the number of refueling events on the FSME from CNG stations refueling transit buses and 12 liter OTR tractors, respectively. A decrease in the number of refueling events increased the FSME from CNG stations. This was mainly due to the increased contribution of compressor-off operation emissions and continuous emissions, resulting from the reduction in CNG fuel delivered. The CNG stations refueling transit buses have higher FSME than those refueling same number of 12 liter OTR tractors.

Table D-1: Total Station Methane Emissions Comparison of Transit Buses and 12 Liter OTR Tractors

\begin{tabular}{|c|r|r|}
\hline $\begin{array}{c}\text { Number of } \\
\text { Refueling Events }\end{array}$ & $\begin{array}{c}\text { Transit Bus } \\
\text { FSME }\end{array}$ & $\begin{array}{c}\text { 12L OTR Tractor } \\
\text { FSME }\end{array}$ \\
\cline { 2 - 3 } & g/kg fuel & g/kg fuel \\
\hline 20 & 2.60 & 1.47 \\
\hline 40 & 1.46 & 0.88 \\
\hline 60 & 1.08 & 0.68 \\
\hline 80 & 0.88 & 0.59 \\
\hline 100 & 0.77 & 0.53 \\
\hline 120 & 0.69 & 0.49 \\
\hline 140 & 0.64 & 0.46 \\
\hline 160 & 0.60 & 0.44 \\
\hline
\end{tabular}

Figure D-1 shows the impact of CNG station utilization on FSME from CNG stations. The reduction in the number of refueling events was found to dramatically increase the FSME from CNG stations, especially when the number of refueling events was low. 


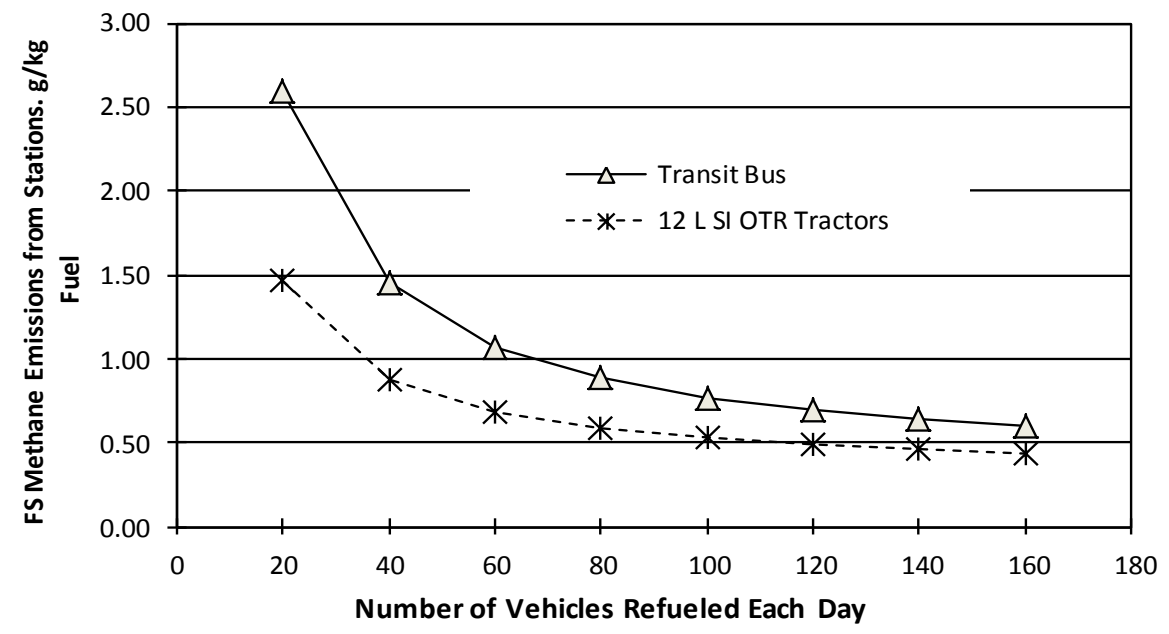

Figure D-1: Effect of Station Utilization on FSME from Compressors in CNG Stations for 12L Transit Buses and OTR Tractors

For a fleet operating numerous identical CNG stations and numerous types CNG vehicles, the total methane emissions from CNG stations were affected by the total CNG fuel delivered, the capacity of each CNG station, the number of CNG stations, and the total refueling events. The type of CNG vehicle, its relative percentage in this fleet, and unevenly utilized CNG stations do not affect the methane emissions from CNG stations, as long as the total fuel consumed and total number of refueling events were constant.

\section{Methane Emissions from CNG Stations in the 2035 CNG Station Population Scenario and High Fuel Consumption}

The methane emissions from CNG stations include the methane emitted from the CNG dispensing nozzles, compressors (including compressor on/off, actuators, packing vent, and dryer), and continuous emissions. Table D-2 shows the estimated methane emissions based on the estimation model with medium population, medium HPDI penetration, and stasis emissions and fuel consumption scenarios for CNG fueled transit buses, refuse trucks, and OTR tractors by assuming each CNG station will serve 80 transit buses, 80 OTR tractors, or 50 refuse trucks, as suggested in the CNG station scenario model.

Table D-2: Methane Emissions from CNG Stations

\begin{tabular}{|c|r|r|r|}
\hline \multirow{2}{*}{ Vehicle Type } & Compressor & Continuous & Nozzle Emissions \\
\cline { 2 - 4 } & $\mathrm{g} / \mathrm{kg}$ fuel & g/day & \multicolumn{2}{|c|}{ g/event } \\
\hline Transit Bus & 0.70 & 816 & 3.61 \\
\hline Refuse Truck* & 1.12 & 816 & 3.61 \\
\hline 9L OTR Tractor & 0.68 & 816 & 3.61 \\
\hline 12L OTR Tractor & 0.49 & 816 & 3.61 \\
\hline
\end{tabular}

*Only 50 vehicles refueled (compared to 80 for all other vehicle types)

Table D-3 shows the FSME (g/kg fuel) from CNG stations when refueling transit buses, refuse trucks, 9 liter short haul tractors, or 12 liter long haul tractors only. The total FSME from CNG 
stations were 0.53 (refueling eighty 12 liter SI engine OTR tractors) to $1.33 \mathrm{~g} / \mathrm{kg}$ fuel (refueling fifty refuse trucks). Among the three sources, compressors were the main contributors to the methane emissions from CNG stations for the 2035 CNG station population scenario.

Table D-3: FSME (g/kg fuel) from CNG Stations

\begin{tabular}{|c|r|r|r|r|}
\hline \multirow{2}{*}{ Vehicle Type } & Compressor & Continuous & Nozzle Emissions & \multicolumn{1}{c|}{ Total } \\
\cline { 2 - 5 } & $\mathrm{g} / \mathrm{kg}$ fuel & $\mathrm{g} / \mathrm{kg}$ fuel & $\mathrm{g} / \mathrm{kg}$ fuel & $\mathrm{g} / \mathrm{kg}$ fuel \\
\hline Transit Bus & 0.70 & 0.14 & 0.043 & 0.88 \\
\hline Refuse Truck & 1.12 & 0.28 & 0.044 & 1.44 \\
\hline 9L OTR Tractor & 0.68 & 0.13 & 0.041 & 0.85 \\
\hline 12L OTR Tractor & 0.49 & 0.07 & 0.022 & 0.59 \\
\hline
\end{tabular}

Impact of CNG Station Utilization on Methane Emissions from CNG Stations

The utilization of CNG stations was represented by the number of CNG vehicles refueled each day. The 2035 CNG station population scenario model assumed that each CNG station would serve 80 transit buses, 80 OTR tractors, or 50 refuse trucks. A CNG station that refueled less than 80 transit buses, 80 OTR tractors, or 50 refuse trucks was defined as an under-utilized CNG station. By comparison, a CNG station that refueled more than 80 transit buses, 80 OTR tractors, or 50 refuse trucks was defined as an over-utilized CNG station. The impact of CNG station utilization on methane emissions from CNG stations was investigated by adjusting the number of transit buses refueled each day.

\section{CNG Stations for Transit Buses}

As shown in Table D-4, an increase in the number of transit buses refueled was found to decrease the FSME from the compressor. This was due to the increased fuel delivery and reduced compressor-off time. However, an increase in the number of transit buses refueled did not affect methane emissions from continuous sources, reported in $\mathrm{g} / \mathrm{day}$. An increase in the number of transit buses refueled would decrease the FSME from CNG stations. An increase in the number of transit buses from 80 to 160 decreased the FSME from 0.88 to $0.69 \mathrm{~g} / \mathrm{kg}$ of CNG fuel delivered (-27.8\%), representing a 27.8\% reduction in FSME. By comparison, a decrease in the number of transit buses refueled from 80 to 40 was found to increase the FSME from 0.88 to $1.46 \mathrm{~g} / \mathrm{kg}$ of CNG fuel $(+64.8 \%)$, an increase of $64.8 \%$. The methane emissions from a seriously underutilized transit buses CNG station, refueling 20 transit buses (25\% of the scenario proposed), were $2.60 \mathrm{~g} / \mathrm{kg}$ fuel, which were 1.94 times of that of CNG stations refueling 80 transit buses each day.

Figure D-2 shows the impact of the number of transit buses refueled each day on the FSME for CNG stations. The increase in the number of transit buses refueled by each CNG station decreased the FSME. This was due to the decreases in the FSME from compressors, as shown in Figure D-3. 
Table D-4: Impact of CNG Station Utilization (Number of Refueling Events) on Methane Emissions from CNG Stations for Transit Buses

\begin{tabular}{|c|c|c|c|c|}
\hline \multirow{3}{*}{$\begin{array}{l}\text { Number of } \\
\text { Vehicles }\end{array}$} & \multicolumn{3}{|c|}{ Emissions Sources } & \multirow{2}{*}{$\begin{array}{c}\text { FSME from CNG } \\
\text { Stations }\end{array}$} \\
\hline & Compressor & $\begin{array}{l}\text { Continuous } \\
\text { Sources }\end{array}$ & $\begin{array}{c}\text { Dispensing } \\
\text { Nozzle }\end{array}$ & \\
\hline & $\mathrm{g} / \mathrm{kg}$ fuel & g/day & g/event & $\mathrm{g} / \mathrm{kg}$ fuel \\
\hline 20 & 1.99 & 816.03 & 3.61 & 2.60 \\
\hline 40 & 1.13 & 816.03 & 3.61 & 1.46 \\
\hline 60 & 0.96 & 816.03 & 3.61 & 1.23 \\
\hline 80 & 0.84 & 816.03 & 3.61 & 1.08 \\
\hline 100 & 0.70 & 816.03 & 3.61 & 0.88 \\
\hline 120 & 0.61 & 816.03 & 3.61 & 0.77 \\
\hline 140 & 0.56 & 816.03 & 3.61 & 0.69 \\
\hline 160 & 0.51 & 816.03 & 3.61 & 0.64 \\
\hline
\end{tabular}

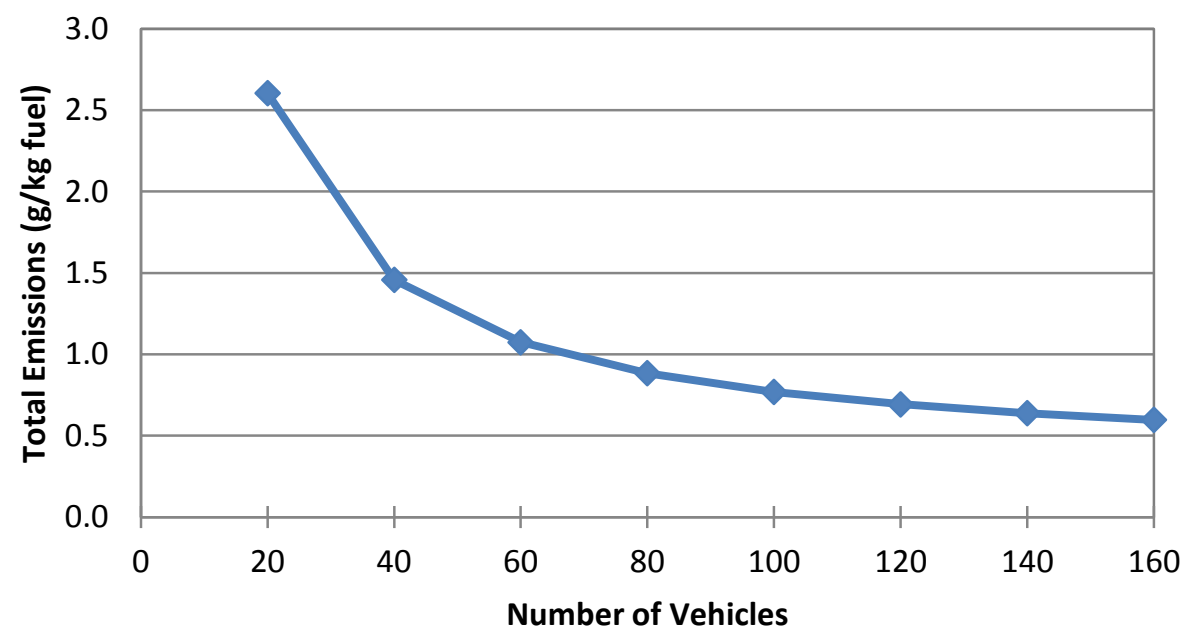

Figure D-2: Effect of Station Utilization on FSME from CNG Stations for Transit Buses

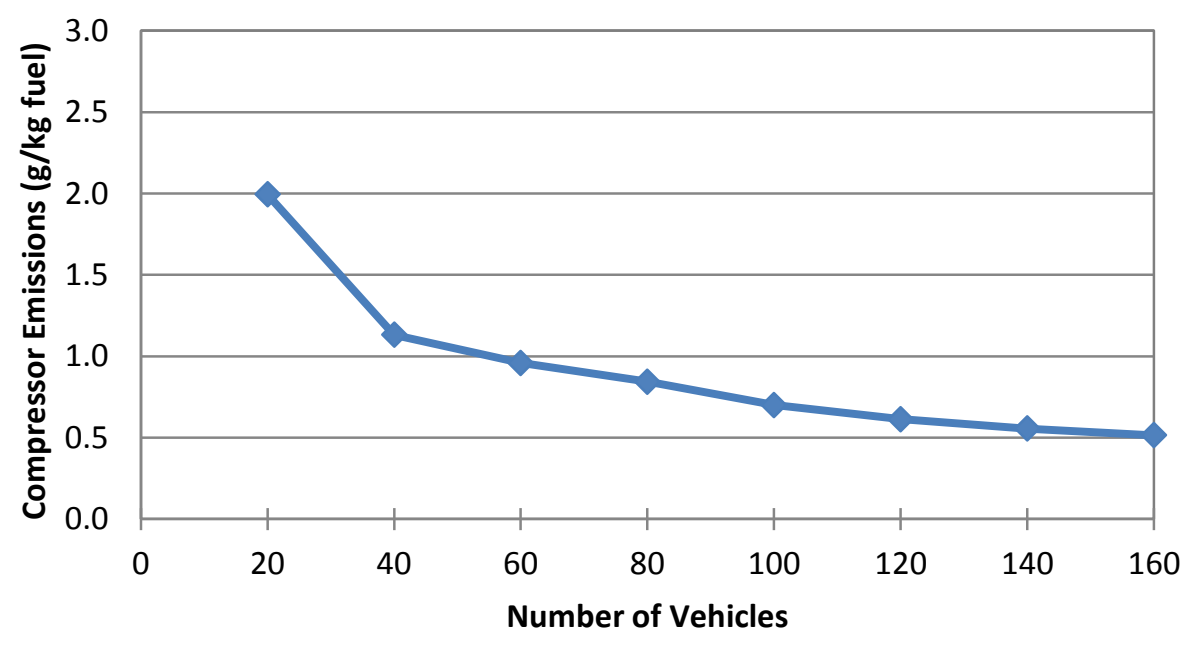

Figure D-3: Effect of Station Utilization on FSME from Compressors in CNG Stations for Transit Buses 
Figure D-4, Figure D-5, and Figure D-6 show the emissions by source for an under-utilized, fully utilized, and over-utilized transit bus station, respectively. When the station was under-utilized the compressor-off emissions were the highest source. The compressor-off emissions decreased and the compressor-on emissions increased significantly as the station refueled more vehicles. The continuous emissions decrease and the nozzle emissions increased slightly as well. The compressor-on emissions dominated for an over-utilized station.

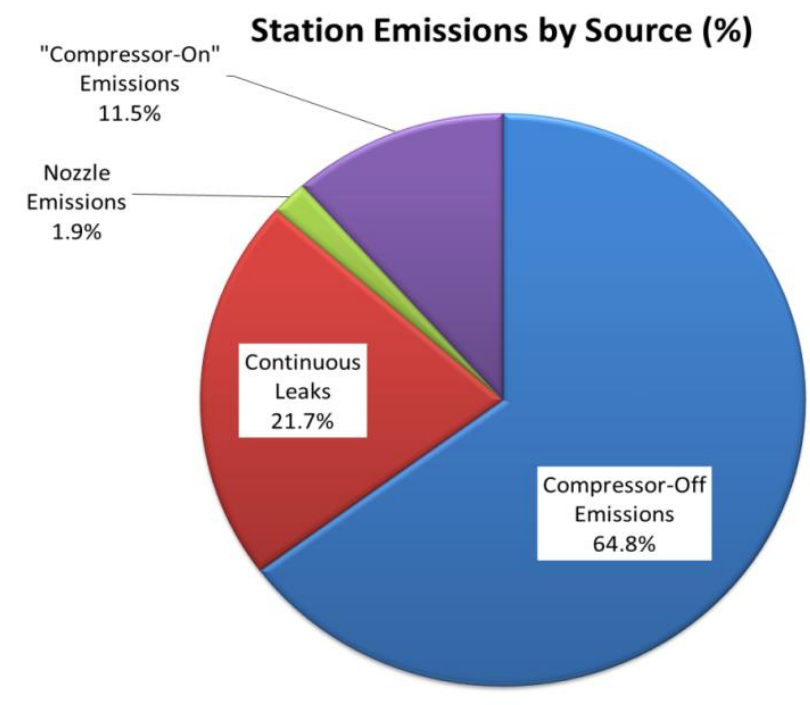

Figure D-4: Station Methane Emissions by Source for an Under-Utilized Transit Bus Station (20 Vehicles per Station)

Station Emissions by Source (\%)

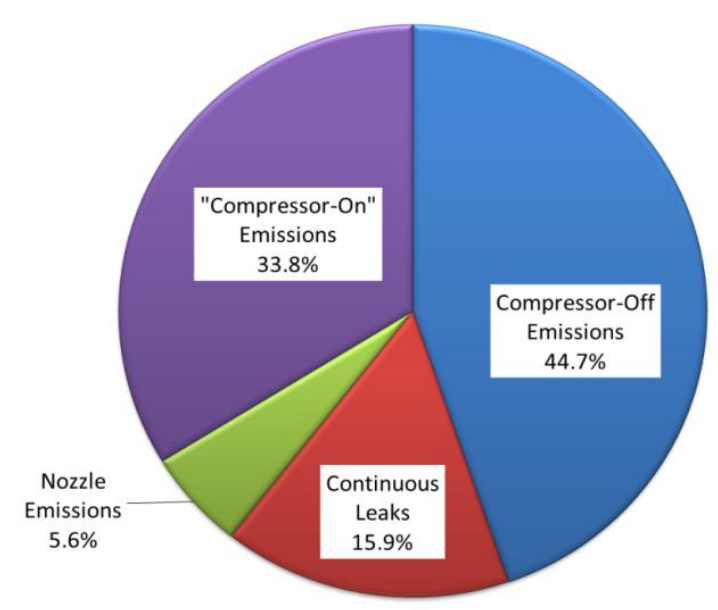

Figure D-5: Station Methane Emissions by Source for a Fully Utilized Transit Bus Station (80 Vehicles per Station) 


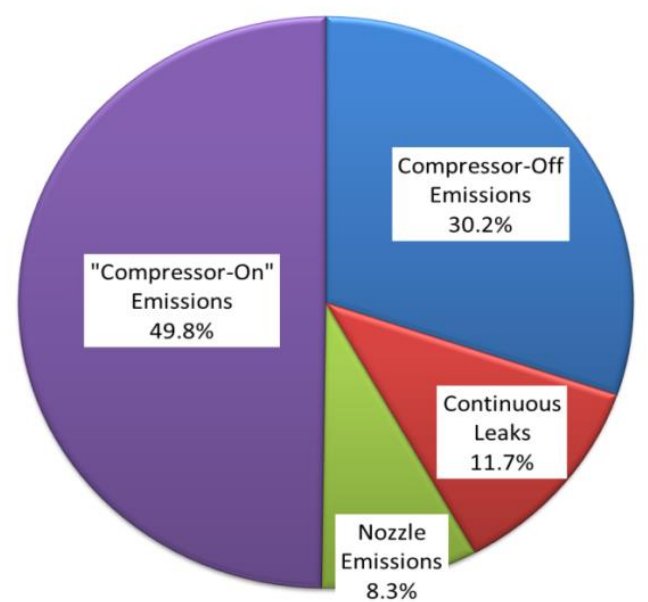

Figure D-6: Station Methane Emissions by Source for an Over-Utilized Transit Bus Station (160 Vehicles per Station)

\section{CNG Stations for 12 Liter SI OTR Tractors}

Table D-5 shows the impact of CNG station utilization on the methane emissions from CNG stations refueling 12 liter OTR tractors. Increasing the number of refueling events decreased the FSME from CNG stations, which was consistent with CNG stations refueling transit buses.

Table D-5: Impact of CNG Station Utilization (Number of Refueling Events) on Methane Emissions from CNG Stations for 12 Liter OTR Tractors

\begin{tabular}{|c|c|c|c|c|c|}
\hline \multirow{3}{*}{$\begin{array}{l}\text { Number of } \\
\text { Vehicles }\end{array}$} & \multicolumn{3}{|c|}{ Emissions Sources } & \multirow[b]{2}{*}{$\begin{array}{l}\text { FSME from } \\
\text { CNG Stations }\end{array}$} & \multirow{2}{*}{$\begin{array}{c}\text { Contribution of } \\
\text { Compressors to } \\
\text { Methane } \\
\text { Emissions from } \\
\text { CNG Station }\end{array}$} \\
\hline & Compressor & $\begin{array}{c}\text { Continuous } \\
\text { Sources }\end{array}$ & $\begin{array}{c}\text { Dispensing } \\
\text { Nozzle }\end{array}$ & & \\
\hline & $\mathrm{g} / \mathrm{kg}$ fuel & g/day & g/event & $\mathrm{g} / \mathrm{kg}$ fuel & $\%$ \\
\hline 20 & 1.16 & 816 & 3.61 & 1.47 & $78.6 \%$ \\
\hline 40 & 0.71 & 816 & 3.61 & 0.88 & $80.9 \%$ \\
\hline 60 & 0.56 & 816 & 3.61 & 0.68 & $82.5 \%$ \\
\hline 80 & 0.49 & 816 & 3.61 & 0.59 & $83.8 \%$ \\
\hline 100 & 0.45 & 816 & 3.61 & 0.53 & $84.7 \%$ \\
\hline 120 & 0.42 & 816 & 3.61 & 0.49 & $85.5 \%$ \\
\hline 140 & 0.40 & 816 & 3.61 & 0.46 & $86.1 \%$ \\
\hline 160 & 0.38 & 816 & 3.34 & 0.44 & $86.6 \%$ \\
\hline
\end{tabular}

Figure D-7 and Figure D-8 show the impact of CNG station utilization on FSME from CNG stations and compressors, respectively, for 12 liter OTR tractors. 


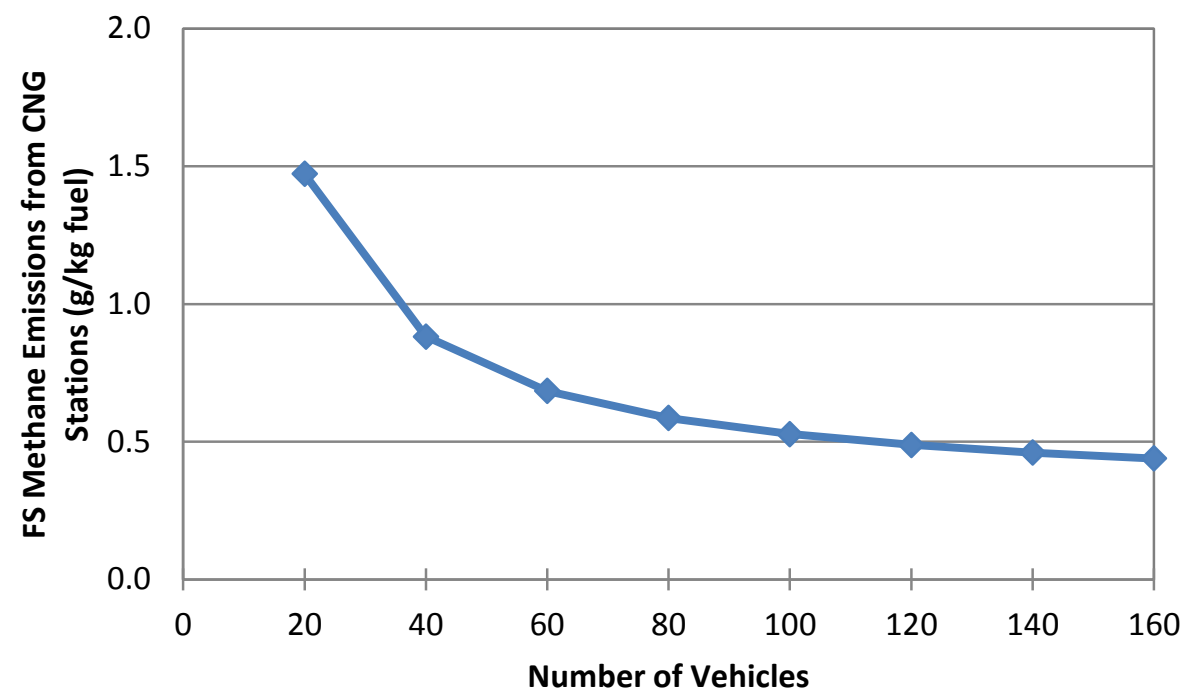

Figure D-7: Effect of Station Utilization on FSME from CNG Stations for 12 Liter OTR Tractors

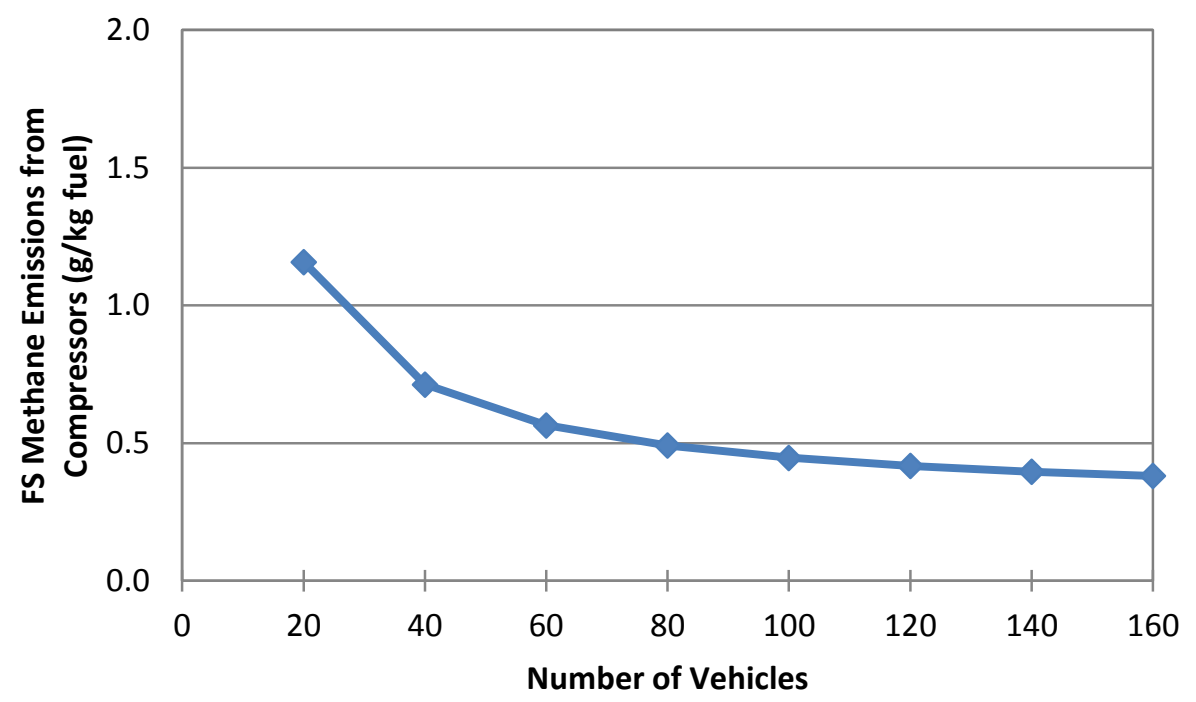

Figure D-8: Effect of Station Utilization on FSME from Compressors in CNG Stations for 12L OTR Tractors

Figure D-9, Figure D-10, and Figure D-11 show the emissions by source for an under-utilized, fully utilized, and over-utilized 12 liter OTR tractor station, respectively. The stations refueling 12 liter OTR tractors showed similar results to the stations refueling transit buses. 


\section{Station Emissions by Source (\%)}

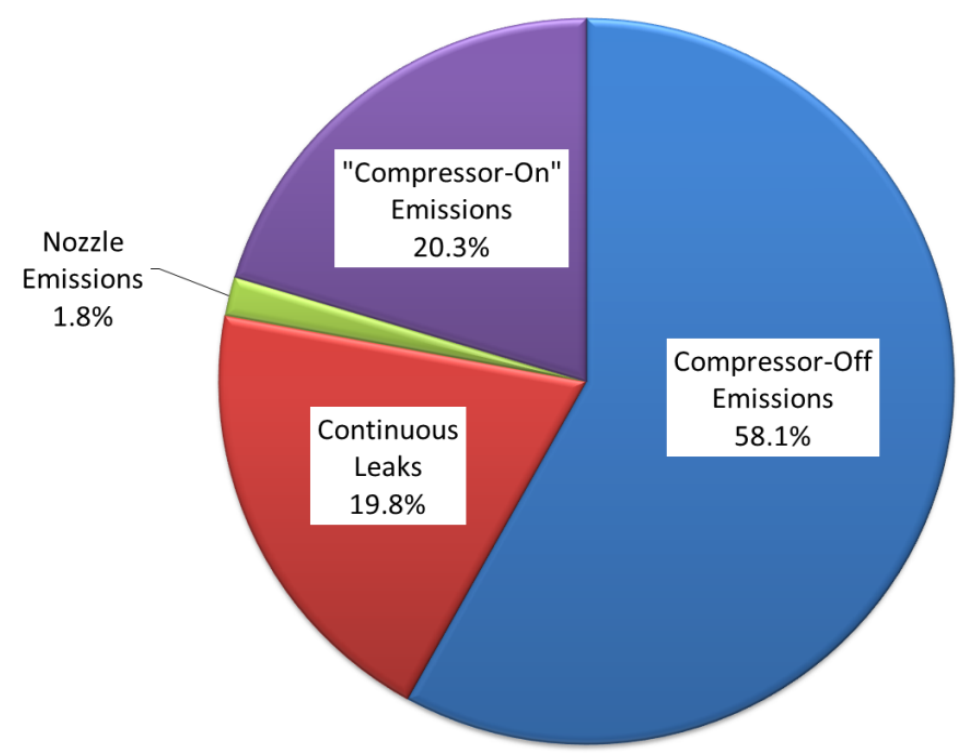

Figure D-9: Station Methane Emissions by Source for an Under-Utilized 12L OTR Tractor Station (20 Vehicles per Station)

\section{Station Emissions by Source (\%)}

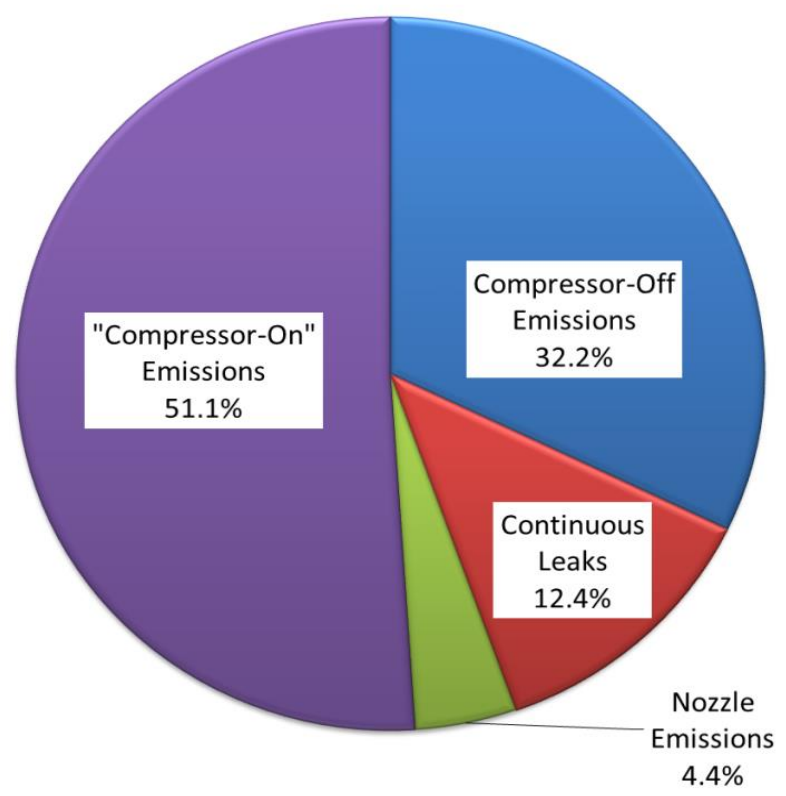

Figure D-10: Station Methane Emissions by Source for a Fully Utilized 12L OTR Tractor Station (80 Vehicles per Station) 


\section{Station Emissions by Source (\%)}

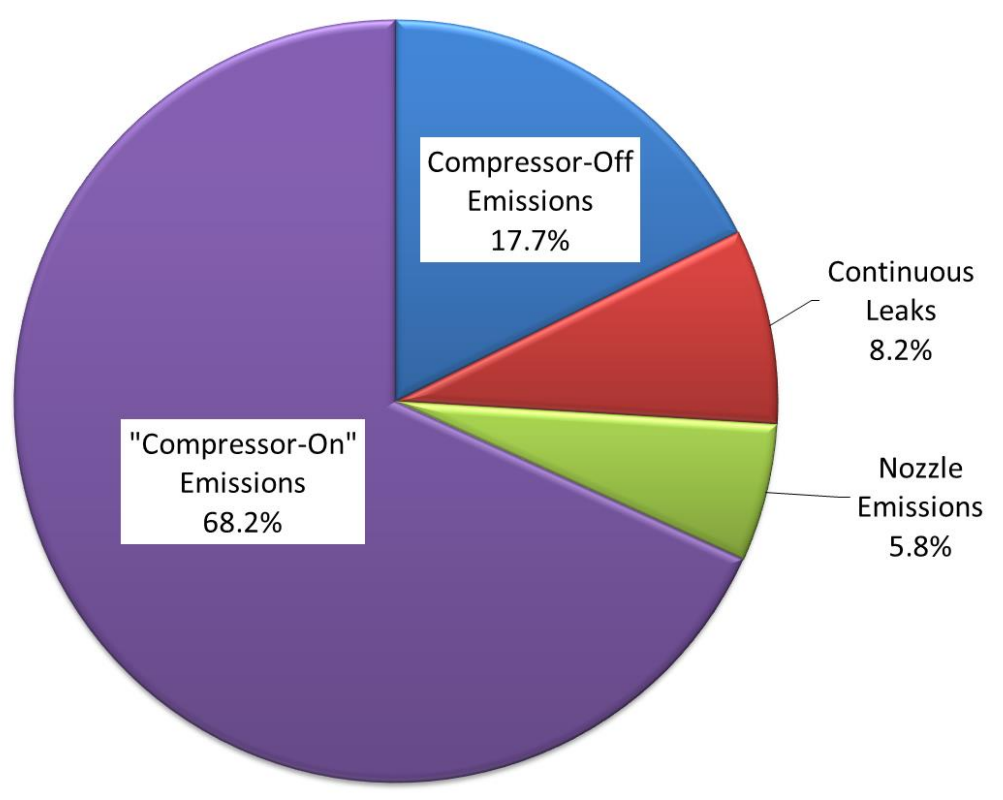

Figure D-11: Station Methane Emissions by Source for an Over-Utilized 12L OTR Tractor Station (160 Vehicles per Station)

Table D-6 compares the FSME from CNG stations refueling transit buses and 12 liter OTR tractors, respectively. The CNG stations refueling transit buses have higher FSME than those refueling the same number of 12 liter OTR tractors, which were due to the delivery of less CNG fuel to transit buses. Figure D-12 shows the impact of the number of CNG vehicles refueling events on the FSME.

Table D-6: FSME from CNG Station Emissions for Transit Buses and 12L OTR Tractors

\begin{tabular}{|c|c|c|}
\hline \multirow{2}{*}{$\begin{array}{c}\text { Number of } \\
\text { Refueling Events }\end{array}$} & $\begin{array}{c}\text { Transit Bus } \\
\text { FSME }\end{array}$ & $\begin{array}{c}\text { 12L OTR Tractor } \\
\text { FSME }\end{array}$ \\
\cline { 2 - 3 } & g/kg fuel & g/kg fuel \\
\hline 20 & 2.60 & 1.47 \\
\hline 40 & 1.46 & 0.88 \\
\hline 60 & 1.08 & 0.68 \\
\hline 80 & 0.88 & 0.59 \\
\hline 100 & 0.77 & 0.53 \\
\hline 120 & 0.69 & 0.49 \\
\hline 140 & 0.64 & 0.46 \\
\hline 160 & 0.60 & 0.44 \\
\hline
\end{tabular}




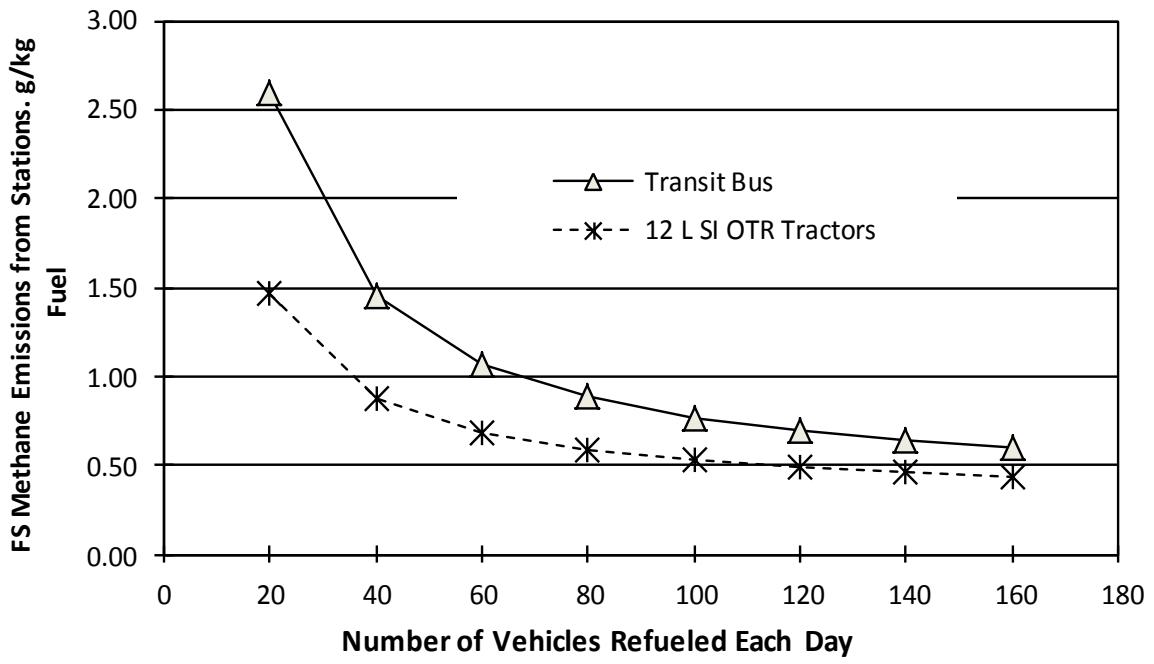

Figure D-12: Effect of Station Utilization on FSME from Compressors in CNG Stations for Transit Buses and 12L OTR Tractors

Figure D-13 shows the impact of the number of refueling events on the contributions of compressors relative to the total methane emissions from CNG stations serving transit buses and 12 liter OTR tractors. Increasing the refueling events was found to increase the contributions of the compressors relative to total methane emissions from CNG stations.

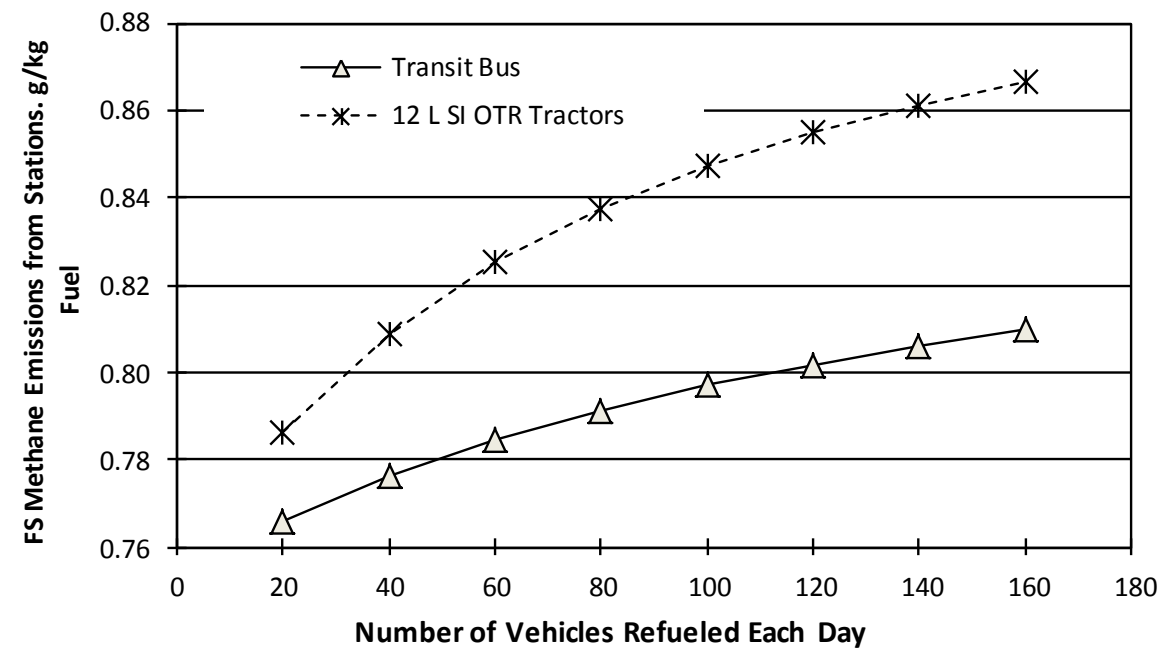

Figure D-13: Contributions of Compressor Emissions to Methane Emissions from Compressors of CNG Stations

\section{Case Study Demonstrating the Independence of Methane Emissions from CNG Stations with Unevenly Utilized CNG Stations}

The impact of uneven (imbalanced) utilization of CNG station on methane emissions from CNG stations and contribution of each source were investigated by examining the methane emissions from CNG stations for different cases, with a fixed number of CNG fuel stations, refueling events (or number of CNG buses), and total CNG fuel delivered per vehicle. 


\section{Effect of Imbalanced Station Utilization on Methane Emissions from CNG Stations}

The impacts of imbalanced utilization of CNG stations on methane emissions from CNG stations were investigated with an assumed $10 \mathrm{CNG}$ stations and 800 refueling events each day. As shown in Table D-7, each station serving 80 refueling events represents an evenly distributed CNG station utilization (case one). Case two represents an extreme of unevenly distributed CNG station utilization, there were 4 seriously under-utilized CNG stations serving 20 refueling events per station, 3 evenly utilized stations serving 80 refueling events per station, and 3 seriously over-utilized CNG stations refueling 160 vehicles per station. Case three represents a medium unevenly utilized CNG stations. There were 4 under-utilized CNG stations serving 50 refueling events per station, 3 evenly utilized stations serving 80 refueling events per station, and 3 overutilized CNG stations refueling 120 vehicles per station. The total methane emissions from CNG stations, including compressor, continuous, and nozzle emissions from a distribution of stations, were calculated and compared.

Table D-7: Summary of Case Studies for Effect of Over-Utilization and Under-Utilization

\begin{tabular}{|c|rr|r|r|r|}
\hline \multirow{2}{*}{ Station Utilization } & \multicolumn{2}{|c|}{$\begin{array}{c}\text { Number of Refueling } \\
\text { Events per Day }\end{array}$} & \multicolumn{3}{|c|}{ Number of CNG Stations } \\
\cline { 2 - 5 } & 20 & 0 & 4 & 0 \\
\hline \multirow{2}{*}{ Under-utilized } & 50 & 0 & 0 & 4 \\
\cline { 2 - 5 } & 80 & 10 & 3 & 3 \\
\hline Normal & 120 & 0 & 0 & 3 \\
\hline \multirow{2}{*}{ Over-utilized } & 160 & 0 & 3 & 0 \\
\cline { 2 - 5 } & & 10 & 10 & 10 \\
\hline \multicolumn{2}{|r|}{ Total Refueling Stations } & 800 & 800 & 800 \\
\hline \multicolumn{2}{|r}{ Total Refueling Events } & 80 & 80 & 80 \\
\hline \multicolumn{2}{|r}{ Average Refueling Events per Station } & & Case 2 & Case 3 \\
\hline
\end{tabular}

Table D-8 shows the methane emissions from ten normally utilized stations, which refuel 80 transit buses at each station per day. With the known FSME of $0.88 \mathrm{~g} / \mathrm{kg} \mathrm{CNG}$ and annual CNG fuel delivered $(21,028,800 \mathrm{~kg})$, the total methane emissions calculated were $18,598 \mathrm{~kg}$.

Table D-8: Total Methane Emissions from 10 CNG Station Refueling 800 Transit Buses. Case 1: Evenly Utilized CNG Stations Refueling 80 Transit Buses in Each Station

\begin{tabular}{|c|r|r|r|c|}
\hline \multirow{2}{*}{$\begin{array}{c}\text { Station } \\
\text { Utilization }\end{array}$} & \multirow{2}{*}{$\begin{array}{c}\text { Number } \\
\text { of Vehicles }\end{array}$} & \multirow{2}{*}{$\begin{array}{c}\text { Number } \\
\text { of Stations }\end{array}$} & FS Methane Emissions & $\begin{array}{c}\text { Annual } \\
\text { Emissions }\end{array}$ \\
\cline { 4 - 5 } & & 10 & $\mathrm{~g} / \mathrm{kg}$ fuel & $\mathrm{kg}$ \\
\hline Normal & 80 & 10 & 0.88 & $\mathbf{1 8 , 5 9 8}$ \\
\hline
\end{tabular}

Table D-9 shows the total methane emissions from the extreme of unevenly utilized CNG stations refueling transit buses. With the known FSME and total fuel delivery of each type of CNG station utilization, the annual methane emissions from this type of fuel stations can be calculated. The annual emissions from each station utilization type was added together to get a total annual emissions from all stations. As shown in Table D-9, the annual methane emissions from these 10 seriously unevenly utilized CNG stations were the same as the ten fully utilized stations refueling transit buses. 
Table D-9: Total Methane Emissions from 10 CNG Station Refueling 800 Transit Buses. Case 2: Seriously Unevenly Utilized CNG Stations

\begin{tabular}{|c|c|c|c|c|}
\hline \multirow[t]{2}{*}{$\begin{array}{c}\text { Station } \\
\text { Utilization }\end{array}$} & \multirow{2}{*}{$\begin{array}{l}\text { Number } \\
\text { of Refueling } \\
\text { Events in } \\
\text { Each Station }\end{array}$} & \multirow[t]{2}{*}{$\begin{array}{l}\text { Number } \\
\text { of CNG } \\
\text { Stations }\end{array}$} & $\begin{array}{c}\text { FS Methane } \\
\text { Emissions from } \\
\text { Each Type Stations }\end{array}$ & $\begin{array}{l}\text { Annual } \\
\text { Emissions }\end{array}$ \\
\hline & & & $\mathrm{g} / \mathrm{kg}$ fuel & $\mathrm{kg}$ \\
\hline $\begin{array}{c}\text { Seriously under- } \\
\text { utilized }\end{array}$ & 20 & 4 & 2.60 & 5,477 \\
\hline Normal & 80 & 3 & 0.88 & 5,580 \\
\hline $\begin{array}{c}\text { Seriously over- } \\
\text { utilized }\end{array}$ & 160 & 3 & 0.60 & 7,542 \\
\hline Total & $\mathrm{N} / \mathrm{A}$ & 10 & N/A & 18,598 \\
\hline
\end{tabular}

Table D-10 shows the total methane emissions from $10 \mathrm{CNG}$ stations involving medium unevenly utilized $\mathrm{CNG}$ stations. The annual emissions calculated were identical to those calculated in case one (shown in Table D-8) and case two (shown in Table D-9).

Table D-10: Total Methane Emissions from 10 CNG Station Refueling 800 Transit Buses. Case 3: Medium Unevenly Utilized CNG Stations

\begin{tabular}{|c|r|r|r|c|}
\hline \multirow{2}{*}{$\begin{array}{c}\text { Station } \\
\text { Utilization }\end{array}$} & \multicolumn{1}{c}{$\begin{array}{c}\text { Number of } \\
\text { Refueling Events }\end{array}$} & \multirow{2}{*}{$\begin{array}{c}\text { Number } \\
\text { of Stations }\end{array}$} & $\begin{array}{c}\text { Total } \\
\text { Emissions }\end{array}$ & $\begin{array}{c}\text { Annual } \\
\text { Emissions }\end{array}$ \\
\cline { 4 - 5 } & 50 & 4 & 1.23 & 6,458 \\
\hline $\begin{array}{c}\text { Medium Under- } \\
\text { Utilized }\end{array}$ & 80 & 3 & 0.88 & 5,580 \\
\hline Normal & 120 & 3 & 0.69 & 6,561 \\
\hline $\begin{array}{c}\text { Medium Over- } \\
\text { Utilized }\end{array}$ & N/A & 10 & N/A & $\mathbf{1 8 , 5 9 8}$ \\
\hline Total & 10 & & \\
\hline
\end{tabular}

Table D-11: FSME from Each Source for Different Utilization Types for Transit Buses

\begin{tabular}{|c|r|r|r|r|}
\hline \multirow{2}{*}{$\begin{array}{c}\text { Number of } \\
\text { Vehicles }\end{array}$} & \multicolumn{2}{|c|}{ FS Methane Emissions from Each Source } & \multirow{2}{*}{ Total } \\
\cline { 2 - 4 } & Compressor & Continuous & $\begin{array}{c}\text { Nozzle } \\
\text { Emissions }\end{array}$ & \\
\cline { 2 - 4 } & $\mathrm{g} / \mathrm{kg}$ fuel & $\mathrm{g} / \mathrm{kg}$ fuel & $\mathrm{g} / \mathrm{kg}$ fuel & $\mathrm{g} / \mathrm{kg}$ fuel \\
\hline 20 & 1.99 & 0.57 & 0.04 & 2.60 \\
\hline 40 & 1.13 & 0.28 & 0.04 & 1.46 \\
\hline 60 & 0.84 & 0.19 & 0.04 & 1.08 \\
\hline 80 & 0.70 & 0.14 & 0.04 & 0.88 \\
\hline 100 & 0.61 & 0.11 & 0.04 & 0.77 \\
\hline 120 & 0.56 & 0.09 & 0.04 & 0.69 \\
\hline 140 & 0.51 & 0.08 & 0.04 & 0.64 \\
\hline 160 & 0.48 & 0.07 & 0.04 & 0.60 \\
\hline
\end{tabular}


Table D-11 shows the FSME from each source for different utilizations for transit buses. The FSME decrease for the compressor, continuous, and total emissions as the station refuels more vehicles per day.

Table D-12 compares the methane emissions from CNG stations and the contribution from each source for three cases of $10 \mathrm{CNG}$ stations serving 800 refueling events each day. The annual methane emissions and contribution of each source to methane emissions calculated in each were identical. With the fixed CNG station population, fixed number of refueling events, and fixed total fuel delivery per vehicle, the deviation of the CNG station utilization from evenly utilized case does not affect the calculated total methane emissions from CNG stations and the contribution of each source to total methane emitted.

Table D-12: Contribution of Each Source to Methane Emissions from CNG Stations for Each Case Study

\begin{tabular}{|c|c|c|c|c|c|c|c|}
\hline \multirow{3}{*}{ Case } & \multicolumn{3}{|c|}{$\begin{array}{l}\text { Annual Methane Emissions } \\
\text { from Each Source }\end{array}$} & \multirow[t]{2}{*}{ Total } & \multicolumn{3}{|c|}{$\begin{array}{l}\text { Contribution of Each Source to } \\
\text { Methane Emissions from CNG Stations }\end{array}$} \\
\hline & Compressor & Continuous & Nozzle & & Compressor & Continuous & Nozzle \\
\hline & $\mathrm{kg}$ & $\mathrm{kg}$ & $\mathrm{kg}$ & $\mathrm{kg}$ & $\%$ & $\%$ & $\%$ \\
\hline Case 1 & 14,717 & 2,981 & 901 & 18,598 & $79.1 \%$ & $16.0 \%$ & $4.8 \%$ \\
\hline Case 2 & 14,717 & 2,981 & 901 & 18,598 & $79.1 \%$ & $16.0 \%$ & $4.8 \%$ \\
\hline Case 3 & 14,717 & 2,981 & 901 & 18,598 & $79.1 \%$ & $16.0 \%$ & $4.8 \%$ \\
\hline
\end{tabular}

The impact of utilization on methane emissions from CNG stations refueling 12 L OTR tractors was also investigated. As shown in Table D-13, Table D-14, Table D-15, and Table D-16, total methane emissions from 10 CNG stations serving 800 refueling events were not affected by the uneven utilization of CNG stations if the number of CNG stations, refueling events, and total fuel delivery per vehicle were constant. These results are consistent with the transit bus analysis.

Table D-13: Total Methane Emissions from 10 CNG Station Refueling 800 OTR Tractors. Case 1: Evenly Utilized CNG Stations Refueling 80 OTR Tractors in Each Station

\begin{tabular}{|c|r|r|r|c|}
\hline \multirow{2}{*}{$\begin{array}{c}\text { Station } \\
\text { Utilization Type }\end{array}$} & \multirow{2}{*}{$\begin{array}{c}\text { Number of Vehicles } \\
\text { Per Station }\end{array}$} & $\begin{array}{c}\text { Number } \\
\text { of Stations }\end{array}$ & $\begin{array}{c}\text { Total } \\
\text { Emissions }\end{array}$ & $\begin{array}{c}\text { Annual } \\
\text { Emissions }\end{array}$ \\
\cline { 4 - 6 } & $\mathrm{g} / \mathrm{kg}$ fuel & $\mathrm{kg}$ \\
\hline Fully & 80 & 10 & 0.59 & $\mathbf{2 3 , 9 1 8}$ \\
\hline
\end{tabular}

Table D-14: Total Methane Emissions from 10 CNG Station Refueling 800 OTR Tractors. Case 2: Seriously Unevenly Utilized CNG Stations

\begin{tabular}{|c|r|r|r|r|}
\hline \multirow{2}{*}{$\begin{array}{c}\text { Station } \\
\text { Utilization }\end{array}$} & \multirow{2}{*}{$\begin{array}{c}\text { Number of } \\
\text { Vehicles }\end{array}$} & \multirow{2}{*}{$\begin{array}{c}\text { Number } \\
\text { of Stations }\end{array}$} & $\begin{array}{c}\text { Total } \\
\text { Emissions }\end{array}$ & $\begin{array}{c}\text { Annual } \\
\text { Emissions }\end{array}$ \\
\cline { 4 - 5 } & & & $\mathrm{g} / \mathrm{kg}$ fuel & \multicolumn{1}{c|}{$\mathrm{Kg}$} \\
\hline Under & 20 & 4 & 1.47 & 6,003 \\
\hline Fully & 80 & 3 & 0.59 & 7,169 \\
\hline Over & 160 & 3 & 0.44 & 10,746 \\
\hline Total & $\mathrm{N} / \mathrm{A}$ & 10 & $\mathrm{~N} / \mathrm{A}$ & $\mathbf{2 3 , 9 1 8}$ \\
\hline
\end{tabular}


Table D-15: Total Methane Emissions from 10 CNG Station Refueling 800 OTR Tractors. Case 3: Medium Unevenly Utilized CNG Stations

\begin{tabular}{|c|r|r|r|c|}
\hline \multirow{2}{*}{$\begin{array}{c}\text { Station } \\
\text { Utilization }\end{array}$} & \multirow{2}{*}{$\begin{array}{c}\text { Number } \\
\text { of Vehicles }\end{array}$} & \multirow{2}{*}{$\begin{array}{c}\text { Number } \\
\text { of Stations }\end{array}$} & $\begin{array}{c}\text { Total } \\
\text { Emissions }\end{array}$ & $\begin{array}{c}\text { Annual } \\
\text { Emissions }\end{array}$ \\
\cline { 4 - 5 } & & & $\mathrm{g} / \mathrm{kg}$ fuel & \multicolumn{1}{c|}{$\mathrm{kg}$} \\
\hline Under & 50 & 4 & 0.76 & 7,784 \\
\hline Fully & 80 & 3 & 0.59 & 7,174 \\
\hline Over & 120 & 3 & 0.49 & 8,954 \\
\hline Total & $\mathrm{N} / \mathrm{A}$ & 10 & $\mathrm{~N} / \mathrm{A}$ & $\mathbf{2 3 , 9 1 8}$ \\
\hline
\end{tabular}

Table D-16: Contribution of Each Source to Methane Emissions from CNG Stations for Each Case Study

\begin{tabular}{|c|c|c|c|c|c|c|c|}
\hline \multirow{3}{*}{ Case } & \multicolumn{3}{|c|}{$\begin{array}{c}\text { Annual Methane Emissions } \\
\text { from Each Source }\end{array}$} & \multicolumn{3}{|c|}{$\begin{array}{c}\text { Contribution of Each Source to } \\
\text { Tethane Emissions from CNG Stations }\end{array}$} \\
\cline { 2 - 6 } & Compressor & Continuous & Nozzle & & Compressor & Continuous & Nozzle \\
\cline { 2 - 6 } & $\mathrm{kg}$ & $\mathrm{Kg}$ & $\mathrm{kg}$ & $\mathrm{kg}$ & $\%$ & $\%$ & $\%$ \\
\hline Case 1 & 10,336 & 1,580 & 477 & 23,918 & $43.2 \%$ & $6.4 \%$ & $1.9 \%$ \\
\hline Case 2 & 10,336 & 1,580 & 477 & 23,918 & $43.2 \%$ & $6.4 \%$ & $1.9 \%$ \\
\hline Case 3 & 10,336 & 1,580 & 477 & 23,918 & $43.2 \%$ & $6.4 \%$ & $1.9 \%$ \\
\hline
\end{tabular}

Methane Emissions from CNG Stations Refueling Multiple Types of Vehicles

The calculation of methane emissions from CNG stations with fleets operating multiple types of CNG vehicles could be challenging because each station may refuel different types of vehicles, especially with unevenly utilized CNG stations and imbalanced vehicle types. In this research, the impact on methane emissions from unevenly utilized CNG stations refueling multiple types of CNG vehicles was investigated by examining methane emissions from $60 \mathrm{CNG}$ stations serving $4800 \mathrm{CNG}$ vehicles including 480 transit buses, 28809 liter short haul OTR tractors, and 144012 liter long haul OTR tractors in two extreme cases. As shown in Table D-17, case one represents the simplest scenario with each type of $\mathrm{CNG}$ vehicle refueled in each type of dedicated CNG stations. Case two represents a scenario with an even distribution of each vehicle type refueled at each CNG station.

Table D-18 shows the total emissions from 60 fully utilized stations refueling one type of vehicle per station. With the calculated FSME from CNG stations and annual total fuel delivery, the methane emissions from CNG stations serving each type of CNG vehicle can be calculated. As shown in Table D-18, the calculated total methane emissions from $60 \mathrm{CNG}$ stations with one type of CNG vehicles refueled in their specific CNG stations (case one), were 122,231 kg. 
Table D-17: Number of Vehicles and Stations for the Multiple Vehicle Types Case Study

\begin{tabular}{|c|c|c|c|}
\hline \multicolumn{4}{|c|}{ Case 1: CNG Vehicles Refueled by Type of CNG Stations } \\
\hline Type of CNG Vehicles Served & Number of Vehicles per Station & $\begin{array}{l}\text { Number } \\
\text { of Stations }\end{array}$ & $\begin{array}{l}\text { Number } \\
\text { of Vehicles }\end{array}$ \\
\hline Transit Buses & 80 & 6 & \\
\hline 9L OTR Tractor & 80 & 36 & \\
\hline 12L OTR Tractor & 80 & 18 & \\
\hline Total & 80 & 60 & 4800 \\
\hline \multicolumn{4}{|c|}{ Case 2: CNG Evenly Refueled in Each CNG Stations } \\
\hline Type of CNG Vehicles Served & $\begin{array}{c}\text { Number of Each Type of Vehicles } \\
\text { Refueled in Each Station }\end{array}$ & \multirow{4}{*}{60} & \\
\hline Transit Buses & 8 & & \\
\hline 9L Short Haul OTR Tractors & 48 & & \\
\hline 12L Long Haul OTR Tractors & 24 & & \\
\hline Total & 80 & 60 & 4800 \\
\hline
\end{tabular}

Table D-18: Total Methane Emissions from 60 CNG Station Refueling 4800 CNG Vehicles. Case 1: Each Type CNG Station Normally Utilized to Serve Specific Type of CNG Vehicles Only

\begin{tabular}{|c|r|r|r|c|}
\hline \multirow{2}{*}{$\begin{array}{c}\text { Vehicle Type } \\
\text { Refueled }\end{array}$} & \multirow{2}{*}{$\begin{array}{c}\text { Number } \\
\text { of Stations }\end{array}$} & \multirow{2}{*}{$\begin{array}{c}\text { Total Number } \\
\text { of Vehicles }\end{array}$} & $\begin{array}{c}\text { FS Methane } \\
\text { Emissions }\end{array}$ & $\begin{array}{c}\text { Annual } \\
\text { Emissions }\end{array}$ \\
\cline { 4 - 5 } & & $\mathrm{g} / \mathrm{kg}$ fuel & $\mathrm{kg}$ \\
\hline Transit Buses & 6 & 480 & 0.88 & 11,159 \\
\hline 9L OTR Tractors & 36 & 2880 & 0.85 & 68,060 \\
\hline 12L OTR Tractors & 18 & 1440 & 0.59 & 43,013 \\
\hline Total & 60 & 4800 & N/A & $\mathbf{1 2 2 , 2 3 1}$ \\
\hline
\end{tabular}

Table D-19 shows the total emissions from 60 CNG stations with each station evenly refueling $80 \mathrm{CNG}$ vehicles including 6 transit buses, 489 liter OTR tractors, and 2412 liter long haul OTR tractors (case two). The total methane emissions calculated were 122,231 kg, which were identical to those calculated in case one, shown in Table D-18. With the fixed number of CNG stations, refueling events, and total fuel delivered per vehicle, the methane emissions from CNG stations were not affected by the distribution of the refueling events at CNG stations and the utilization factor of each station.

Table D-19: Total Emissions from One Fully Utilized Station Type Refueling Three Different Vehicle Types per Station (60 Total)

\begin{tabular}{|c|r|r|r|r|}
\hline \multirow{2}{*}{$\begin{array}{c}\text { Vehicle Type } \\
\text { Refueled }\end{array}$} & $\begin{array}{c}\text { Number of Refueling } \\
\text { Events for Each Type } \\
\text { of Vehicle per Station }\end{array}$ & \multirow{2}{*}{$\begin{array}{c}\text { Number } \\
\text { of Stations }\end{array}$} & $\begin{array}{c}\text { Total Number } \\
\text { of Vehicles }\end{array}$ & $\begin{array}{c}\text { Annual } \\
\text { Emissions }\end{array}$ \\
\cline { 5 - 6 } & 8 & N/A & 480 & kg \\
\hline Transit Buses & 48 & N/A & 2880 & N/A \\
\hline 9L OTR Tractors & 24 & N/A & 1440 & N/A \\
\hline 12L OTR Tractors & 80 & 60 & 4800 & $\mathbf{1 2 2 , 2 3 1}$ \\
\hline Total & & &
\end{tabular}

Appendix D-41 


\section{Equation Calculating Methane Emissions from CNG Stations}

The survey and audit of CNG stations reported the methane emissions from each source and the capacity of CNG stations. The sources of methane emissions from CNG stations include compressor, nozzle, and continuous emissions. The total methane emissions (m) from CNG stations can be calculated by equation (D.1).

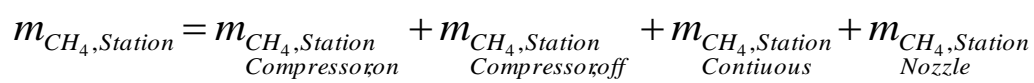

The emissions of methane from the compressor while operating can be calculated from the known mass flow rates of fugitive methane $(\dot{m})$ and the time period of compressor operation $(\mathrm{t})$, calculated from the total fuel delivery. Equation (D.2) was used to calculate the emissions of the compressor while it was operating.

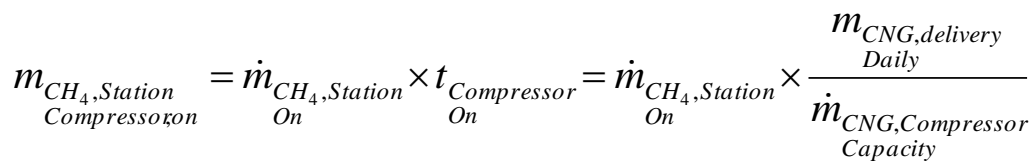

The methane emissions from CNG stations when the compressor was not in operation can be calculated by equation (D.3).

$$
\begin{aligned}
& m_{\text {Compresso }, \text { Off }}=\dot{m}_{\text {Off }_{4}, \text { Station }} \times t_{\text {Comp ressor }}=\dot{m}_{\text {On }_{4}, \text { Station }} \times\left(24-t_{\text {Compressor }}\right)
\end{aligned}
$$

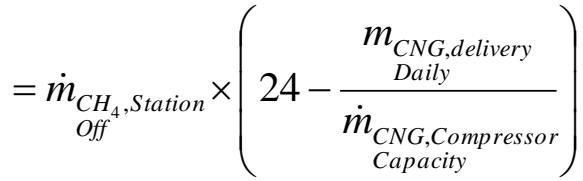

The methane emissions from continuous emissions can be calculated by using equation (D.4).

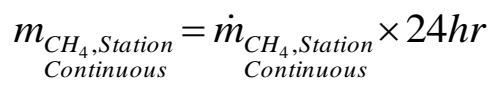

The methane emissions from the nozzle can be calculated by using equation (D.5).

$$
m_{\mathrm{CH}_{4} \text {,Station }}=\underset{\mathrm{CH}_{\text {Nozzle Station }}}{m_{\text {Nozleach RefuelingEvent }}} \times n_{\begin{array}{c}
\text { refuelingevent } \\
\text { each day }
\end{array}}
$$

Equation (D.1), equation (D.2), equation (D.3), equation (D.4) and equation (D.5) were combined to yield equation (D.6).

$$
\begin{aligned}
& m_{\mathrm{CH}_{4}, \text { Station }}=m_{\text {Compressoron }}+m_{\text {Compressoroff }}+m_{\text {Contiuous }}+m_{\mathrm{CH}_{4}, \text { Station Station }}
\end{aligned}
$$

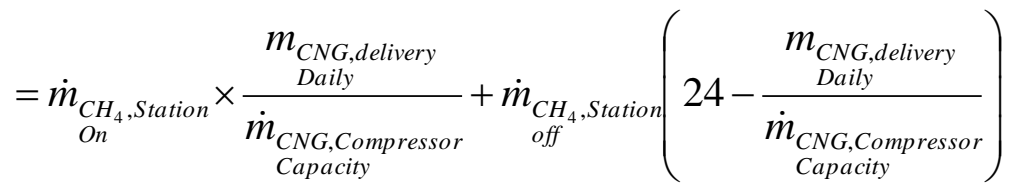

$$
\begin{aligned}
& +\underset{\text { Continuous }}{\dot{m}_{\mathrm{CH}_{4} \text {,Station }}} \times 24 h r+m_{\mathrm{CH}_{4} \text {,Station }}^{\text {Nozzleeach RefuelingEvent }} \times n_{\text {refuelingevent }} \times
\end{aligned}
$$


For a specific CNG station, the rate of methane emissions from the compressor while operating

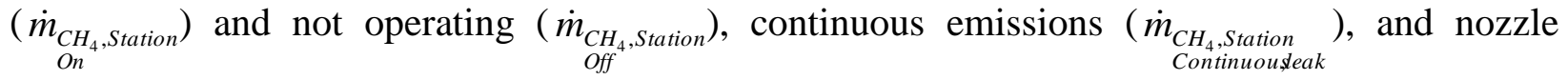
emissions for each refueling event $\left(m_{\mathrm{CH}_{4} \text {,Station }}^{\text {Nozzleeach RefuelingEvent }}\right)$ were constant. Accordingly, the methane emissions from CNG stations were affected only by the total fuel delivery, capacity of the compressors, and the number of refueling events. The rate of methane emissions were not affected by the type of vehicles refueled, shown in equation (D.7).

$$
m_{\mathrm{CH}_{4}, \text { Station }}=f\left(m_{\text {Caily delivery }}, \dot{m}_{\text {CapG,Compressor }}, n_{\text {refuelingevent }}\right)
$$

The FSME were also a function of the total fuel delivery, capacity of the compressors, and the number of refueling events, as shown in equation (D.8).

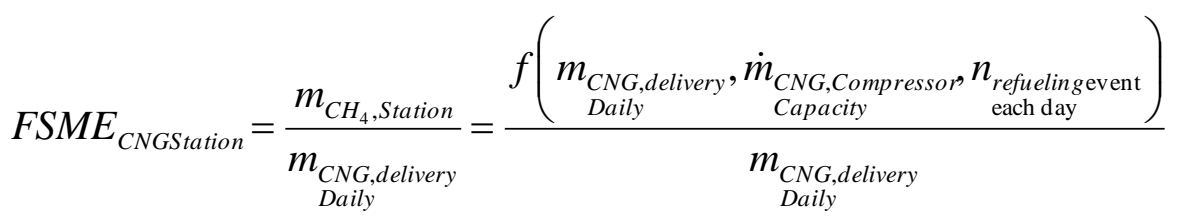

$$
\begin{aligned}
& =g\left(m_{\begin{array}{c}
\text { CNG,delivery } \\
\text { Daily }
\end{array}}, \dot{m}_{\begin{array}{c}
\text { CNG,Compressor } \\
\text { Capacity }
\end{array}}, n_{\text {refuelingevent }}\right)
\end{aligned}
$$

For a fleet with numerous CNG stations (same capacity and same methane emissions characteristics) and numerous types of CNG vehicles, equation (D.9), an integration of equation (D.1) can be used to calculate the methane emissions.

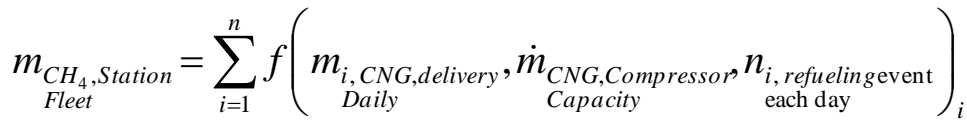

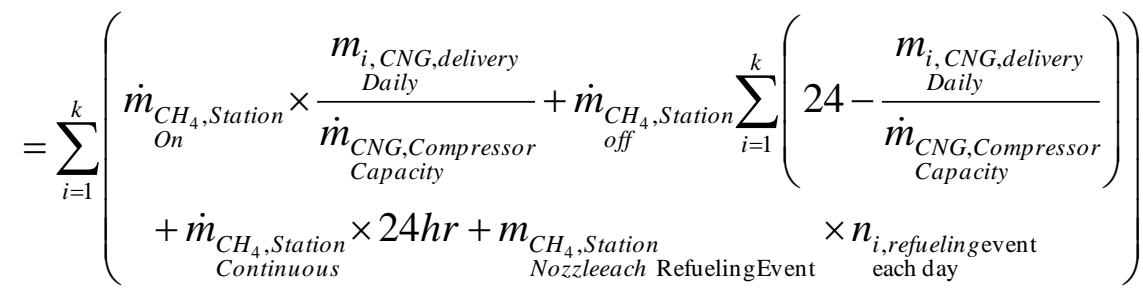

Equation (D.9) can be simplified to equation (D.10).

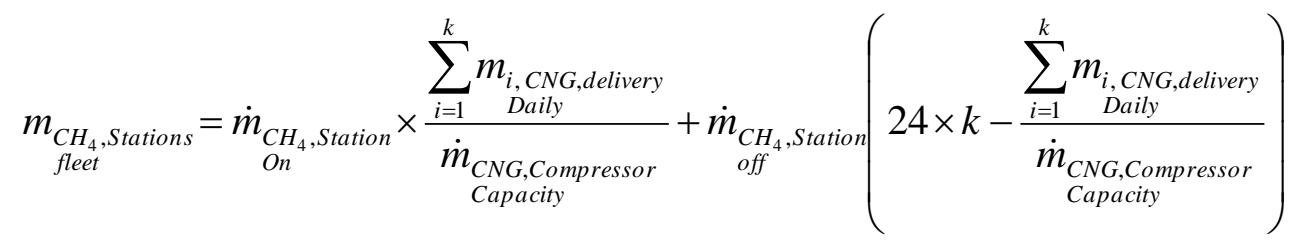

$$
\begin{aligned}
& +k \times \dot{m}_{\substack{\mathrm{CH}_{4} \text {,Station } \\
\text { Continuous }}} \times 24 h r+m_{\substack{\mathrm{CH}_{4}, \text { Station } \\
\text { Nozzleeach RefuelingEvent }}} \times \sum_{\substack{i=1 \\
\text { each day }}}^{k} n_{\begin{array}{c}
i, \text { refuelingent } \\
\text { each }
\end{array}}
\end{aligned}
$$




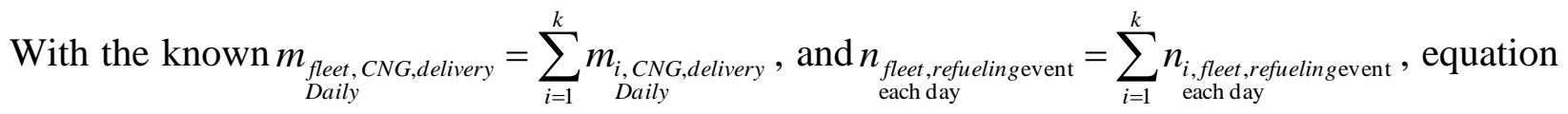
(D.10) can be re-written as:

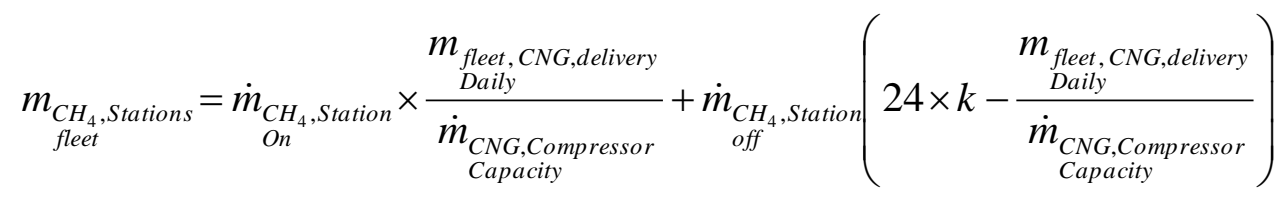

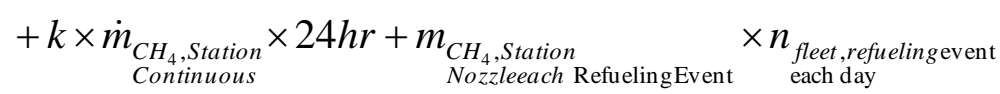

For a fleet operating numerous identical CNG stations and numerous types of CNG vehicles, the total methane emissions from CNG stations were affected by the total CNG fuel delivered, the capacity of each fuel station, the number of CNG stations, and the total refueling events. The type of CNG vehicle and its relative percentage in this fleet does not affect the methane emissions from CNG stations. 


\section{Appendix E Effect of Using a Standard CNG Station on Methane Emissions}

\section{Summary}

This document reports the impact of using a standard station in lieu of the average of the measured CNG stations on FSME. Transit buses were used as an example. In this document, the utilization of CNG stations was represented by the number of CNG vehicles refueled each day. As described by the $2035 \mathrm{CNG}$ station population scenario, each CNG station would serve 80 transit buses, 80 OTR tractors, or 50 refuse trucks. The impact of using a standard CNG station on methane emissions from CNG stations was investigated by comparing the emissions from the standard station with the average emissions from all of the measured CNG stations.

The standard station was created to have the same annual emissions as the average of the individual measured stations. Table E-1 shows the CNG station emissions in the units used in the estimation model. The standard station yields the same results as the average of the measured stations for each vehicle type. The continuous and nozzle emissions were not dependent on the amount of fuel dispensed in these units.

Table E-1: Compressor, Continuous, and Nozzle Emissions for an Average of All Measured Stations and the Standard Station

\begin{tabular}{|c|c|r|r|r|}
\hline \multirow{2}{*}{ Vehicle Type } & \multirow{2}{*}{$\begin{array}{c}\text { Compilation } \\
\text { Type }\end{array}$} & Compressor & Continuous & Nozzle \\
\cline { 3 - 5 } & g/kg fuel & g/day & g/event \\
\hline \multirow{2}{*}{ Transit Bus } & Average & 0.70 & 816 & 3.61 \\
\cline { 2 - 5 } & Standard & 0.70 & 816 & 3.61 \\
\hline \multirow{2}{*}{$\begin{array}{c}\text { Refuse } \\
\text { Truck* }\end{array}$} & Average & 1.12 & 816 & 3.61 \\
\cline { 2 - 5 } & Standard & 1.12 & 816 & 3.61 \\
\hline \multirow{2}{*}{$\begin{array}{c}\text { 9L OTR } \\
\text { Tractor }\end{array}$} & Average & 0.68 & 816 & 3.61 \\
\cline { 2 - 5 } & Standard & 0.68 & 816 & 3.61 \\
\hline \multirow{2}{\text{12LOTR}}{\begin{tabular}{c} 
Tractor \\
\cline { 2 - 5 }
\end{tabular}} & Average & 0.49 & 816 & 3.61 \\
\cline { 2 - 5 } & Standard & 0.49 & 816 & 3.61 \\
\hline
\end{tabular}

Table E-2 shows the FSME (g/kg fuel) from CNG stations when refueling transit buses, refuse trucks, 9 liter short haul tractors, or 12 liter long haul tractors only. The total FSME from CNG stations were $0.53 \mathrm{~g} / \mathrm{kg}$ fuel (refueling eighty 12 liter SI engine OTR tractors) to $1.33 \mathrm{~g} / \mathrm{kg}$ fuel (refueling fifty refuse trucks). Among the three sources, compressors were the main contributors to the total emissions of methane from CNG stations for the $2035 \mathrm{CNG}$ station population scenario. The standard station has the same results as the average of the measured stations. 
Table E-2: Compressor, Continuous, and Nozzle FSME for an Average of All Measured Stations and the Standard Station

\begin{tabular}{|c|c|r|r|r|r|}
\hline \multirow{2}{*}{ Vehicle Type } & \multirow{2}{*}{$\begin{array}{c}\text { Compilation } \\
\text { Type }\end{array}$} & Compressor & Continuous & Nozzle & \multicolumn{1}{|c|}{ Total } \\
\cline { 3 - 6 } & g/kg fuel & $\mathrm{g} / \mathrm{kg}$ fuel & $\begin{array}{c}\mathrm{g} / \mathrm{kg} \\
\text { fuel }\end{array}$ & $\begin{array}{c}\mathrm{g} / \mathrm{kg} \\
\text { fuel }\end{array}$ \\
\hline \multirow{2}{*}{ Transit Bus } & Average & 0.70 & 0.14 & 0.04 & 0.88 \\
\cline { 2 - 6 } & Standard & 0.70 & 0.14 & 0.04 & 0.88 \\
\hline \multirow{2}{*}{$\begin{array}{c}\text { Refuse } \\
\text { Truck* }\end{array}$} & Average & 1.12 & 0.28 & 0.04 & 1.44 \\
\cline { 2 - 6 } & Standard & 1.12 & 0.28 & 0.04 & 1.44 \\
\hline \multirow{2}{*}{$\begin{array}{c}\text { 9L OTR } \\
\text { Tractor }\end{array}$} & Average & 0.68 & 0.13 & 0.04 & 0.85 \\
\cline { 2 - 6 } 12L OTR & Standard & 0.68 & 0.13 & 0.04 & 0.85 \\
\hline \multirow{2}{*}{ Tractor } & Average & 0.49 & 0.07 & 0.02 & 0.59 \\
\cline { 2 - 6 } & Standard & 0.49 & 0.07 & 0.02 & 0.59 \\
\hline
\end{tabular}

Effect of Using a Standard Station on Methane Emissions

The emissions rates from each emissions source were averaged so that one station could be used to represent the average of the measured stations. The transit bus stations were used and as example. Table E-3 shows the compressor flow rate and the emissions rate of the compressor when it was operating and when it was not for stations refueling transit buses. The flow rate was the same as the average of the six stations. The emissions rates were not. Each emissions rate from each station had to be scaled to reflect the change in capacity, which correlates to the amount of time per day the stations operate. The dryer emissions were calculated with the same equation as the compressor while it was operating.

Table E-3: Compressor Flow Rate and Emissions Rate for Each Station and Standard Station for Transit Buses

\begin{tabular}{|c|c|c|c|c|}
\hline \multirow[t]{2}{*}{ Station ID } & $\begin{array}{l}\text { Compressor } \\
\text { Flow Rate }\end{array}$ & $\begin{array}{l}\text { Compressor } \\
\text { Flow Rate }\end{array}$ & $\begin{array}{l}\text { Compressor-On } \\
\text { Emissions Rate }\end{array}$ & $\begin{array}{l}\text { Compressor-Off } \\
\text { Emissions Rate }\end{array}$ \\
\hline & CFM & $\mathrm{kg} / \mathrm{hr}$ & $\mathrm{g} / \mathrm{hr}$ & $\mathrm{g} / \mathrm{hr}$ \\
\hline 1 & 800 & 970 & 3.2 & 19.4 \\
\hline 2 & 1,376 & 1,669 & $1,878.1$ & 376.9 \\
\hline 3 & 800 & 970 & - & 2.4 \\
\hline 4 & 800 & 970 & 19.6 & 6.7 \\
\hline 5 & 800 & 970 & 338.3 & 0.8 \\
\hline 6 & 1,088 & 1,320 & $1,087.5$ & 4.8 \\
\hline 7 & 800 & 970 & - & 1.5 \\
\hline 8 & 800 & 970 & 16.9 & 1.6 \\
\hline Average & 908 & 1,101 & 418.0 & 51.8 \\
\hline Standard Station & 908 & 1,101 & 322.0 & 53.7 \\
\hline
\end{tabular}

Table E-4 shows the compressor, continuous, and nozzle emissions for each transit bus station and the standard transit bus station. The average of the emissions from each station was the same as the standard station. 
Table E-4: Compressor, Continuous, and Nozzle Emissions for each Transit Bus Station and the Standard Transit Bus Station (kg/day)

\begin{tabular}{|c|r|r|r|r|r|}
\hline \multirow{2}{*}{ Station ID } & $\begin{array}{c}\text { Compressor- } \\
\text { On/Dryer } \\
\text { Emissions }\end{array}$ & $\begin{array}{c}\text { Compressor-Off } \\
\text { Emissions }\end{array}$ & $\begin{array}{c}\text { Actuator } \\
\text { Emissions }\end{array}$ & $\begin{array}{c}\text { Continuous } \\
\text { Emissions }\end{array}$ & $\begin{array}{c}\text { Nozzle } \\
\text { Emissions }\end{array}$ \\
\cline { 2 - 7 } & $\mathrm{kg} / \mathrm{day}$ & $\mathrm{kg} /$ day & $\mathrm{kg} /$ day & \multicolumn{1}{c|}{$\mathrm{kg} /$ day } & $\mathrm{kg} /$ day \\
\hline 1 & 0.02 & 0.82 & 0.00 & 0.02 & 0.29 \\
\hline 2 & 6.49 & 16.79 & 0.00 & 2.16 & 0.29 \\
\hline 3 & 0.00 & 0.10 & 0.00 & 0.99 & 0.29 \\
\hline 4 & 0.22 & 0.28 & 0.00 & 0.65 & 0.29 \\
\hline 5 & 2.25 & 0.03 & 0.05 & 0.26 & 0.29 \\
\hline 6 & 4.74 & 0.21 & 0.00 & 1.63 & 0.29 \\
\hline 7 & 0.00 & 0.06 & 0.00 & 0.01 & 0.29 \\
\hline 8 & 0.10 & 0.07 & 0.00 & 0.80 & 0.29 \\
\hline Average & 1.73 & 2.30 & 0.01 & 0.82 & 0.29 \\
\hline Standard Station & 1.73 & 2.30 & 0.01 & 0.82 & 0.29 \\
\hline
\end{tabular}

Table E-5 shows the CNG station emissions in the units used in the estimation model. The standard station yields the same results as the average of the measured stations for each vehicle type. The continuous and nozzle emissions were not dependent on the amount of fuel dispensed in the units of grams per day and grams per event, respectively.

Table E-5: Compressor, Continuous, and Nozzle Emissions for an Average of All Measured Stations and the Standard Station

\begin{tabular}{|c|c|r|r|r|}
\hline \multirow{2}{*}{ Vehicle Type } & \multirow{2}{*}{$\begin{array}{c}\text { Compilation } \\
\text { Type }\end{array}$} & Compressor & Continuous & Nozzle \\
\cline { 3 - 5 } & g/kg fuel & g/day & g/event \\
\hline \multirow{2}{*}{ Transit Bus } & Average & 0.70 & 816 & 3.61 \\
\cline { 2 - 5 } & Standard & 0.70 & 816 & 3.61 \\
\hline \multirow{2}{*}{$\begin{array}{c}\text { Refuse } \\
\text { Truck* }\end{array}$} & Average & 1.12 & 816 & 3.61 \\
\cline { 2 - 5 } & Standard & 1.12 & 816 & 3.61 \\
\hline \multirow{2}{*}{$\begin{array}{c}\text { 9L OTR } \\
\text { Tractor }\end{array}$} & Average & 0.68 & 816 & 3.61 \\
\cline { 2 - 5 } & Standard & 0.68 & 816 & 3.61 \\
\hline \multirow{2}{\text{12LOTR}}{\begin{tabular}{c} 
Tractor \\
\cline { 2 - 5 }
\end{tabular}} & Average & 0.49 & 816 & 3.61 \\
\cline { 2 - 5 } & Standard & 0.49 & 816 & 3.61 \\
\hline
\end{tabular}

Table E-6 shows the FSME (g/kg fuel) from CNG stations when refueling transit buses, refuse trucks, 9 liter short haul tractors, or 12 liter long haul tractors only. The total FSME from CNG stations were $0.53 \mathrm{~g} / \mathrm{kg}$ fuel (refueling eighty 12 liter SI engine OTR tractors) to $1.33 \mathrm{~g} / \mathrm{kg}$ fuel (refueling fifty refuse trucks). Among the three sources, compressors were the main contributors to the total emissions of methane from CNG stations for the $2035 \mathrm{CNG}$ station population scenario. The standard station has the same results as the average of the measured stations. 
Table E-6: Compressor, Continuous, and Nozzle FSME for an Average of All Measured Stations and the Standard Station

\begin{tabular}{|c|c|r|r|r|r|}
\hline \multirow{2}{*}{ Vehicle Type } & \multirow{2}{*}{$\begin{array}{c}\text { Compilation } \\
\text { Type }\end{array}$} & Compressor & Continuous & Nozzle & Total \\
\cline { 3 - 6 } & g/kg fuel & $\mathrm{g} / \mathrm{kg}$ fuel & $\begin{array}{c}\mathrm{g} / \mathrm{kg} \\
\text { fuel }\end{array}$ & $\begin{array}{c}\mathrm{g} / \mathrm{kg} \\
\text { fuel }\end{array}$ \\
\hline \multirow{2}{*}{ Transit Bus } & Average & 0.70 & 0.14 & 0.04 & 0.88 \\
\cline { 2 - 6 } & Standard & 0.70 & 0.14 & 0.04 & 0.88 \\
\hline \multirow{2}{*}{$\begin{array}{c}\text { Refuse } \\
\text { Truck* }\end{array}$} & Average & 1.12 & 0.28 & 0.04 & 1.44 \\
\cline { 2 - 6 } & Standard & 1.12 & 0.28 & 0.04 & 1.44 \\
\hline \multirow{2}{*}{$\begin{array}{c}\text { 9L OTR } \\
\text { Tractor }\end{array}$} & Average & 0.68 & 0.13 & 0.04 & 0.85 \\
\hline \multirow{2}{*}{$\begin{array}{c}\text { 12L OTR } \\
\text { Tractor }\end{array}$} & Standard & 0.68 & 0.13 & 0.04 & 0.85 \\
\cline { 2 - 6 } & Average & 0.49 & 0.07 & 0.02 & 0.59 \\
\hline
\end{tabular}

Equations Used to Calculate the Emissions Rate of the Standard Station

The scaled stations should have the same total mass of methane emissions as the average of the measured stations. Each measured station needs to follow the same constraint as well. The scaled emissions were calculated by using the following equation:

$$
\underset{\text { on }}{m_{\text {original.comp }}}=m_{\text {scaled.comp }} \text { on }
$$

The mass of the methane emissions when the compressor was in operation, for each station including the standard station, was calculated by the following equation:

$$
\underset{\text { on }}{\operatorname{comp}}=\underset{\text { on }}{\operatorname{tcomp}} * \dot{m}_{\mathrm{CH}_{4}}
$$

Compressor operation time was calculated by the following equation:

$$
\underset{\text { on }}{t_{\text {comp }}}=\frac{m_{\text {total }}}{\dot{m}_{\text {capacity }}}
$$

Combining equation (E.2) and equation (E.3) yields the following equation:

$$
\underset{\text { on }}{m_{\text {comp }}}=\frac{m_{\text {total }}}{\dot{m}_{\text {capacity }}} * \underset{\text { on }}{\dot{m}_{\mathrm{CH}_{4}}}
$$

The compressor-on emissions rate was calculated by combining equation (E.1) and equation (E.4). Equation (E.4) was used for the original measured data and the scaled data for each station. The following equation was used to find the emissions rate of the compressor while it was operating:

$$
\dot{m}_{\mathrm{CH}_{4} \text { scaled }}=\frac{\dot{m}_{\text {capacity }}}{\text { scaled }_{\text {capacity }}}{ }_{\begin{array}{c}
\text { original } \\
\text { oring }
\end{array}} \dot{m}_{\mathrm{CH}_{4} \text { original }}
$$

The dryer emissions were calculated by the same equation. The compressor emissions when the compressor was not in operation were solved using a different equation. The scaled stations 
should have the same total mass of methane emissions as the average of the measured stations. Each measured station needs to follow the same constraint as well. The scaled emissions were calculated by using the following equation:

$$
\underset{\text { off }}{m_{\text {original.comp }}}=m_{\text {scaled.comp }}
$$

The mass of the methane emissions when the compressor was not in operation, for each station including the standard station, was calculated by the following equation:

$$
m_{\text {off }}=t_{\text {off }} * \dot{m}_{C_{4}}
$$

Compressor non-operation time was calculated by the following equation:

$$
\underset{\text { off }}{t c o m p}=24-\underset{\text { on }}{t c o m p}=24-\frac{m_{\text {total }}}{\dot{m}_{\text {capacity }}}
$$

Combining equation (E.7) and equation (E.8) yields the following equation:

$$
\underset{\text { off }}{m_{\text {comp }}}=\left(24-\frac{m_{\text {total }}}{\dot{m}_{\text {capacity }}}\right) * \underset{\dot{m}_{\text {off }}}{\dot{C H}_{4}}
$$

The compressor-on emissions rate was calculated by combining equation (E.6) and equation (E.9). Equation (E.9) was used for the original measured data and the scaled data for each station. The following equation was used to find the emissions rate of the compressor while it was not operating:

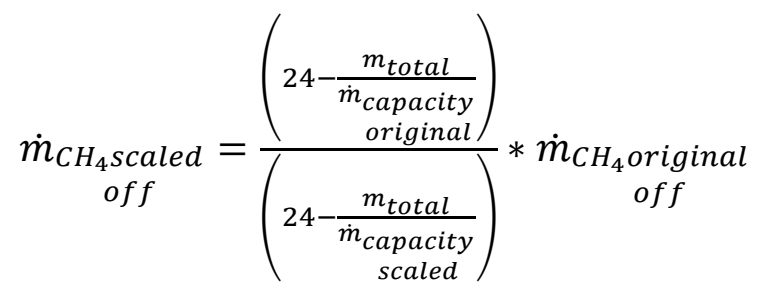




\section{Appendix F LNG Station Data Processing}

\section{Summary of Methane Emissions from LNG Station}

This document reports the procedure of estimating methane emissions from LNG fuel stations, including those from fuel dispensing nozzles (g/event), continuous emissions (g/day), manual vehicle tank venting prior to refueling ( $\%$ of fuel), station fuel tank BOG ( $\%$ of fuel), and bulk fuel delivery ( $\%$ of fuel). Audits, which included detection and quantification of methane emissions, were performed at six LNG stations. Two of the six were long term audits. Estimates from the LNG fueling stations were incorporated into the overall methane estimation model for the heavy-duty natural gas transportation sector.

The estimates presented were based on the following scenarios:

(1) Each LNG station would refuel 80 OTR tractors per operational day;

(2) Each vehicle would be refueled once per operational day with 6 operational days per week;

(3) Annual fuel consumption values based on the estimation model;

Table F-1 shows the estimated methane emissions from LNG stations in the units to be used in the methane emissions estimation model. All of the vehicle types have the same emissions because the emissions rates were independent of fuel use and number of vehicles refueled per day. The nozzle emissions were $17.7 \mathrm{~g} / \mathrm{event}$. The continuous station emissions were $12.8 \mathrm{~g} / \mathrm{day}$. The manual vehicle fuel tank vent emissions prior to refueling were $0.25 \%$ of fuel consumed for all HPDI engine vehicles. However there was no observed ventilation of SI engine vehicles, so the rate of occurrence was 0 . The station fuel tank BOG emissions were $0.1 \%$ of fuel consumed for all vehicles. The delivery emissions were $0.128 \%$ of fuel consumed for all vehicles. Table F-2 shows the current FSME from each type of LNG vehicle (in unit $\mathrm{g} / \mathrm{kg}$ fuel). The current estimated FSME were 4.95 to $5.08 \mathrm{~g} / \mathrm{kg}$ fuel consumed.

Table F-1: Average Methane Emissions from LNG Stations

\begin{tabular}{|c|c|r|r|r|r|}
\hline $\begin{array}{c}\text { Vehicle Type } \\
\text { Refueled at } \\
\text { LNG Station }\end{array}$ & $\begin{array}{c}\text { Nozzle } \\
\text { Emissions }\end{array}$ & Continuous & $\begin{array}{c}\text { Manual Vehicle } \\
\text { Tank Venting }\end{array}$ & $\begin{array}{c}\text { Station Fuel } \\
\text { Tank BOG }\end{array}$ & Delivery \\
\cline { 2 - 6 } & g/event & \multicolumn{1}{c|}{ g/day } & \% Total Fuel & \% Total Fuel & \% Total Fuel \\
\hline 9L SI OTR Tractor & 17.7 & 12.8 & 0.250 & 0.100 & 0.128 \\
\hline 12L SI OTR Tractor & 17.7 & 12.8 & 0.250 & 0.100 & 0.128 \\
\hline 15L HPDI OTR Tractor & 17.7 & 12.8 & 0.250 & 0.100 & 0.128 \\
\hline
\end{tabular}

Table F-2: Average FSME from LNG Stations

\begin{tabular}{|c|c|c|c|c|c|c|}
\hline $\begin{array}{l}\text { OTR Tractor } \\
\text { Type Refueled }\end{array}$ & $\begin{array}{c}\text { Nozzle } \\
\text { Emissions }\end{array}$ & Continuous & $\begin{array}{l}\text { Manual Vehicle } \\
\text { Tank Venting }\end{array}$ & $\begin{array}{c}\text { Station Fuel } \\
\text { Tank BOG }\end{array}$ & Delivery & Total \\
\hline At LNG Station & $\mathrm{g} / \mathrm{kg}$ fuel & $\mathrm{g} / \mathrm{kg}$ fuel & $\mathrm{g} / \mathrm{kg}$ fuel & $\mathrm{g} / \mathrm{kg}$ fuel & $\mathrm{g} / \mathrm{kg}$ fuel & $\mathrm{g} / \mathrm{kg}$ fuel \\
\hline 9L SI & 0.234 & 0.051 & 2.500 & 1.000 & 1.280 & 5.08 \\
\hline 12L SI & 0.127 & 0.028 & 2.500 & 1.000 & 1.280 & 4.95 \\
\hline 15L HPDI & 0.134 & 0.029 & 2.500 & 1.000 & 1.280 & 4.96 \\
\hline
\end{tabular}




\section{Methane Emissions from LNG Dispensing Nozzle}

Table F-3 shows the methane emissions measured from dispensing nozzles for four of the six LNG stations audited and two additional facilities, labeled A and B. The minimum, maximum, and average nozzle emissions were $0.1,330.4$, and $17.7 \mathrm{~g} / \mathrm{event}$, respectively.

Table F-3: Total Nozzle Emissions from All LNG Stations

\begin{tabular}{|c|c|c|c|}
\hline Station ID & $\frac{\text { Nozzle Emissions }}{\text { g/event }}$ & Station ID & $\frac{\text { Nozzle Emissions }}{\text { g/event }}$ \\
\hline$A$ & 8.9 & 2 & 4.9 \\
\hline$A$ & 45.4 & 2 & 0.4 \\
\hline 4 & 9.5 & 2 & 2.3 \\
\hline 4 & 4.2 & 2 & 2.0 \\
\hline 4 & 5.5 & 2 & 0.6 \\
\hline 4 & 13.8 & 2 & 0.7 \\
\hline 4 & 13.6 & $B$ & 12.4 \\
\hline 4 & 59.1 & $B$ & 20.8 \\
\hline 4 & 16.1 & $B$ & 33.4 \\
\hline 2 & 13.1 & 6 & 0.5 \\
\hline 2 & 1.6 & 6 & 2.3 \\
\hline 2 & 4.0 & 6 & 2.8 \\
\hline 2 & 0.1 & 6 & 2.2 \\
\hline 2 & 0.7 & 6 & 26.6 \\
\hline 2 & 1.9 & 6 & 1.4 \\
\hline 2 & 10.4 & 6 & 330.4 \\
\hline 2 & 35.8 & 6 & 39.0 \\
\hline 2 & 11.6 & 6 & 2.9 \\
\hline 2 & 4.2 & 5 & 2.9 \\
\hline 2 & 0.8 & 5 & 4.8 \\
\hline 2 & 2.1 & 5 & 5.6 \\
\hline 2 & 0.2 & Average & 17.7 \\
\hline
\end{tabular}

In this research, the average nozzle emissions were considered the nozzle emissions from each station. Table F-4 shows the total methane emissions from fuel dispensing nozzles of a LNG station refueling 80 vehicles each day (LNG station population scenario model). An assumption of one vehicle refueling event per day was made. The total nozzle emissions calculated were 1.4 $\mathrm{kg} /$ day.

Table F-4: Total Nozzle Emissions from LNG Stations

\begin{tabular}{|c|c|c|}
\hline \multicolumn{3}{|c|}{ Nozzle Emissions } \\
\hline Nozzle Emissions & Refueling Events & Total Nozzle Emissions \\
\hline g/event & event/day & $\mathrm{kg} /$ day \\
\hline 17.7 & 80 & 1.4 \\
\hline
\end{tabular}




\section{Methane Emissions from Continuous Methane Emissions of LNG Station}

Table F-5 shows the continuous methane emissions from all stations. The average continuous emissions were $12.80 \mathrm{~g} / \mathrm{hr}$. The rate of continuous emissions was not affected by the number of refueling events or fuel delivery.

Table F-5: Methane Emissions from Continuous Emissions Sources

\begin{tabular}{|c|r|}
\hline Station ID & $\begin{array}{c}\text { Continuous Emissions } \\
\text { (g/hr) }\end{array}$ \\
\hline 1 & 53.06 \\
\hline 2 & 0.92 \\
\hline 3 & 0.24 \\
\hline 4 & 16.62 \\
\hline 5 & 5.97 \\
\hline 6 & 0.01 \\
\hline Average & 12.80 \\
\hline
\end{tabular}

\section{Methane Emissions from Manual Vehicular Tank Venting Prior to Refueling}

Observations from the long term station audits showed that LNG vehicle fuel tank manual venting released nearly $5 \%$ of the methane used. This practice should be avoided. However the fraction of tanks that were manually vented was not known precisely. An assumption of one in twenty HPDI engine OTR tractors venting was made for the stasis scenario. Therefore $0.25 \%$ of fuel or $2.5 \mathrm{~g} / \mathrm{kg}$ fuel was used as the input to the estimation model for the stasis scenario. There was no observed manual ventilation for SI engine OTR tractors.

\section{Methane Emissions from Station Fueling Tank BOG}

Boil-off gas emissions are not known nationally. Observations and a model created by WVU researchers provide some insight into station fuel tank BOG emissions. For a fully utilized station, no BOG will occur. For example, one of the audited stations dispensed 3,000 gallons per day and no emissions would occur. This station served fewer vehicles than 80 , the value used as an assumption for a fully utilized station in this research. However if a station were severely underutilized, distributing about 1,500 gallons per day, about 5\% of the total fuel would be vented to the atmosphere. Few of these types of stations are anticipated to exist in year 2035. An assumption of one in fifty stations was made. Therefore the input value to the estimation model was $0.1 \%$ of total fuel consumed for station fuel tank BOG.

\section{Methane Emissions from Bulk Fuel Delivery}

Observations, albeit from a small sample size, from the long term station audits showed that delivery methane emissions ranged from $0.08 \%$ to $0.128 \%$, with one high emissions event neglected. A conservative estimate of $0.128 \%$ was used an input to the estimation model. 


\section{Total Methane Emissions from Six LNG Stations}

Methane emissions from LNG stations, based on the present (2014) vehicle population and fuel consumption scenario for LNG fueled OTR tractors were estimated. Table F-6 shows the average methane emissions from six LNG stations in the units used in the estimation model. The emissions were all the same because the same stations were assumed for all vehicle types and the emissions were not dependent on the amount of fuel dispensed or number of vehicles, for these units.

Table F-6: Estimated Methane Emissions from All LNG Stations

\begin{tabular}{|c|r|r|r|r|r|}
\hline $\begin{array}{c}\text { Vehicle Type } \\
\text { Refueled at } \\
\text { LNG Station }\end{array}$ & $\begin{array}{c}\text { Nozzle } \\
\text { Emissions }\end{array}$ & Continuous & $\begin{array}{c}\text { Manual Vehicle } \\
\text { Tank Venting }\end{array}$ & $\begin{array}{c}\text { Station Fuel } \\
\text { Tank BOG }\end{array}$ & Delivery \\
\cline { 2 - 6 } & g/event & g/day & \% Total Fuel & \% Total Fuel & \% Total Fuel \\
\hline 9L SI OTR Tractor & 17.7 & 12.8 & 0.250 & 0.100 & 0.128 \\
\hline 12L SI OTR Tractor & 17.7 & 12.8 & 0.250 & 0.100 & 0.128 \\
\hline 15L HPDI OTR Tractor & 17.7 & 12.8 & 0.250 & 0.100 & 0.128 \\
\hline Average & 17.7 & 12.8 & 0.250 & 0.100 & 0.128 \\
\hline
\end{tabular}

Table F-7 shows the average LNG station emissions for all LNG vehicles in comparable units ( $\mathrm{g} / \mathrm{kg}$ fuel). The station refueling the 9 liter OTR tractor had the highest continuous, nozzle, and total emissions because the vehicle had the lowest annual fuel consumption per vehicle. The manual vehicle tank ventilation, station fuel tank BOG, and delivery emissions were constant among all applicable vehicles.

Table F-7: Average FSME from LNG Stations

\begin{tabular}{|c|r|r|r|r|r|r|}
\hline $\begin{array}{c}\text { OTR Tractor } \\
\text { Type Refueled } \\
\text { At LNG Station }\end{array}$ & $\begin{array}{c}\text { Nozzle } \\
\text { Emissions }\end{array}$ & Continuous & $\begin{array}{c}\text { Manual Vehicle } \\
\text { Tank Venting }\end{array}$ & $\begin{array}{c}\text { Station Fuel } \\
\text { Tank BOG }\end{array}$ & Delivery & Total \\
\hline 9L SI & 0.234 & $\mathrm{~g} / \mathrm{kg}$ fuel & $\mathrm{g} / \mathrm{kg}$ fuel & $\mathrm{g} / \mathrm{kg}$ fuel & $\mathrm{g} / \mathrm{kg}$ fuel & $\mathrm{g} / \mathrm{kg}$ fuel \\
\hline 12L SI & 0.127 & 0.051 & 2.500 & 1.000 & 1.280 & 5.06 \\
\hline 15L HPDI & 0.134 & 0.029 & 2.500 & 1.000 & 1.280 & 4.93 \\
\hline Average & 0.165 & 0.036 & 2.500 & 1.000 & 1.280 & 4.94 \\
\hline
\end{tabular}




\title{
Appendix G Effect of LNG Station Utilization on Methane Emissions
}

\begin{abstract}
Summary
This document reports the impact of LNG station utilization on FSME from LNG stations, using 15 liter HPDI engine long haul OTR tractors and 12 liter SI engine LNG long haul OTR tractors as examples. In this document, the utilization of LNG stations was represented by the number of LNG vehicles refueled in per station each day. As described in this 2035 LNG station population scenario model, each LNG station would serve 80 OTR tractors per station. A LNG station that refueled less than 80 OTR tractors was defined as an under-utilized LNG station. By comparison, a LNG station that refueled more than 80 OTR tractors was defined as an over-utilized LNG station. The impact of LNG station utilization on methane emissions from LNG stations was investigated by examining the impact of the number of refueling events on the FSME from LNG stations. It is important to note that station fuel tank BOG and bulk fuel delivery emissions were excluded from the utilization case study.

Table G-1 compares the impact of the number of refueling events on the FSME from LNG stations refueling 15 liter HPDI engine long haul OTR tractors and 12 liter SI engine LNG long haul OTR tractors, respectively. A decrease in the number of refueling events increased the FSME from LNG stations. This was mainly due to the increased contribution of continuous emissions, resulting from the reduction in LNG fuel delivered. The LNG stations refueling 15 liter HPDI engine OTR tractors had higher FSME than those refueling same number of 12 liter OTR tractors.
\end{abstract}

Table G-1: Total LNG Station Methane Emissions Comparison of 15 Liter HPDI and 12 Liter SI OTR Tractors

\begin{tabular}{|c|r|r|}
\hline \multirow{2}{*}{$\begin{array}{c}\text { Number } \\
\text { of Vehicles }\end{array}$} & $\begin{array}{c}\text { 15L HPDI OTR } \\
\text { Tractor FSME }\end{array}$ & $\begin{array}{c}\text { 12L SI OTR } \\
\text { Tractor FSME }\end{array}$ \\
\cline { 2 - 3 } & g/kg fuel & g/kg fuel \\
\hline 20 & 2.75 & 2.74 \\
\hline 40 & 2.69 & 2.68 \\
\hline 60 & 2.67 & 2.66 \\
\hline 80 & 2.66 & 2.65 \\
\hline 100 & 2.66 & 2.65 \\
\hline 120 & 2.65 & 2.65 \\
\hline 140 & 2.65 & 2.64 \\
\hline 160 & 2.65 & 2.64 \\
\hline
\end{tabular}

Figure G-1 shows the impact of LNG station utilization on FSME from LNG stations. The reduction in the number of refueling events was found to increase the FSME from LNG stations. 


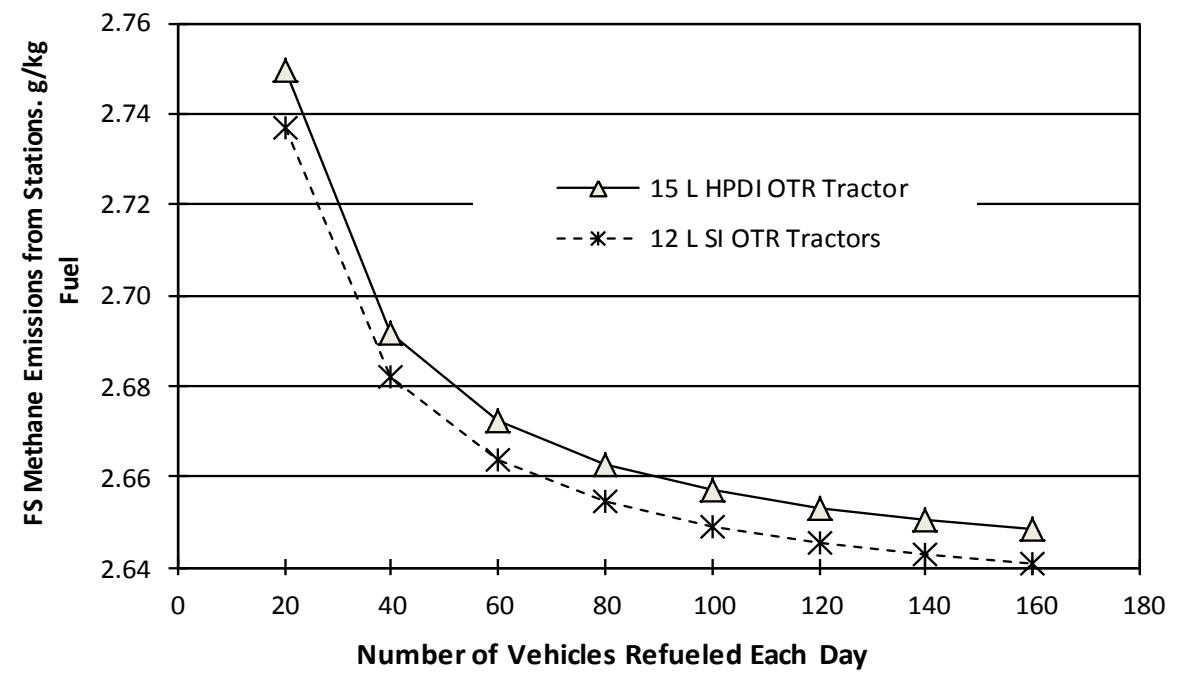

Figure G-1: Effect of Station Utilization on FSME from LNG Stations for 12L SI and 15L HPDI OTR Tractors

For a fleet operating numerous identical LNG stations and numerous types of LNG vehicles, the total methane emissions from LNG stations were affected by the total LNG fuel delivered and the total refueling events. The type of LNG vehicle, relative percentage in a fleet, and unevenly utilized LNG stations do not affect the methane emissions from LNG stations, as long as the total number of vehicles for each vehicle type remains constant and total fuel delivery were constant.

Note: the methane emissions from LNG storage tank BOG and bulk fuel delivery were not included in the current model.

\section{Methane Emissions from LNG Stations in the 2035 LNG Station Population Scenario}

The methane emissions from LNG stations include the methane emitted from the LNG dispensing nozzles, manual venting from vehicles prior to refueling, and continuous emissions. Table G-2 shows the estimated methane emissions based on the 2035 LNG station population scenario and fuel consumption scenario (current measurement or 2035 high scenario) for LNG fueled OTR tractors by assuming each LNG station will refuel 80 OTR tractors per day, as suggested in the LNG station scenario model.

Table G-2: Methane Emissions from LNG Stations

\begin{tabular}{|c|r|r|r|}
\hline \multirow{2}{*}{ Vehicle Type } & Manual Tank Venting & Continuous & Nozzle Emissions \\
\cline { 2 - 4 } & \% Total Fuel & g/day & \multicolumn{2}{|c|}{ g/event } \\
\hline 9L SI OTR Tractor & 0.25 & 12.8 & 17.7 \\
\hline 12L SI OTR Tractor & 0.25 & 12.8 & 17.7 \\
\hline 15L HPDI OTR Tractor & 0.25 & 12.8 & 17.7 \\
\hline
\end{tabular}

Table G-3 shows the FSME (g/kg fuel) from LNG stations when refueling 809 liter short haul OTR tractors, 12 liter long haul OTR tractors, or 15 liter HPDI engine long haul OTR tractors only (excluding LNG storage tank BOG and bulk fuel delivery). The total FSME from LNG stations were 2.655 (refueling eighty 12 liter SI engine OTR tractors) to $2.785 \mathrm{~g} / \mathrm{kg}$ fuel 
(refueling eighty 9 liter OTR tractors). Among the three sources, manual venting of vehicles prior to refueling was the main contributor to the emissions of methane from LNG stations for the 2035 LNG station population scenario.

Table G-3: FSME (g/kg fuel) from LNG Station

\begin{tabular}{|c|r|r|r|r|}
\hline \multirow{2}{*}{ Vehicle Type } & Nozzle Emissions & Continuous & Manual Venting & \multicolumn{1}{c|}{ Total } \\
\cline { 2 - 5 } & $\mathrm{g} / \mathrm{kg}$ fuel & $\mathrm{g} / \mathrm{kg}$ fuel & $\mathrm{g} / \mathrm{kg}$ fuel & $\mathrm{g} / \mathrm{kg}$ fuel \\
\hline 9L OTR Tractor & 0.234 & 0.051 & 2.500 & 2.785 \\
\hline 12L OTR Tractor & 0.127 & 0.028 & 2.500 & 2.655 \\
\hline 15L HPDI OTR Tractor & 0.134 & 0.029 & 2.500 & 2.663 \\
\hline
\end{tabular}

Impact of LNG Station Utilization on Methane Emissions from LNG Stations

The utilization of LNG stations was represented by the number of LNG vehicles refueled each day. The 2035 LNG station population scenario model assumed that each LNG station would serve 80 OTR tractors. A LNG station that refueled less than 80 OTR tractors was defined as an under-utilized LNG station. By comparison, a LNG station that refueled more than 80 OTR tractors was defined as an over-utilized LNG station. The impact of LNG station utilization on methane emissions from LNG stations was investigated by adjusting the number of 15 liter HPDI engine OTR tractors refueled each day.

\section{LNG Stations for 15 Liter HPDI Engine OTR Tractors}

As shown in Table G-4, an increase in the number of 15 liter HPDI engine OTR tractors refueled per day was found to decrease the FSME from the LNG stations. This was due to increased fuel delivery. However, an increase in the number of 15 liter HPDI engine OTR tractors refueled did not affect methane emissions from continuous sources, reported in g/day. An increase in the number of 15 liter HPDI engine OTR tractors from 80 to 160 decreased the FSME from 2.66 to $2.65 \mathrm{~g} / \mathrm{kg}$ of LNG fuel delivered, representing a $0.5 \%$ reduction in FSME. By comparison, a decrease in the number of 15 liter HPDI engine OTR tractors refueled from 80 to 40 was found to increase the FSME from 2.66 to $2.69 \mathrm{~g} / \mathrm{kg}$ of LNG fuel (+1.1\%). The methane emissions from a seriously underutilized 15 liter HPDI engine OTR tractor LNG station, refueling 2015 liter HPDI engine OTR tractors ( $25 \%$ of the scenario proposed), were $2.75 \mathrm{~g} / \mathrm{kg}$ fuel, which were $3.3 \%$ higher than that refueling 8015 liter HPDI engine OTR tractors each day. The increase in the number of 15 liter HPDI engine OTR tractors refueled by each LNG station gradually decreased the FSME.

Figure G-2 shows the impact of the number of 15 liter HPDI engine OTR tractors refueled each day on the FSME for LNG stations. The increase in the number of 15 liter HPDI engine OTR tractors refueled by each LNG station gradually decreased the FSME. 
Table G-4: Impact of LNG Station Utilization (Number of Refueling Events) on Methane Emissions from LNG Stations for 15L HPDI OTR Tractors

\begin{tabular}{|c|c|c|c|c|}
\hline \multirow{3}{*}{$\begin{array}{l}\text { Number } \\
\text { of } \\
\text { Vehicles }\end{array}$} & \multicolumn{3}{|c|}{ Emissions } & \multirow{2}{*}{$\begin{array}{l}\text { FSME from } \\
\text { LNG Stations }\end{array}$} \\
\hline & $\begin{array}{c}\text { Manual } \\
\text { Vent }\end{array}$ & Continuous & $\begin{array}{c}\text { Nozzle } \\
\text { Emissions }\end{array}$ & \\
\hline & $\mathrm{g} / \mathrm{kg}$ fuel & g/day & g/event & $\mathrm{g} / \mathrm{kg}$ fuel \\
\hline 20 & 2.50 & 307.28 & 17.70 & 2.75 \\
\hline 40 & 2.50 & 307.28 & 17.70 & 2.69 \\
\hline 60 & 2.50 & 307.28 & 17.70 & 2.67 \\
\hline 80 & 2.50 & 307.28 & 17.70 & 2.66 \\
\hline 100 & 2.50 & 307.28 & 17.70 & 2.66 \\
\hline 120 & 2.50 & 307.28 & 17.70 & 2.65 \\
\hline 140 & 2.50 & 307.28 & 17.70 & 2.65 \\
\hline 160 & 2.50 & 307.28 & 17.70 & 2.65 \\
\hline
\end{tabular}

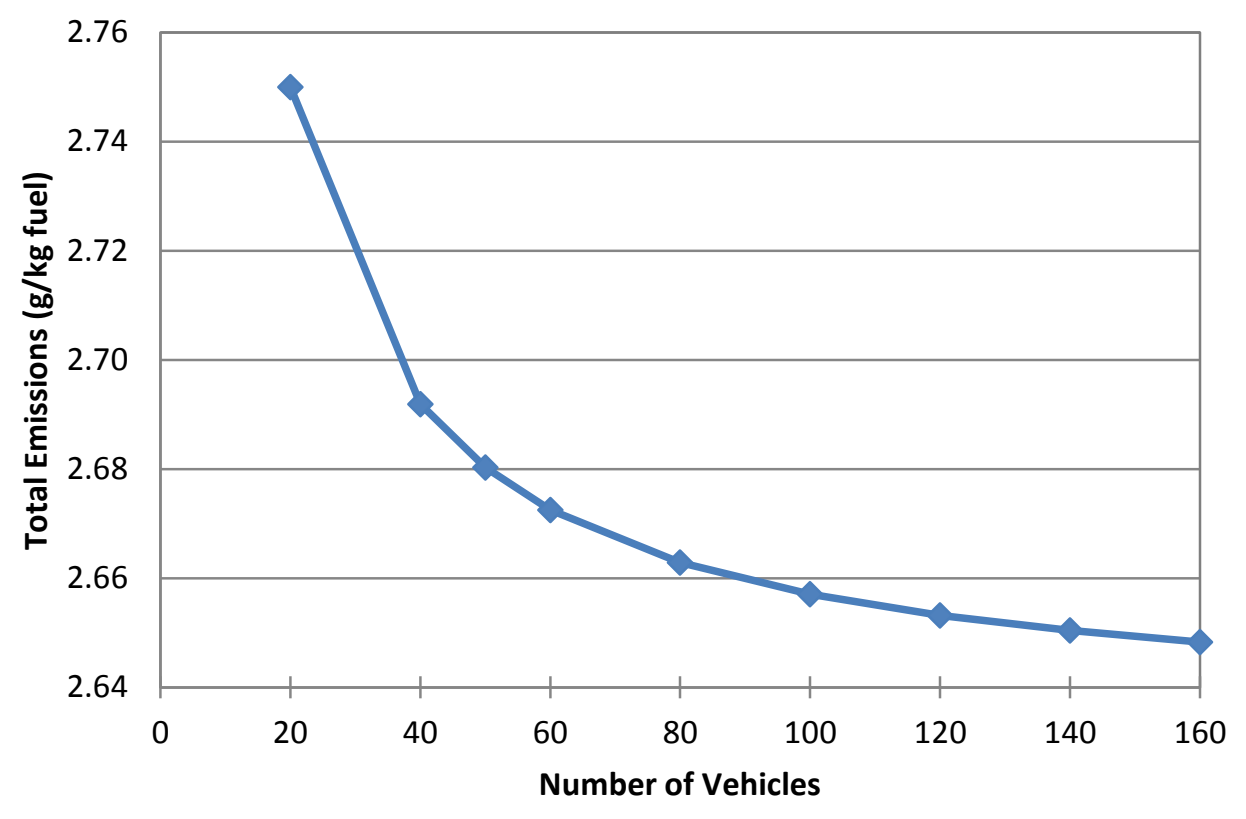

Figure G-2: Effect of Station Utilization on FSME from LNG Stations for 15L HPDI OTR Tractors

The impact of uneven (imbalanced) utilization of LNG station on methane emissions from LNG stations and contribution of each source were investigated by examining the methane emissions from LNG stations for different cases, with a fixed number of LNG fuel stations, refueling events (or number of LNG OTR tractors), and total LNG fuel delivered per vehicle.

Table G-5 compares the FSME from LNG stations refueling 15 liter HPDI engine OTR tractors and 12 liter SI engine LNG OTR tractors, respectively. The LNG stations refueling 15 liter HPDI engine OTR tractors have higher FSME than those refueling the same number of 12 liter SI engine OTR tractors, which were due to the delivery of less LNG fuel to 15 liter HPDI engine OTR tractors. 
The impact of uneven (imbalanced) utilization of LNG station on methane emissions from LNG stations and contribution of each source were investigated by examining the methane emissions from LNG stations for different cases, with a fixed number of LNG fuel stations, refueling events (or number of LNG OTR tractors), and total LNG fuel delivered per vehicle.

Table G-5: FSME from LNG Station Emissions for 15L HPDI and 12L SI OTR Tractors

\begin{tabular}{|c|r|r|}
\hline \multirow{2}{*}{$\begin{array}{c}\text { Number } \\
\text { of Vehicles }\end{array}$} & $\begin{array}{c}\text { 15L HPDI OTR Tractor } \\
\text { FSME }\end{array}$ & $\begin{array}{c}\text { 12L OTR Tractor } \\
\text { FSME }\end{array}$ \\
\cline { 2 - 3 } & g/kg fuel & g/kg fuel \\
\hline 20 & 2.75 & 2.74 \\
\hline 40 & 2.69 & 2.68 \\
\hline 60 & 2.67 & 2.66 \\
\hline 80 & 2.66 & 2.65 \\
\hline 100 & 2.66 & 2.65 \\
\hline 120 & 2.65 & 2.65 \\
\hline 140 & 2.65 & 2.64 \\
\hline 160 & 2.65 & 2.64 \\
\hline
\end{tabular}

\section{Case Study Demonstrating the Independence of Methane Emissions from LNG Stations with Unevenly Utilized LNG Stations}

\section{Effect of Imbalanced Station Utilization on Methane Emissions from LNG Stations}

The impact of imbalanced utilization of LNG stations on methane emissions from LNG stations were investigated with an assumed 10 LNG stations and 800 refueling events each day. As shown in Table G-6, each station serving 80 refueling events represents an evenly distributed LNG station utilization (case one). Case two represents an extreme of unevenly distributed LNG station utilization, there were 4 seriously under-utilized LNG stations serving 20 refueling events per station, 3 evenly utilized stations serving 80 refueling events per station, and 3 seriously over-utilized LNG stations refueling 160 vehicles per station. Case three represents medium unevenly utilized LNG stations. There were 4 under-utilized LNG stations serving 50 refueling events per station, 3 evenly utilized stations serving 80 refueling events per station, and 3 overutilized LNG stations refueling 120 vehicles per station. The total methane emissions from LNG stations, including compressor, continuous, and nozzle emissions from a distribution of stations, were calculated and compared.

Table G-7 shows the total emissions from ten fully utilized stations refueling 15 liter HPDI engine OTR tractors. The FSME and annual emissions were $2.66 \mathrm{~g} / \mathrm{kg}$ fuel and $102,922 \mathrm{~kg}$ of fuel, respectively. 
Table G-6: Summary of Case Studies for Effect of Over-Utilization and Under-Utilization

\begin{tabular}{|c|r|r|r|r|}
\hline \multirow{2}{*}{ Station Utilization } & Number of Vehicles & \multicolumn{4}{|c|}{ Population of LNG Stations } \\
\cline { 3 - 6 } & Refueled per Day & Case 1 & Case 2 & Case 3 \\
\hline \multirow{2}{*}{ Under } & 20 & 0 & 4 & 0 \\
\cline { 2 - 5 } & 50 & 0 & 0 & 4 \\
\hline Normal & 80 & 10 & 3 & 3 \\
\hline \multirow{2}{*}{ Over } & 120 & 0 & 0 & 3 \\
\cline { 2 - 5 } & 160 & 0 & 3 & 0 \\
\hline \multicolumn{2}{|c|}{ Total Refueling Stations } & 10 & 10 & 10 \\
\hline \multicolumn{2}{|c|}{ Total Refueling Events } & 800 & 800 & 800 \\
\hline \multicolumn{2}{|c|}{ Average Refueling Events per Station } & 80 & 80 & 80 \\
\hline
\end{tabular}

Table G-7: Total Emissions from a Distribution of Ten Fully Utilized Stations Refueling 15L HPDI OTR Tractors (10 Total)

\begin{tabular}{|c|r|r|r|r|c|}
\hline \multirow{2}{*}{$\begin{array}{c}\text { Station } \\
\text { Utilization }\end{array}$} & \multirow{2}{*}{$\begin{array}{c}\text { Number } \\
\text { of Vehicles }\end{array}$} & \multirow{2}{*}{$\begin{array}{c}\text { Number } \\
\text { of Stations }\end{array}$} & Total Emissions & $\begin{array}{c}\text { Annual } \\
\text { Fuel Delivered }\end{array}$ & Annual Emissions \\
\cline { 4 - 6 } & & $\mathrm{g} / \mathrm{kg}$ fuel & $\mathrm{Kg}$ & $\mathrm{kg}$ \\
\hline Normal & 80 & 10 & 2.66 & $38,651,200$ & $\mathbf{1 0 2 , 9 2 2}$ \\
\hline
\end{tabular}

Table G-8 shows the total methane emissions from the extreme of unevenly utilized LNG stations refueling 15 liter HPDI engine OTR tractors. With the known FSME and total fuel delivery of each type of LNG station utilization, the annual methane emissions from this type of fuel stations can be calculated. The annual emissions from each station utilization type were added together to get a total annual emissions from all stations. The annual methane emissions from these 10 seriously unevenly utilized LNG stations were the same as the ten fully utilized stations refueling 15 liter HPDI engine OTR tractors.

Table G-8: Total Methane Emissions from 10 LNG Station Refueling 80015 Liter HPDI OTR Tractors. Case 1: Evenly Utilized LNG Stations Refueling 8015 Liter HPDI OTR Tractors in Each Station

\begin{tabular}{|c|r|r|r|r|r|}
\hline \multirow{2}{*}{$\begin{array}{c}\text { Station } \\
\text { Utilization }\end{array}$} & \multirow{2}{*}{$\begin{array}{c}\text { Number } \\
\text { of } \\
\text { Vehicles }\end{array}$} & \multirow{2}{*}{$\begin{array}{c}\text { Number } \\
\text { of } \\
\text { Stations }\end{array}$} & $\begin{array}{c}\text { Total } \\
\text { Smissions }\end{array}$ & $\begin{array}{c}\text { Annual Fuel } \\
\text { Delivered }\end{array}$ & $\begin{array}{c}\text { Annual } \\
\text { Emissions }\end{array}$ \\
\cline { 6 - 7 } & 20 & 4 & 2.75 & $3,865,120$ & $\mathrm{~g}$ fuel \\
\hline Under & 80 & 3 & 2.66 & $11,595,360$ & 30,629 \\
\hline Fully & 160 & 3 & 2.65 & $23,190,720$ & 61,417 \\
\hline Over & N/A & 10 & N/A & $38,651,200$ & $\mathbf{1 0 2 , 9 2 2}$ \\
\hline Total & & &
\end{tabular}

Table G-9 shows the total emissions from the distribution of over-, under-, and fully utilized stations refueling 15 liter HPDI engine OTR tractors for case 2. The annual emissions were the same as the ten fully utilized stations and the distribution of utilized stations refueling 15 liter HPDI engine OTR tractors from case 1. 
Table G-9: Total Methane Emissions from 10 LNG Station Refueling 80015 Liter HPDI OTR Tractors. Case 2: Seriously Unevenly Utilized LNG Stations

\begin{tabular}{|c|r|r|r|r|c|}
\hline \multirow{2}{*}{$\begin{array}{c}\text { Station } \\
\text { Utilization }\end{array}$} & Number of Vehicles & \multirow{2}{*}{$\begin{array}{c}\text { Number } \\
\text { of Stations }\end{array}$} & $\begin{array}{c}\text { Total } \\
\text { Emissions }\end{array}$ & $\begin{array}{c}\text { Annual Fuel } \\
\text { Delivered }\end{array}$ & $\begin{array}{c}\text { Annual } \\
\text { Emissions }\end{array}$ \\
\cline { 4 - 6 } & & & $\mathrm{g} / \mathrm{kg}$ fuel & $\mathrm{Kg}$ & $\mathrm{kg}$ \\
\hline Under & 50 & 4 & 2.68 & $9,662,800$ & 25,899 \\
\hline Fully & 80 & 3 & 2.66 & $11,595,360$ & 30,877 \\
\hline Over & 120 & 3 & 2.65 & $17,393,040$ & 46,147 \\
\hline Total & N/A & 10 & N/A & $38,651,200$ & $\mathbf{1 0 2 , 9 2 2}$ \\
\hline
\end{tabular}

Table G-10 shows the total methane emissions from 10 LNG stations involving medium unevenly utilized LNG stations. The annual emissions calculated were identical to those calculated in case one (shown in Table G-8) and case two (shown in Table G-9).

Table G-10: FSME from Each Source for Different Utilization Types for 15L HPDI OTR Tractors

\begin{tabular}{|c|c|c|c|c|}
\hline \multirow{3}{*}{$\begin{array}{c}\text { Number of } \\
\text { Refueling Events }\end{array}$} & \multicolumn{3}{|c|}{ FSME from Each Source } & \multirow{2}{*}{$\begin{array}{l}\text { FSME from } \\
\text { LNG Stations }\end{array}$} \\
\hline & Manual Vent & Continuous & Nozzle Emissions & \\
\hline & $\mathrm{g} / \mathrm{kg}$ fuel & $\mathrm{g} / \mathrm{kg}$ fuel & $\mathrm{g} / \mathrm{kg}$ fuel & $\mathrm{g} / \mathrm{kg}$ fuel \\
\hline 20 & 2.50 & 0.12 & 0.128 & 2.75 \\
\hline 40 & 2.50 & 0.06 & 0.128 & 2.69 \\
\hline 60 & 2.50 & 0.04 & 0.128 & 2.67 \\
\hline 80 & 2.50 & 0.03 & 0.128 & 2.66 \\
\hline 100 & 2.50 & 0.02 & 0.128 & 2.66 \\
\hline 120 & 2.50 & 0.02 & 0.128 & 2.65 \\
\hline 140 & 2.50 & 0.02 & 0.128 & 2.65 \\
\hline 160 & 2.50 & 0.01 & 0.128 & 2.65 \\
\hline
\end{tabular}

Table G-11 compares the methane emissions from LNG stations and the contribution from each source for three cases of 10 LNG stations serving 800 refueling events per day. The annual methane emissions and contribution of each source to methane emissions calculated in each were identical. With the fixed LNG station population, fixed number of refueling events, and fixed total fuel delivery per vehicle, the deviation of the LNG station utilization from the evenly utilized case does not affect the calculated total methane emissions from LNG stations and the contribution of each source to the total methane emitted.

Table G-11: Methane Emissions from Each Source for Each Case Study

\begin{tabular}{|c|c|c|c|c|c|c|c|}
\hline \multirow{3}{*}{ Case } & \multicolumn{3}{|c|}{$\begin{array}{l}\text { Annual Methane Emissions } \\
\text { from Each Source }\end{array}$} & \multirow{2}{*}{ Total } & \multicolumn{3}{|c|}{ Contribution of each source } \\
\hline & Manual vent. & Continuous & Nozzle & & Manuel vent. & Continuous & Nozzle \\
\hline & $\mathrm{kg}$ & $\mathrm{kg}$ & $\mathrm{kg}$ & $\mathrm{kg}$ & $\%$ & $\%$ & $\%$ \\
\hline Case 1 & 96,628 & 1,122 & 5,172 & 102,922 & $93.9 \%$ & $1.1 \%$ & $5.0 \%$ \\
\hline Case 2 & 96,628 & 1,122 & 5,172 & 102,922 & $93.9 \%$ & $1.1 \%$ & $5.0 \%$ \\
\hline Case 3 & 96,628 & 1,122 & 5,172 & 102,922 & $93.9 \%$ & $1.1 \%$ & $5.0 \%$ \\
\hline
\end{tabular}

The impact of utilization on methane emissions from LNG stations refueling 12 liter OTR tractors was also investigated. As shown in Table G-12, Table G-13, and Table G-14, the total methane emissions from 10 LNG stations serving 800 refueling events were not affected by the 
uneven utilization of LNG stations if the number of LNG stations, refueling events, and total fuel delivery per vehicle were constant.

Table G-12: Total Methane Emissions from 10 LNG Station Refueling 800 12L OTR Tractors. Case 1: Evenly Utilized LNG Stations Refueling 80 OTR Tractors in Each Station

\begin{tabular}{|c|r|r|r|c|c|}
\hline \multirow{2}{*}{$\begin{array}{c}\text { Station } \\
\text { Utilization Type }\end{array}$} & \multirow{2}{*}{$\begin{array}{c}\text { Number } \\
\text { of Vehicles }\end{array}$} & \multirow{2}{*}{$\begin{array}{c}\text { Number } \\
\text { of Stations }\end{array}$} & $\begin{array}{c}\text { Total } \\
\text { Emissions }\end{array}$ & $\begin{array}{c}\text { Annual Fuel } \\
\text { Delivered }\end{array}$ & $\begin{array}{c}\text { Annual } \\
\text { Emissions }\end{array}$ \\
\cline { 4 - 6 } & & $\mathrm{g} / \mathrm{kg}$ fuel & $\mathrm{kg}$ & $\mathrm{kg}$ \\
\hline Normal & 80 & 10 & 2.65 & $40,763,200$ & $\mathbf{1 0 8 , 2 0 2}$ \\
\hline
\end{tabular}

Table G-13: Total Methane Emissions from 10 LNG Station Refueling 800 12L OTR Tractors. Case 2: Seriously Unevenly Utilized LNG Stations

\begin{tabular}{|c|r|r|r|r|c|}
\hline \multirow{2}{*}{$\begin{array}{c}\text { Station } \\
\text { Utilization }\end{array}$} & \multicolumn{1}{|c|}{$\begin{array}{c}\text { Number } \\
\text { of } \\
\text { Vehicles }\end{array}$} & \multirow{2}{*}{$\begin{array}{c}\text { Number of } \\
\text { Stations }\end{array}$} & $\begin{array}{c}\text { Total } \\
\text { Emissions }\end{array}$ & $\begin{array}{c}\text { Annual Fuel } \\
\text { Delivered }\end{array}$ & $\begin{array}{c}\text { Annual } \\
\text { Emissions }\end{array}$ \\
\cline { 4 - 6 } & 20 & & $\mathrm{~g} / \mathrm{kg}$ fuel & $\mathrm{kg}$ & $\mathrm{kg}$ \\
\hline Under & 80 & & 2.74 & $4,076,320$ & 11,157 \\
\hline Fully & 160 & 3 & 2.65 & $12,228,960$ & 32,461 \\
\hline Over & N/A & 10 & 2.64 & $24,457,920$ & 64,585 \\
\hline Total & 10 & N/A & $40,763,200$ & $\mathbf{1 0 8 , 2 0 2}$ \\
\hline
\end{tabular}

Table G-14: Total Methane Emissions from 10 LNG Station Refueling 800 12L OTR Tractors. Case 3: Medium Unevenly Utilized LNG Stations

\begin{tabular}{|c|r|r|r|r|r|}
\hline \multirow{2}{*}{$\begin{array}{c}\text { Station } \\
\text { Utilization }\end{array}$} & $\begin{array}{c}\text { Number } \\
\text { of } \\
\text { Vehicles }\end{array}$ & \multirow{2}{*}{$\begin{array}{c}\text { Number of } \\
\text { Stations }\end{array}$} & $\begin{array}{c}\text { Total } \\
\text { Emissions }\end{array}$ & $\begin{array}{c}\text { Annual Fuel } \\
\text { Delivered }\end{array}$ & $\begin{array}{c}\text { Annual } \\
\text { Emissions }\end{array}$ \\
\cline { 4 - 6 } & $\mathrm{g} / \mathrm{kg}$ fuel & $\mathrm{kg}$ & $\mathrm{kg}$ \\
\hline Under & 50 & 4 & 2.67 & $10,190,800$ & 27,219 \\
\hline Fully & 80 & 3 & 2.65 & $12,228,960$ & 32,461 \\
\hline Over & 120 & 3 & 2.65 & $18,343,440$ & 48,523 \\
\hline Total & N/A & 10 & N/A & $40,763,200$ & $\mathbf{1 0 8 , 2 0 2}$ \\
\hline
\end{tabular}

Methane Emissions from LNG Stations Refueling Multiple Types of Vehicles

The calculation of methane emissions from LNG stations with fleets operating multiple types of LNG vehicles could be challenging because each station may refuel different types of vehicles, especially with unevenly utilized LNG stations and imbalanced vehicle types. In this research, the impact on methane emissions from unevenly utilized LNG stations refueling multiple type of LNG vehicles was investigated by examining methane emissions from 60 LNG stations serving 4800 LNG vehicles including 16809 liter SI engine short haul OTR tractors, 96012 liter SI engine long haul OTR tractors, and 216015 liter HPDI engine long haul OTR tractors in two extreme cases. As shown in Table G-15, case one represents a simplest scenario with each type of LNG vehicle refueled in each type of dedicated LNG stations. Case two represents a scenario with an even distribution of these vehicles refueled at each LNG station. 
Table G-15: Number of Vehicles and Stations for the Multiple Vehicle Types Case Study

\begin{tabular}{|c|c|c|}
\hline \multicolumn{2}{|c|}{ Individual Station Types } \\
\hline Vehicle Type & Number of Vehicles & Number of Stations \\
\hline 9L OTR Tractor & 80 & 21 \\
\hline 12L OTR Tractor & 80 & 12 \\
\hline 15L OTR Tractors & 80 & 27 \\
\hline Total & 80 per station & 60 \\
\hline \multicolumn{2}{|c|}{ Mixed Station Type } \\
Type of LNG Vehicle Served & $\begin{array}{c}\text { Number of Each Type of Vehicles } \\
\text { Refueled in Each Station }\end{array}$ \\
\hline 9L OTR Tractor & 16 & \\
\hline 12L OTR Tractor & 36 & 60 \\
\hline 15L OTR Tractors & 80 & 60 \\
\hline Total & \multicolumn{2}{|c|}{28} \\
\hline
\end{tabular}

Table G-16 shows the total emissions from 60 fully utilized stations refueling one type of vehicle per station. With the calculated FSME from LNG stations and annual total fuel delivery, the methane emissions from LNG stations serving each type of LNG vehicle can be calculated. The calculated total methane emissions from 60 LNG stations with one type of LNG vehicles refueled in their specific LNG stations (case one), were 537,207 kg.

Table G-16: Total Methane Emissions from 60 LNG Station Refueling 4800 LNG Vehicles. Case 1: Each Type LNG Station Normally Utilized to Serve Specific Type of LNG Vehicles Only

\begin{tabular}{|c|r|r|r|r|}
\hline \multirow{2}{*}{ Vehicle Type } & Number & Total Number & Total Station Emissions & Annual Emissions \\
\cline { 4 - 5 } & of Stations & of Vehicles & $\mathrm{g} / \mathrm{kg}$ fuel & \multicolumn{1}{c|}{$\mathrm{kg}$} \\
\hline 9L OTR Tractors & 21 & 1680 & 2.78 & 129,474 \\
\hline 12L OTR Tractors & 12 & 960 & 2.65 & 129,843 \\
\hline 15L OTR Tractors & 27 & 2160 & 2.66 & 277,890 \\
\hline Total & 60 & 4800 & $\mathrm{~N} / \mathrm{A}$ & $\mathbf{5 3 7 , 2 0 7}$ \\
\hline
\end{tabular}

Table G-17 shows the total emissions from 60 LNG stations with each station evenly refueling 80 LNG vehicles, including 289 liter SI engine short haul OTR tractors, 1612 liter SI engine long haul OTR tractors, and 3615 liter HPDI engine long haul OTR tractors (case two). The total methane emissions calculated were $537,207 \mathrm{~kg}$, which were identical to those calculated in case one shown in Table G-17. With a fixed number of LNG stations, refueling events, and total fuel delivered per vehicle, the methane emissions from LNG stations were not affected by the distribution of the refueling events at LNG stations and the utilization factor of each station. 
Table G-17: Total Emissions from One Fully Utilized Station Type Refueling Three Different Vehicle Types per Station (60 Total)

\begin{tabular}{|c|r|r|r|r|}
\hline \multirow{2}{*}{$\begin{array}{c}\text { Vehicle Type } \\
\text { Refueled }\end{array}$} & $\begin{array}{c}\text { Number of Refueling } \\
\text { Events for Each Type } \\
\text { of Vehicle per Station }\end{array}$ & $\begin{array}{c}\text { Number } \\
\text { of Stations }\end{array}$ & $\begin{array}{c}\text { Total Number } \\
\text { of Vehicles }\end{array}$ & $\begin{array}{c}\text { Annual } \\
\text { Emissions }\end{array}$ \\
\cline { 5 - 6 } & 28 & N/A & 1680 & Kg \\
\hline 9L OTR Tractors & 16 & N/A & 960 & N/A \\
\hline 12L OTR Tractors & 36 & N/A & 2160 & N/A \\
\hline 15L OTR Tractors & 80 & 60 & 4800 & $\mathbf{5 3 7 , 2 0 7}$ \\
\hline Total & &
\end{tabular}

\section{Conclusion}

For a fleet operating numerous identical LNG stations and numerous types of LNG vehicles, the total methane emissions from LNG stations were affected by the total LNG fuel delivered, and the total refueling events. The type of LNG vehicle and its relative percentage in this fleet refueled does not affect the methane emissions from LNG stations.

\section{Appendix H Refuse Truck Activity Distance and Duration}

This document reports the development of the refuse truck activity model by examining the operation characteristics of 3 chassis dynamometer driving schedules, 3 in-use measurements from Texas A\&M, 5 in-use measurements from NC State, and 26 driving schedules measured directly by WVU during actual operation for two refuse trucks with a portable emissions measurement system (PEMS). The microtrips derived from the refuse truck emissions test driving schedules were broken into idle (microtrip average velocity lower than $0.2 \mathrm{mph}$ ) mode and non-idle (microtrip average velocity higher than $0.2 \mathrm{mph}$ ) microtrips. The non-idle microtrips were sorted to city, arterial, and highway activities by the average velocity, as shown in Table $\mathrm{H}-1$.

Table H-1: Bins of Average Speed for Each Activity

\begin{tabular}{|c|c|}
\hline Activity & Bin of Average Speed (mph) \\
\hline Idle & {$[0,0.2]$} \\
\hline City & $(0.2,10]$ \\
\hline Arterial & $(10,40]$ \\
\hline Highway & $>40$ \\
\hline
\end{tabular}

The microtrips in each activity bin were combined to develop the total duration and distance of vehicle operation and the average speed without idle in each activity as shown in Table H-2. The average refuse truck velocity derived from 37 refuse truck driving schedules was $10.5 \mathrm{mph}$. 
Table H-2: Distance and Duration of Refuse Truck Operation in Each Activity

\begin{tabular}{|c|c|c|c|c|c|c|}
\hline \multirow{2}{*}{ Activities } & \multirow{2}{*}{ Idle } & \multirow{2}{*}{ City } & \multirow{2}{*}{ Arterial } & \multirow{2}{*}{ Highway } & \multicolumn{2}{|c|}{ Sum } \\
\cline { 6 - 8 } & & & & & Without Idle & With idle \\
\hline Distance (mile) & 0.0 & 14.4 & 46.4 & 34.8 & 95.6 & 95.6 \\
\hline Time (s) & 15,089 & 7,762 & 7,420 & 2,664 & 17,846 & 32,935 \\
\hline Avg. Velocity (mph) & 0.0 & 6.7 & 22.5 & 47.0 & 19.3 & 10.5 \\
\hline
\end{tabular}

Table $\mathrm{H}-3$ shows the percentage of refuse truck operation distance and duration in each activity during the 37 driving schedules examined. The distance of refuse truck operation in city, arterial, and highway operation were $15.1 \%, 48.6 \%$, and $36.4 \%$, respectively. Idle time was $45.8 \%$ of the total duration for refuse truck operation.

Table H-3: Percentage of Distance and Duration in Each Activity

\begin{tabular}{|l|r|l|r|r|l|}
\hline & \multicolumn{1}{|c|}{ Idle } & City & Arterial & Highway & Total \\
\hline \% miles operation & $0.0 \%$ & $15.1 \%$ & $48.6 \%$ & $36.4 \%$ & $100.0 \%$ \\
\hline \% time operation & $45.8 \%$ & $23.6 \%$ & $22.5 \%$ & $8.1 \%$ & $100.0 \%$ \\
\hline
\end{tabular}

\section{Refuse Truck Driving Schedules}

This document reports the development of the refuse truck activity model by examining the operation characteristics of 3 chassis dynamometer driving schedules, 3 in-use measurements from Texas A\&M, 5 in-use measurements from NC State, and 26 refuse truck driving schedules measured directly by WVU during actual operation for two refuse trucks with a PEMS. An explanation of the driving schedules used is shown in Table H-4.

Table H-4: Driving Schedules Used in this Study

\begin{tabular}{|c|l|}
\hline Driving Schedule & \multicolumn{1}{c|}{ Explanation } \\
\hline AQMDRTC1 & Air Quality Management District cycle based on William H. Martin Cycle developed by WVU \\
\hline AQMDRTC2 & Air Quality Management District cycle based on William H. Martin Cycle developed by WVU \\
\hline OCRTC & Orange County Refuse Truck Cycle based on data from Orange County, CA \\
\hline TAMU1Test1 & Texas A\&M data from refuse trucks near El Paso, TX \\
\hline TAMU2Test1 & Texas A\&M data from refuse trucks near El Paso, TX \\
\hline TAMU2Test2 & Texas A\&M data from refuse trucks near El Paso, TX \\
\hline WVUV12 & WVU data from refuse trucks near Los Angeles, CA \\
\hline WVUV13 & WVU data from refuse trucks near Los Angeles, CA \\
\hline NCST2 & North Carolina State data from refuse trucks near Raleigh, NC \\
\hline NCST3 & North Carolina State data from refuse trucks near Raleigh, NC \\
\hline NCST4 & North Carolina State data from refuse trucks near Raleigh, NC \\
\hline NCST5 & North Carolina State data from refuse trucks near Raleigh, NC \\
\hline NCST6 & North Carolina State data from refuse trucks near Raleigh, NC \\
\hline
\end{tabular}

One example of a collection route driving schedule measured by WVU is shown in Figure H-1. This driving schedule includes travel to the location and refuse collection. 


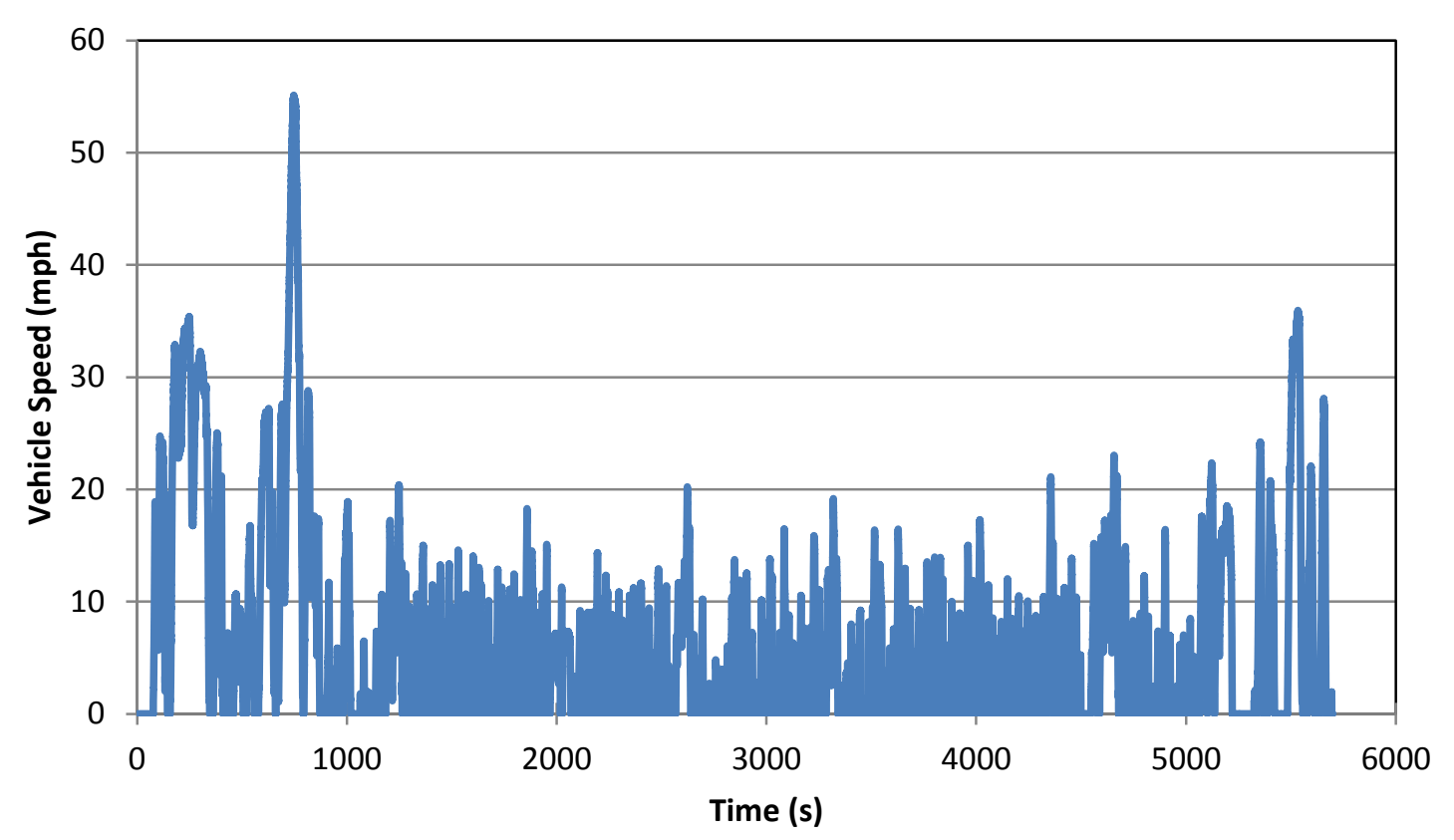

Figure H-1: Collection Route Measured by WVU

\section{Development of Refuse Truck Operation Activities}

The refuse truck driving schedules were broken into idle microtrips (average velocity lower than $0.2 \mathrm{mph}$ ) and non-idle microtrips (average velocity higher than $0.2 \mathrm{mph}$ ). Microtrips were defined as a portion of data where the vehicle speed starts from idle, accelerates to a speed, travels an indeterminate distance, and decelerates to a stop. The velocity profile of each non-idle microtrip was processed to derive the distance, time of vehicle operation, and average velocity of each non-idle microtrip. The microtrips of each driving schedule were sorted into city, arterial and highway activities by the average velocity as shown in Table H-5.

Table H-5: Bins of Average Speed for Each Activity

\begin{tabular}{|c|c|}
\hline Activity & Average Speed Bin (mph) \\
\hline Idle & {$[0,0.2]$} \\
\hline City & $(0.2,10]$ \\
\hline Arterial & $(10,40]$ \\
\hline Highway & $>40$ \\
\hline
\end{tabular}

All microtrips sorted into each activity for each driving schedule were combined to derive the total distance and duration of refuse truck operation in each activity. The original raw data for distance and duration traveled is shown in Table H-6 and Table H-7, respectively.

Since the in-use tests were much longer than the chassis dynamometer tests, the in-use tests were all scaled to $8 \mathrm{mph}$ to give less weight to the on-road driving schedules. Table $\mathrm{H}-8$ and Table H-9 show the distance and duration, respectively, for each activity for each vehicle. All microtrips for each activity of each driving schedule were combined to derive the total distance 
and duration of refuse truck operation in each activity, which are shown in the last row of Table H-8 and Table H-9, respectively.

Table H-6: Original Distance of Refuse Truck Operation in Each Activity

\begin{tabular}{|c|r|r|r|r|r|}
\hline Driving Schedule & Idle & \multicolumn{1}{c|}{ City } & Arterial & Highway & \multicolumn{1}{c|}{ Sum } \\
\hline AQMDRTC1 & 0.0 & 0.3 & 5.9 & 0.0 & 6.2 \\
\hline AQMDRTC2 & 0.0 & 0.9 & 5.9 & 0.0 & 6.8 \\
\hline OCRTC & 0.0 & 0.3 & 2.4 & 0.0 & 2.7 \\
\hline TAMU1Test1 & 0.0 & 27.3 & 11.6 & 45.3 & 84.2 \\
\hline TAMU2Test1 & 0.0 & 5.1 & 8.9 & 17.8 & 31.8 \\
\hline TAMU2Test2 & 0.0 & 4.6 & 8.8 & 16.9 & 30.3 \\
\hline WVUV12 & 0.0 & 6.5 & 12.7 & 15.5 & 34.6 \\
\hline WVUV13 & 0.0 & 4.2 & 13.5 & 24.5 & 42.2 \\
\hline NCST2 & 0.0 & 12.2 & 75.1 & 58.4 & 145.6 \\
\hline NCST3 & 0.0 & 18.0 & 36.1 & 15.6 & 69.6 \\
\hline NCST4 & 0.0 & 10.8 & 59.6 & 17.6 & 87.9 \\
\hline NCST5 & 0.0 & 8.6 & 39.3 & 45.0 & 93.0 \\
\hline NCST6 & 0.0 & 14.5 & 57.3 & 39.7 & 111.5 \\
\hline Sum & 0.0 & 113.2 & 336.9 & 296.3 & 746.4 \\
\hline
\end{tabular}

Table H-7: Original Duration of Refuse Truck Operation in Each Activity

\begin{tabular}{|c|r|r|r|r|r|}
\hline Driving Schedule & \multicolumn{1}{|c|}{ Idle } & \multicolumn{1}{c|}{ City } & \multicolumn{1}{c|}{ Arterial } & Highway & \multicolumn{1}{c|}{ Sum } \\
\hline AQMDRTC1 & 431.2 & 235.5 & 703.3 & 0.0 & $1,370.0$ \\
\hline AQMDRTC2 & $1,012.5$ & 706.2 & 703.3 & 0.0 & $2,422.0$ \\
\hline OCRTC & 575.0 & 270.5 & 316.6 & 0.0 & $1,162.1$ \\
\hline TAMU1Test1 & $5,718.0$ & $7,213.0$ & $2,072.0$ & $3,781.0$ & $18,784.0$ \\
\hline TAMU2Test1 & $3,516.0$ & $4,049.0$ & $1,358.0$ & $1,449.0$ & $10,372.0$ \\
\hline TAMU2Test2 & $11,314.0$ & $3,898.0$ & $2,034.0$ & $1,160.0$ & $18,406.0$ \\
\hline WVUV12 & $9,745.3$ & $3,689.9$ & $2,176.6$ & $1,134.1$ & $16,745.9$ \\
\hline WVUV13 & $3,926.6$ & $2,345.5$ & $2,522.7$ & $1,739.5$ & $10,534.3$ \\
\hline NCST2 & $21,990.0$ & $7,566.0$ & $13,643.0$ & $4,507.0$ & $47,706.0$ \\
\hline NCST3 & $11,372.0$ & $1,977.0$ & $5,195.0$ & $1,200.0$ & $19,744.0$ \\
\hline NCST4 & $14,397.0$ & $7,559.0$ & $9,753.0$ & $1,809.0$ & $33,518.0$ \\
\hline NCST5 & $7,228.0$ & $5,584.0$ & $7,189.0$ & $3,188.0$ & $23,189.0$ \\
\hline NCST6 & $16,917.0$ & $9,874.0$ & $10,980.0$ & $3,030.0$ & $40,801.0$ \\
\hline Sum & $108,142.6$ & $54,967.6$ & $58,646.5$ & $22,997.6$ & $244,754.3$ \\
\hline
\end{tabular}


Table H-8: Scaled Distance of Refuse Truck Operation in Each Activity

\begin{tabular}{|c|r|r|r|r|r|}
\hline Driving Schedule & Idle & City & Arterial & Highway & Sum \\
\hline AQMDRTC1 & 0.0 & 0.3 & 5.9 & 0.0 & 6.2 \\
\hline AQMDRTC2 & 0.0 & 0.9 & 5.9 & 0.0 & 6.8 \\
\hline OCRTC & 0.0 & 0.3 & 2.4 & 0.0 & 2.7 \\
\hline TAMU1Test1* & 0.0 & 2.6 & 1.1 & 4.3 & 8.0 \\
\hline TAMU2Test1* & 0.0 & 1.3 & 2.2 & 4.5 & 8.0 \\
\hline TAMU2Test2* & 0.0 & 1.2 & 2.3 & 4.5 & 8.0 \\
\hline WVUV12* $^{*}$ & 0.0 & 1.5 & 2.9 & 3.6 & 8.0 \\
\hline WVUV13* $^{*}$ & 0.0 & 0.8 & 2.6 & 4.6 & 8.0 \\
\hline NCST2* & 0.0 & 0.7 & 4.1 & 3.2 & 8.0 \\
\hline NCST3* & 0.0 & 2.1 & 4.1 & 1.8 & 8.0 \\
\hline NCST4* & 0.0 & 1.0 & 5.4 & 1.6 & 8.0 \\
\hline NCST5* & 0.0 & 0.7 & 3.4 & 3.9 & 8.0 \\
\hline NCST6* & 0.0 & 1.0 & 4.1 & 2.9 & 8.0 \\
\hline Sum & 0.0 & 14.4 & 46.4 & 34.8 & 95.6 \\
\hline
\end{tabular}

*Data scaled to 8 miles

Table H-9: Scaled Duration of Refuse Truck Operation in Each Activity

\begin{tabular}{|c|r|r|r|r|c|}
\hline Driving Schedule & \multicolumn{1}{c|}{ Idle } & \multicolumn{1}{c|}{ City } & Arterial & Highway & Sum \\
\hline AQMDRTC1 & 431.2 & 235.5 & 703.3 & 0.0 & $1,370.0$ \\
\hline AQMDRTC2 & $1,012.5$ & 706.2 & 703.3 & 0.0 & $2,422.0$ \\
\hline OCRTC & 575.0 & 270.5 & 316.6 & 0.0 & $1,162.1$ \\
\hline TAMU1Test1* & 543.3 & 685.3 & 196.9 & 359.2 & $1,784.7$ \\
\hline TAMU2Test1* & 885.7 & $1,020.0$ & 342.1 & 365.0 & $2,612.7$ \\
\hline TAMU2Test2* & $2,982.5$ & $1,027.5$ & 536.2 & 305.8 & $4,852.0$ \\
\hline WVUV12* $^{*}$ & $2,254.5$ & 853.6 & 503.5 & 262.4 & $3,874.1$ \\
\hline WVUV13* $^{*}$ & 744.0 & 444.4 & 478.0 & 329.6 & $1,996.1$ \\
\hline NCST2* & $1,207.9$ & 415.6 & 749.4 & 247.6 & $2,620.6$ \\
\hline NCST3* & $1,306.5$ & 227.1 & 596.8 & 137.9 & $2,268.3$ \\
\hline NCST4* & $1,309.7$ & 687.6 & 887.2 & 164.6 & $3,049.1$ \\
\hline NCST5* & 622.1 & 480.6 & 618.7 & 274.4 & $1,995.7$ \\
\hline NCST6* & $1,213.8$ & 708.4 & 787.8 & 217.4 & $2,927.4$ \\
\hline Sum & $15,088.6$ & $7,762.5$ & $7,419.8$ & $2,663.8$ & $32,934.7$ \\
\hline
\end{tabular}

*Data scaled to 8 miles

Table H-10 shows the distance and duration of refuse truck operation in each activity for all of the driving schedules examined. The average velocities without idle in city, arterial, and highway activities of the driving schedules examined were $6.7,22.5$, and $47.0 \mathrm{mph}$, respectively. The average velocity of these driving schedules without idle was $19.3 \mathrm{mph}$. The average velocity of these driving schedules with idle was $10.5 \mathrm{mph}$. 
Table H-10: Distance and Duration of Refuse Truck Operation in Each Activity

\begin{tabular}{|c|c|c|c|c|c|c|}
\hline \multirow{2}{*}{ Activities } & \multirow{2}{*}{ Idle } & \multirow{2}{*}{ City } & \multirow{2}{*}{ Arterial } & \multirow{2}{*}{ Highway } & \multicolumn{2}{|c|}{ Sum } \\
\cline { 6 - 7 } & & & & & Without Idle & With idle \\
\hline Distance (mile) & 0.0 & 14.4 & 46.4 & 34.8 & 95.6 & 95.6 \\
\hline Time (s) & 15,089 & 7,762 & 7,420 & 2,664 & 17,846 & 32,935 \\
\hline Avg. Velocity (mph) & 0.0 & 6.7 & 22.5 & 47.0 & 19.3 & 10.5 \\
\hline
\end{tabular}

Table H-11 shows the average speed for each activity for each vehicle. The overall average speed for all driving schedules tested was $10.5 \mathrm{mph}$, which matches Table H-10. Table H-12 and Table H-13 show the percentage of the distance and duration, respectively, for each activity for each vehicle. Most of the microtrips were classified as arterial activity by distance (48.6\% of total miles) or idle by duration ( $45.8 \%$ of the total duration).

Table H-11: Refuse Truck Average Speed (mph) for Each Activity

\begin{tabular}{|c|r|r|r|r|r|}
\hline Driving Schedule & Idle & City & Arterial & Highway & Average of Entire Driving Schedule \\
\hline AQMDRTC1 & 0.0 & 4.8 & 30.0 & N/A & 16.2 \\
\hline AQMDRTC2 & 0.0 & 4.8 & 30.0 & N/A & 10.1 \\
\hline OCRTC & 0.0 & 3.9 & 27.1 & N/A & 8.3 \\
\hline TAMU1Test1* & 0.0 & 13.6 & 20.2 & 43.1 & 16.1 \\
\hline TAMU2Test1* & 0.0 & 4.5 & 23.6 & 44.2 & 11.0 \\
\hline TAMU2Test2* & 0.0 & 4.3 & 15.6 & 52.5 & 5.9 \\
\hline WVUV12* & 0.0 & 6.3 & 21.0 & 49.1 & 7.4 \\
\hline WVUV13* & 0.0 & 6.5 & 19.3 & 50.7 & 14.4 \\
\hline NCST2* & 0.0 & 5.8 & 19.8 & 46.7 & 11.0 \\
\hline NCST3* & 0.0 & 32.8 & 25.0 & 46.8 & 12.7 \\
\hline NCST4* & 0.0 & 5.1 & 22.0 & 35.0 & 9.4 \\
\hline NCST5* & 0.0 & 5.6 & 19.7 & 50.9 & 14.4 \\
\hline NCST6* & 0.0 & 5.3 & 18.8 & 47.2 & 9.8 \\
\hline All Driving Schedules & 0.0 & 6.7 & 22.5 & 47.0 & 10.5 \\
\hline
\end{tabular}

*Data scaled to 8 miles in distance traveled 
Table H-12: Percentage of Distance (\%) Driven for Each Activity

\begin{tabular}{|c|c|r|r|r|c|}
\hline Driving Schedule & Idle & \multicolumn{1}{c|}{ City } & Arterial & Highway & Sum \\
\hline AQMDRTC1 & $0.0 \%$ & $5.1 \%$ & $94.9 \%$ & $0.0 \%$ & $100.0 \%$ \\
\hline AQMDRTC2 & $0.0 \%$ & $13.8 \%$ & $86.2 \%$ & $0.0 \%$ & $100.0 \%$ \\
\hline OCRTC & $0.0 \%$ & $10.8 \%$ & $89.2 \%$ & $0.0 \%$ & $100.0 \%$ \\
\hline TAMU1Test1 & $0.0 \%$ & $32.4 \%$ & $13.8 \%$ & $53.8 \%$ & $100.0 \%$ \\
\hline TAMU2Test1 & $0.0 \%$ & $15.9 \%$ & $28.1 \%$ & $56.0 \%$ & $100.0 \%$ \\
\hline TAMU2Test2 & $0.0 \%$ & $15.2 \%$ & $29.1 \%$ & $55.7 \%$ & $100.0 \%$ \\
\hline WVUV12 & $0.0 \%$ & $18.7 \%$ & $36.7 \%$ & $44.7 \%$ & $100.0 \%$ \\
\hline WVUV13 & $0.0 \%$ & $10.0 \%$ & $32.0 \%$ & $58.0 \%$ & $100.0 \%$ \\
\hline NCST2 & $0.0 \%$ & $8.4 \%$ & $51.5 \%$ & $40.1 \%$ & $100.0 \%$ \\
\hline NCST3 & $0.0 \%$ & $25.8 \%$ & $51.8 \%$ & $22.4 \%$ & $100.0 \%$ \\
\hline NCST4 & $0.0 \%$ & $12.2 \%$ & $67.7 \%$ & $20.0 \%$ & $100.0 \%$ \\
\hline NCST5 & $0.0 \%$ & $9.3 \%$ & $42.3 \%$ & $48.5 \%$ & $100.0 \%$ \\
\hline NCST6 & $0.0 \%$ & $13.0 \%$ & $51.4 \%$ & $35.6 \%$ & $100.0 \%$ \\
\hline All Driving Schedules & $0.0 \%$ & $15.1 \%$ & $48.6 \%$ & $36.4 \%$ & $100.0 \%$ \\
\hline
\end{tabular}

Table H-13: Percentage of Duration (\%) for Each Activity

\begin{tabular}{|c|c|c|r|r|c|}
\hline Driving Schedule & Idle & City & Arterial & Highway & \multicolumn{1}{c|}{ Sum } \\
\hline AQMDRTC1 & $31.5 \%$ & $17.2 \%$ & $51.3 \%$ & $0.0 \%$ & $100.0 \%$ \\
\hline AQMDRTC2 & $41.8 \%$ & $29.2 \%$ & $29.0 \%$ & $0.0 \%$ & $100.0 \%$ \\
\hline OCRTC & $49.5 \%$ & $23.3 \%$ & $27.2 \%$ & $0.0 \%$ & $100.0 \%$ \\
\hline TAMU1Test1 & $30.4 \%$ & $38.4 \%$ & $11.0 \%$ & $20.1 \%$ & $100.0 \%$ \\
\hline TAMU2Test1 & $33.9 \%$ & $39.0 \%$ & $13.1 \%$ & $14.0 \%$ & $100.0 \%$ \\
\hline TAMU2Test2 & $61.5 \%$ & $21.2 \%$ & $11.1 \%$ & $6.3 \%$ & $100.0 \%$ \\
\hline WVUV12 & $58.2 \%$ & $22.0 \%$ & $13.0 \%$ & $6.8 \%$ & $100.0 \%$ \\
\hline WVUV13 & $37.3 \%$ & $22.3 \%$ & $23.9 \%$ & $16.5 \%$ & $100.0 \%$ \\
\hline NCST2 & $46.1 \%$ & $15.9 \%$ & $28.6 \%$ & $9.4 \%$ & $100.0 \%$ \\
\hline NCST3 & $57.6 \%$ & $10.0 \%$ & $26.3 \%$ & $6.1 \%$ & $100.0 \%$ \\
\hline NCST4 & $43.0 \%$ & $22.6 \%$ & $29.1 \%$ & $5.4 \%$ & $100.0 \%$ \\
\hline NCST5 & $31.2 \%$ & $24.1 \%$ & $31.0 \%$ & $13.7 \%$ & $100.0 \%$ \\
\hline NCST6 & $41.5 \%$ & $24.2 \%$ & $26.9 \%$ & $7.4 \%$ & $100.0 \%$ \\
\hline All Driving Schedules & $45.8 \%$ & $23.6 \%$ & $22.5 \%$ & $8.1 \%$ & $100.0 \%$ \\
\hline
\end{tabular}

Table H-14 shows the percentage of refuse truck operational distance and duration for all driving schedules examined. The distances for refuse truck operation in city, arterial, and highway operation were $15.1 \%, 48.6 \%$, and $36.4 \%$, respectively. The refuse trucks spent $45.8 \%$ of the total operational time during idle operation. 
Table H-14: Percentage of Distance and Duration of Refuse Truck Operation Each Activity

\begin{tabular}{|l|r|l|r|r|l|}
\hline & \multicolumn{1}{|l|}{ Idle } & City & Arterial & Highway & Total \\
\hline \% miles operation & $0.0 \%$ & $15.1 \%$ & $48.6 \%$ & $36.4 \%$ & $100.0 \%$ \\
\hline \% time operation & $45.8 \%$ & $23.6 \%$ & $22.5 \%$ & $8.1 \%$ & $100.0 \%$ \\
\hline
\end{tabular}




\section{Appendix I Transit Bus Activity Distance and Duration}

\section{Summary}

This document reports the development of the transit bus activity model by examining the operation characteristics of 12 transit bus driving schedules widely used in fuel economy and emissions testing. The microtrips derived from the transit bus emissions test driving schedules were broken into idle (velocity lower than $0.2 \mathrm{mph}$ ) mode and non-idle (average velocity higher than $0.2 \mathrm{mph}$ ) microtrips. The non-idle microtrips were sorted to city, arterial, and highway activities by the average velocity, as shown in Table I-1.

Table I-1: Bins of Average Speed for Each Activity

\begin{tabular}{|c|c|}
\hline Activity & Bin of Average Speed (mph) \\
\hline Idle & {$[0,0.2]$} \\
\hline City & $(0.2,10]$ \\
\hline Arterial & $(10,40]$ \\
\hline Highway & $>40$ \\
\hline
\end{tabular}

The microtrips in each category were combined to develop the total duration and distance of vehicle operation and the average speed without idle in each activity as shown in Table I-2. The average transit bus velocity derived from 12 transit bus driving schedules was $12.7 \mathrm{mph}$, which was designed to match the average speed of transit buses reported by American Public Transportation Association in 2013 [APTA, 2013] and WVU in 2007 [Clark, et al., 2007].

Table I-2: Distance and Duration of Transit Bus Operation in Each Activity

\begin{tabular}{|c|c|c|c|c|c|c|}
\hline \multirow{2}{*}{ Activities } & \multirow{2}{*}{ Idle } & \multirow{2}{*}{ City } & \multirow{2}{*}{ Arterial } & \multirow{2}{*}{ Highway } & \multicolumn{2}{|c|}{ Sum } \\
\cline { 6 - 7 } & & & & & Without Idle & With idle \\
\hline Distance (mile) & 0.0 & 3.9 & 62.6 & 4.3 & 70.9 & 70.9 \\
\hline Duration (s) & $5,735.8$ & $2,119.0$ & $11,924.0$ & 311.1 & $14,354.1$ & $20,089.9$ \\
\hline Avg. Velocity, $\mathrm{mph}$ & 0.0 & 6.6 & 18.9 & 49.8 & 17.8 & 12.7 \\
\hline
\end{tabular}

Table I-3 shows the percentage of transit bus operation distance and duration in each activity during the 12 driving schedules examined. The distance of transit bus operation in city, arterial, and highway operation were $5.6 \%, 88.3 \%$, and $6.1 \%$, respectively. Idle time was $28.6 \%$ of the total duration for transit bus operation.

Table I-3: Percentage of Distance and Duration in Each Activity

\begin{tabular}{|l|r|r|r|r|r|}
\hline & \multicolumn{1}{|c|}{ Idle } & \multicolumn{1}{c|}{ City } & \multicolumn{1}{c|}{ Arterial } & \multicolumn{1}{l|}{ Highway } & Total \\
\hline$\%$ miles operation & $0.0 \%$ & $5.6 \%$ & $88.3 \%$ & $6.1 \%$ & $100.0 \%$ \\
\hline$\%$ time operation & $28.6 \%$ & $10.5 \%$ & $59.4 \%$ & $1.5 \%$ & $100.0 \%$ \\
\hline
\end{tabular}




\section{Transit Bus Driving Schedules}

This document reports the development of the transit bus activity model by examining the operation characteristics of 12 transit bus driving schedules widely used in fuel economy and emissions testing in the US, shown in Table I-4. The 12 emissions and fuel economy driving schedules represent the operation characteristics of transit buses in major cities in the U.S.

Table I-4: Driving Schedules Used in this Study

\begin{tabular}{|c|c|l|}
\hline \multicolumn{2}{|c|}{ Driving Schedule } & \multicolumn{1}{c|}{ Explanation } \\
\hline 1 & Beeline & Bee-line system serving Westchester County, NY areas \\
\hline 2 & CSHVC & City Suburban Heavy Vehicle Route developed by West Virginia University \\
\hline 3 & Houston & Metropolitan Authority of Harris County serving the Houston area \\
\hline 4 & KCM & King County Metro serving the Seattle area (non-commuter) \\
\hline 5 & KAT & Knoxville Area Transit serving the Knoxville, TN area \\
\hline 6 & Liberty & Liberty Lines serving Westchester County, NY areas \\
\hline 7 & Manhattan & Metropolitan Transportation Authority serving Manhattan, NY area \\
\hline 8 & NY Bus & Metropolitan Transportation Authority serving congested NY areas \\
\hline 9 & OCTA & Orange County Transportation Authority serving Orange County, CA area \\
\hline 10 & SF & San Francisco Municipal Transportation Agency serving San Francisco area \\
\hline 11 & WMATA & Washington Metropolitan Area Transit Authority serving DC area \\
\hline 12 & Commuter* & Commuter segments of KCM and WMATA Commute routes \\
\hline
\end{tabular}

* The mileage traveled during commuter driving schedule was adjusted to obtain the average vehicle operation speed of $12.7 \mathrm{mph}$.

The KAT driving schedule, developed based on operation data of the Knoxville Area Transit [Gao, et al., 2014], included over 3000 seconds idle operation as shown in Figure I-1. In this document, the long idle microtrip at the end of this driving schedule was removed, as shown in Figure I-2.

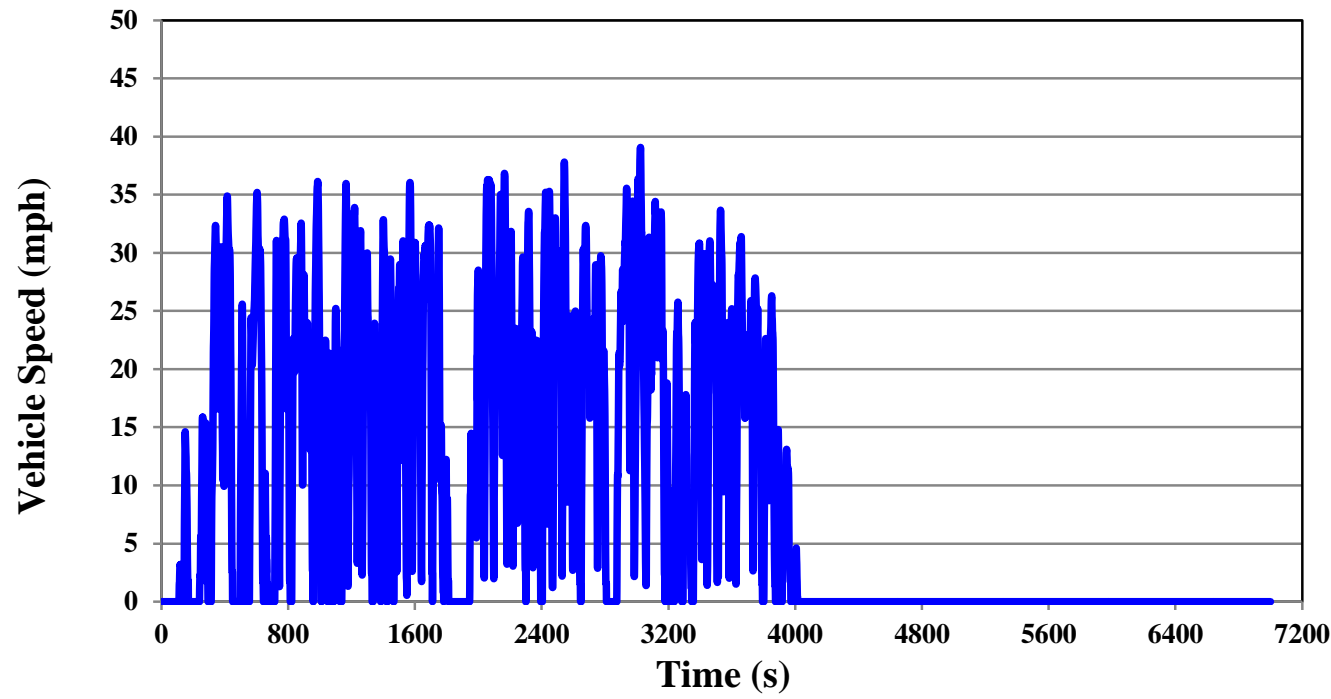

Figure I-1: KAT Driving Schedule Reported in Literature [Gao, et al., 2014] 


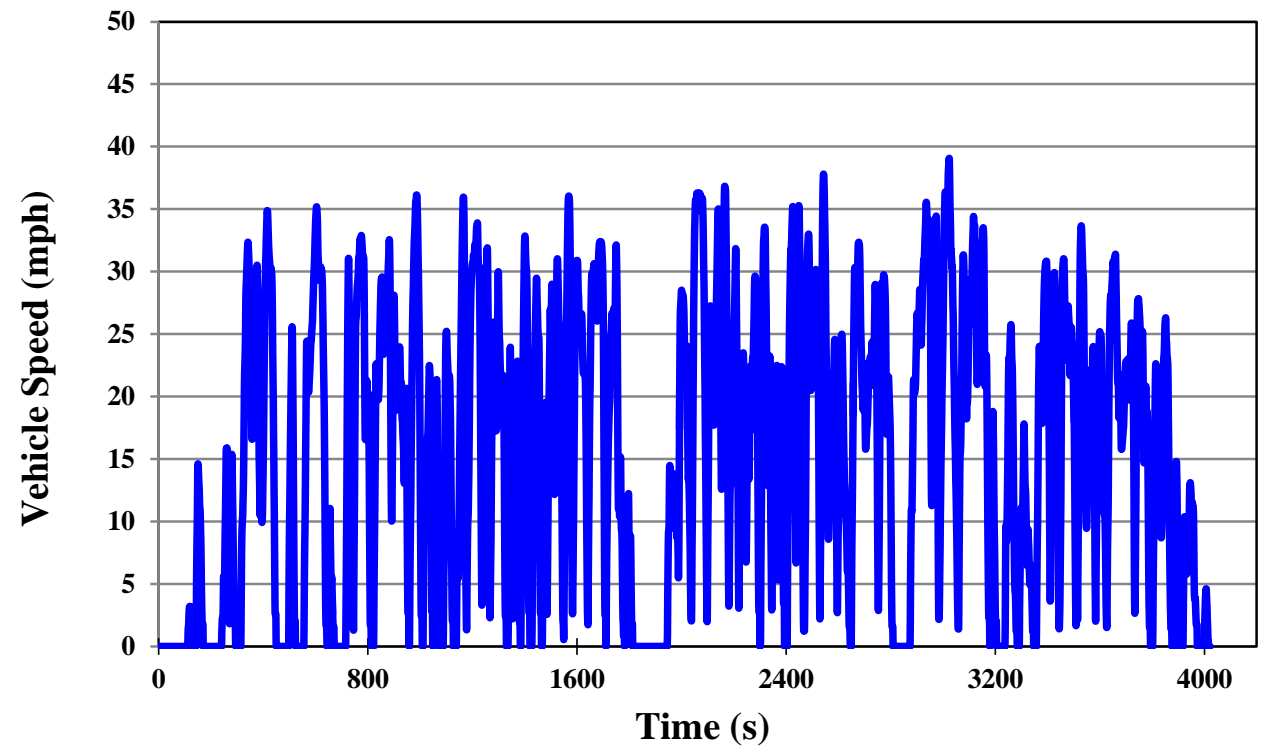

Figure I-2: KAT Driving Schedule with the Long Idle Operation Period Removed [Gao, et al., 2014]

The commuter driving schedule, as shown in Figure I-3, was developed by referencing the operational data of transit buses performing commuting routes of the King County Metro (first microtrip) and WMATA (second microtrip) driving schedules.

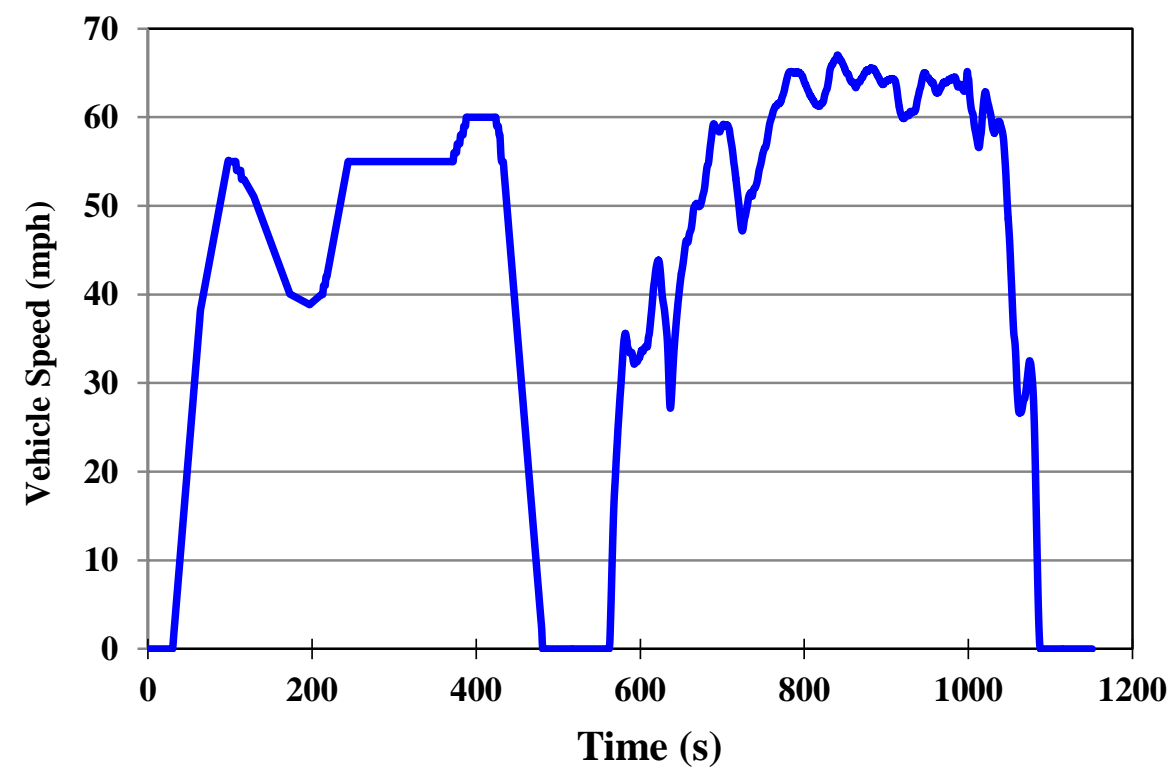

Figure I-3: Commuter Driving Schedule Developed by WVU

\section{Development of Transit Bus Operation Activities}

The transit bus driving schedules were broken into idle microtrips (average velocity lower than $0.2 \mathrm{mph}$ ) and non-idle microtrips (average velocity higher than $0.2 \mathrm{mph}$ ). Micro trips were defined as a portion of data where the vehicle speed starts from idle, accelerates to a speed, travels an indeterminate distance, and decelerates to a stop. The velocity profile of each non-idle microtrip was processed to derive the distance and duration of vehicle operation, and average 
velocity of each non-idle microtrip. The microtrips of each driving schedule were sorted into city, arterial and highway activities by the average velocity without idle as shown in Table I-5.

Table I-5: Bins of Average Speed for Each Activity

\begin{tabular}{|c|c|}
\hline Activity & Average Speed Bin (mph) \\
\hline Idle & {$[0,0.2]$} \\
\hline City & $(0.2,10]$ \\
\hline Arterial & $(10,40]$ \\
\hline Highway & $>40$ \\
\hline
\end{tabular}

All microtrips were sorted into each activity for each driving schedule and combined to derive the total distance and duration of transit bus operation in each activity. Table I-6 and Table I-7 show the distance and duration, respectively, for each activity during each driving schedule. All microtrips for each activity of each driving schedule were combined to derive the total distance and duration of transit bus operation in each activity, which are shown in the last row of Table I-6 and Table I-7, respectively.

Table I-6: Distance of Transit Bus Operation in Each Activity

\begin{tabular}{|c|r|r|r|r|r|}
\hline Driving Schedule & Idle & City & Arterial & Highway & Sum \\
\hline Beeline & 0.0 & 0.2 & 6.6 & 0.0 & 6.8 \\
\hline CSHVC & 0.0 & 0.2 & 6.5 & 0.0 & 6.7 \\
\hline Houston & 0.0 & 0.2 & 5.3 & 0.0 & 5.5 \\
\hline KAT & 0.0 & 0.6 & 16.5 & 0.0 & 17.1 \\
\hline KCM & 0.0 & 0.0 & 6.9 & 0.0 & 7.0 \\
\hline Liberty & 0.0 & 0.3 & 6.0 & 0.0 & 6.3 \\
\hline Manhattan & 0.0 & 0.6 & 1.5 & 0.0 & 2.1 \\
\hline NY Bus & 0.0 & 0.3 & 0.4 & 0.0 & 0.6 \\
\hline OCTA & 0.0 & 0.2 & 6.3 & 0.0 & 6.5 \\
\hline SF & 0.0 & 0.8 & 2.9 & 0.0 & 3.6 \\
\hline WMATA & 0.0 & 0.5 & 3.8 & 0.0 & 4.3 \\
\hline Commuter* & 0.0 & 0.0 & 0.0 & 4.3 & 4.3 \\
\hline Sum & 0.0 & 3.9 & 62.6 & 4.3 & 70.9 \\
\hline & & & & &
\end{tabular}

* The mileage traveled during commuter driving schedule was adjusted to obtain the average vehicle operation speed of $12.7 \mathrm{mph}$. 
Table I-7: Duration of Transit Bus Operation in Each Activity

\begin{tabular}{|c|r|r|r|r|r|}
\hline Driving Schedule & \multicolumn{1}{c|}{ Idle } & \multicolumn{1}{c|}{ City } & \multicolumn{1}{c|}{ Arterial } & Highway & \multicolumn{1}{c|}{ Sum } \\
\hline Beeline & 431.0 & 100.0 & $1,171.0$ & 0.0 & $1,702.0$ \\
\hline CSHVC & 397.0 & 137.0 & $1,167.0$ & 0.0 & $1,701.0$ \\
\hline Houston & 710.0 & 160.0 & 931.0 & 0.0 & $1,801.0$ \\
\hline KAT & 735.0 & 320.0 & $2,962.0$ & 0.0 & $4,017.0$ \\
\hline KCM & 323.0 & 19.0 & $1,125.0$ & 0.0 & $1,467.0$ \\
\hline Liberty & 606.0 & 172.0 & $1,105.0$ & 0.0 & $1,883.0$ \\
\hline Manhattan & 394.0 & 280.0 & 416.0 & 0.0 & $1,090.0$ \\
\hline NY Bus & 393.0 & 121.0 & 87.0 & 0.0 & 601.0 \\
\hline OCTA & 407.0 & 118.0 & $1,385.0$ & 0.0 & $1,910.0$ \\
\hline SF & 352.0 & 364.0 & 769.0 & 0.0 & $1,485.0$ \\
\hline WMATA & 706.0 & 328.0 & 806.0 & 0.0 & $1,840.0$ \\
\hline Commuter* & 281.8 & 0.0 & 0.0 & 311.1 & 592.8 \\
\hline Sum & $5,735.8$ & $2,119.0$ & $11,924.0$ & 311.1 & $20,089.8$ \\
\hline
\end{tabular}

* The mileage traveled during commuter driving schedule was adjusted to obtain the average vehicle operation speed of $12.7 \mathrm{mph}$.

Table I-8 shows the distance and duration of transit bus operation in each activity for the 12 driving schedules examined. The average velocities without idle in city, arterial, and highway activities of the 12 driving schedules examined were $6.6,18.9$, and $49.8 \mathrm{mph}$, respectively. The average velocity of these driving schedules without idle was $17.8 \mathrm{mph}$. The average velocity of these driving schedules with idle was $12.7 \mathrm{mph}$, which is consistent with the average velocity of transit bus operation in the US reported in literature [Clark, et al., 2007; APTA, 2013].

Table I-8: Distance and Duration of Transit Bus Operation in Each Activity

\begin{tabular}{|c|c|c|c|c|c|c|}
\hline \multirow{2}{*}{ Activities } & \multirow{2}{*}{ Idle } & City & \multirow{2}{*}{ Arterial } & \multirow{2}{*}{ Highway } & \multicolumn{2}{|c|}{ Sum } \\
\cline { 6 - 7 } & & & & & Without Idle & With Idle \\
\hline Distance (mile) & 0.0 & 3.9 & 62.6 & 4.3 & 70.9 & 70.9 \\
\hline Duration (s) & $5,735.8$ & $2,119.0$ & $11,924.0$ & 311.1 & 14354.1 & $20,089.9$ \\
\hline $\begin{array}{c}\text { Average velocity } \\
\text { mph }\end{array}$ & 0.0 & 6.6 & 18.9 & 49.8 & 17.8 & 12.7 \\
\hline
\end{tabular}

Table I-9 shows the average speed for each activity during each driving schedule. There was a wide range of average speeds for each driving schedule. The overall average speed for all driving schedules tested was $12.7 \mathrm{mph}$. 
Table I-9: Transit Bus Average Speed (mph) for Each Activity

\begin{tabular}{|c|r|r|r|r|r|}
\hline Driving Schedule & Idle & City & Arterial & Highway & Average of Entire Driving Schedule \\
\hline Beeline & 0.0 & 5.4 & 20.4 & N/A & 14.4 \\
\hline CSHVC & 0.0 & 5.3 & 20.0 & N/A & 14.1 \\
\hline Houston & 0.0 & 5.5 & 20.5 & N/A & 11.1 \\
\hline KAT & 0.0 & 6.9 & 20.1 & N/A & 15.4 \\
\hline KCM & 0.0 & 9.0 & 22.2 & N/A & 17.1 \\
\hline Liberty & 0.0 & 7.2 & 19.4 & N/A & 12.0 \\
\hline Manhattan & 0.0 & 7.6 & 12.7 & N/A & 6.8 \\
\hline NY Bus & 0.0 & 7.8 & 14.6 & N/A & 3.7 \\
\hline OCTA & 0.0 & 7.2 & 16.4 & N/A & 12.3 \\
\hline SF & 0.0 & 7.6 & 13.4 & N/A & 8.8 \\
\hline WMATA & 0.0 & 5.4 & 16.9 & N/A & 8.3 \\
\hline Commuter* & 0.0 & N/A & N/A & 50.1 & 26.3 \\
\hline All Driving Schedules & 0.0 & 6.7 & 18.9 & 50.1 & 12.7 \\
\hline
\end{tabular}

* The mileage traveled during commuter driving schedule was adjusted to obtain the average vehicle operation speed of $12.7 \mathrm{mph}$.

Table I-10 and Table I-11 show the percentage of the distance driven and duration, respectively, for each activity during each driving schedule. Most of the microtrips were classified as arterial activity, $88.3 \%$ of total distance and $59.4 \%$ of the total duration.

Table I-10: Percentage of Distance (\%) Driven for Each Activity

\begin{tabular}{|c|c|r|r|r|c|}
\hline Driving Schedule & Idle & \multicolumn{1}{c|}{ City } & Arterial & Highway & Sum \\
\hline Beeline & $0.0 \%$ & $2.2 \%$ & $97.8 \%$ & $0.0 \%$ & $100.0 \%$ \\
\hline CSHVC & $0.0 \%$ & $3.0 \%$ & $97.0 \%$ & $0.0 \%$ & $100.0 \%$ \\
\hline Houston & $0.0 \%$ & $4.4 \%$ & $95.6 \%$ & $0.0 \%$ & $100.0 \%$ \\
\hline KAT & $0.0 \%$ & $3.6 \%$ & $96.4 \%$ & $0.0 \%$ & $100.0 \%$ \\
\hline KCM & $0.0 \%$ & $0.7 \%$ & $99.3 \%$ & $0.0 \%$ & $100.0 \%$ \\
\hline Liberty & $0.0 \%$ & $5.5 \%$ & $94.5 \%$ & $0.0 \%$ & $100.0 \%$ \\
\hline Manhattan & $0.0 \%$ & $28.8 \%$ & $71.2 \%$ & $0.0 \%$ & $100.0 \%$ \\
\hline NY Bus & $0.0 \%$ & $42.5 \%$ & $57.5 \%$ & $0.0 \%$ & $100.0 \%$ \\
\hline OCTA & $0.0 \%$ & $3.6 \%$ & $96.4 \%$ & $0.0 \%$ & $100.0 \%$ \\
\hline SF & $0.0 \%$ & $21.2 \%$ & $78.8 \%$ & $0.0 \%$ & $100.0 \%$ \\
\hline WMATA & $0.0 \%$ & $11.4 \%$ & $88.6 \%$ & $0.0 \%$ & $100.0 \%$ \\
\hline Commuter* & $0.0 \%$ & $0.0 \%$ & $0.0 \%$ & $100.0 \%$ & $100.0 \%$ \\
\hline All Driving Schedules & $0.0 \%$ & $5.6 \%$ & $88.3 \%$ & $6.1 \%$ & $100.0 \%$ \\
\hline
\end{tabular}

* The mileage traveled during commuter driving schedule was adjusted to obtain the average vehicle operation speed of 12.7 mph. 
Table I-11: Percentage of Duration (\%) for Each Activity

\begin{tabular}{|c|c|r|r|r|c|}
\hline Driving Schedule & Idle & \multicolumn{1}{c|}{ City } & Arterial & Highway & Sum \\
\hline Beeline & $25.3 \%$ & $5.9 \%$ & $68.8 \%$ & $0.0 \%$ & $100.0 \%$ \\
\hline CSHVC & $23.3 \%$ & $8.1 \%$ & $68.6 \%$ & $0.0 \%$ & $100.0 \%$ \\
\hline Houston & $39.4 \%$ & $8.9 \%$ & $51.7 \%$ & $0.0 \%$ & $100.0 \%$ \\
\hline KAT & $18.3 \%$ & $8.0 \%$ & $73.7 \%$ & $0.0 \%$ & $100.0 \%$ \\
\hline KCM & $22.0 \%$ & $1.3 \%$ & $76.7 \%$ & $0.0 \%$ & $100.0 \%$ \\
\hline Liberty & $32.2 \%$ & $9.1 \%$ & $58.7 \%$ & $0.0 \%$ & $100.0 \%$ \\
\hline Manhattan & $36.1 \%$ & $25.7 \%$ & $38.2 \%$ & $0.0 \%$ & $100.0 \%$ \\
\hline NY Bus & $65.4 \%$ & $20.1 \%$ & $14.5 \%$ & $0.0 \%$ & $100.0 \%$ \\
\hline OCTA & $21.3 \%$ & $6.2 \%$ & $72.5 \%$ & $0.0 \%$ & $100.0 \%$ \\
\hline SF & $23.7 \%$ & $24.5 \%$ & $51.8 \%$ & $0.0 \%$ & $100.0 \%$ \\
\hline WMATA & $38.4 \%$ & $17.8 \%$ & $43.8 \%$ & $0.0 \%$ & $100.0 \%$ \\
\hline Commuter* & $47.5 \%$ & $0.0 \%$ & $0.0 \%$ & $52.5 \%$ & $100.0 \%$ \\
\hline All Driving Schedules & $28.6 \%$ & $10.5 \%$ & $59.4 \%$ & $1.5 \%$ & $100.0 \%$ \\
\hline
\end{tabular}

* The mileage traveled during commuter driving schedule was adjusted to obtain the average vehicle operation speed of $12.7 \mathrm{mph}$.

Table I-12 shows the percentage of transit bus operational distance and duration for all driving schedules examined. The distance operated during city, arterial, and highway activities were $5.6 \%, 88.3 \%$, and $6.1 \%$ of the total distance for transit bus operation, respectively. The transit bus spent $28.6 \%$ of the total operational time during the idle activity.

Table I-12: Percentage of Distance and Duration of Transit Bus Operation in Each Activity

\begin{tabular}{|c|r|r|r|r|c|}
\hline Activities & \multicolumn{1}{|c|}{ Idle } & \multicolumn{1}{c|}{ City } & Arterial & Highway & \multicolumn{1}{c|}{ Sum } \\
\hline \% of distance & $0.0 \%$ & $5.6 \%$ & $88.3 \%$ & $6.1 \%$ & $100.0 \%$ \\
\hline$\%$ of duration & $28.6 \%$ & $10.5 \%$ & $59.4 \%$ & $1.5 \%$ & $100.0 \%$ \\
\hline
\end{tabular}




\section{Appendix J OTR Tractor Activity Distance and Duration}

West Virginia University reviewed the operational characteristic data of heavy-duty OTR tractor and processed the data to obtain the fraction of vehicle mileage traveled (VMT) in each velocity bin. For example, Boriboonsomsin et al. [2011] conducted a detailed examination of heavy-duty vehicle operation characteristics and exhaust emissions measured during different driving schedules. The operation characteristics of heavy-duty OTR tractors operating on both restricted roads and unrestricted roads in urban and rural areas were examined through data logging of engine ECU. The data (over 15 million miles) obtained were processed and reported as AvgSpeedDistribution, defined as the fraction of driving time for each source type, road type, day, and hour in each average speed bin. There were 16 speed bins in MOVES, with the average speed values of 2.5 (speed $<2.5 \mathrm{mph}), 5(2.5 \mathrm{mph}<=$ speed $<7.5 \mathrm{mph}), 10(7.5 \mathrm{mph}<=$ speed $<12.5$ $\mathrm{mph}), \ldots, 70$ (67.5 $\mathrm{mph}<=$ speed $<72.5 \mathrm{mph})$, and 75 (72.5 mph $<=$ speed) [U.S. EPA, 2010]. WVU researchers further processed the data reported by Boriboonsomsin et al. [2011] to obtain the fraction of VMT in each speed bin and the accumulated fraction of VMT. Figure J-1 shows the variation in the fraction of VMT for each speed bin and the accumulated fraction. WVU will process all data reported in this document further and obtain the operational characteristic data of vehicles for urban and rural areas, including restricted and unrestricted roads. Data were developed by processing data reported in Figure 4-8 and Figure 4-11 in Boriboonsomsin et al. [2011].

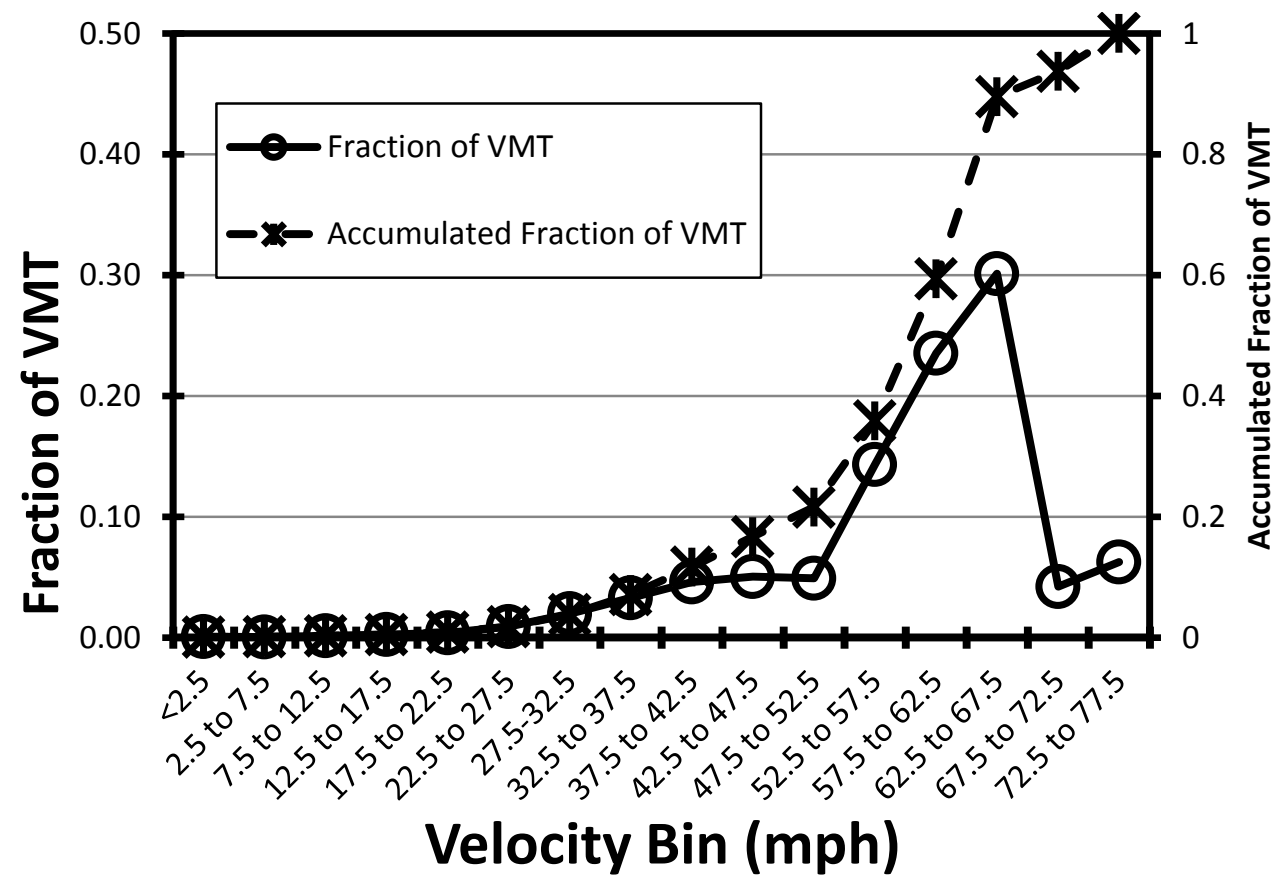

Figure J-1: VMT and Accumulated Fraction of VMT for Heavy-duty OTR Tractors Operated on Urban Restricted Roads. [Boriboonsomsin et al., 2011]

Capps et al. of Oak Ridge National Laboratory explored the operation characteristics of heavyduty OTR tractors in a DOE funded project. The objective of the project was to collect, analyze, 
and archive data and information related to Class-8 heavy-duty OTR tractor operation in realworld highway environments [Capps, et al., 2008]. The vehicle operation data were reported as AvgSpeedDistribution in 16 speed bins (speed $<5 \mathrm{mph}, 5 \sim 10 \mathrm{mph}, \ldots \ldots ., 75$ to $85 \mathrm{mph}$ ). The data reported in this document were further processed to obtain the fraction of VMT and accumulated fraction of VMT in each speed bin (shown in Figure J-2). The data were derived from 637,557 miles of data recorded.

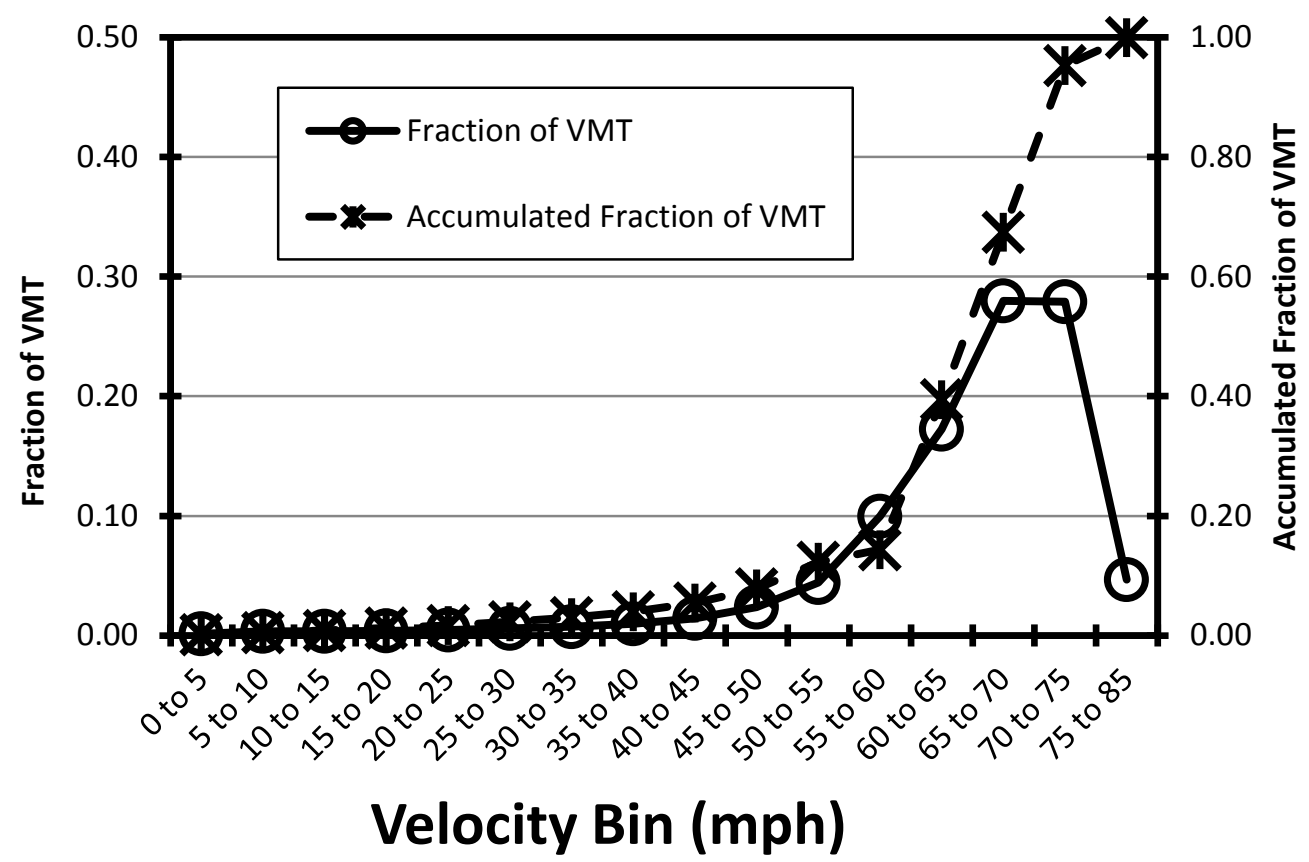

Figure J-2: Fraction of VMT and Accumulated Fraction of VMT of Heavy-duty OTR Tractor Operation.

[Table 24, page 97, Capps, et al., 2008]

Table J-1 compares the vehicle operation data derived from data reported by $\mathrm{U}$ of California and ORNL for long haul heavy-duty OTR tractors. It was evident that the data represents the highway operation of heavy-duty OTR tractors. The total distance for each activity was used as inputs in the estimation model.

Table J-1: Fraction of VMT and Total Annual Distance of Long Haul Heavy-duty OTR Tractors

\begin{tabular}{|c|r|r|r|r|}
\hline & ORNL [Capps et al., 2008] & U of California [Boriboonsomsin et al., 2011] & Average & \multicolumn{1}{c|}{ Miles } \\
\hline Activity & N.A. & Urban and Rural Restricted & N.A. & N.A. \\
\hline Idle & $0.00 \%$ & $0.00 \%$ & $0.00 \%$ & 0 \\
\hline City & $0.49 \%$ & $0.21 \%$ & $0.35 \%$ & 350 \\
\hline Arterial & $3.50 \%$ & $9.06 \%$ & $6.28 \%$ & 6,280 \\
\hline Highway & $96.00 \%$ & $90.74 \%$ & $93.37 \%$ & 93,370 \\
\hline
\end{tabular}

Huai, et al., examined the operation activity characteristics of HD OTR tractors through the analysis of 270 ECM data sets obtained from the California Air Resources Board (CARB). Table J-2 shows the distribution of operation time of HD OTR tractors operated at idle, creep (0 10 $\mathrm{mph}$ ), transient (11 45 $\mathrm{mph}$ ), and cruise (over $45 \mathrm{mph}$ ) for long haul and medium haul operation, 
respectively. With the assumed average velocity in each mode as shown in Table J-3, the distribution of operation time can be processed to derive the fraction of VMT in each speed mode. As shown in Table J-3, the operation of HD OTR tractors was dominated by cruise operation. The fraction of VMT at long-haul and medium haul operation was 0.938 and 0.884 , respectively. It was evident that the operation of long haul operation was dominated by highway operation. The speed bins were slightly different. However the data were consistent with the data shown in Table $\mathrm{J}-1$ and used to help validate the input data.

Table J-2: Time Fraction of Heavy-duty OTR Tractor Operation for Each Speed Bin [Huai et al., 2006]

\begin{tabular}{|c|l|r|}
\hline & Long haul & \\
\hline Idle & 0.395 & 0.395 \\
\hline $0 \sim 10 \mathrm{mph}$ (Creep) & 0.033 & 0.278 \\
\hline $11-45 \mathrm{mph}$ (Transient) & 0.076 & 0.041 \\
\hline Over 45 mph (Cruise) & 0.496 & 0.286 \\
\hline
\end{tabular}

Table J-3: Fraction of VMT of Heavy-duty OTR Tractor Operation for Each Speed Bin [Huai et al., 2006]

\begin{tabular}{|c|c|c|c|}
\hline \multirow{2}{*}{ Activity } & \multirow{2}{*}{$\begin{array}{l}\text { Average velocity } \\
\text { assumed, (mph) }\end{array}$} & \multicolumn{2}{|c|}{ Fraction of VMT Estimated } \\
\hline & & Long haul & Medium haul \\
\hline Idle & 0 & 0 & 0 \\
\hline 0 10 mph (Creep) & 5 & 0.004 & 0.062 \\
\hline 11-45 mph (Transient) & 28 & 0.057 & 0.051 \\
\hline Over 45 mph (Cruise) & 70 & 0.938 & 0.888 \\
\hline
\end{tabular}

A study by Wagner [2007] showed idle percentages from long haul heavy-duty OTR tractors with various heating and cooling systems. The idle time of the control vehicles were used, as the vehicles with the cooling and heating systems installed were reported to be cost inefficient and not likely to be an accurate representation of standard long haul heavy-duty OTR tractors. Table J-4 shows the percentage of idle time and the total hours of idle for long haul heavy-duty OTR tractors used as an input in the estimation model.

Table J-4: Percentage of Idle and Total Idle Time for Long Haul heavy-Duty OTR Tractors [Wagner, 2007]

\begin{tabular}{|c|c|c|}
\hline System & $\begin{array}{c}\text { Percent } \\
\text { Idle }\end{array}$ & $\begin{array}{c}\text { Hours } \\
\text { Idle* }\end{array}$ \\
\hline Webasto cab heater & $27.0 \%$ & 2.16 \\
\hline Webasto Parking Cooler & $23.0 \%$ & 1.84 \\
\hline Bergstrom Nite System & $16.0 \%$ & 1.28 \\
\hline Caterpillar MorElectric & $27.0 \%$ & 2.16 \\
\hline Average & $\mathbf{2 3 . 3 \%}$ & $\mathbf{1 . 8 6}$ \\
\hline
\end{tabular}

* The total hours were based on an 8 hour work day

Table J-5 shows the operation data derived from data reported by ORNL for short haul heavyduty OTR tractors. The distances were used as inputs in the estimation model. A study by Ostria [1996] shows that intercity heavy-duty delivery tractors had 36 percent idle operation. 
Table J-5: Fraction of VMT and Total Annual Distance of Short Haul Heavy-duty OTR Tractors [Boriboonsomsin et al., 2011]

\begin{tabular}{|c|r|r|}
\hline Activity & Percent Miles (\%) & Distance Traveled (mi) \\
\hline Idle & $0.00 \%$ & 0 \\
\hline City & $1.45 \%$ & 725 \\
\hline Arterial & $37.89 \%$ & 18,945 \\
\hline Highway & $60.66 \%$ & 30,330 \\
\hline
\end{tabular}

Table J-6 shows the percentage of time during idle and the percentage of miles during all activities for long haul and short haul OTR tractors. The long haul tractors, which have mostly highway travel, have higher average speeds than the short haul OTR tractors, which operate more in urban areas. Though the long haul tractors operate mostly within the highway activity, there was significant percentage of idle due to sleeper cab representation.

Table J-6: Percentage of Time During Idle and Percentage of Miles During All Activities for Long Haul and Short Haul OTR Tractors

\begin{tabular}{|c|c|c|c|r|r|}
\hline \multirow{2}{*}{ Vehicle Type } & Time Percentage & \multicolumn{4}{|c|}{ Distance Percentage } \\
\cline { 2 - 6 } & Idle & Idle & City & Arterial & Highway \\
\hline Long Haul & $23.30 \%$ & $0.00 \%$ & $0.35 \%$ & $6.28 \%$ & $93.37 \%$ \\
\hline Short Haul & $36.00 \%$ & $0.00 \%$ & $1.45 \%$ & $37.89 \%$ & $60.66 \%$ \\
\hline
\end{tabular}




\section{Appendix K Population Scenarios}

The number of natural gas vehicles is expected to continue to grow in the future. Table K-1 shows the current vehicle population by two different research companies. Both companies show similar results for the total vehicle population. There were about 130,000-135,000 natural gas vehicles in the U.S. estimated for today (ANGA a, 2012; ANGA b, 2012; NGV America a, 2013).

Table K-1: Current U.S. Natural Gas Vehicle Population

\begin{tabular}{|c|c|c|c|}
\hline ID & Total & Research Company & Report Year \\
\hline ANGA Low & 100,118 & \multirow{2}{*}{$\begin{array}{c}\text { America's Natural } \\
\text { Gas Alliance (a) }\end{array}$} & \multirow{2}{*}{2012} \\
\hline ANGA High & 154,466 & & \\
\hline ANGA Average & 130,000 & $\begin{array}{c}\text { America's Natural } \\
\text { Gas Alliance (b) }\end{array}$ & 2012 \\
\hline NGV America & 135,000 & $\begin{array}{l}\text { Natural Gas Vehicles } \\
\text { for America }\end{array}$ & 2013 \\
\hline
\end{tabular}

Table K-2 shows the current population for heavy-duty natural gas vehicles in the U.S. OTR tractors were the dominant vehicle in the other heavy-duty truck row. A high percentage of the estimated natural gas vehicle population was transit buses.

Table K-2: Current U.S. Heavy-duty Natural Gas Vehicle Population [ANGA a, 2012]

\begin{tabular}{|l|r|r|r|r|r|r|r|r|}
\hline \multicolumn{7}{|c|}{ On-Road Heavy-Duty Applications (>14,000 Ibs GVR) } \\
\hline & \multicolumn{2}{|c|}{ U.S. NGV Population } & \multicolumn{2}{|c|}{$\begin{array}{l}\text { U.S. Market } \\
\text { Penetration } \\
\text { (By Vehicle Count) }\end{array}$} & \multicolumn{2}{|c|}{$\begin{array}{c}\text { U.S. Annual NGV } \\
\text { Fuel Use } \\
\text { (Thousand DGE) }\end{array}$} & \multicolumn{3}{c|}{$\begin{array}{c}\text { U.S. Market } \\
\text { Penetration } \\
\text { (By Fuel Use) }\end{array}$} \\
\hline & Low & High & Low & High & Low & High & Low & High \\
\hline Transit Bus & 8500 & 12320 & $13.0 \%$ & $18.0 \%$ & 149200 & 151365 & $22.0 \%$ & $23.0 \%$ \\
\hline Refuse Truck & 1300 & 1500 & $1.4 \%$ & $1.6 \%$ & 12856 & 14833 & $1.4 \%$ & $1.6 \%$ \\
\hline School Bus & 1360 & 2300 & $0.3 \%$ & $0.5 \%$ & 1696 & 2827 & $0.3 \%$ & $0.5 \%$ \\
\hline Other Heavy-duty Truck & 9818 & 14778 & $0.2 \%$ & $0.3 \%$ & 161833 & 161838 & $0.4 \%$ & $0.4 \%$ \\
\hline Total & 20978 & 30898 & $0.2 \%$ & $0.3 \%$ & 325585 & 330863 & $0.7 \%$ & $25.5 \%$ \\
\hline
\end{tabular}

The objective of the model is to predict the emissions in the future. Table K-3 shows the estimated vehicle population forecasts. The research companies gave forecasts in different ways depending on the market the company were serving. Projections were given in terms of total vehicles (light-, medium-, and heavy-duty), number or percent of sales for a given year, or total fuel consumed (ANGA a, 2012; ANGA b, 2012; Gallagher 2013, EIA 2013, NYT 2013, Navigant Research 2013). 
Table K-3: U.S. Natural Gas Vehicle Future Projections

\begin{tabular}{|c|c|c|c|c|c|c|c|}
\hline ID & $\begin{array}{l}\text { Prediction } \\
\text { Year }\end{array}$ & $\begin{array}{l}\text { Total NG } \\
\text { Vehicles }\end{array}$ & $\begin{array}{l}\text { Total } \\
\text { Sales }\end{array}$ & $\begin{array}{l}\text { Total NG Fuel } \\
\text { Consumption }\end{array}$ & $\begin{array}{l}\text { Research } \\
\text { Company }\end{array}$ & Report Title & $\begin{array}{l}\text { Report } \\
\text { Year }\end{array}$ \\
\hline ANGA & 2035 & $16,000,000$ & N/A & $\begin{array}{l}2.2 \text { TCF or } 17 \\
\text { billion DGE }\end{array}$ & $\begin{array}{l}\text { America's } \\
\text { Natural Gas } \\
\text { Alliance }\end{array}$ & $\begin{array}{l}\text { U.S. and Canadian Natural Gas Vehicle } \\
\text { Market Analysis: Natural Gas Vehicle } \\
\text { Industry Overview }\end{array}$ & 2012 \\
\hline ANGA & 2035 & N/A & N/A & $\begin{array}{l}3.9 \text { billion DGE } \\
\text { heavy-duty }\end{array}$ & $\begin{array}{l}\text { America's } \\
\text { Natural Gas } \\
\text { Alliance }\end{array}$ & $\begin{array}{l}\text { U.S. and Canadian Natural Gas Vehicle } \\
\text { Market Analysis: Natural Gas Vehicle } \\
\text { Industry Overview }\end{array}$ & 2012 \\
\hline ACTP & 2030 & N/A & $\begin{array}{l}50 \% \\
\text { heavy- } \\
\text { duty }\end{array}$ & N/A & ACT Research & $\begin{array}{l}\text { U.S. Class } 8 \text { Truck Transportation \& } \\
\text { Natural Gas: Evolution, Revolution or } \\
\text { Bust? }\end{array}$ & 2013 \\
\hline ACTR & 2030 & $\begin{array}{l}1,284,000 \\
\text { heavy-duty }\end{array}$ & $\begin{array}{c}51 \% \\
\text { heavy- } \\
\text { duty }\end{array}$ & N/A & ACT Research & $\begin{array}{l}\text { The Future of Natural Gas Engines in } \\
\text { Heavy Duty Trucks: The Diesel of } \\
\text { Tomorrow? }\end{array}$ & 2013 \\
\hline NPC & 2050 & N/A & $42 \%$ & N/A & $\begin{array}{l}\text { National } \\
\text { Petroleum } \\
\text { Council } \\
\end{array}$ & $\begin{array}{l}\text { The Future of Natural Gas as a } \\
\text { Transportation Fuel - Findings of the NPC } \\
\text { Study }\end{array}$ & 2013 \\
\hline EIA & 2040 & $\mathrm{~N} / \mathrm{A}$ & N/A & $\begin{array}{c}1.03 \\
\text { quadrillion } \\
\text { Btu heavy- } \\
\text { duty }\end{array}$ & $\begin{array}{l}\text { U.S. Energy } \\
\text { Information } \\
\text { Administration }\end{array}$ & Annual Energy Outlook 2013 & 2013 \\
\hline NYTE & 2035 & N/A & $\begin{array}{l}275,000 \\
\text { or } 34 \%\end{array}$ & N/A & $\begin{array}{l}\text { New York } \\
\text { Times (EIA) }\end{array}$ & $\begin{array}{l}\text { Trucking Industry Is Set to Expand Its Use } \\
\text { of Natural Gas }\end{array}$ & 2013 \\
\hline NYTC & 2020 & $\begin{array}{l}30 \% \text { of heavy- } \\
\text { duty trucks }\end{array}$ & N/A & N/A & $\begin{array}{l}\text { New York } \\
\text { Times } \\
\text { (Citigroup) }\end{array}$ & $\begin{array}{l}\text { Trucking Industry Is Set to Expand Its Use } \\
\text { of Natural Gas }\end{array}$ & 2013 \\
\hline NR & 2020 & $35,000,000$ & N/A & $\mathrm{N} / \mathrm{A}$ & $\begin{array}{l}\text { Navigant } \\
\text { Research }\end{array}$ & $\begin{array}{l}\text { Global Natural Gas Vehicle Sales and } \\
\text { Refueling Infrastructure Forecasts: } 2013- \\
2020\end{array}$ & 2013 \\
\hline
\end{tabular}

The heavy-duty vehicle projections were analyzed in more detail for the scenarios. The EIA prediction is shown in Figure K-1. The consumption of natural gas for the heavy-duty transportation sector is expected to increase in the future. This correlates to the number of vehicles. The projected increase was roughly fivefold between 2030 and 2040.

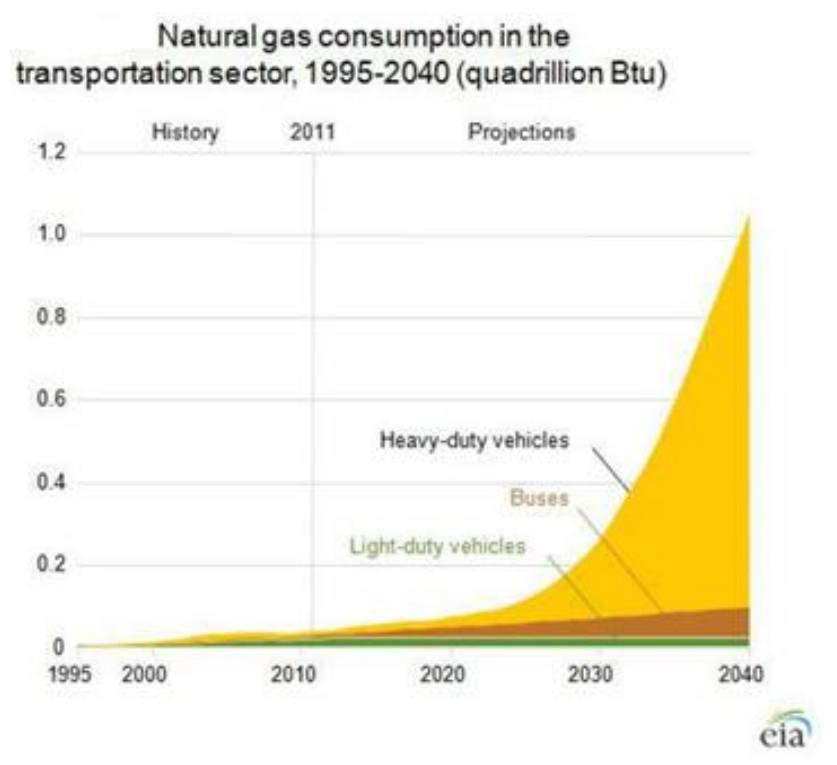

Figure K-1: EIA Natural Gas Vehicle Projection [EIA, 2013] 
The EIA data for 2030 and 2040 is shown in Table K-4. Heavy-duty vehicles consume $22.5 \%$ of all natural gas in the transportation sector in 2030. As stated previously, the total number of vehicles was projected to be about 25 million. If $22.5 \%$ of those vehicles were heavy-duty vehicles, there were about 5,617,557 heavy-duty vehicles projected by the EIA for the year 2030 . Heavy-duty vehicles were projected to consume $97.9 \%$ of all natural gas in the transportation sector in 2040. If $97.9 \%$ of those vehicles were heavy-duty vehicles, there were about $24,475,000$ heavy-duty vehicles projected by the EIA for the year 2040. The number of vehicles is based on current average DGE fuel economy and VMT from multiple literature sources (EIA, 2013; Caterpillar, 2006; Chesapeake Energy, n.d.; de la Houssaye \& White, n.d.; FairTran, 2010; Fisk, 2013; Gaines et al, 2006; Gordon et al, 2003; Greyhound, n.d.; Laver et al, 2007; NRCRA, 2010; EPA MOVES, 2010; William, 2012).

Table K-4: EIA Natural Gas Consumption Projection for 2030 and 2040 in the Transportation Sector

\begin{tabular}{|c|r|r|r|r|}
\hline \multicolumn{6}{|c|}{ Natural gas consumption in the transportation sector (quadrillion Btu) } \\
\hline & Light-duty Vehicles & Buses & $\begin{array}{c}\text { Heavy-duty Vehicles } \\
\text { (less buses) }\end{array}$ & $\begin{array}{c}\text { Total Heavy-duty } \\
\text { Vehicles }\end{array}$ \\
\hline 2030 Projection $\left(10^{15} \mathrm{Btu}\right)$ & 0.023 & 0.050 & 0.187 & 0.237 \\
\hline Percent of Total Market $(\%)$ & $2.2 \%$ & $4.7 \%$ & $17.7 \%$ & $22.5 \%$ \\
\hline 2040 Projection $\left(10^{15} \mathrm{Btu}\right)$ & 0.023 & 0.077 & 0.954 & 1.031 \\
\hline Percent of Total Market $(\%)$ & $2.1 \%$ & $7.3 \%$ & $90.5 \%$ & $97.9 \%$ \\
\hline
\end{tabular}

ACT Research projects a significantly different amount of vehicles. ACT Research's projections are shown in Figure K-2. 1,461,000 vehicles were projected to be produced from 2013 to 2030. Due to wear, only 1,284,000 heavy-duty vehicles should remain in 2030 (ACT, 2012).

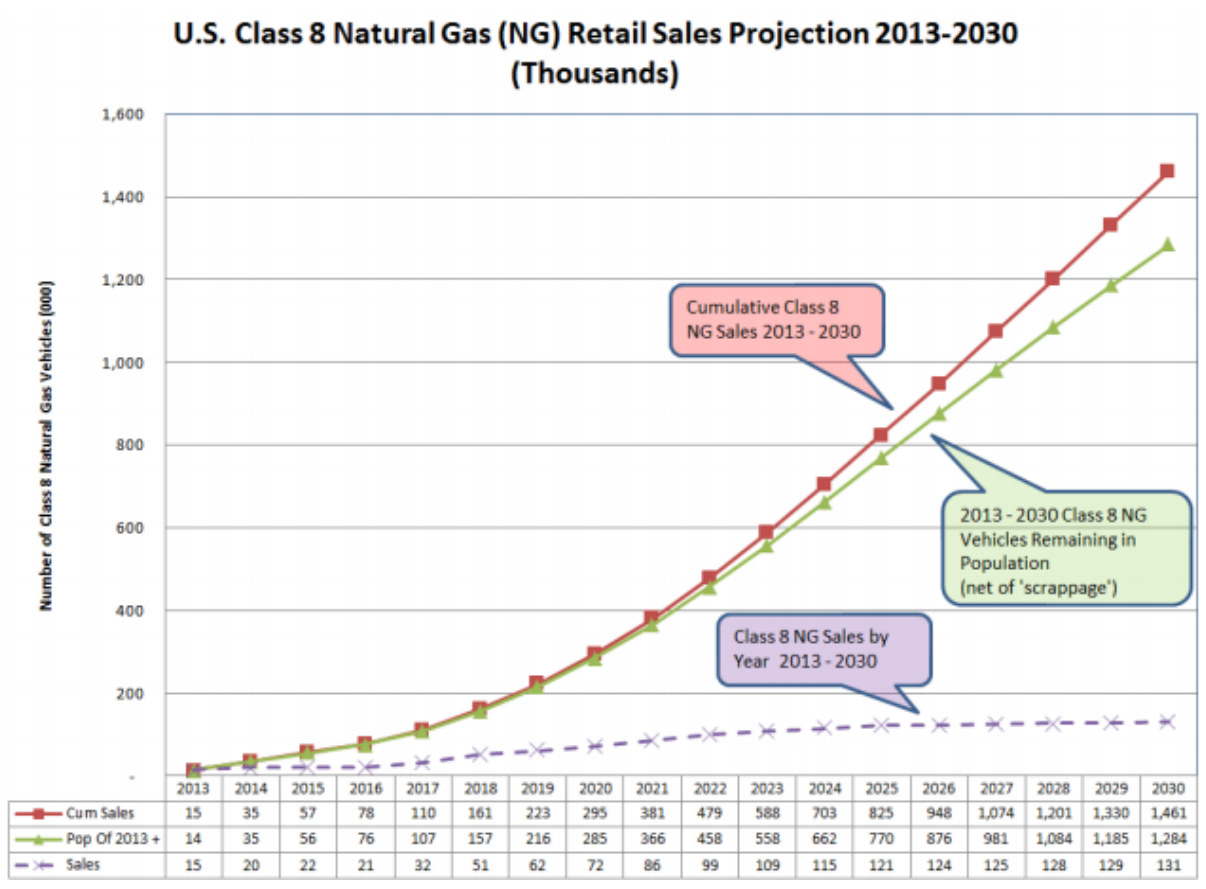

Figure K-2: ACT Research Vehicle Projection Until 2030 [ACT, 2013] 
The following sources of the data were used for the HD natural vehicle scenario:

- U.S. Energy Information Administration (EIA).

- The total BTUs of NG to be consumed by heavy-duty vehicles from current to 2040 (no need for the data to be extrapolated)

- Fuel consumption data of HD natural gas vehicles were based on test data from this research

- National Petroleum Council (NPC)

○ Market share of heavy-duty vehicles from current to 2040 (no need for the data to be extrapolated) (See Figure K-3)

- NPC projected HD NGV market share at reference case assuming the energy policy, ratio of oil price and natural gas price in the future will be comparable to the current one.

- The low penetration case was developed with the assumed low oil price;

○ The high penetration case was developed with the assumed high oil price;

- Americas Commercial Transportation (ACT) Research Co.

- HD natural gas vehicles to be sold each year from current to 2030

○ Data from 2030 to 2035 were calculated by the estimated market share, based on data up to 2030 .

○ Based on the assumption of an 10 year service life

- American Clean Skies Foundation (ACSF)

- Market share of heavy-duty vehicles from current to 2025

- Data from 2025 to 2035 were calculated by the estimated market share from the ACFS data up to 2025. Details about the market share can be found in Figure $\mathrm{K}-4$.

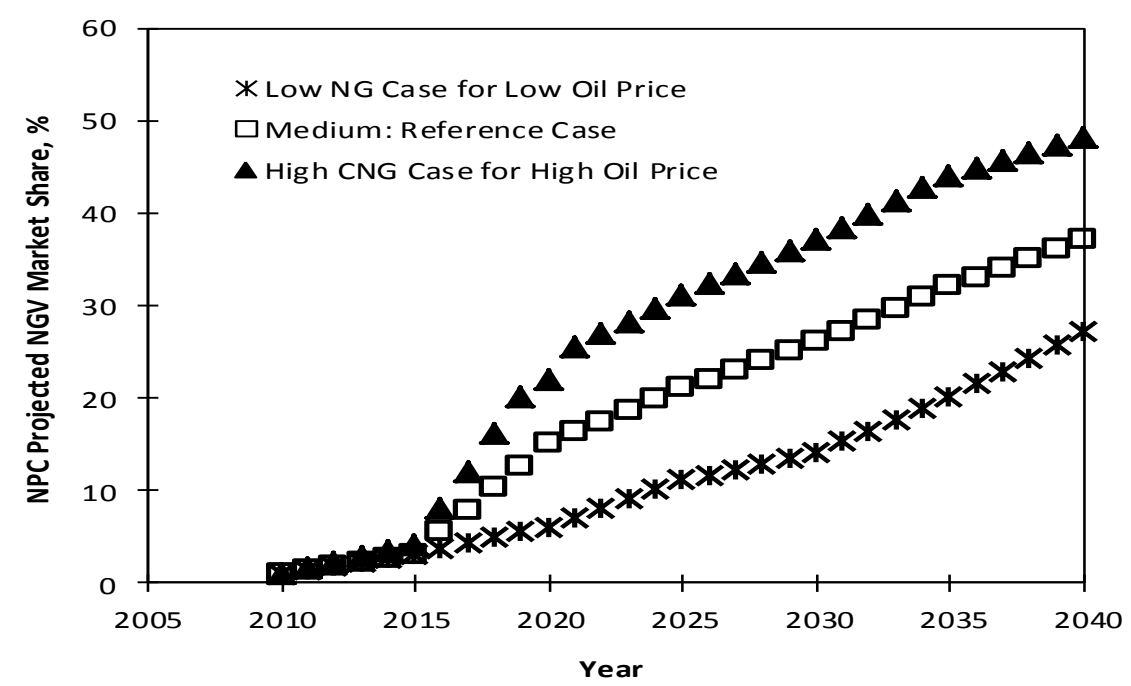

Figure K-3: NPC Projected HD NGV Market Share for Low, Medium (Reference Case), and high Penetration [NPC, 2012] 
Figure K-4 compares the estimated market share of HD NG vehicles for data reported by ACT, ACSF, and NPC (reference case). The market share projected by ACT is the most aggressive one, followed by ACSF, and NPC.

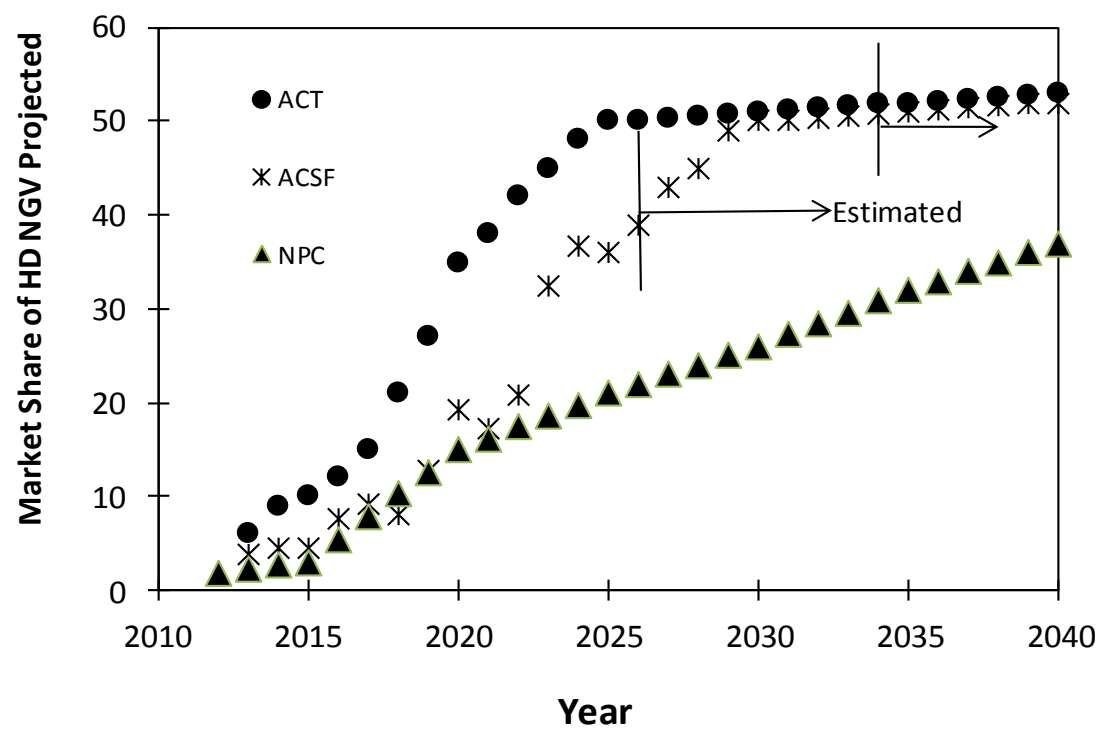

Figure K-4: Market Share of HD Natural Gas Vehicles Projected by ACT, ACFS, and NPC (reference case) [ACT 2012, ACSF 2013, and NPC 2012]

Figure K-5 compares the market share of HD Natural Gas Vehicles Projected by ACT [2012], ACFS [2013], and NPC [2012] including low, reference case, and high market share. The high penetration projected by NPC is lower than that projected by ACSF and ACT.

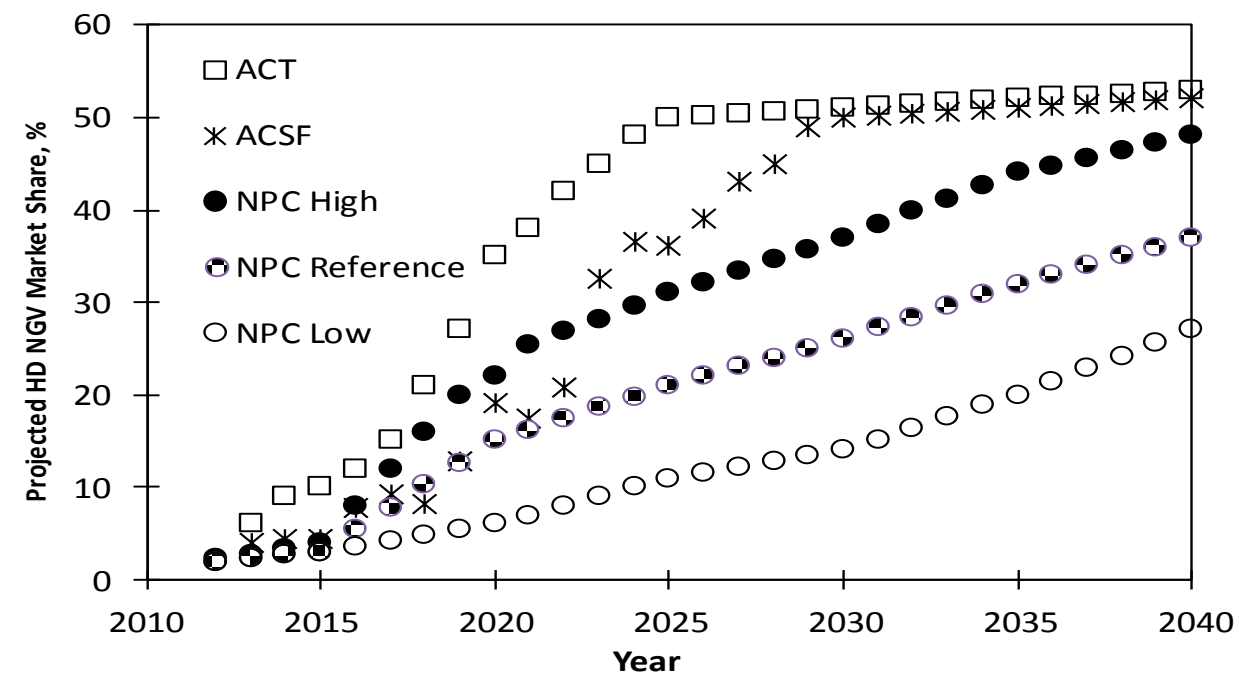

Figure K-5: Market Share of HD Natural Gas Vehicles Projected by ACT, ACFS, and NPC (reference case) [ACT 2012, ACSF 2013, and NPC 2012]

The HD natural gas vehicle population estimated was further processed to develop a low, medium, and high penetration scenario. The low penetration scenario was developed by 
averaging the data reported by EIA and NPC. The medium penetration scenario was developed by averaging the data reported by all four sources. The high penetration scenario was developed by averaging the data reported by ACT and ACFS. Figure K-7 shows the projected low, medium, and high scenario of HD NG vehicles estimated with data shown in Figure K-6. Based on the data shown in Figure K-6, the estimated HD NG vehicle populations for low, medium, and high scenarios are 542.2 thousand, 908.7 thousand, and 1,275.3 thousand, respectively. The percentage of HD NG vehicles relative to the total HD vehicle population was calculated based on a total HD vehicle population of 2.5 million. The projected population of HD natural gas vehicles was $21.69 \%, 36.35 \%$, and $51.01 \%$ of the total population of heavy-duty vehicles $(2.5$ million).

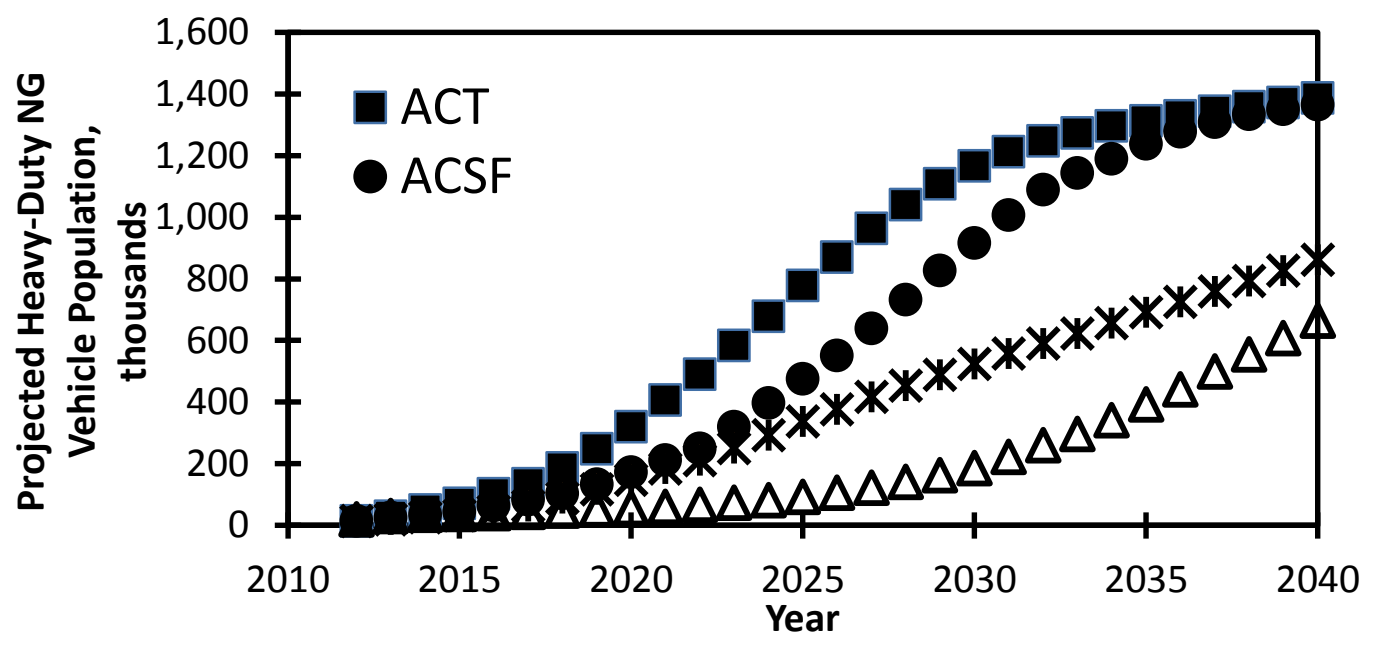

Figure K-6: Comparison of the Populations of Heavy-duty NG Vehicles Projected by EIA, NPC, ACSF, and ACT. [EIA, 2013, ACT 2012, ACSF 2013, and NPC 2012]

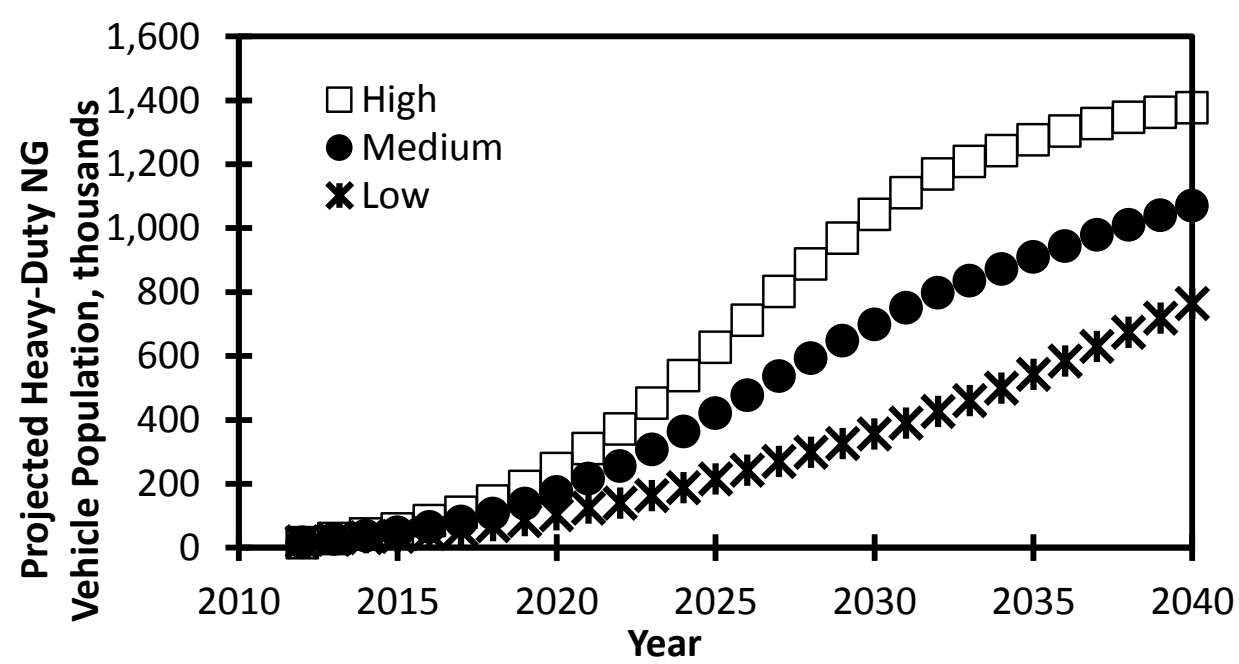

Figure K-7: The Projected Low, Medium, and High Penetration Scenario

Low, medium, and high population scenarios for the U.S. HD NG vehicle sector in 2035 developed from literature data are shown in Table K-5. The population of OTR tractors was 
calculated by subtracting the population of NG refuse trucks and transit buses from the projected population of total heavy-duty NG vehicles.

Table K-5: The Scenarios for USA Heavy-duty NG Vehicle Sector in 2035

\begin{tabular}{|c|c|c|c|c|c|}
\hline & Vehicle Type & $\begin{array}{l}\text { Refuse Truck } \\
\text { (CNG only) }\end{array}$ & $\begin{array}{l}\text { Transit Bus } \\
\text { (CNG only) }\end{array}$ & $\begin{array}{l}\text { OTR Tractor* } \\
\text { (CNG/LNG) }\end{array}$ & Total* \\
\hline \multicolumn{2}{|c|}{$\begin{array}{l}\text { Projected population of each type } \\
\text { of vehicle (includes all fuel types) }\end{array}$} & 160,000 & 70,000 & $2,270,000$ & $2,500,000$ \\
\hline \multirow{2}{*}{ Low } & $\begin{array}{l}\% \text { of population of } \\
\text { each type of vehicle }\end{array}$ & $50.00 \%$ & $30.00 \%$ & $19.44 \%$ & $21.69 \%$ \\
\hline & $\begin{array}{l}\text { Projected population of } \\
\text { each type of NG vehicle }\end{array}$ & 80,000 & 21,000 & 441,200 & 542,200 \\
\hline \multirow{2}{*}{ Medium } & $\begin{array}{l}\% \text { of population of } \\
\text { each type of vehicle }\end{array}$ & $65.00 \%$ & $45.00 \%$ & $34.06 \%$ & $36.35 \%$ \\
\hline & $\begin{array}{l}\text { Projected population of } \\
\text { each type NG vehicle }\end{array}$ & 104,000 & 31,500 & 773,200 & 908,700 \\
\hline \multirow{2}{*}{ High } & $\begin{array}{l}\% \text { of population of } \\
\text { each type of vehicle }\end{array}$ & $80.00 \%$ & $60.00 \%$ & $48.69 \%$ & $51.01 \%$ \\
\hline & $\begin{array}{l}\text { Projected population of } \\
\text { each type NG vehicle }\end{array}$ & 128,000 & 42,000 & $1,105,300$ & $1,275,300$ \\
\hline
\end{tabular}

* The percentage of NG vehicles was calculated with the assumed HD vehicle population of $2,500,000$ excluding school buses $(500,000)$

\section{Future Scenario Assumptions}

1. All transit buses will be powered by CNG ISL G engines or similar engine technologies.

2. All refuse trucks will be powered by CNG ISL $\mathrm{G}$ engines or similar engine technologies.

3. The ratio of long haul (regional and interstate) and short haul (local regional) OTR tractors is 1:1. This is supported by the latest EPA MOVES vehicle population data for short-haul (963 thousands) and long haul (1,028 thousands) combination trucks [Eilbert, 2013].

4. $40 \%$ of short-haul trucks will be powered by LNG ISL G engines or similar engine technologies and $60 \%$ will be powered by CNG ISL G engines or similar engine technologies.

5. $50 \%$ of long-haul trucks will be powered by LNG HPDI (2.0), $25 \%$ by CNG ISX G or similar engine technologies, and $25 \%$ by LNG ISX G engines or similar engine technologies, for the medium HPDI penetration scenario (control case).

Table K-6 shows the projected scenarios of the HD OTR tractors in 2035. 
Table K-6: The Scenarios for USA HD OTR Tractors in 2035

\begin{tabular}{|c|c|c|c|c|c|c|}
\hline Vehicle Category & \multicolumn{2}{|c|}{ Short Haul ( $\leq 320$ hp) } & \multicolumn{3}{|c|}{ Long Haul (>320 hp) } & Total \\
\hline Population Fraction of HD NG OTR Market & \multicolumn{2}{|c|}{$50 \%$} & \multicolumn{3}{|c|}{$50 \%$} & $100 \%$ \\
\hline HD NG Engine Technology & SI & SI & SI & HPDI & SI & \\
\hline Fuel Type & $\mathrm{CNG}$ & LNG & $\mathrm{CNG}$ & LNG & LNG & \\
\hline Population Fraction of Vehicle Category & $60 \%$ & $40 \%$ & $25 \%$ & $50 \%$ & $25 \%$ & \\
\hline Population Fraction of Total OTR Tractors & $30 \%$ & $20 \%$ & $12.5 \%$ & $25 \%$ & $12.5 \%$ & $100 \%$ \\
\hline Low & 132,360 & 88,240 & 55,150 & 110,300 & 55,150 & 441,200 \\
\hline Medium & 231,960 & 154,640 & 96,650 & 193,300 & 96,650 & 773,200 \\
\hline High & 331,590 & 221,060 & 138,162 & 276,325 & 138,163 & $1,105,300$ \\
\hline
\end{tabular}

Table K-7 shows the number of stations to be built in North America. America's Natural Gas Association (ANGA) predicts that there will be roughly 12,800 new stations, consisting of 12,100 CNG stations and 700 LNG stations, for heavy-duty vehicles (ANGA, 2012).

Table K-7: Future Station Population

\begin{tabular}{|c|c|c|c|c|c|c|c|}
\hline ID & $\begin{array}{c}\text { Prediction } \\
\text { Year }\end{array}$ & $\begin{array}{c}\text { Total } \\
\text { Stations }\end{array}$ & $\begin{array}{c}\text { LNG } \\
\text { Stations }\end{array}$ & CNG Stations & $\begin{array}{l}\text { Research } \\
\text { Company }\end{array}$ & Report Title & $\begin{array}{c}\text { Report } \\
\text { Year }\end{array}$ \\
\hline ANGA & 2035 & $\begin{array}{c}25,600 \mathrm{New} \\
\text { Stations }\end{array}$ & $\begin{array}{l}700 \text { New } \\
\text { Stations }\end{array}$ & $\begin{array}{c}24,900 \text { New } \\
\text { Stations }\end{array}$ & $\begin{array}{l}\text { America's } \\
\text { Natural Gas } \\
\text { Alliance }\end{array}$ & $\begin{array}{l}\text { U.S. and Canadian Natural Gas } \\
\text { Vehicle Market Analysis: Natural } \\
\text { Gas Vehicle Industry Overview }\end{array}$ & 2012 \\
\hline ANGAHD & 2035 & $\begin{array}{l}\text { 12,800 New } \\
\text { Heavy-Duty } \\
\text { Stations }\end{array}$ & $\begin{array}{l}700 \text { New } \\
\text { Heavy-duty } \\
\text { Stations }\end{array}$ & $\begin{array}{l}\text { 12,100 New } \\
\text { Heavy-duty } \\
\text { Stations }\end{array}$ & $\begin{array}{l}\text { America's } \\
\text { Natural Gas } \\
\text { Alliance }\end{array}$ & $\begin{array}{l}\text { U.S. and Canadian Natural Gas } \\
\text { Vehicle Market Analysis: Natural } \\
\text { Gas Vehicle Industry Overview }\end{array}$ & 2012 \\
\hline
\end{tabular}

In this scenario, WVU proposes to estimate the population of CNG/LNG stations with the assumption that each CNG (or LNG) fuel station will serve 50 refuse trucks, 80 transit buses, or 80 OTR tractors. The estimated population of NG fuel stations for refuse trucks and transit bus can be found in Table K-8. The estimated population of CNG and LNG fuel stations for the OTR tractors can be found in Table K-9. Table K-10 shows the estimated CNG and LNG fuel stations for the HD NG vehicle sector in 2035. Based on the data collected, or estimated, there will be about 7,000 to 18,500 natural gas stations in 2035 (ANGA, 2012).

Table K-8: Projected Population of NG Fuel Stations for HD Natural Gas Refuse Tuck and Transit Bus in 2035

\begin{tabular}{|c|l|r|r|}
\hline \multicolumn{2}{|c|}{ Vehicle Type } & $\begin{array}{r}\text { Refuse Truck } \\
\text { (CNG only) }\end{array}$ & $\begin{array}{r}\text { Transit Bus } \\
\text { (CNG only) }\end{array}$ \\
\hline Low & Projected population of CNG stations & 1600 & 263 \\
\hline Medium & Projected population of CNG stations & 2080 & 394 \\
\hline High & Projected population of CNG stations & 2560 & 525 \\
\hline
\end{tabular}


Table K-9: Projected Population of NG Fuel Stations for HD OTR Tractors in 2035

\begin{tabular}{|c|c|c|c|c|c|c|}
\hline & OTR Tractor Type & Short & Haul & & ng $\mathrm{Ha}$ & \\
\hline & Vehicle Tyne & CNG & LNG & CNG & LNG & LNG \\
\hline & & & & & & \\
\hline & NG Fuel Station Type & CNG & LNG & CNG & LNG & LNG \\
\hline Low & Projected population of CNG stations & 1655 & 1103 & 690 & 1379 & 690 \\
\hline Medium & Projected population of CNG stations & 2900 & 1933 & 1209 & 2417 & 1209 \\
\hline High & Projected population of CNG stations & 4788 & 3189 & 1993 & 3986 & 1993 \\
\hline
\end{tabular}

Table K-10: Projected Population of NG Fuel Stations for HD NG Vehicle Sector in 2035

\begin{tabular}{|c|c|c|c|c|}
\hline \multicolumn{2}{|r|}{ NG Fuel Station Type } & CNG & LNG & Total \\
\hline Low & Projected population of CNG stations & 3945 & 3172 & 7117 \\
\hline Medium & Projected population of CNG stations & 6189 & 5559 & 11748 \\
\hline High & Projected population of CNG stations & 9341 & 9168 & 18509 \\
\hline
\end{tabular}

